\title{
TIPOLOGÍA PSICOLÓGICA Y PSICOPATOLÓGICA DEL SUICIDIO EN LAS OBRAS DE FIODOR DOSTOIEVSKI
}

Tesis presentada para aspirar al grado de Doctor en Medicina por la licenciada $\mathrm{M}^{\mathrm{a}}$ Teresa Cañas Cañas

Director: Prof. Dr. D. Pedro Gómez Bosque

Codirector: Prof. Dr. D. José Angel Macías Fernández

DEPARTAMENTO DE PSIQUIATRÍA

FACULTAD DE MEDICINA UNIVERSIDAD DE VALLADOLID 
En memoria de Eugenia

A mis padres

A Fernando 


\section{Agradecimientos}

Deseo expresar especialmente mi agradecimiento al Prof. Gómez Bosque por proponerme el tema de este trabajo, compartir su sabiduría, su completa disponibilidad y su inestimable apoyo. Y a su mujer Eugenia, que ya no está con nosotros, que fue quien sugirió por primera vez la posibilidad de esta tesis y cuyo estímulo fue imprescindible para sus inicios. Muchas gracias.

Al Prof. Macias, por aceptar participar en este trabajo, sin cortapisas ni vacilaciones, y por sus valiosísimas aportaciones.

A la Prof. Nieves López, por su generosa labor, eficaz y silenciosa, allanando obstáculos y solucionando trabas.

Y en general, a todos los miembros del Departamento de Psiquiatría del Hospital Universitario de Valladolid, que durante años me han brindado sus conocimientos y su amistad.

A mi familia, por aceptar mi exilio voluntario en la estepa siberiana. Con un guiño cariñoso a mi tía Pilar Barrera, por sus cuadros y su alegría.

A los compañeros y amigos que han estado conmigo en esta época "dostoievskiana".

Y, sobre todo, a Fernando, el verdadero impulsor de este trabajo y de casi todo lo demás. 


\section{INDICE}

I. Introducción ................................................ 8

II. Revisión bibliográfica ................................... 12

A. Suicidio .............................................. 13

1. Marco cultural e histórico del suicidio ............ 14

a) Definición del suicidio ........................... 14

b) El suicidio en la cultura occidental ......... 15

c) Concepciones culturales y religiosas sobre el suicidio en otras sociedades ................... 28

2. El suicidio en Psiquiatría .......................... 31

a) El suicidio en la Historia de la psiquiatría ... 31

b) Fenómenos suicidas: Tentativas de suicidio, ideas suicidas, parasuicidios y acciones autodestructivas

c) Diagnóstico psiquiátrico y suicidio ........... 42

d) Enfermedad médica y suicidio ............... 52

3.Teorías psicológicas explicativas del suicidio ..... 55

a) Teorías psicoanalíticas ........................ 55

b) Otras teorías psicológicas ...................... 62

c) Etapas en el proceso suicida ................. 71 
4. Estudios sociológicos …...................................... 73

a) El estudio de Durkheim sobre el suicidio ............. 73

b) Otras teorias sociológicas …............................. 75

5. Factores de riesgo suicida ..................................... 78

a) Factores psicosociales, económicos y ambientales. 78

b) Factores biológicos ....................................... 86

6. Tipología del suicidio y de los fenómenos suicidas ...... 93

a) Clasificación de los fenómenos suicidas de Enrique Rojas 93

b) Tipologia de Durkheim ..................................... 102

c) Otras tipologías ............................................. 116

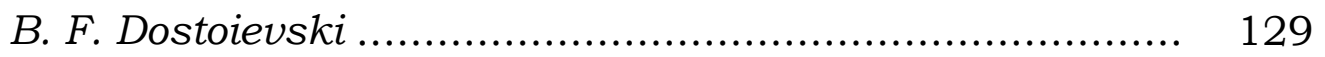

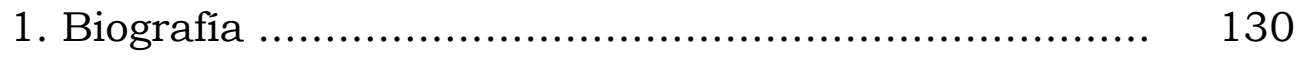

a) Infancia y adolescencia $(1821-1837)$................. 130

b) San Petesburgo (1837-1849) ........................... 132

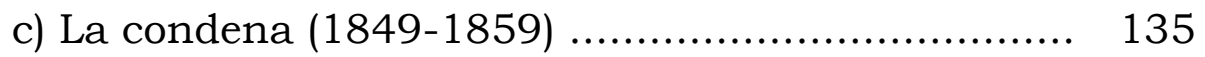

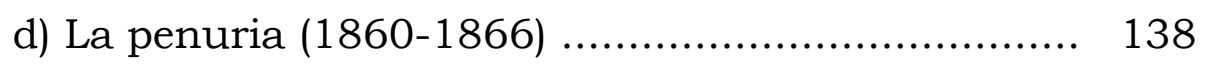

e) Residencia en el extranjero (1867-1871) ............. 142

f) Años de bienestar (1871-1881) ........................ 145

2. Obras principales ........................................... 156

3. Dostoievski según Freud …................................. 162 
A. Obras estudiadas .............................................. 170

1. Memorias del subsuelo ................................ 170

2. El cocodrilo ............................................ 177

3. Crimen y castigo …................................. 178

4. El jugador ............................................. 180

5. El Idiota .................................................... 182

6. El eterno marido ..................................... 184

7. Los demonios …..................................... 186

8. El adolescente ..................................... 192

9. Los hermanos Karamázov ............................ 194

10. Diario de un escritor ................................. 198

B. Método de estudio ................................................ 201

IV. Resultados y discusión .................................... 204

A. Listado de fenómenos suicidas en las obras estudiadas ......................................................... 205 
$B$ Tipos de actos suicidas

1. El suicidio infantil

2. El suicidio como huida: Víctimas adultas de la humillación y la miseria

3. El suicidio en trastornos psicóticos

4. El suicidio en el juego patológico

5. El suicidio en el alcoholismo

6. El suicidio en el narcisismo maligno

7. El suicidio "lógico"

8. El suicidio violento

9. El suicidio "romántico"

10. El suicidio como forma de renacer

11. El suicidio por sentimientos de culpa

12. El suicido egoísta

13. El suicidio anómico

C. Reflexiones de Fiodor Dostoieuski sobre el fenómeno

1. Datos biográficos relevantes en relación con su concepción del suicidio

2. El suicidio según la doctrina ortodoxa rusa

3. La disertación sociológica del stárets Zósima: Un preludio del estudio sobre el suicidio en la sociedad occidental realizado por Durkheim

4. El suicidio como "enfermedad moral" 
I. INTRODUCCIÓN 
Las intuiciones de los grandes literatos de todas las épocas han sido utilizadas a lo largo del tiempo por la psiquiatría para el conocimiento de lo que, en un amplio sentido, se conoce como "vida humana". La psicología que precisa el psiquiatra, la que le puede acercar al conocimiento de la vida del hombre al que se califica generalmente como enfermo, se encuentra frecuentemente plasmada de forma precisa en las grandes obras literarias. Y esto sucede porque el pensamiento "ideo-espiritual", propio del poeta (entendiendo la poesía en su más amplio significado) puede llegar a conocer la realidad tanto como el pensamiento "conceptualracional" del científico. Es más, en el conocimiento del alma humana el poeta se adelanta en muchas ocasiones al científico (Gómez Bosque, 1993).

Entre estos grandes literatos se encuentra, en un puesto destacado, Fiodor Dostoievski, el gran novelista ruso del siglo XIX. Sus obras tienen una crucial importancia para los psiquiatras porque, como dijo Cabaleiro Goás (1951), es el escritor que ha creado en la literatura mundial el más elevado número de personajes psicopatológicos y los ha descrito con una mayor perfección. Ya contemporáneos suyos destacaron el gran peso que tenía la patología mental en sus novelas. Así, el afamado crítico literario Belinski consideraba que las obras de Dostoievski posteriores a Pobres gentes (su primera novela) no pasaban de ser casos de desquiciamiento mental, cuyos valores no lograban transcender a la de cualquier historia clínica.

Psiquiatras de la talla de K. Jaspers y S. Freud han utilizado sus obras y su personalidad para ahondar en los misterios de la mente humana. Karl Jaspers, en su Psicopatología general (1913) recurre a sus obras para describir fenómenos como la alteración de la temporalidad, las vivencias del aura epiléptica y los estados reactivos a situaciones de aislamiento; Sigmund Freud (1927) apeló a la trayectoria biográfica de Dostoievski para ilustrar una de sus teorías más conocidas: el complejo de Edipo. Otras personalidades geniales, alejadas del ámbito de la Psiquiatría, han reconocido su innegable deuda a la sabiduría psicológica de este autor: un contemporáneo suyo, reconocido actualmente como uno de los más grandes transformadores de los valores modernos, F. Nietzsche, tras leer Memorias del subsuelo, afirmaba, que Dostoievski, aparte de Stendhal, es el psicólogo con quien "mejor se entiende" (Valverde, 1993); Albert Einstein aseguraba que Dostoievski le había aportado más que cualquier científico, incluido Gauss (Stange, 2001); su libro de cabecera fue Los hermanos Karamázov. 
La sabiduría psicológica de Dostoievski, universalmente reconocida, proviene tanto de sus experiencias vitales y su excelente capacidad de autoobservación como de su alta dosis de "fantasía real" o "fantasía creativa" (Gómez Bosque, 1993); con respecto al primer punto, como se expone en el apartado biográfico, Dostoievski vivió profundas experiencia existenciales que incorporó a las tramas de sus novelas, como son entre otras, la experiencia del amor, de la pérdida, de la condena a pena de muerte con un simulacro de ejecución, del presidio, de las auras místicas producto de la epilepsia, de la pasión por el juego y su penuria consecuente; a través de "la fantasía real", Dostoievski fue capaz con sus invenciones de captar la realidad tal como es en sí misma y por tanto contienen un importante componente de verdad. Los "mitos" inventados por Dostoievski, dice Gómez Bosque (1993), son, simultáneamente expresión de sus ideas, de sus deseos, de sus sentimientos, de sus pasiones, pero también objetivación verdadera de lo "humano universal".

Esta fantasía creativa de Dostoievski le permitió anticiparse en la descripción de muchos fenómenos animicos que posteriormente estudió el psicoanálisis y que en la actualidad son considerados verdaderos por la mayoría de los psiquiatras. Entre ellos, la existencia del inconsciente, el simbolismo de los sueños, los mecanismos de defensa y la disociación de la personalidad. Su contribución a la descripción de algunos trastornos mentales (como la ludopatía o los síntomas psicopatológicos de la epilepsia temporal) continúa vigente en la actualidad, aunque insuficientemente conocida por los médicos que tratan estas patologias. Como René Girard (1978) afirma, "la elaboración de modelos y de un sistema conceptual que haga finalmente justicia a la rigurosa percepción de un Dostoievski es no menos necesaria para la psiquiatría que para los estudios literarios. A mi juicio, esta es la única dirección en que puedan revitalizarse ambas esferas y convertir estas disciplinas en las aliadas que deberian ser. Sólo una seudociencia va contra las máximas obras de nuestra herencia literaria. Una verdadera ciencia justificará la visión de dichas obras y confirmará su superioridad" (p. 90).

Siguiendo los planteamientos previamente expuestos, se me propuso, como tema de tesis doctoral, el estudio de la tipología psicológica y psicopatológica del suicidio en las obras de este autor, dada la gran importancia de esta conducta dentro de la psiquiatría. En las novelas de Dostoievski existen un número elevado de manifestaciones suicidas, entendiendo por tales, suicidios consumados, suicidios frustrados, intentos de suicidio, ideas autoliticas y amenazas suicidas. Estos fenómenos se describen por el gran novelista en un grupo variopinto de 
personajes, que incluye individuos de ambos sexos, de distintas edades (desde niños hasta ancianos) y de diferente estrato sociocultural (desde siervos hasta aristócratas). En muchas ocasiones las motivaciones del personaje para el suicidio están minuciosamente elaboradas en el transcurso de la novela. Además, en los artículos periodísticos que constituyen Diario de un escritor, el tema del suicidio será uno de los más profusamente tratados. Sólo en el año 1876 aparecerán descritos nueve suicidios, la mayoría entresacados de noticias de prensa.

Más en concreto, nuestro trabajo de tesis doctoral consiste en:

Enumerar los personajes de las obras de Dostoievski, desde el año 1864 hasta su muerte, en los que aparece el fenómeno objeto del estudio.

Caracterizar estos personajes en tipos psicológicos y psicopatológicos.

Contrastar estos hallazgos con las diferentes teorías, tanto clásicas como actuales, sobre la génesis y el desarrollo de los diferentes actos suicidas.

En las páginas que siguen hacemos una exposición pormenorizada del contenido de esta tesis doctoral. 
II. REVISIÓN BIBLIOGRÁFICA 
A. SUICIDIO 


\section{Marco cultural e histórico del suicidio}

\section{a. Definición del suicidio}

El suicidio se define como la acción voluntaria por la que una persona se priva de la vida. El término proviene del latín: sui (de sí mismo) y cadere (matar).

Los términos "suicidio" y "suicida" son relativamente recientes. Según algunas fuentes surgió por primera vez en Gran Bretaña en el siglo XVII y según otras en Francia en el siglo XVIII. Según estas últimas, se cree que la palabra tiene su origen en el abate Prévost en 1734 de quien la retomaria el abate Desfontaines y posteriormente Voltaire y los enciclopedistas (Clemente y González, 1996). Fue introducido por la Academia Francesa en el léxico francés en 1762 para reemplazar el término de "homicidio de sí mismo". Según los anglosajones, la palabra "suicidio" fue utilizada por primera vez bien por Charleton en 1651 o por Browne en su obra Religio Medici, publicada en 1642. Fue incluida en un diccionario inglés en 1656, en el Glossographia de Blunt (Díaz y cols., 1997).

En España no fue incluida en el Diccionario de la Real Academia hasta su quinta edición, publicada en 1817. Se piensa que el término apareció por primera vez en nuestro país en la obra $L a$ falsa filosofía y el ateísmo de Fray Fernando de Ceballos en 1772.

No obstante, el suicidio es un fenómeno universal que ha estado presente en todas las épocas y culturas, siendo valorado de diferente forma en las distintas sociedades dependiendo de las creencias religiosas, pensamientos filosóficos, estructuras sociopolíticas y culturales e ideas escatológicas. 


\section{b. El suicidio en la cultura occidental}

\section{Grecia y Roma}

En Grecia, la reacción ante el suicidio varía entre el elogio, la tolerancia y la condena.

En la mitología griega ya aparecen varios suicidios entre los que se encuentran los siguientes: El primer suicidio literario, el ahorcamiento de Yocasta, madre de Edipo, se presenta como algo encomiable, una salida honrosa a una situación intolerable. Egeo, al creer que su hijo Teseo ha sido vencido por el Minotauro, se arroja al mar, que en adelante llevará su nombre; Erigone se ahorca de pena al descubrir el cadáver de su padre, desatando entre las mujeres atenienses una epidemia de suicidios; Leucaca se tira de una roca para evitar que Apolo la viole, etc. (Alvarez, 1971).

La lista de filósofos griegos que pusieron fin a su vida es interminable: Anaxágoras, Codro, Mereceo, Demóstenes, Cleomenes I, Cleomenes III, Isócrates, Zenón, Diógenes, Empédocles, Safo, etc. (Carbonell y González, 1997).

Filolao, un destacado pitagórico del siglo V a.C., predica sobre la perversidad del suicidio, ya que considera que los hombres no son dueños de sí mismos sino que pertenecen a los dioses (Guthrie, 1984).

Platón condena el suicidio ya que va contra el mandato del destino (Leyes) y porque los dioses son nuestros guardianes y nosotros somos una posesión de ellos por lo que un hombre deberia esperar y no acabar con la vida hasta que Dios le llame (Fedón). No obstante, se muestra indulgente cuando el suicidio se realiza por "dolor excesivo", "deshonor" o "desesperación". Aunque Sócrates repudie el suicidio al mismo tiempo hace a la muerte deseable: es la entrada a un mundo de presencias ideales del cual la realidad terrena es una mera sombra. Se cree que el Fedón inspiró al filósofo Cleombroto a ahogarse y que Catón, la noche previa a su suicidio, lo leyó dos veces (Alvarez, 1971).

Para Aristóteles el problema del suicidio es principalmente sociopolítico, considerándolo un acto contra sí mismo y contra el estado y justificando que dichos sujetos pierdan algunos derechos. Dice en su Etica Nicomaquéa: "el hombre que voluntariamente, en un arrebato de ira, se mata a sí mismo, lo hace en contra de la 
recta razón, lo cual no lo prescribe la ley; luego, obra injustamente. Pero ¿contra quién? ¿No es verdad que contra la ciudad y no contra sí mismo? Sufre, en efecto, voluntariamente, pero nadie es objeto de un trato injusto voluntariamente. Por eso, también la ciudad lo castiga y se impone al que intenta destruirse a sí mismo cierta privación de derechos civiles, como culpable de injusticia contra la ciudad" (1138 $)$.

En Atenas el suicidio era permitido sólo cuando fuera autorizado por los magistrados públicos, debiéndose pedir autorización al Senado, como documenta el sofista griego Libanio (314-395), el cual refiere (Durkheim, 1897): "Aquel que no quiera vivir más tiempo que exponga sus razones al Senado y, después de haber obtenido licencia, se quite la vida. Si la existencia te es odiosa, muere; si estás maltratado por la fortuna, bebe cicuta; si te hallas abrumado por el dolor, abandona la vida. Que el desgraciado cuente su infortunio; que el magistrado les suministre el remedio y su miseria tendrá fin".

En Roma existió posteriormente una institución similar a ésta, permitiéndose el suicidio si era debido al aburrimiento de la vida o servía para evitar alguna situación deshonrosa, pero existiendo leyes muy rigurosas contra los suicidios de los soldados, los esclavos, y personas acusadas de delitos (Sarró y de la Cruz, 1991). Para el derecho romano el delito de suicidio era estrictamente económico. No ofendía a la moral ni a la religión; solo a las inversiones de capital de los poseedores de esclavos y al erario estatal.

El suicidio será aceptado por estoicos y epicúreos pero en un principio sólo en circunstancias excepcionales: Los estoicos consideraban que el suicidio era un ejemplo extremo de conducta contraria a los propios intereses del hombre en la mayoría de las circunstancias, pero que podia, no obstante, ser racionalmente defendida en determinadas circunstancias (Long, 1975). Se dice que Zenón, el fundador del estoicismo, se ahorcó a los noventa y ocho años, a causa de la irritación que le provocó la dislocación de un pulgar. (Alvarez, 1971).

No obstante, en el estoicismo romano se glorifica cada vez más el estado de la persona en el que ésta se ha convertido en juez libre de "vivir o morir" según la razón. El estoico es un hombre que puede morir desde el momento en que la razón se lo mande. No es el acto exterior del suicidio lo que se glorifica, sino una cierta libertad interior que lo permite $y$ lo ordena en ciertas circunstancias. La figura más representativa del estoicismo romano y defensor del derecho al suicidio fue Lucio Anneo Séneca, 
que se suicidó en el año 65 d.C. por orden del emperador Nerón. Séneca considera que la vida es potestad del individuo, por lo que propone el suicidio como una salida honrosa a una vida infructifera y dolorosa a la que todo hombre tiene derecho, como por ejemplo en los casos en que la edad pase factura e impida vivir como se debiera: "No renunciaré a la vejez mientras deje intacta la mejor parte de mí. Pero si empieza a debilitar mi mente, si destruye mis facultades una por una, si no me deja vida sino aliento, abandonaré este pútrido y vacilante edificio. No huiré con la muerte de la enfermedad mientras ésta se pueda curar y deje mi muerte intacta. No levantaré la mano contra mí mismo a causa del dolor, porque morir así es dejarse vencer. Pero sé que si debo sufrir sin esperanza de alivio partiré, no por miedo al propio dolor, sino porque me impide todo aquello por lo que viviria" (Nulan, 1993). También dice: "No debes vivir bajo la necesidad, pues no hay para ti ninguna necesidad de vivir" (Landsberg, 1942).

El filósofo estoico Epicteto, nacido esclavo (aproximadamente 50130 d.C.) también aprueba el suicidio. Epicteto sugiere que, para algunos de nosotros, hay situaciones que sobrepasan los limites soportables y que, cuando las cosas se vuelven insoportables, se puede desear acabar con la vida. Dice poéticamente: "A pesar de todo, recuerda que la puerta permanece abierta. No seas más miedoso que un niño. Pues cuando ellos están cansados de jugar gritan "No jugaré más", asi también cuando tú estés en una situación similar grita "No jugaré más" y parte. Pero si te quedas, no llores... ¿Hay humo en la habitación? Si es leve, me quedo. Si es grave, me voy. Pero debes recordar y tener en cuenta que la puerta permanece abierta" (Discursos, Libro 1, cap. 24, 25) (Fieser, 1998).

El estoicismo terminará siendo, por tanto, una filosofia de la autonomía del ser racional que tiene su centro vital en una filosofía de la muerte libre.

\section{El cristianismo antiguo y el suicidio}

La moral cristiana es la única que se opone al suicidio de manera absoluta y sin posibilitar ninguna excepción (Landsberg, 1942).

En el Antiguo Testamento se habla del suicidio de Sansón, Saúl, Abimelech, Achitofel y en el Nuevo Testamento del de Judas Iscariote, sin hacer más referencias al tema (Rodríguez Juan, 1997). En el caso de Saúl se describe su enfermedad mental, que 
termina en su suicidio, y se interpreta como causada por un espíritu maligno enviado por Dios.

En los primeros años del cristianismo no sólo es tolerado sino también aprobado por la iglesia. Entre los donatistas, el suicidio fue propiciado como una forma de lograr antes la vida eterna.

Cuando el cristianismo accede al poder, se empieza a realizar una condena cada vez más explícita del suicidio. En el caso de Judas su traición llega a pasar a segundo plano siendo el hecho de ahorcarse su conducta más denigrada. A los que se suicidan llegan a llamarles "discípulos de Judas" y personifican, como Judas, la traición a la humanidad.

Aunque en los primeros años del cristianismo no haya una condena explícita del suicidio, paulatinamente la actitud de la Iglesia que mantiene el poder va siendo más intransigente, sobre todo tras la autoridad ejercida por San Agustín, quien en La ciudad de Dios dice basándose en el "no matarás" bíblico: "No matarás a nadie, ni a ti, ni a otro, ya que el que se mata a sí mismo, ¿no es acaso el asesino del hombre?" (Rodríguez Juan, 1997). Para S. Agustín el suicidio no está justificado en ningún caso, ni por sufrimiento personal, ni por miedo a posibles castigos, ni por los más elevados razonamientos, ya que la persona más sabia es la que encara los problemas de la vida y no huye de ellos.

En el concilio de Arlés (452) se habla del suicidio como un crimen, efecto de un furor diabólico; en el de Orleans (533) se prohibe el entierro (requisito imprescindible para lograr la salvación) a los suicidas que se matan al ser acusados de un crimen; en el de Braga (562) esta sanción se hace universal, sea cual sea la situación; en el de Toledo (693) se excomulga a los que intentan suicidarse con las consiguientes consecuencias civiles (Rodríguez Juan, 1997).

\section{$\underline{\text { Edad media }}$}

Dante Alighieri (1265-1321) en su canto XIII de El Infierno en La Divina Comedia describe el recinto "donde se castiga a los violentos contra sí mismos" que son transformados en troncos en los que anidan arpias donde serán colgados los cuerpos ("los despojos") tras la resurrección de la carne. Dice el suicida en el Infierno: "Como los demás iremos a recoger nuestros despojos, más no por eso logrará ninguna recobrarlos, pues no es justo tener aquello de 
que uno se ha privado. Aquí los trasladaremos, y quedarán colgados nuestros cuerpos por esta lúgubre selva, cada uno del árbol que está atormentada su alma".

Santo Tomás de Aquino (s. XIII) en Summa Teológica da los siguientes argumentos contra el suicidio (Fieser, 1998): El primer argumento está basado en la ley natural o fin natural de una cosa: el suicidio es contrario al fin natural de la vida humana. Además, añade a este argumento que la persona no puede disponer de sí mismo porque no se pertenece a sí mismo sino, como ya decía Aristóteles, a la sociedad. Pero además el suicidio es un acto contra Dios que ha dado la vida al hombre y del que somos propiedad como el esclavo es propiedad de su amo. Para Santo Tomas el suicidio es el más grave de los pecados aunque anota que existen una serie de vesanías que hacen a la persona "irresponsable" de sus actos. También considera que el sujeto puede actuar por una ofuscación pasajera. Con estas opiniones empieza a distinguirse entre la consideración religiosa y el concepto de enfermedad mental (Rodríguez Juan, 1997).

En la edad media el suicidio era considerado como la victoria del diablo y se actuaba contra el cadáver como castigo y ejemplo; pero a partir del siglo XIV empiezan las primeras instrucciones y normas judiciales que justifican los suicidios que se creen cometidos en un acto de locura.

\section{Renacimiento}

En el siglo XVI la filosofia griega y romana es redescubierta y se cuestiona la condena incondicional del suicidio.

Erasmo de Rotterdam en Elogio de la locura (1509) defiende el suicidio como liberación de una vida insufrible.

Tomas Moro en su Utopía (1516) propone y aconseja el suicidio y la eutanasia ante enfermedades incurables: "Mas si la enfermedad no es sólo inmedicable sino que también veja y atormenta de continuo, entonces los sacerdotes y los magistrados exhortan al hombre a que, pues está ya sobreviviendo a su propia muerte al estar incapacitado para las funciones todas de la vida, ser molesto a los otros y oneroso a sí mismo, no se determine a alimentar por más tiempo su ruina y su pena, ni dude en morir, ya que la vida es un tormento... obrará asimismo piadosa y santamente, puesto que seguirá a este propósito los consejos de los 
sacerdotes, esto es, de los intérpretes de Dios. A quienes persuaden de esto, o acaban ellos espontáneamente con su vida por la inedia o, amodorrecidos, se les pone fin sin que sientan la muerte. No suprimen a nadie que no lo quiera ni disminuyen en nada su atención hacia él; el que los persuadidos acaben de ese modo lo tienen por cosa honorífica" (Moro, 1516).

Años más tarde Montaigne (1588) escribirá a favor del suicidio criticando los argumentos medievales de Providencia divina. Así, dice: "Dios nos da licencia suficiente cuando nos pone en un estado tal que el vivir es para nosotros peor que el morir" (Landsberg, 1942).

El poeta y clérigo inglés John Donne será otro de los pensadores renacentistas que expondrá varios razonamientos a favor del suicidio en su obra Biothanatos. Una declaración de la paradoja, o tesis, de que el homicidio de sí no es tan naturalmente pecado que no pueda ser de otro modo (1608). Esta obra no se publicaria hasta 1646, quince años después de la muerte del escritor.

Robert Burton, autor suicida de Anatomía de la melancolía (1621) replantea el tema contra el prejuicio de la época. Rechaza la justificación estoica del suicidio como acto de dignidad razonada y autoafirmación. Considera que el suicidio no es racional, ni digno, ni mesurado; que las personas solamente se matan porque su vida se ha vuelto intolerable.

No obstante, el suicidio se condena a nivel popular y se sigue tratando cruelmente a los que intentan suicidarse o al cadáver de los que lo consiguen. En Lille, al cadáver se le tira por la ventana o se le hace pasar por la parte inferior del umbral con la cara contra la tierra para evitar que el suicida pueda encontrar el camino de vuelta (Delumeau, 1978). La Ordenanza criminal publicada por Luis XIV en 1670 pronuncia una condena regular ad perpetuam rei memorian; el cuerpo, arrastrado sobre unas andas, cara a tierra, por las calles y encrucijadas, es luego colgado o echado al muladar; los bienes son confiscados; los nobles son degradados y declarados plebeyos; se talan sus bosques, se demuelen sus castillos y se rompen sus escudos (Durkheim, 1897).

\section{La época de la Ilustración}

En el siglo XVIII las creencias tradicionales son reexaminadas desde una perspectiva escéptica, racional y empírica. Se desafian los argumentos teológicos contra el suicidio y este es reivindicado 
como un derecho humano, aunque muchas personalidades de la Iglesia y las leyes continúan defendiendo de forma vehemente el punto de vista tradicional.

En Francia, Montesquieu (1689-1755) critica las drásticas represalias que sufren los sujetos que se suicidan o intentan suicidarse y Voltaire afirma que de la misma manera que es lícito sacrificar la vida por Dios, la patria y otras personas o causas, también es lícito sacrificar la vida propia por uno mismo.

En Inglaterra, Hume (1711-1776) realiza una de las más famosas defensas filosóficas del suicidio de este periodo en su ensayo Sobre el suicidio. Este ensayo fue impreso para su publicación en 1757 y estructurado en cinco discursos pero por presiones políticas Hume no lo publicó. El trabajo apareció en 1777 , un año después de la muerte de Hume, y fue rápidamente reprimido. En este ensayo, Hume enfoca la problemática del suicidio desde el punto de vista tradicional de ética basada en el deber (Fieser, 1998). Si el suicidio es inmoral, entonces debe violar algún deber para con Dios, uno mismo o los otros. Hume refuta cada una de estas posibilidades. La mayor parte de sus argumentos se focalizan en si el suicidio viola los deberes para con Dios. Sus principales argumentos contra esto son:

1. Hay una norma propia establecida por Dios para dos clases de naturaleza (leyes fisicas en el mundo natural y acciones con finalidad en el mundo animal).

2. Como norma, Dios ha dado a los humanos libertad para alterar la naturaleza para su propia felicidad.

3. El suicidio es un ejemplo de alteración del curso de la naturaleza para nuestra propia felicidad.

4. No hay razones contundentes para que este ejemplo sea una excepción a la norma.

5. Por tanto, el suicidio no viola el plan de Dios.

Muchos de los argumentos de Hume se centran en la premisa cuatro. Una posible crítica que Hume expone a esta premisa sería que la vida humana es importante de forma única y especial. Él argumenta que en un esquema más amplio de las cosas nuestra vida no es más importante que la de una ostra. Otra critica sería que Dios es el que debe determinar cuando alguien debe morir. Hume contesta que si el momento de la muerte es por completo cosa de Dios, entonces debería ser también erróneo alargar la vida 
gracias a la Medicina. Otra posible crítica podría ser que el suicidio interfiere el orden natural de las cosas creado por Dios. Pero nosotros construimos refugios artificiales para protegernos del mal tiempo, etc. y claramente interferimos en el orden natural de las cosas.

Para Hume los argumentos basados en la Providencia fallan porque no hay diferencias relevantes entre, dice, desviar el río Nilo de su curso natural y acabar con la propia vida por desviar la sangre de su canal normal. También argumenta que cuando la vida llega a ser insoportable, un Dios absolutamente bueno no nos impediría acabar nuestras miserias a través del suicidio.

Sobre si el suicidio viola nuestros deberes para con otros, Hume ofrece una serie de argumentos como el siguiente sobre la reciprocidad social (Fieser, 1998):

1. Cuando morimos, no hacemos daño a la sociedad sino sólo cesamos de hacer bien.

2. Nuestra responsabilidad de hacer bien está directamente relacionada con el beneficio que recibimos de la sociedad.

3. Cuando muero no puedo recibir por más tiempo beneficios.

4. Por consiguiente, no tengo deber de hacer bien.

Hume sostiene que no se está obligado a hacer un pequeño bien a la sociedad a expensas de un gran daño a uno mismo. Siguiendo las consecuencias de este razonamiento, expone que si la propia existencia es una carga para la sociedad, entonces el suicidio es permisible. Para Hume, la mayoría de la gente se mata en esta situación.

Con respecto a si el suicidio viola el deber con uno mismo, Hume argumenta que todos los suicidios se realizan por buenas razones personales, ya que existe un fuerte miedo natural a la muerte y se requieren motivos igualmente fuertes para vencer ese miedo.

Por tanto, Hume defiende claramente el derecho "a una muerte responsable" y rebate los principios por los que se condena al suicidio, promovidos por "la superstición y la falsa religión".

En su ensayo Suicidio Inmanuel Kant (1724-1804) argumenta que el suicidio es un error porque degrada al hombre por debajo de los animales. Kant analiza dos justificaciones frecuentes con respecto al suicidio y rechaza ambas (Fieser, 1998). Primero, 
algunos pueden considerar que el suicidio es permisible ya que es asunto de la libertad pues no viola los derechos de otros. Kant responde que el más alto deber para con uno mismo es la autoconservación y que se puede tratar el propio cuerpo como se plazca siempre que estas acciones surjan desde el principio de autoconservación. Segundo, algunos podrian dar ejemplos históricos que sugieren que el suicidio es en ocasiones virtuoso. Por ejemplo, en la historia romana, Catón, que fue un símbolo de la resistencia contra Cesar, se dio cuenta que no podía resistir por más tiempo; continuar viviendo una vez derrotado desilusionaria a los defensores de la libertad. Kant sostiene que éste es el único ejemplo de esta clase y por tanto no puede ser usado como regla general en defensa del suicidio. No obstante, el principal argumento de Kant contra el suicidio es que las personas consideran que su vida tiene un valor único inherente (Fieser, 1998). Al matarse uno mismo se prescinde de su humanidad y se convierte en algo que es tratado como una bestia. Kant sugiere también que si una persona es capaz de suicidarse, es capaz de cualquier crimen. Según Kant "el que no respeta su vida no es capaz en principio de contenerse en los vicios más espantosos" (Fieser, 1998). Kant concluye: "El suicidio no es abominable porque lo prohiba Dios; Dios lo prohibe porque es abominable"

Al final de este siglo, el tratamiento brutal a los suicidas es suavizado en algunas partes de Europa. Con la Revolución Francesa las leyes contra el suicidio son omitidas y pierde su carácter criminal; el código penal prusiano de 1794 no castiga el intento de suicidio. Pero la moral común lo reprueba y la Iglesia sigue prohibiéndolo y castigándolo. Se mantiene la negativa a enterrar a los suicidas en el cementerio y es común ensañarse arrastrándolo con el cadáver colgándolo cabeza abajo, como en Francia, o clavándole una estaca en el corazón, como en Inglaterra, donde también se confiscaban todos sus bienes (que eran incorporados a la Corona), para luego darle un entierro indigno o ninguno. No obstante, esta pena exagerada se habia hecho desde hace tiempo inaplicable por lo que el Jurado interpretaba la ley declarando, muy a menudo, que el suicida habia obrado en un momento de locura $y$, por consiguiente, era irresponsable (Durkheim, 1897).

El Derecho ruso era igual de severo. Si el suicida no parecía haber obrado bajo la influencia de una enfermedad mental, crónica o pasajera, se consideraba nulo su testamento y todas las disposiciones que hubiera podido tomar en relación a su muerte. Se negaba la sepultura cristiana. La simple tentativa era castigada con una multa que fijaba la autoridad eclesiástica (Durkheim, 1897). 


\section{E1 Siglo XIX}

Los escritores del Romanticismo de finales de XVIII y principios de XIX contribuyen a glorificar el suicidio como el último acto heroico de un hombre libre (Byron, Keats y Shelley en Inglaterra, Lermontov en Rusia, Chateaubriand y Lamartine en Francia, Novalis y Goethe en Alemania). Por ejemplo, para Novalis el acto filósofico por excelencia sería, sin duda alguna, el suicidio. Si una fecha podría considerarse como el inicio del Romanticismo, esta no será otra que 1774 , la fecha de la publicación de Las desventuras del joven Werther de Goethe. Con el suicidio de su protagonista, una epidemia de suicidios invade Europa en los que el libro es encontrado al lado del cadáver. En él, por supuesto, se defiende el derecho del hombre a disponer de su propia vida.

El suicidio empieza a ser un acto alabado y "recomendado" en ciertas situaciones como, por ejemplo, entre los oficiales militares europeos el suicidio con pistola era la respuesta esperada si no era posible pagar las deudas de juego.

Desde la Antigüedad hasta principios del siglo XIX el suicidio fue considerado una cuestión legal, filosófica, ética, y religiosa: A partir de esta fecha, el suicidio va a ser considerado principalmente desde un punto de vista sociológico, psiquiátrico y psicológico. Su aproximación ya no va a ser principalmente filosófica y teológica, sino médica y se va a estudiar en profundidad la personalidad, los trastornos mentales y las condiciones sociales relacionados con el acto suicida. No obstante, los filósofos del siglo XIX y XX continúan elaborando sus teorías sobre el suicidio, aunque desde una perspectiva diferente.

Schopenhauer en $E l$ mundo como voluntad y representación (1818), considera que el suicidio, lejos de negar la voluntad de vivir, la afirma enérgicamente. El suicida ama la vida, pero no en las condiciones en que se le ofrece. El suicida quisiera vivir, pero que la vida fuese de otro modo. Por tanto, en el suicidio el individuo se niega como tal individuo, pero su mismo acto es una profesión de voluntad de vida para la especie. El suicidio no es, pues, posibilidad de no ser en absoluto, sino que confirma que la voluntad universal se manifiesta en el dolor pero no puede ser suprimida. El suicida confirma con su muerte que la voluntad es vida, ya que la muerte no toca en absoluto la realidad transcendente y verdadera. Lo que en nosotros muere es tan sólo la individuación. El núcleo de nuestra esencia -la voluntad, que es voluntad de vivir - no es afectado en modo alguno por la muerte. 
Con el suicidio el individuo niega sólo su individuación, pero no el error primordial, la voluntad de vivir. No obstante, Schopenhauer es muy crítico con la condena del suicidio como crimen que hace la religión cristiana y las leyes de su época, ya que según él "nada hay en el mundo sobre lo cual tenga cada uno un derecho tan indiscutible como su propia vida y persona" (1851).

Nietzsche en el apartado De la muerte libre pone en boca de Zaratustra (1883): "Morir a tiempo: eso es lo que Zaratustra enseña"; "Libre para la muerte y libre en la muerte, un santo que dice no cuando ya no es tiempo de decir sí: así es como él entiende de vida y de muerte".

\section{E1 Siglo XX}

Hasta principios del siglo XX no surge en Europa la opinión predominante en la sociedad del suicidio como conducta patológica resultado de un trastorno mental. Esta concepción del suicidio es impuesta y popularizada desde la perspectiva psiquiátrica. Según refiere Hudson (1983) en 1967 en Estados Unidos el Instituto Nacional de Salud Mental se pronuncia oficialmente considerando el suicidio como una enfermedad y se funda una revista médica, el Boletín de Suicidiología. Se realizan conferencias en que se estudian las causas, tratamiento y prevención de esta nueva enfermedad. No obstante, los fenómenos de autolisis no han cambiado. Así que lo que fue considerado un pecado en el siglo XVIII y un crimen en el XIX es en el XX considerado una enfermedad. En los estudios epidemiológicos que se realizan se concluye que la gran mayoría de los suicidios (más del 90\%) son realizados por personas que en el momento de cometerlo presentaban algún trastorno psiquiátrico (Gosh y Victor, 1995).

Aun así, algunos filósofos como los existencialistas van a continuar reflexionando sobre el suicidio y se oponen al tratamiento del suicidio como conducta patológica.

Wittgenstein (1914-1916) señala que el suicidio es el eje sobre el cual gira todo sistema ético: "Si está permitido el suicidio, está permitido todo. Si no está permitido nada, no está permitido el suicidio. Esto ilumina la naturaleza de la ética, pues el suicidio es, por así decir, el pecado elemental. Y cuando uno lo investiga es como si investigase el vapor del mercurio para comprender la naturaleza de los vapores $¿ \mathrm{O}$ bien ni el suicidio es en sí mismo ni bueno ni malo? (Citado en Alvarez, 1971). 
Karl Jaspers, filósofo y psiquiatra, dice: "Solamente el hombre, una vez que puede darse cuenta de la muerte, se encuentra delante de la posibilidad del suicidio. El no sólo puede conscientemente poner en peligro su vida sino puede también decidir si quiere o no vivir. La muerte vuelve a entrar en la esfera de su libertad". Continúa diciendo: "quien ha participado de cerca del drama de un suicidio, si está dotado de algún sentido de humanidad y está de algún modo inclinado a ver claras las cosas del alma, encontrará que no hay un motivo único que pueda sólo desde sí explicar su advenimiento. Al fin de cuentas, permanece siempre un misterio" Muchas veces, aquello que arroja a alguien al suicidio es el estado insoportable de angustia, como en las melancolias pero "el origen primero e incondicionado del suicidio permanece como secreto para la persona singular, y no puede revelarse a los otros" (1948) (Citado en Rovaletti, 1998).

Albert Camus, escribe su célebre frase en su ensayo sobre el absurdo El mito de Sisifo (1951): "No hay más que un problema filosófico verdaderamente serio: el suicidio. Juzgar si la vida vale o no vale la pena de vivirla es responder a la pregunta fundamental de la filosofia". Para Camus el suicidio no puede ser la conclusión del absurdo, ni el suicidio corporal que elimina la conciencia ni el suicidio moral del hombre con el sometimiento al absoluto irracional en la filosofia, o al consuelo y la esperanza que ofrece la religión. El razonamiento absurdo rechaza el suicidio y su conclusión última es "el mantenimiento de esa confrontación desesperada entre la interrogación humana y el silencio humano" (1953). Para Camus, suicidarse sería confesar que la vida debiera tener un sentido, que se ha descubierto que no lo tiene y que, por consiguiente, se renuncia a ella. No hay otra salida que tomar conciencia de lo absurdo y vivir la vida, que "se vivirá tanto mejor si no tiene sentido".

Desde otra perspectiva, Marcel también considera que el conocimiento de la posibilidad del suicidio es la base de las vivencias existenciales.

Por último, reseñar las concepciones de E. M. Cioran, para quien suicidarse da fundamento y dignidad al ser humano, pues no es lo mismo esperar la muerte que provocarla. Pero la propuesta que maneja Cioran no es la del suicidio directo como tal, porque matarse se convertiria en la esperanza de la desesperanza. La tesis que propone es que la idea de suicidio es el punto culminante de la lucidez que suple a la muerte efectiva, una toma de conciencia que al pasar al acto se desmiente, es la búsqueda de una libertad interior. Pensar en matarse sienta bien, pensar en ello hace tan libres como el acto mismo. La idea del suicidio tiene relación con lo 
que no tiene solución, es una experiencia-límite. Para Cioran, es en la idea del suicidio y no en el acto donde el ser humano encuentra su verdadera dimensión liberadora (Pinzón León, 2000).

Esta filosofia secular también ha influido en la percepción del suicidio que tiene nuestra sociedad, tendiendo actualmente a diferenciar dos tipos de suicidio: suicidio no patológico y suicidio patológico. El respeto a la voluntad y derechos del individuo hace que se considere en el primer caso el suicidio como un acto racional, una elección de la muerte frente al dolor. El suicidio puede representar la única solución lógica que concuerda con los intereses del individuo, como por ejemplo, la de algunos sujetos con enfermedades incurables. Esta perspectiva ha llevado a la aparición de movimientos que apoyan el suicidio como un derecho de los pacientes terminales, llegando incluso en los mismos al suicidio asistido por el médico. Los referéndum sobre esta cuestión llevados a cabo en varios estados de Norteamérica han sido negativos para esta opción; no obstante, el escaso margen de la derrota refleja un apoyo creciente por parte de la sociedad (Gosh y Víctor, 1995). En Holanda se ha legalizado recientemente la eutanasia. 


\section{c. Concepciones culturales y religiosas sobre el suicidio en otras sociedades}

La referencia conocida más antigua sobre el suicidio es egipcia: "La muerte está hoy ante mí como la curación de un hombre enfermo... como la añoranza de un hombre por ver su casa de nuevo después de muchos años de cautividad..." Hombre debatiendo con su alma sobre el suicidio (Egipto, aprox. 2100 a.c.) (Breasted, 1912). En el Antiguo Egipto el suicidio era visto como un acto neutral, ya que la muerte era solo un paso de una forma de existencia a otra y un medio de evitar la desgracia, el abandono, la culpa o la perdida del amado.

Los vikingos pensaban que Valhalla, la morada de Odín (dios de la guerra y la inteligencia), con sus fiestas perpetuas para héroes y dioses era reservada para los guerreros muertos en el campo de batalla. Los suicidas eran tras éstos los mejor tratados; la gente que moría en la cama sólo podía comer con los pinches de cocina y dormir en el granero.

Durkheim (1897) hace una revisión (pp. 224-5) sobre algunas sociedades que aprobaron los suicidios: los godos creian que los que mueren de muerte natural estaban destinados a pudrirse eternamente en antros llenos de animales ponzoñosos. En los límites de las tierras de los Visigodos, había una roca elevada llamada "La roca de los abuelos", desde cuya altura se precipitaban los viejos que se cansaban de vivir. Estos suicidios de viejos, dice Durkheim, eran también casi obligados en los Tracios, los los Hérulos y los Celtas españoles; estos últimos asignaban una mansión de delicias a los que se daban muerte y un espantoso subterráneo a los que morian de vejez o de decrepitud. Algo similar sucedía en India. En Ceos, los hombres que llegaban a cierta edad se reunían en un solemne festín para beber la cicuta alegremente con la cabeza coronada de flores. Lo mismo ocurría entre los Trogloditas y en los Leres.

En China, durante el gobierno del emperador Chi-Koang-Ti, unos quinientos filósofos de la escuela de Confucio se precipitaron al mar para no sobrevivir a la quema de sus libros sagrados (Sarró y de la Cruz, 1991).

En Africa, el suicidio en la antigüedad era frecuente. Uno de los grandes reyes, Sesostris, se mató en su vejez serenamente y con lucidez. 
En el Islamismo, el suicidio es condenado explícitamente en sus reglas y ordenanzas básicas. Mahoma dice en El Corán: "El hombre no muere sino por voluntad de Dios, según el libro que fija el término de su vida" "Cuando el término llegue, no podrá ni retrasarlo ni adelantarlo ni un solo instante" "Hemos decretado que la muerte os hiera por turno y nadie podrá contradecirnos" En la civilización mahometana la virtud que se coloca por encima de todas las demás es la sumisión absoluta a la voluntad divina, la resignación dócil que hace soportarlo todo con paciencia (Durkheim, 1897).

El Talmud hebreo solo permite el suicidio en caso de persecuciones religiosas (Rodríguez Juan, 1997). En la ley judía el suicidio es considerado una de las transgresiones más terribles.

El Budismo acepta el suicidio en casos de enfermedad incurable.

El Hinduismo permite el suicidio en muy pocos casos. Según Durkheim (1897) en las leyes de Manú si el hombre ha llegado ya a cierta edad y ha dejado un hijo por lo menos, puede suicidarse. Los libros sagrados hindúes describen diversas formas de darse muerte voluntariamente, e incluso hoy en día los discípulos de los brahmanes se suicidan frecuentemente (Carbonell y González, 1997).

Rodríguez Juan (1997) resume en su magnífica introducción las diferentes maneras de considerar el suicidio en diferentes sociedades: en la India, los fieles de la secta Jaina se arrojan a las ruedas del carro de su divinidad y la viuda hindú se inmola en la pira funeraria de su esposo (esto última ceremonia se llamó "sutee" y hasta 1892 no fue declarada ilegal). Durkheim refiere en su libro El suicidio (1897) que en 1817 se suicidaron 706 viudas tan solo en la provincia de Bengala y, en 1821, se contaron 2366 en toda la India; Las mujeres estériles y los reyes que abdican se suicidan en la tribu Yuruba de Nigeria; en las tribus sioux y cheyenne de Norteamérica el suicidio está muy unido a sus costumbres sociales; En Japón el suicidio es el precio que se paga por haber faltado a un papel prescrito por la sociedad y existen diferentes nombres para los suicidios según la causa: para después de una derrota, por responsabilidad, para proteger a los suyos, como protesta, etc. (Rodríguez Juan, 1997). El hara-kiri o muerte por desentrañamiento es excepcionalmente valorada. Durante la segunda guerra mundial los pilotos kamikaces japoneses consideraban un honor realizar misiones suicidas estrellando su avioneta sobre objetivos enemigos. 
En los años que siguieron al descubrimiento de América se dio un fenómeno poco recordado por los historiadores: los suicidios masivos de aborígenes que, en las islas del Caribe, prefirieron la muerte al sometimiento y se arrojaban al mar en grupos.

Según Malinowski, quien trabajó en uno de sus libros el tema del delito entre los indigenas de las Islas Trobriand, existen entre éstos, una serie de mecanismos que permiten, además de restablecer el orden social, la redención plena - y no de palabra como ocurre en nuestra cultura- del sujeto que se sospecha ha transgredido la ley de la comunidad. Uno de estos mecanismos es la hechicería, el otro el suicidio. Respecto del último, si bien es un dispositivo extremo de redención, es muy eficaz en el sentido que permite conservar el buen nombre de la familia del sujeto que se cree ha delinquido. La muerte voluntaria del individuo, producida en una acto ritual público, es considerada como una demostración de inocencia del sujeto (Malinowski, 1985).

Emil Kraepelin expone en Las manifestaciones de la locura (1920) la importancia de las investigaciones etnológicas para el estudio de los trastornos psiquiátricos. Él mismo se percató que el suicidio se desconocia casi totalmente en Java entre sus enfermos, lo que Kraepelin relacionó con la ausencia de cuadros melancólicos que observó. 


\section{El suicidio en Psiquiatria}

\section{a. El suicidio en la Historia de la Psiquiatria}

La concepción patológica del suicidio surgió en la primera mitad del siglo XIX a partir de los estudios de los psiquiatras de la escuela francesa (Hernandez Martínez, 1997) y coincide con el nacimiento de la psiquiatría moderna..

Ya a principios del siglo XIX se inician las investigaciones sobre las alteraciones morfológicas y funcionales en las personas que intentaban suicidarse y se busca su causa en localizaciones cerebrales.

Pinel (1745-1826), en su clasificación de las enfermedades mentales introduce el suicidio como una conducta patológica, como "sintoma de melancolía". Critica la creencia de que el suicidio es una enfermedad propia de los ingleses, argumentando que también existe en Francia (Sarró y de la Cruz, 1991).

Su discípulo Esquirol (1838) realiza una concepción clínica y patológica considerándolo un trastorno mental: "el suicidio ofrece todos los caracteres de la enajenación de las facultades mentales" "el hombre solo atenta contra su vida cuando está afectado de delirio y los suicidas son alienados". Desde esta concepción, Esquirol considera que el suicidio no debería ser castigado con la ley (Durkheim, 1897). No obstante, en otras ocasiones Esquirol se referirá al suicidio "como una crisis de afección moral que es provocada por las múltiples afecciones e incidencias de la vida". Además, Esquirol señala que las ideas de suicidio son universales y a menudo normales: "no hay un solo individuo que no haya tenido ideas de suicidio e incluso deseos de precipitarse, cuando se encuentra en un lugar elevado" (Hernandez Martínez, 1997). Por tanto, en otras ocasiones considera el suicidio como un fenómeno consecutivo a un gran número de causas diversas y añade que no es una enfermedad por sí mismo (Durkheim, 1897). Entre estas causas nombra la ambición, la venganza, el orgullo, la ira, el temor, los remordimientos, los amores contrariados, los problemas familiares y las dificultades económicas (Sarró y de la Cruz, 1991).

Jean Pierre Falret, conocido por su descripción de la locura circular, también realizó algunos estudios sobre el suicidio y 
también lo considera resultado de una enfermedad mental (Durkheim, 1897).

Brierre de Boismont recoge en 1856 una casuística de 4595 suicidios consumados y considera que el suicidio es la última manifestación de la desesperación y que además de los trastornos psiquiátricos, los problemas sociales de la época pueden formar parte también de la etiología suicida (Sarró y de la Cruz, 1991).

Emil Kraepelin en su Introducción a la clinica psiquiátrica (1905) dedica la primera lección de su libro al estudio de la melancolía en categorias que denomina de la siguiente forma: melancolía simple con ansiedad y delirio de autoacusación, melancolía con ideas de suicidio y melancolía con ideas delirantes.

Con el cambio de siglo aparecen dos nuevas líneas de investigación novedosas y totalmente opuestas: la sociológica cuyo fundador es Durkheim con su libro El suicidio y la psicoanalítica por Freud. Estas dos concepciones van a influir de forma definitiva en la concepción y valoración del suicidio dentro la psiquiatría.

Durkheim (1897) realiza su propia definición de suicidio: "Se llama suicidio todo caso de muerte que resulte, directa o indirectamente, de un acto, positivo o negativo, realizado por la víctima misma, sabiendo ella que debía producir este resultado. La tentativa es el mismo acto que hemos definido, detenido en su camino, antes de que dé como resultado la muerte". Esta definición se corresponde al acto individual, aunque Durkheim estudia principalmente las causas sociales por las que las cifras de suicidios permanecen constantes en cada sociedad y por las que varian de una sociedad a otra. No obstante, Durkheim no olvida los factores extrasociales o individuales entre los que ocupa un primer lugar la enfermedad mental o "estados psicopáticos". Este autor considera que hay un gran número de suicidios que no corresponden a personas con enfermedad mental, o sea, que son deliberados y que lo que entra en esta deliberación no es psicótico. Para el autor, por tanto, no todos los suicidios corresponden a patología psiquiátrica, por lo que es preciso investigar otros factores, que el autor realiza desde una perspectiva sociológica. En esta definición se incluiría no sólo el acto de darse muerte, sino también el acto de no rehuir la muerte, como en el caso de los mártires.

Freud propone un concepto totalmente opuesto al de Durkheim en relación al suicidio, considerándolo un homicidio o agresividad introyectada y cuya base radica en el instinto de muerte (Thanatos). Menninger (1938) en su obra ya clásica El hombre 
contra sí mismo analiza el suicidio desde los presupuestos de Freud, o sea, desde el instinto de muerte o impulsos primarios de destructividad en contraposición con el instinto de vida o impulsos primarios creadores y constructivos. Si los impulsos destructivos no son neutralizados por estos y no pueden, además, ser exteriorizados, estos impulsos destructivos se vuelven contra el Yo y sobreviene la autodestrucción con el deseo de matar (impulsos derivados de la agresividad primaria), de ser matado (impulsos derivados de una modificación de la agresividad primaria) y de morir. Esta autodestrucción puede ser total (el suicidio) o parcial (formas crónicas y atenuadas de autodestrucción).

A partir de estos autores se desarrolla la teoría y concepción del suicidio a lo largo del siglo y surgen las controversias sobre la existencia o no del suicidio no patológico así como sobre la diferenciación de los suicidios consumados y las tentativas, los conceptos de suicidio crónico, parasuicidios, equivalentes suicidas etc.

Previamente Delmas, hacia 1932, expone sus teorías de que todos los suicidios son patológicos y ligados a trastornos constitucionales aislados. Rojas (1978) resume su doctrina en los siguientes puntos:

1. Todo suicidio implica una enfermedad mental. A veces son desequilibrios emocionales, trastornos neuróticos, etc.

2. El suicidio es un síntoma y no una enfermedad; sintoma ligado a las constituciones psicopáticas de Delmas, sobre todo las ciclotimicas y las hiperemotivas.

3. El suicidio está ligado a la ansiedad "orgánica", considerando este trastorno de origen biológico que aparece en diferentes enfermedades mentales.

Deshaies en 1947 critica esta visión de la psiquiatría clásica sobre el suicidio como síntoma patológico. Indica que el razonamiento lógico del suicidio como acto de locura se basa en un silogismo falso: si algunas personas son suicidas y algunos enfermos mentales se suicidan, los suicidas son enfermos mentales (Sarró y de la Cruz, 1991).

A pesar de ello, en 1967 en Estados Unidos el Instituto Nacional de Salud Mental se pronuncia oficialmente considerando el suicidio como una patología (Hudson, 1983). 
La Organización Mundial de la Salud (OMS), en 1969, intenta consensuar la terminología e introduce el concepto de acto suicida como "todo hecho por el que un individuo se causa a sí mismo una lesión, cualquiera que sea el grado de intención letal y de conocimiento del verdadero móvil".

En la octava revisión de la Clasificación Internacional de Enfermedades (1968) se intentan establecer criterios operativos y claros dentro de las categorías de suicidio (Hernandez Martínez, 1997). Se incluyen en el capítulo XVII por una parte el suicidio consumado y las tentativas de suicidio y por otra las lesiones autoinflingidas intencionadas. Se avisa asimismo que el mismo acto podrá tener un valor diferente según las influencias religiosas, culturales y sociales.

En la CIE 9 se recoge por un lado los intentos de suicidio y por otra el suicidio y las lesiones autoinflingidas que han de codificarse con el código E” (Hernandez Martínez, 1997).

En la CIE 10 (1992) en el capítulo XX se incluyen los suicidios y las lesiones intencionalmente autoinfligidas de X60 a X84, siendo codificado según el método utilizado independientemente que el resultado sea de muerte o no, sin valorar la finalidad del acto, la voluntariedad ni la motivación.

En las clasificaciones de los trastornos mentales realizadas por la American Psychiatric Association (APA) no se incluyen los suicidios como códigos diferentes. En el DSM-IV (1994) el suicidio consumado, las amenazas y tentativas y las ideas de autolísis aparecen como síntomas asociados en numerosos trastornos. Son criterios diagnósticos para el episodio depresivo mayor y el trastorno limite de personalidad. Además, la existencia de intentos de suicidio por sí sola origina una puntuación muy baja (20 como máximo) en la Escala de Evaluación de Actividad Global (EEAG) con la que se valora del Eje V.

Actualmente no existe unanimidad en la concepción del suicidio, aunque se tiende a contemplarlo como un acto individual patológico, sintoma de un trastorno mental. La psiquiatria ha impuesto su perspectiva, aunque dentro de la misma están empezando a aparecer nuevas conceptualizaciones más flexibles (Clemente y González, 1996). 


\section{b. Fenómenos suicidas: Tentativas de suicidio, ideas suicidas, parasuicidios y acciones autodestructivas}

Los antecedentes teóricos de las conductas autodestructivas sin resultado de muerte también provienen de los estudios de Durkheim y Freud.

Para Durkheim (1897), como se ha puntualizado previamente, la tentativa es el mismo acto pero "detenido en su camino, antes de que dé como resultado la muerte". Considera que hay suicidio cuando la víctima, en el momento que realiza el acto suicida, sabe con certeza lo que resulta de él. Pero si la certeza no es muy firme, si hay dudas, es un hecho nuevo con relaciones de parentesco con el suicidio, formas embrionarias de éste. Para Durkheim existe un "continuum" que engloba los suicidios consumados, las tentativas de suicidio, los actos de valor y abnegación en los que se pone en peligro la vida y las acciones negligentes e imprudentes.

Como hemos visto anteriormente, para Menninger (1938) existen formas parciales, crónicas y atenuadas de autodestrucción. En estas formas existiria un deseo inconsciente de morir mientras que la falta de un deseo inconsciente de morir explicaria los fracasos en las tentativas. Los tres tipos de suicidio parcial descritos por Menninger son:

1. suicidio crónico en el que incluye alcoholismo, ascetismo y martirio, invalidez crónica y neurótica, conducta antisocial y psicosis.

2. suicidio localizado como las automutilaciones, las enfermedades fingidas o autoexplotación de las dolencias, la policirugia, los accidentes intencionados y la impotencia y frigidez.

3. suicidio orgánico en enfermedades en las que el ánimo o los deseos del sujeto influyen sobre la evolución.

Por tanto, Menninger amplía el concepto suicida a una extensa gama de posibilidades autodestructivas heterogéneas, concepción que ha sido seguida por muchos autores, como Scheidman (1963) que habla de la muerte "sub-intencionada" y Meerloo (1966) quien acuña el término de suicidio "oculto", todos ellos conceptos similares a los de suicidio orgánico de Menninger (Clemente y González, 1996). Rojas (1978) diferencia suicidio activo en el que el sujeto tiene un comportamiento claro dirigido a su muerte y el pasivo en el que el sujeto va progresivamente mostrando una 
actitud indiferente frente a la vida, no haciendo nada por mantener su integridad física. Otro autor que expone este punto de vista es Farberow (1980) quien propone los conceptos de conducta autodestructiva directa e indirecta. Las primeras corresponden a todas aquellas conductas autoliticas conscientes e intencionadas, se busque o no la muerte, mientras que las conductas autodestructivas indirectas engloban no sólo enfermedades como la anorexia, la interrupción de la medicación prescrita en una enfermedad, las dependencias de sustancias ilícitas, sino también el consumo de tabaco y los excesos de alcohol, los deportes arriesgados etc. (Clemente y González, 1996). Por tanto, se amplía para muchos autores (principalmente psicoanalistas) de tal manera el concepto de suicidio que éste termina englobando aquellos actos que sin ser perjudiciales tampoco están encaminados a la conservación de la vida o que el psicoanálisis ha entendido como contrarios al instinto de vida.

Para algunos autores, como Stengel y Cook en los años cincuenta, la naturaleza y la psicodinamia de la tentativa es diferente a la del suicidio aun cuando ambos tengan varios puntos en común: mientras que el suicidio consumado sería una autoagresión, el intento de suicidio significará muchas veces una acción agresiva contra los otros (Rojas, 1978).

En este sentido se expresa Castilla del Pino (1966) cuando refiere que lo que distingue el intento de suicidio del suicidio es el hecho de que en éste la muerte es la finalidad, mientras que en el primero la muerte se trasforma en el medio con el cual obtener un tipo peculiar de relación humana. El que intenta el suicidio ejecuta una serie de actos que pueden conducirle a la muerte, pero que en todo momento están supeditados a la "presencia real o virtual del otro". Por tanto, el intento de suicidio en cierta medida es una simulación, ya que quiere obtener, aún con el riesgo de su muerte, un tipo de gratificación sádica y no masoquista. Según este autor, en el intento de suicidio las relaciones objetales no están perdidas, sino tan solo temen perderse: el intento de suicidio está más dirigido al otro -al objeto- que a sí mismo y es un casi desesperado último intento para conseguir de nuevo su amor y cuidado. Por eso, el intento de suicidio es siempre resultado de una angustia temor a la pérdida del objeto- mientras el suicidio es la anulación del sentido de la vida merced a la conciencia de la pérdida definitiva e irreparable del objeto.

Esta concepción es expresada también por Kreitman en 1969 (Clemente y González, 1996) quien considera que el suicidio tiene una intencionalidad de morir que no tienen otras conductas autodestructivas y acuña el concepto de parasuicidio o lesión 
deliberada para designar el conjunto de conductas donde el sujeto de forma voluntaria e intencional se produce daño físico, cuya consecuencia es el dolor, desfiguración o daño de alguna función y/o parte de su cuerpo, sin la intención aparente de matarse. Se incluye en esta definición las autolaceraciones (como cortes en las muñecas, los autoenvenenamientos (o sobredosis medicamentosas) y la autoquemaduras; este término, por tanto, no engloba a los suicidios frustrados.

El intento de suicidio es, para Baechler (en Ramírez, 1998), lo que no es el suicidio propiamente dicho, a saber: "un llamado, un signo de alguien que aún espera respuesta, hasta un umbral que, una vez superado, se convierte en suicidio efectivo". Según este autor, hay que separar los suicidios de los "intentos de suicidios", cada vez más frecuentes. Estos aumentan porque aumenta la atención que se les presta y ese es el objetivo de muchos suicidas fallidos.

No obstante, la tentativa de suicidio, al igual que el propio suicidio, es una conducta y puede ser tanto una llamada de atención, como una forma de descarga emocional o de solicitar ayuda, un ensayo del propio suicidio, un paso previo al mismo y en muchos casos un suicidio frustrado.

Para diferenciar el tipo de tentativa se han expuesto numerosos criterios como la gravedad de la misma, la eficacia del método, si es impulsiva o existe premeditación, si el sujeto tiene antecedentes autolíticos, las manifestaciones de intencionalidad que haga el sujeto después. Los intentos sin fines letales son más frecuentes en las mujeres, mientras que la consumación es más probable en los varones (Proporción varón/mujer para el suicidio consumado de $3 / 1$ ). También son más frecuentes en los jóvenes (con menos de 35 años), mientras que la consumación es más frecuente en ancianos (a partir de los 60 años) (Gosh y Víctor, 1995). Los métodos del intento sin intención letal obviamente tienden a ser escasamente mortales - por ejemplo, autointoxicación medicamentosa por debajo del límite mortal, cortes superficiales en la muñeca en comparación con métodos altamente mortales como por ejemplo las armas de fuego o el ahorcamiento. El entorno también va a diferenciar las tentativas con intención letal de las que tienen otras motivaciones: $\mathrm{El}$ paciente que hace un intento en su casa o donde puede ser descubierto, contrasta con el paciente que escoge un entorno aislado, donde hay pocas posibilidades de rescate. El método y el entorno son muy importantes para determinar la posibilidad de rescate que ha considerado el enfermo: cuanto menor es la posibilidad, más serio y potencialmente mortal es el intento. 
No obstante, la valoración de la intencionalidad de la tentativa continúa siendo un asunto controvertido, dificil de evaluar de forma fiable $\mathrm{y}$ sujeto a diferentes interpretaciones $\mathrm{y}$ factores individuales (Conde y cols., 2001).

Existe un riesgo del $40 \%$ aproximadamente de reincidencia en las tentativas de suicidio. La proporción suicidio consumado/ tentativa de suicidio es $1 / 18$. Desde un punto de vista epidemiológico, la tentativa de suicidio es el principal factor predictor de suicidio consumado. Se ha descrito que al menos el $1 \%$ de las personas que realizan un intento suicidio muere por suicidio consumado un año después del intento, un 3\% a los 3-8 años y hasta el 13-35\% a los 5 años (Roy, 1995; Arranz Estévez, 1997 (1); Conde y cols., 2001).

A modo de sintesis, Rojas (1978) realiza la siguiente definición: "se entiende por suicidio aquella conducta o conjunto de conductas que, dirigidas por el propio sujeto, conducen a la muerte ("suicidio consumado") o a una situación de gravedad mortal ("suicidio frustrado") bien de forma activa o pasiva. Estas conductas hay que diferenciarlas, en lo posible, de aquellas que no buscan la muerte ni de forma inmediata, ni mediata, sino que manipulan con la idea de la muerte propia, buscando a su través otros fines bien distintos (estimación, consideración, reafirmación, fines catárticos, etc,). A este apartado pertenecen algunos "intentos de suicidio, chantajes, simulaciones". Este autor diferencia tres formas suicidas básicas: Suicidio consumado, suicidio frustrado e intento de suicidio, entendiendo por suicidio todas ellas.

Por tanto, el concepto de suicidio en psiquiatría abarca tanto el suicidio consumado como la tentativa de suicidio. La mayoria de los psiquiatras, por el contrario, no van a considerar conductas suicidas a aquellas conductas autoagresivas que no son conscientes y cuya finalidad no es la muerte. Diferenciaremos los siguientes conceptos dentro del término general de conducta suicida:

1. Suicidio frustrado: Acción de suicidio que no ha conseguido su fin, teniendo el paciente de forma consciente intención de llegar a él.

2. Suicidio consumado: Es el intento que ha tenido éxito bien como expresión de los auténticos deseos suicidas o como una casualidad no deseada dentro del comportamiento suicida. No siempre es fácil establecer el diagnóstico con seguridad, ya 
que ciertos suicidios pueden confundirse con accidentes y viceversa.

3. Conductas suicidas: Son las encaminadas a conseguir ese fin, consciente o inconscientemente, o el aniquilamiento de una de sus partes.

4. Intento de suicidio: Aquellos actos autolesivos deliberados que no tienen un desenlace fatal, bien porque la conducta autoagresiva es interrumpida en el curso de su desarrollo, bien porque su realización no comporta daños físicos mortales para el individuo (Martínez Rodríguez, 1995).

5. Simulación suicida: Es la acción de suicidio que no llega a su fin, por no existir auténtica intención de llegar a él.

6. Riesgo de suicidio: Es la posibilidad de que un paciente atente deliberadamente contra su vida. Dicho riesgo se incrementa si existe la idea de minusvalía de la vida, deseo de muerte por considerarla un descanso, amenazas y tentativas suicidas previas.

7. Ideación suicida: amplia gama de pensamientos de muerte, ideas e imágenes de carácter general tipo "la vida no merece la pena", "la vida no tiene sentido", con representación de la propia muerte y planes de suicidio o amenazas autolíticas. Implica frecuentemente un riesgo suicida.

Según Rojas (1978) esta ideación suicida puede tener un carácter fundamentalmente obsesivo, como un trastorno del contenido del pensamiento o un carácter impulsivo, o sea, sin sentido de lucha, como un impulso vital de muerte.

Castilla del Pino (1966) ha realizado un análisis fenomenológico de estas ideaciones suicidas en los enfermos depresivos: Refiere que muy frecuentemente la idea de suicidio tiene un carácter obsesivo o fóbico, que tienen por sí mismos una peculiaridad dinamicopsicológica que las distingue de la simple idea de suicidio. Estas dos formas dinámicas traducen las posibles modalidades en la actitud de la persona ante el suicidio o la idea de suicidio. Así, por ejemplo, muchos enfermos se sienten torturados porque la idea de suicidio se presenta independientemente de su voluntad pero sin sentimiento de extrañeza de pertenencia al yo. Reconocen no desear el suicidio, pero la idea de que han de hacerlo o podrian hacerlo está constantemente en su conciencia. El carácter compulsivo de la idea de suicidio es mayor cuanto más se repudia el suicidio como acto inmoral, pecaminoso, etc. Hay, en el fondo, 
un deseo de suicidio que no se quiere reconocer así como tampoco se reconoce el trastorno de la persona que revela la pérdida del objeto. O sea, hay un rechazo total de la propia estructura y dinámica intrapersonal. El autor esquematiza el dinamismo que rige a la idea obsesiva de suicidio en los siguientes puntos:

a) Deseo inconsciente de matarse.

b) Represión.

c) Racionalización de la estructura depresiva: si reprimo ese deseo es que no lo deseo.

d) Trasformación obsesiva del deseo: debo matarme, a pesar de que no lo deseo = absurdidad de la presentación de la idea.

Por el contrario, la idea fóbica del suicidio tiene un dinamismo más simple. Aparece en aquellas personas en que el superyo no es rígido. Su esquema es el siguiente:

a) Deseo de matarse.

b) Represión.

c) Aceptación de la existencia del deseo.

d) Duda acerca de la eficacia de la represión = angustia ante la posibilidad de que se convierta en acto.

Estas ideas fóbicas se presentan en depresiones reactivas más que en depresiones endógenas e indican una inseguridad radical del yo para controlar posibles instancias contrarias a él mismo. La angustia tiene aquí tanto una función de alarma ante la existencia de tales instancias como una función protectora; cuanto más se teme una cosa tanto más lejos se está de realizar aquello que se teme.

Tanto las ideas suicidas fóbicas como obsesivas indican para Castilla del Pino improbabilidad de que la idea llegue a plasmarse en acto, porque solo cuando al suicidio no se le rechaza porque el superyo es vencido, o cuando el suicidio no se le rechaza porque no angustia -porque no se le teme- se puede libremente llevar a cabo. La obsesión y la angustia son expresión tanto de la existencia de un rechazo del deseo como de la existencia de dispositivos que la persona adopta para defenderse del deseo y de su conversión en acto. 
Pero lo que el obsesivo y fóbico del suicidio rechazan no es solo el suicidio sino aquello que hace posible que la idea de suicidio surja, o sea, la pérdida del objeto o irreparable carencia de sentido que su existencia fracasada posee: el reconocimiento de su fracaso. 


\section{c. Diagnóstico psiquiátrico y suicidio}

La relación entre enfermedad mental y suicidio es conocida desde hace siglos. De Boismont ya afirmaba en 1856 de forma lapidaria que "el que se suicida es un desdichado o un loco". Como se ha comentado previamente, aunque Durkheim (1897) estudió principalmente las causas sociales del suicidio no olvidó los factores extrasociales o individuales entre los que ocupa un primer lugar la enfermedad mental o "estados psicopáticos".

Durkheim sigue en su libro El suicidio (1897) la clasificación de Jousset y Moreau de Tours sobre los suicidios de alienados, la cual distingue entre:

1. Suicidio maniático: Como consecuencia de alucinaciones o concepciones delirantes de la manía, caracterizado por la inconstancia e inestabilidad.

2. Suicidio melancólico: Relacionado con la depresión. Puede haber alucinaciones e ideas delirantes que se caracteriza por ser fijas, por su constancia, tenacidad y cronicidad.

3. Suicidio obsesivo: No por motivos reales ni imaginarios, sino por la idea fija de la muerte, por el deseo de matarse contra el que el enfermo lucha y llamado también suicidio ansioso.

4. Suicidio impulsivo o automático: Sin motivos y causado por un impulso brusco e irresistible.

Durkheim añade como estado psicopático que puede conducir al suicidio el alcoholismo y la neurastenia. No obstante, para Durkheim un gran número de suicidios no serian producidos por una enfermedad mental.

Esta consideración no es avalada por la mayoria de los estudios psiquiátricos realizados: En el estudio ya clásico de Robins y col. (1959) se analizaron las vidas e historias de 134 habitantes de St. Louis, que cometieron suicidio entre mayo de 1956 y mayo de 1957 y se llegó a los siguientes resultados: el 94\% de los sujetos que consumaron el suicidio padecían un trastorno psiquiátrico y el 98\% alguna enfermedad. Estas enfermedades eran fundamentalmente trastornos recurrentes del estado de ánimo $(45 \%)$ o alcoholismo (23\%). Más recientemente, otros estudios han hallado resultados similares: el $90 \%$ de los sujetos que se suicidan presentaba un trastorno psiquiátrico en el momento de su 
fallecimiento. Se calcula que el riesgo de suicidio entre los pacientes psiquiátricos es entre 3 y 12 veces mayor que entre las personas no afectadas por enfermedad mental. Un pequeño porcentaje de suicidios se dan en personas que han sufrido la pérdida de un ser querido, desastres económicos o de posición social. También existe una tasa de suicidios en pacientes no psiquiátricos con enfermedades terminales (cáncer, por ejemplo), pero incluso éstos solamente justifican un 5\% del número total de suicidios. En la actualidad un gran número de psiquiatras consideran que la enfermedad mental es un condición necesaria aunque insuficiente para el suicidio (González y cols., 1997).

Alrededor del $70 \%$ de los suicidas presenta depresión o alcoholismo. En los adultos, los diagnósticos psiquiátricos y factores precipitantes varian con la edad. El consumo de drogas y el trastorno antisocial de la personalidad son más frecuentes en los menores de 30 años, mientras que en los mayores de esta edad predominan los trastornos del estado de animo; en cuanto a los factores precipitantes en los menores de 30 años fueron la separación, el rechazo, el desempleo y los problemas legales y en los mayores de 30 años las enfermedades (Roy, 1995).

También se ha observado que ciertos diagnósticos psiquiátricos en paciente suicidas se asocian con el intento o su consumación. Los pacientes suicidas con trastornos adaptativos y de la personalidad (especialmente los trastornos de personalidad del Grupo B) son más propensos a llevar a cabo intentos no mortales, mientras que los suicidas con trastornos del ánimo, psicosis y problemas de drogadicción tienden a consumar el intento (Gosh y Victor, 1995).

En estudios prospectivos, como el estudio Iowa 500 (Roy, 1995) ha hallado una mayor proporción de suicidios en pacientes psiquiátricos $(5,5 \%)$ que en casos control, que fueron las personas que ingresaron durante el mismo período para someterse a apendicectomías o herniorrafia $(0,6 \%)$, lo que confirma la asociación entre suicidio y patología psiquiátrica. Además, en este estudio se vio que en los familiares de primer grado de los pacientes psiquiátricos el riesgo de suicidio fue casi 8 veces superior al de los familiares de los controles y en aquellos pacientes psiquiátricos que se suicidaron fue 4 veces más elevado que en aquellos de los que no se suicidaron.

Algunos autores, como Baechler (1975), critican la equiparación actual de suicidio a enfermedad mental a la que se ha llegado con los datos previamente expuestos. Este autor considera los suicidios no tanto un producto de la enfermedad en sí como de los efectos 
que tal situación tiene sobre el sujeto (vulnerabilidad ante los conflictos, mayor número de problemas para una menor capacidad resolutiva, debilidad vital, etc.) (Clemente y González, 1996).

Los trastornos psiquiátricos en los que existe un mayor riesgo de suicidio son:

\section{Trastornos depresivos}

Los trastornos del estado anímico constituyen la categoría diagnóstica más frecuente entre las personas que se suicidan. Los estudios muestran que la presencia de un trastorno anímico en los sujetos suicidas varía entre el 30\% y el 77\% (Gosh y Víctor, 1995; Roy, 1995).

Se estima que, aproximadamente el $15 \%$ de los pacientes (uno de cada seis) con trastornos animicos se suicidan (Gosh y Víctor, 1995; Schneider y cols., 2001). Sin embargo, muchos de los estudios que apoyan este $15 \%$ no diferencian entre los distintos tipos de depresión (unipolar, bipolar, distimias) e incluyen depresiones asociadas a otras patologias psiquiátricas, como puede ser el abuso de alcohol y otras drogas (Miró, 2000). Además, en muchos de ellos se incluyen poblaciones tratadas y no tratadas (Gosh y Víctor, 1995). Aunque existen datos escasos sobre la tasa de suicidios en la población tratada, la experiencia clínica sugiere que es significativamente inferior al $15 \%$.

Se ha observado que la tasa de consumación del suicidio asociado al trastorno bipolar no tratado alcanza hasta el $20 \%$, siendo la tasa ligeramente más alta en los trastornos bipolares que en los unipolares. La mayoría de los autores están de acuerdo en que el factor predisponente de esta superioridad es el estado bipolar mixto. La experiencia clínica sugiere que el estado bipolar mixto se asocia con un riesgo especialmente elevado de suicidio debido a la peligrosa combinación de un estado muy disfórico y un grado muy elevado de energía y perturbación. Del mismo modo, los pacientes con trastorno bipolar II presentan un mayor riesgo de suicidio.

En aquellas depresiones con síntomas psicóticos o síntomas melancólicos el riesgo suicida es más elevado. En el primer caso las ideas delirantes congruentes (culpa, ruina) o incongruentes (paranoides, hipocondriacas) conllevan a un riesgo de suicidio cinco veces superior a los pacientes con otros trastornos del estado de ánimo (Gosh y Víctor, 1995; Schneider y cols., 2001). En el segundo caso la desesperanza y el comienzo o final del episodio 
depresivo se asocian a un mayor riesgo, ya que en la fase de estado el retardo psicomotor y la inhibición bloquean muchas veces el paso al acto suicida.

La ambivalencia con respecto al suicidio en el depresivo endógeno va a estar entre el desear-hacerlo y no-deber-hacerlo mientras que en el depresivo neurótico está entre desear y no desear hacerlo (Castilla del Pino, 1966).

\section{Trastornos de ansiedad}

Uno de los hallazgos más importantes de los últimos años es que la ansiedad, y concretamente la crisis de pánico, constituye un factor de riesgo de suicidio a corto plazo importante. En el Programa "Psicobiología de la Depresión" del NIMH se recogen los resultados de un seguimiento de diez años en 954 pacientes con trastornos afectivos mayores (Roy, 1995). Los autores describieron nueve factores que se correlacionaron con el suicidio. Seis de ellos lo hicieron con el suicidio durante el primer año de seguimiento y fueron los siguientes: ataques de pánico, ansiedad psíquica grave, disminución de la concentración, insomnio generalizado, abuso del alcohol y anhedonia. Dichos factores, incluyendo la posibilidad de utilizar el alcohol como automedicación para la ansiedad, demostraron la importancia de los síntomas de la ansiedad como marcadores del riesgo de suicidio a corto plazo. Los tres factores restantes que se correlacionaron con el suicidio después del primer año de seguimiento, concretamente en los nueve años restantes, ya habian sido identificado previamente en otros estudios: antecedentes de intentos de suicidio previos, ideación suicida y desesperanza. Por tanto, se considera que la ansiedad en los trastornos depresivos mayores incrementa el riesgo de suicidio a corto plazo.

Ha habido numerosos estudios contradictorios con respecto a la relación del trastorno de pánico con el suicidio. Segui y Canet (1997) han realizado una exhaustiva revisión de estos estudios concluyendo que el trastorno de pánico no complicado apenas aumenta el riesgo suicida. La elevada comorbilidad con otras enfermedades psiquiátricas que incrementan el riesgo suicida (como son los trastornos afectivos, las drogodependencias o los trastornos de personalidad) es lo que explica las altas tasas de conductas autoliticas que aparecen en algunos estudios. 


\section{$\underline{\text { Trastorno por uso de sustancias psicoactivas }}$}

La dependencia a sustancias psicoactivas, sean alcohol o drogas, aumenta gravemente el riesgo de suicidio en un paciente. Es importante observar en este grupo diagnóstico que, aunque el alcohol es la sustancia con mayor prevalencia por si solo, la mayoria de los suicidios ocurren en aquellas personas que abusan de múltiples sustancias. Después de los trastornos anímicos, la drogodependencia constituye el diagnóstico más frecuente realizado en las víctimas del suicidio. El riesgo vitalicio de suicidio en los alcohólicos oscila entre 3\%-15\% (o sea, el riesgo es sesenta a ciento veinte veces más alto que el de la población general) (Roy, 1995). Se calcula que un $25 \%$ de todos los suicidios están relacionados con el alcohol y entre $5-27 \%$ de todas las muertes en alcohólicos son debidas al suicidio. A pesar de ello, el abuso de varias drogas a la vez se relaciona todavía más estrechamente con el suicidio.

En el San Diego Suicide Study (Citado en Gosh y Víctor, 1995) se identificó un abuso mixto de drogas en el $67 \%$ de los suicidios consumados de los adultos jóvenes, y en el $46 \%$ de los suicidios en los adultos a partir de los treinta años. En los últimos años, la prevalencia del consumo de cocaina en forma de crack ha aumentado de forma muy importante, con el consiguiente aumento de los suicidios relacionados con su abuso. En un estudio reciente sobre suicidios consumados en la ciudad de Nueva York, uno de cada cinco individuos había consumido cocaína en los días previos al suicidio (Citado en Gosh y Víctor, 1995). En los heroinómanos se calcula que la tasa de suicidio es veinte veces superior que en la población general (Roy, 1995).

Los drogodependientes que se suicidan suelen ser varones jóvenes que consumen alcohol y otras drogas paralelamente, tienen antecedentes de sobredosis y trastornos psiquiátricos concomitantes, especialmente de origen depresivo. Aunque el suicidio en personas con drogodependencia sucede a veces después de muchos años de evolución de la enfermedad, a menudo es precedido en las seis semanas de una pérdida interpersonal importante. Varios factores favorecen el comportamiento suicida: disponibilidad de dosis letales, administración intravenosa, personalidad antisocial, estilo de vida caótico, impulsividad y en particular momentos de disforia e intoxicación.

En los sujetos con drogodependencia se han encontrado varias similitudes entre los que realizan un intento de suicidio y los que lo consuman, como son la presencia de un diagnóstico psiquiátrico, especialmente la depresión mayor, el trastorno de personalidad 
antisocial, abuso mixto de drogas, trastornos de pánico, trastorno fóbico o ansiedad generalizada. Al igual que los que consumaban el suicidio, los que realizaban un intento tenian antecedentes familiares de alcoholismo y habian experimentado problemas relacionados con el alcohol de forma precoz, generalmente poco después de los veinte años. La principal diferencia entre el grupo de pacientes que intentan suicidarse y los que lo consuman en diferentes estudios, es que los intentos son más frecuentes en mujeres.

El trastorno depresivo y alcoholismo constituyen una combinación muy frecuente y especialmente fatídica que subraya la importancia de reconocer la depresión en el paciente alcohólico. En estudios epidemiológicos como el ECA (Epidemiologic Catchment Area) realizado en más de veinte mil individuos en la comunidad y en diversas instituciones, en cinco ciudades de los Estados Unidos, se recoge que aproximadamente el 30\% de la población con un diagnóstico de depresión a lo largo de la vida presenta un diagnóstico de alcoholismo, mientras que aproximadamente un $40 \%$ de los pacientes con dependencia del alcohol presentan un diagnóstico a lo largo de la vida de depresión. Los sintomas depresivos pueden ser el resultado de un trastorno afectivo subyacente, pero también pueden ser el resultado de los efectos tóxicos directos del alcohol, la alteración hepática y la malnutrición, así como de síndromes cerebrales orgánicos secundarios a traumatismos craneales (Gosh y Víctor, 1995).

Los alcohólicos que se suicidan tienen algunas características comunes y otras diferentes a las de las demás toxicomanías: al igual que en estas suelen ser varones $(80 \%)$, pero de mediana edad, solteros, solitarios y bebedores empedernidos. El 40\% de los alcohólicos que se suicidan ha intentado quitarse la vida con anterioridad. El 50\% sufrió la ruptura de una relación afectiva importante durante el año previo (Roy, 1995). Otros factores de riesgo para el suicidio en el alcoholismo son el desempleo y el padecimiento de una enfermedad grave.

Aparte del riesgo subyacente de suicidio que existe en la propia dependencia del alcohol, la intoxicación alcohólica aguda también aumenta dicho riesgo. Alcohol y drogas producen desinhibición y suprimen la reticencia residual frente al suicidio en el sujeto con drogodependencia, y de este modo sirven como factor precipitante agudo del mismo. El superyo ha sido definido de forma ingeniosa "como la parte del espíritu soluble en alcohol" (Castilla del Pino, 1966). Más aún, la desinhibición y una escasa capacidad de discernimiento asociados a la intoxicación pueden llevar a comportamientos de alto riesgo como las autolesiones y las 
sobredosis. Así, por ejemplo, en un estudio se observó que el $88 \%$ de los pacientes alcohólicos con depresión asociada se habían planteado el suicidio en la semana previa a la hospitalización mientras que el $40 \%$ realmente lo habia intentado, por lo general tras una gran ingesta de alcohol.

\section{Esquizofrenia}

Entre el $10 \%$ y el $15 \%$ de los pacientes con esquizofrenia fallecen por suicidio. La mayoría se quita la vida en los primeros años de evolución, de manera que los esquizofrénicos que se suicidan suelen ser bastante jóvenes. Alrededor del $75 \%$ de los pacientes es soltero y el $50 \%$ realizó una tentativa de autolísis previamente. En la esquizofrenia el riesgo de suicidio máximo no aparece durante la fase aguda sino cuando la psicosis está bajo control y el esquizofrénico se encuentra en la fase de recuperación depresiva de la enfermedad. Las dos terceras partes de los esquizofrénicos que se suicidan presentan sintomatología depresiva; muy pocos lo realizan por mandatos alucinatorios o para escapar de delirios persecutorios. Algunos autores (citado en Gosh y Víctor, 1995) consideran que estos resultados son causados porque los clínicos son más propensos a hospitalizar a personas esquizofrénicas cuando éstas presentan sintomas psicóticos frente a los síntomas depresivos. El efecto de esta práctica es que el esquizofrénico que experimenta de forma activa alucinaciones en forma de órdenes o delirios de persecución es hospitalizado y se evita su suicidio; por el contrario, el esquizofrénico desmoralizado y sin síntomas productivos no es hospitalizado, y por este motivo no es protegido frente a la conducta suicida.

El riesgo de suicidio en la esquizofrenia, al igual que en otros trastornos, parece ser máximo durante el período posterior a la hospitalización. Un tercio de los pacientes se suicida poco después del alta y más de las tres cuartas partes en los seis meses posteriores a la hospitalización (Roy, 1995). Este hallazgo es compatible con la observación de que el riesgo máximo aparece no durante el periodo psicótico, sino cuando éste ya se ha resuelto. En ese momento, los pacientes de hecho tienen un mayor concienciación de su trastorno y pueden reconocer con mayor claridad la realidad de su situación. Posteriormente, en el curso ambulatorio de su enfermedad, los pacientes pueden haber desarrollado estrategias y haberse adaptado a las nuevas circunstancias de su existencia. La implicación clínica de ello es que en la fase posthospitalaria, entre las primeras semanas y los tres primeros meses del alta, el clinico debe estar muy alerta frente a las autopercepciones del paciente, su reconocimiento de la 
realidad, sus estrategias de adaptación y los sistemas de apoyo (Gosh y Víctor, 1995).

Los pacientes esquizofrénicos de mayor riesgo son por lo tanto varones jóvenes, generalmente en los primeros años del trastorno, que se encuentran en remisión y sin sintomas psicóticos, pero permanecen deprimidos y han llegado a la conclusión de que su vida es esencialmente diferente de lo que era anteriormente. Por ejemplo, un estudio realizado por Drake y Cotton (Citado en Gosh y Víctor, 1995) encontró que entre los esquizofrénicos que cometían suicidio, habia un mayor porcentaje con educación universitaria, con mayor conciencia de la gravedad de su patología y un miedo más intenso a un deterioro mayor, en comparación con aquellos pacientes que no se habian suicidado. Estos autores también observaron que la depresión secundaria de los pacientes esquizofrénicos que predisponía al suicidio se caracterizaba como malestar psicológico y desesperanza, más que un trastorno depresivo mayor con signos vegetativos.

\section{Trastornos de la personalidad}

Aunque continúa la polémica sobre si hay o no una personalidad suicida, la mayoría de los autores concluyen que no hay una personalidad con características específicas que predispongan al suicidio aunque algunas características psicológicas como sentimientos de desamparo y desesperanza, agotamiento, sentimientos de inutilidad, vergüenza, culpa, etc., suelen ser comunes en los suicidas (Rubio Larrosa, 1997).

En los trastornos de personalidad hay una mayor incidencia de conductas autoliticas y suicidios consumados, especialmente en los trastornos antisocial, limite, histriónico y narcisista (o sea, en los trastornos de personalidad del grupo B). El trastorno límite de personalidad asociado con los trastornos afectivos va a ser la causa más frecuente de suicidio consumado (Rubio Larrosa, 1997). Además, el peor pronóstico de los trastornos mentales y la mala respuesta al tratamiento cuando existe comorbilidad con los trastornos de personalidad hace elevar el riesgo de presentar conductas autolíticas:

\section{Trastorno limite de personalidad:}

Este trastorno se caracteriza por un patrón general de inestabilidad en las relaciones interpersonales, la autoimagen y la afectividad y una notable inestabilidad (DSM-IV). Algunos autores 
consideran el trastorno límite de personalidad como un equivalente de la personalidad suicida.

En la conducta suicida en un paciente con personalidad límite hay que distinguir entre, por una parte, un intento potencialmente mortal, y por otra, la automutilación crónica o los intentos de suicidio como forma de vida.

La incidencia de suicidios consumados en los pacientes con personalidad límite varía entre el 3\% y el 8\% (Gosh y Victor, 1995).

Con respecto a la psicopatología específica de este trastorno, Kernberg (1984) (Gosh y Victor, 1995) describe los rasgos especiales que se asocian a un elevado riesgo de suicidio: impulsividad, desesperanza, desesperación, comportamiento antisocial y frialdad interpersonal. También describe las características de aquellos pacientes en los que la automutilación y los intentos de suicidio constituyen una "forma de vida" y de esta forma pueden predisponer más al parasuicidio que al suicidio consumado. Para este autor, habría pacientes límites con "masoquismo infantil" que utilizarian el comportamiento suicida para mantenerse conectados con su entorno. Estos comportamientos por tanto aparecen durante los ataques de ira intensos mezclados con momentos bruscos de depresión temporal. Están diseñados para establecer un control sobre su entorno al hacer aparecer sentimientos de culpabilidad en los que le rodean, por ejemplo, después de romper con una relación interpersonal. En otro grupo de pacientes límites el comportamiento suicida es reflejo de un "narcisismo maligno". Estos pacientes experimentan un aumento de la autoestima y obtienen la confirmación de su grandiosidad patológica con el comportamiento suicida. Estas personas transmiten una sensación de calma y "triunfo" sobre el miedo a la destrucción, en contraste con el miedo de sus cuidadores y parientes, que se esfuerzan en evitar que estos pacientes se autolesionen.

\section{Trastorno antisocial:}

Caracterizado por un patrón general de desprecio y violación de los derechos de los demás (DSM-IV). Se calcula que el $5 \%$ de los pacientes con trastorno antisocial de la personalidad se suicida (Roy, 1995). Según Rubio Larrosa (1997) la conducta suicida de los antisociales son una forma primaria de mal control de la agresividad más que una conducta suicida bien elaborada. 


\section{Trastorno histriónico de la personalidad:}

Se caracteriza por un patrón general de excesiva emotividad y búsqueda de atención (DSM-IV). Presentan frecuentes conductas autoliticas cuyo fin no es suicida, sino chantajes afectivos o llamadas de atención.

\section{Trastorno narcisista de la personalidad:}

Caracterizado, según el DSM-IV, por un patrón general de grandiosidad (en la imaginación o el comportamiento), una necesidad de admiración y una falta de empatía. Se ha descrito que el riesgo suicida es elevado cuando existe comorbilidad con el trastorno limite (Stone, 1989) o si presenta un deterioro de su imagen personal (Rubio Larrosa, 1997). 


\section{d. Enfermedad médica y suicidio}

Los exámenes de autopsia de víctimas de suicido revelan que entre el 25 y el $75 \%$ padecian enfermedades físicas y se calcula que en el $11-51 \%$ de los suicidios, éstas contribuyen de forma decisiva en la motivación para el suicidio (Roy, 1995). Por tanto, un número significativo de personas que se suicidan padecen una o más enfermedades físicas, a menudo crónicas. En las personas de edad, la presencia de un trastorno orgánico doloroso o invalidante parece ser un factor determinante para buscar la propia muerte.

Existe mayor riesgo suicida en enfermos somáticos si son varones, tienen más de cincuenta años, es viudo o separado, se encuentran en situación de desempleo o jubilación o viven en medio rural. Son factores precipitantes el dolor, la invalidez, la cronicidad, el descubrir un pronóstico nefasto, el miedo a una agonía prolongada, la falta de apoyo emocional y el ingreso en un centro hospitalario (Sarró y de la Cruz, 1991).

Diversos estudios señalan que la mayoría de los pacientes que padecen una enfermedad médica y llevan a cabo una conducta suicida, sufren también algún trastorno psiquiátrico, sobre todo depresión. El riesgo de desarrollar trastornos mentales en enfermedades crónicas es claro, bien por ellas mismas o bien por las consecuencias biológicas o psicosociales que conllevan, o por la terapéutica utilizada. El suicidio puede ocurrir en el contexto de una depresión mayor, un trastorno adaptativo, un delirium o un trastorno orgánico del ánimo.

Las enfermedades orgánicas que producen aumento del riesgo de suicidio son:

- Cáncer: La prevalencia de cáncer en víctimas por suicidio puede llegar a ser hasta veinte veces superior que en la población normal (Domenech Bisen, 1997) En las mujeres, el $70 \%$ presenta cáncer de mama o genital (Roy, 1995). El riesgo es mayor tras recibir el diagnóstico, durante la quimioterapia $\mathrm{y}$ en la fase terminal. Los factores de riesgo de suicidio específicos en pacientes con cáncer son (Martínez Pascual, 1998):

1. Enfermedad avanzada, mal pronóstico: el $86 \%$ de los suicidios en pacientes con cáncer ocurren en los estados avanzados de la enfermedad. Generalmente, el mal pronóstico y la enfermedad avanzada van unidos. Los 
pacientes con enfermedad terminal tienen más riesgo de suicidio porque tienen más complicaciones de la enfermedad como dolor, depresión, delirium y síntomas deficitarios.

2. Dolor incontrolado: la mayoría de los suicidios son en aquellos pacientes con dolor severo, a menudo controlado de forma inadecuada o mal tolerado. Generalmente se asocia a alteraciones psicológicas y del estado de ánimo.

3. Depresión: los trastornos depresivos afectan al 50\% de los suicidios. Los cuadros depresivos en el cáncer se correlacionan con la influencia fisiológica de la enfermedad sobre el estado de ánimo, la acción de los tratamientos médicos utilizados o las limitaciones psicosociales derivadas de la propia enfermedad.

4. Delirium: La prevalencia de delirium entre pacientes con cáncer es de $25-40 \%$ y aumenta al $85 \%$ en estados terminales.

5. Pérdida de control: algunos estudios han demostrado que el suicidio es más frecuente en aquellas personas que tienen la necesidad de controlar todo lo referente a su cuidado y enfermedad.

6. Psicopatología preexistente.

7. Historia previa de intentos de suicidio.

- Enfermedades neurológicas como epilepsia, esclerosis múltiple, enfermedad de Parkinson, traumatismos craneales, tumores cerebrales, enfermedad de Hughtinton, enfermedades vasculares, demencia. Las enfermedades del sistema nervioso son las que ocupan el primer lugar en el indice de prevalencia de patologia fisica que causan suicidio. La incidencia de suicidios en epilépticos es casi cuatro veces mayor que la existente en la población normal (González y cols., 1997).

- Enfermedades cardiovasculares: Infarto agudo de miocardio, hipertensión arterial.

- Enfermedades reumatológicas: Artritis reumatoide, dolor.

- Enfermedades gastrointestinales: Ulcera péptica, gastrectomía, enfermedad de Crohn, cirrosis hepática, 
patología biliar. Se cree que la elevada proporción de úlceras pépticas entre las personas suicidas se deben probablemente a que el alcoholismo es la causa última de las mismas (González y cols., 1997).

- Enfermedades renales: Insuficiencia renal crónica, diálisis.

- Enfermedades urogenitales: hipertrofia prostática, infecciones, cirugía urológica.

- Enfermedades endocrinas: alteraciones tiroideas, enfermedad de Cushing, síndrome de Klinefelter, hiperparatiroidismo, diabetes mellitus, hiperprolactinemia.

- Enfermedades respiratorias: asma, bronquitis crónica.

- Sindrome de inmunodeficiencia adquirida: En los pacientes con SIDA el suicidio es 36 veces más frecuente que en los grupos control (González y cols., 1997).

- Enfermedades hematológicas: Anemia, porfiria aguda intermitente.

- Trastornos ginecológicos: síndrome premenstrual.

- Alteraciones de los órganos de los sentidos

- Síndrome de fatiga crónica 


\section{Teorias psicológicas explicativas del suicidio}

\section{a. Teorias psicoanaliticas}

Aunque Freud no tratase el suicidio ampliamente, sus obras van a sentar las bases sobre las que el psicoanálisis estudiará el suicidio.

Freud en 1909 en su libro Psicopatología de la vida cotidiana en el primer capítulo describe el impacto que en él había producido el suicidio de un paciente.

Al año siguiente, en sus Contribuciones al simposio sobre el suicidio (1910) vincula el suicidio de los adolescentes a los traumas que encuentran en la vida. En esa perspectiva, Freud considera como una función ética de la familia y la escuela el ser soporte de los sujetos y de empujarlos hacia el placer del vivir. Ante la vida implacable, dice, la escuela debería ser una alternativa de juego y escenificación de la misma, quitándole su carácter traumático y debería encaminar el sujeto hacia un despertar del interés por la vida y por el mundo exterior.

En su artículo de 1917 Duelo y melancolía dice literalmente: "el yo no puede darse muerte sino ... cuando puede dirigir contra sí mismo la hostilidad que tiene hacia un objeto" (T.II, p. 2097). Freud relaciona en este trabajo el suicidio con la depresión y la agresión introyectada: el origen del suicidio está en el deseo de matar a otro, principalmente a un ser amado que provoca ambivalencia $y$ es previamente introyectado, provocando un sentimiento de culpabilidad que llevaria a dirigir hacia sí mismo su agresividad, matándose a sí mismo. Esta visión del suicidio como un homicidio frustrado o agresividad interiorizada ya habia sido expuesta por Stekel en 1910 en el simposio sobre el suicidio realizado por la Sociedad Psicoanalítica de Viena (Sarró y de la Cruz, 1991).

En 1920, en Más allá del principio del placer, modifica la base teórica del concepto de destrucción y agresión, que deja de ser patrimonio de las pulsiones de autoconservación, para convertirse en una nueva pulsión: la pulsión de muerte (Thánatos), contrapuesta al impulso de vida (Eros). Desde esta perspectiva, la melancolía surgiría también desde la autodestructividad que ya no sólo se atacaría al objeto dentro del yo narcisista, como expresión de hostilidad del yo hacia el objeto, sino como destructividad 
primaria, surgida de la base pulsional del ello y facilitada, además, por un goce masoquista que contribuye al mantenimiento de la autodestructividad, aunque constituye al mismo tiempo una tentativa de ligadura de la pulsión de muerte liberada. Se privilegia aquí, para sintetizar, a la defusión pulsional, que genera la autodestructividad primaria, como paso preliminar de la destructividad dirigida hacia el objeto.

En El Yo y el Ello, de 1923, además de instalar la segunda tópica, renueva la vigencia de la dualidad de las pulsiones de vida y de muerte: La tarea de la libido o de la pulsión de vida, dice Freud, es volver inicua la pulsión de muerte, a través de desviaciones hacia el mundo exterior, bajo la forma de aprehensión, dominio o voluntad de poder. Se trata del sadismo originario que deja, no obstante, como residuo un masoquismo primordial, un masoquismo erógeno que en parte se ha transformado en libido, pero que de otra parte continua teniendo como objeto al ser propio. En el corazón del narcisismo, habita entonces la pulsión de muerte, y por tanto, el yo puede matarse cuando introvierte las investiduras amorosas desengañadas, que recubrian sus semejantes perdidos o sus ideales defraudados, fracasados; cuando el destino de la pulsión dirigida hacia afuera se ve sin objeto, la pulsión de muerte que en él se sublimaba, puede retornar sobre el sujeto con toda su carga destructora.

En cuanto al superyo, no sólo es un severo o cruel censor del incesto, sino también una instancia con función "protectora y salvadora". El superyo no es sólo sádico y cruel, sino que es capaz de amar al yo, siempre que éste cumpla con las condiciones impuestas de rehusar el incesto y el parricidio. En el suicida el superyo, por el contrario, se comporta como un déspota caprichoso que utiliza la pulsión de muerte para ensañarse en el yo, en esa inmisericorde furia arrastra todo el sadismo y lo torna masoquismo, para transformarse en "un puro cultivo de la pulsión de muerte" que exige al sujeto el sacrificio de su vida. Es el mecanismo que hace recaer sobre sí mismo la destructividad dirigida hacia un semejante amado que ha causado una herida narcisista en el sujeto. La acción hacia ese objeto queda subrogada en esa introversión avasalladora, en su retorno sobre el yo.

Por tanto, su idea en Duelo y Melancolía, de que el yo sólo puede darse muerte a sí mismo si, en el fondo, se trata en verdad de atacar a otro, ya no puede sostenerse tan estrictamente y no sólo desde la teoría de la pulsión de muerte (Gautier, 2000). En la melancolía es evidente que la conciencia moral ataca al objeto introyectado en el yo narcisista, pero también ataca al yo. Freud afirma que el yo que no se siente amado por el superyo prefiere 
morir, porque los sentimientos de culpabilidad que se dan (inconsciente y consciente) en la melancolía, están en el yo, que es atacado por el superyo, que le reprocha sus tendencias eróticas y agresivas prohibidas.

Marcos Gutier (2000) resume los factores necesarios para el suicidio según Freud en:

1. Ataques o abandono del superyo al yo.

2. Ataques del superyo al objeto introyectado en el yo narcisista.

3. Defusión pulsional muy grave (como dice Freud en su Esquema de 1938: "vastas tormentas instintivas") que libere montos considerables de pulsión de muerte.

Karl Menninger, en su obra clásica de 1938, El hombre contra sí mismo desarrolla una teoría del suicidio siguiendo los presupuestos de Freud. Este autor elabora los siguientes puntos en el estudio del suicidio (p. 75-77):

1. La destructividad en el mundo no puede ser achacada tan sólo a las fuerzas de la Naturaleza o el destino, sino que debe ser atribuida también al propio hombre.

2. Que este espíritu de destrucción de la Humanidad incluye una gran cantidad de autodestrucción, en contradicción con el axioma de que el instinto de conservación es la primera ley de vida.

3. Que la mejor forma de explicar estos hechos es la hipótesis de Freud sobre el instinto de muerte (Thánatos) o impulsos de destructividad contrapuesto al instinto de vida (Eros) o impulsos constructivos y son las diferentes fases entre estos dos impulsos lo que constituye el fenómeno psicológico y biológico de la vida.

4. Estos impulsos son, según Freud, originalmente autodirigidos pero progresivamente se van extrovertiendo en relación con el crecimiento y las experiencias vitales. En sus contactos con los demás, el individuo primero reacciona con la extroversión de sus tendencias agresivas y luego con la extroversión de sus tendencias constructivas o eróticas que por fusión con las primeras pueden alcanzar variables grados de neutralización de la destructividad, desde la total hasta casi ninguna. 
5. Si se interrumpen estas vinculaciones externas o son demasiado grandes las dificultades en mantenerlas, los impulsos destructivos y constructivos se vuelven hacia el Yo.

6. Si tiene lugar esta desvinculación, dominan y prevalecen las tendencias destructivas, sobreviene la autodestrucción en mayor o menor grado hallándose en este caso el deseo de matar y de ser matado y también las formas erotizadas de estos dos deseos.

7. Si los impulsos autodestructivos son superados y parcial aunque no totalmente neutralizados aparecerán formas parciales o crónicas de autodestrucción, que son llamados por el autor suicidios parciales (con sus tres tipos: crónicos, localizados y orgánicos) y que incluyen múltiples conductas autodestructivas heterógeneas.

8. Si los impulsos destructivos sobrepasan en mucho los constructivos, aparece la provocación inmediata de la propia muerte llamada suicidio.

9. Que en los suicidios aparecen siempre elementos de por lo menos dos de los siguientes orígenes, y posiblemente tres. Son: a) impulsos derivados de la agresividad primaria que se cristaliza como un deseo de matar (al objeto que ha sido introyectado), b) impulsos derivados de una modificación de esta primitiva agresividad al actuar la conciencia (provocando sentimientos de culpabilidad) que se cristaliza como deseo de ser matado c) el deseo de morir, que determinará la consumación del suicidio, debiendo sumarse a la intención consciente de morir el deseo inconsciente de morir.

10. Que todo esto "se halla complicado con factores exteriores, actitudes sociales, pautas familiares, costumbres de la comunidad, y también por aquellas distorsiones de la realidad que se dan cuando existe un desarrollo incompleto de la personalidad" Menninger añade en este punto: "El individuo cuyas experiencias infantiles llegan a inhibir su crecimiento emocional hasta el punto de hacer dificil para él establecer y mantener los apropiados objetos externos de absorción de sus amores y odios, será posiblemente aquel cuya capacidad para comprobar la realidad está tan deteriorada como para convertir el suicidio en simplemente otro juego más, parecido al escondite o al regreso al paraíso".

11. Que no se explica el suicidio por herencia, sugestión o factores precipitantes inmediatos, sino que la firme 
progresión de las tendencias de autodestructividad aparecen mucho antes de la consumación.

Para Bowlby (Clemente y González, 1996) por el contrario, el suicidio no supone la existencia del impulso de muerte, sino que se puede explicar como una reacción a la frustración. Este autor enlaza la teoría de la melancolía con la del suicidio, identificando elementos comunes a ambas como son la culpabilidad, el deseo de ser castigado, la regresión y represión de los instintos, la introyección, etc.

Para Lewin en el suicidio subyace la idea de renacer, de volver a la madre, resultado de la fusión del yo y superyo (Clemente y González, 1996).

Glover explica el suicidio como una sobrecarga de energía psíquica ante la que se ve incapaz de actuar, siendo el suicidio una estrategia de escape a la misma (Clemente y Gonzalez, 1996)

Ringel describe en 1953 el síndrome presuicida como un cuadro clínico que anuncia la intención y el deseo de muerte (Rojas, 1978) y que está compuesto de tres síntomas:

1. Estrechamiento de la vida psíquica, con una pérdida de las fuerzas dirigidas hacia el exterior. Hay un aislamiento progresivo, que constituye uno de los factores esenciales en el desarrollo suicida. También aparece una falta de autonomía con aferramiento a otras personas y descenso de la capacidad vital.

2. Inhibición de la agresividad, que no es descargada hacia fuera y se vuelve contra él mismo.

3. Huida a la irrealidad apareciendo las fantasías de suicidio que son pensamientos o representaciones sobre la propia muerte.

Para K. Horney (1942) el acto suicida se fragua por una discrepancia entre el "Yo real" y el "Yo idealizado", que propone una "alienación del yo". En el marco de una alienación grave, un impuso repentino hacia sí mismo produce el acto suicida (González y Ramos, 1997).

Con un punto de vista similar, Jung, desde su propia conceptualización del self, propone su teoría del suicidio. Cuando no existe correlación entre el yo (que representa la realidad) y el self (que representa las expectativas que para y de sí tiene el sujeto 
en la sociedad), aparece una interpretación peyorativa de la vida y que acerca a la persona a la muerte (Clemente y González, 1996). Jung propone también cuatro dimensiones fenomenológicas y una tipologia del suicidio.

Ramírez (1998) resume algunas de las concepciones de Lacan sobre el suicidio: Bajo las investiduras narcisistas, bajo los ideales, se oculta, a nivel inconsciente, una última aspiración del sujeto al reposo y la muerte eterna, como un objeto enigmático y horroroso que coloca siniestramente un suicida en la esencia humana, un objeto llamado en los matemas de Lacan: objeto (a) y que señala que no hay otro goce que el de morir. El melancólico, intenta atravesar los semblantes narcisistas, pasar a través de su imagen, atacarla, para alcanzar ese objeto ominoso que lo trasciende; ensaya atrapar aquello que lo gobierna y escapa a su dominio: "y cuya caída lo arrastra a la precipitación al suicidio, con ese automatismo, ese mecanismo, ese carácter necesario y radicalmente alienado con el cual... se hacen los suicidios melancólicos...”

Otros psicoanalistas actuales no creen que el suicidio se asocie a una psicodinámica específica (Roy, 1995) como es la agresividad hacia el objeto introyectado. Estudios recientes demuestran que la agresión hacia otros - o sea, el comportamiento violento- a menudo va unido a la conducta suicida. En los sujetos violentos estudiados, el suicidio generalmente se asociaba a ataques de ira consciente, y por lo tanto la ira debía interpretarse como un factor psicológico subyacente importante. En los pacientes suicidas tanto violentos como no violentos existen factores psicológicos similares: rabia, miedo, ansiedad, discontrol del impulso, suspicacia y rebeldía. Sin embargo, mientras que en los pacientes no violentos es importante la correlación entre tristeza y riesgo de suicidio, esta correlación no se observa en los pacientes violentos (Gosh y Victor, 1995).

De forma implícita en estas consideraciones previas para explicar el suicidio está la concepción de que la muerte significa lo mismo para todas las personas que se suicidan. En 1957 Wahl llama la atención sobre esto refiriendo que no se puede entender los mecanismos dinámicos mas profundos hasta que no se comprenda su relación con la muerte y el significado inconsciente que tiene la muerte para cada uno. Choron (1968) también llama la atención sobre los diferentes significados conscientes e inconscientes que tiene la muerte para las diferentes personas y que facilitan o inhiben el suicidio. Así, para una persona creyente que se sienta muy culpable el castigo eterno en el infierno puede 
ser un castigo seductor mientras que para la mayoría de la gente sea un motivo para no suicidarse (Proença, 2001).

En este sentido, otros autores psicoanalistas han revisado varios de los significados comunes de la muerte y fantasias que presentan los pacientes que cometen suicidio: deseos de venganza, desquite, poder, control o castigo; de reparación, sacrificio o restitución; de evasión o sueño o de rescate, renacimiento, reunión con los muertos o una nueva vida, vergüenza y humillación (Gosh y Víctor, 1995) (Roy, 1995): La fantasia de la reunión con un objeto perdido a través de la muerte puede justificar el fenómeno de los suicidios en los aniversarios, así como los suicidios que ocurren durante el periodo de duelo; la fantasía del renacimiento se relaciona con la de identificación con el objeto perdido: los pacientes se ven a ellos mismos como incompletos en ausencia del objeto ausente y ven la reunión a través del suicidio como una forma de renacimiento; el suicidio y sus intentos como desquite, búsqueda de poder y del control se observan en aquellos pacientes que sienten que la única forma de sobreponerse a una situación es a través del control de la vida o la muerte; el suicidio como venganza se correlacionaría con la teoría freudiana clásica de que el sujeto desea de forma inconsciente matar el objeto perdido ambivalente. Como extensión de esto, la ira inconsciente y el impulso homicida se observan como una necesidad de autocastigo o expiación. El paciente se siente culpable por el odio que siente por el objeto y el suicidio no solamente sirve como venganza, sino que también consigue la expiación; la vergüenza y la humillación son otros dos factores que a veces subyacen en el suicidio. Determinados sujetos pueden considerar el suicidio como un mecanismo para "salvar las apariencias" tras sufrir una humillación social, como en el caso de una pérdida súbita de estatus o poder económico (Gosh y Víctor, 1995). 


\section{b. Otras teorias psicológicas}

\section{Teoria de Beck : Triada cognitiva}

Para los psicólogos cognitivos los aspectos psicológicos esenciales en la mayor parte de los actos suicidas son la ansiedad, la culpa, la dependencia, la desesperanza, la indefensión y el abandono (Hernandez Martínez, 1997).

Para Aaron T. Beck (1979) la sintomatología depresiva surge de forma progresiva de patrones cognitivos negativos y distorsionados a través de lo que llama triada cognitiva (visión negativa del mundo, visión negativa de sí mismo y tendencia a interpretar las experiencias de una forma negativa). Para este autor todos los sintomas de la depresión, incluyendo las ideas suicidas, pueden interpretarse como consecuencia de estas cogniciones distorsionadas. Así, las ideas de suicidio son interpretadas como una expresión extrema de un deseo de escapar de los problemas y situaciones que le parecen intolerables e imposibles de resolver, por lo que se sienten desesperanzados. La desesperanza es un factor clave en la ideación suicida y es definida por Beck como un sistema de esquemas cognitivos sobre experiencias negativas de futuro (Hernández Martínez, 1997). Existe una elevada asociación de la desesperanza con el riesgo suicida a largo plazo. No siendo específica de la depresión, la desesperanza puede acompañar a la desmoralización en otros trastornos como son la esquizofrenia, los trastornos de la ansiedad, y los trastornos crónicos de origen médico. Beck ha elaborada una escala (Escala de desesperanza de Beck) para valorar en qué grado una persona tiene esperanzas negativas sobre el futuro (Gosh y Victor, 1995). Este autor considera que las cuestiones que se relacionan más directamente con el pesimismo como son la sensación de fracaso, el desagrado de uno mismo y la ideación suicida identifican en los pacientes depresivos aquellos con más riesgo suicida.

Kobler \& Stotland (1964) (en Proença, 2001) aplicaron estos conceptos de esperanza y desesperanza para estudiar el dramático aumento de suicidios en pacientes psiquiátricos de un hospital. Este incremento fue relacionado con el deterioro del optimismo de los profesionales por problemas administrativos y conflictos de liderazgo.

Además de la desesperanza, autores como Hendin (en Gosh y Victor, 1995) y Castilla del Pino (1966) han identificado la desesperación como otro factor importante del suicidio. La 
desesperación implica no solamente un sentimiento de desesperanza por un cambio, sino también el sentimiento de que la vida es imposible sin dicho cambio. En su significación originaria implica carencia de todo futuro, o mejor, carencia de interés en el futuro. La culpabilidad es considerada también como otro componente afectivo de la desesperación.

\section{Teoria de Seligman: La indefensión aprendida}

Seligman fundamenta su teoría de la indefensión aprendida en la idea de que la percepción continuada por parte de un sujeto de no correlación entre los objetivos esperados de sus actos y los resultados de los mismos puede provocar en éste un sentimiento de impotencia e incapacidad de control. Esta experiencia de incontrolabilidad provoca un sentimiento de indefensión y déficits en la personalidad a nivel motivacional, cognitivo y emocional que se traducen en depresión y, en su intensidad máxima, en suicidio.

\section{Teoria de Kelly: Los constructos personales}

La teoria de Kelly (1961) sobre el suicidio se fundamenta en su teoría general denominada "teoría de los constructos personales". Esta teoría se basa en la idea de que la realidad es independiente de la interpretación que cada sujeto haga de ella, siendo esta última la que orienta y condiciona la conducta. Según Kelly, la experiencia valida las expectativas personales cuando se cumplen nuestras anticipaciones y niega nuestros marcos de predicción cuando no se cumplen nuestras expectativas. O sea, se trata de "confrontar el pensamiento con la realidad" (Clemente y González, 1996).

A partir de esta teoría, Kelly explica el suicidio como un acto por el cual el individuo trata de validar su vida, es decir, darle un sentido. Por tanto, para este autor el suicidio no tiene tanto una intencionalidad autodestructiva como la de prolongar y dar significado a la vida. Las dos razones por las que Kelly explica el suicidio son:

1. El futuro es obvio para el individuo y por tanto incapaz de motivarle; no tiene sentido esperar, ya que todo está perdido. Este planteamiento lo hacen con frecuencia los depresivos; Se ha perdido la esperanza. 
2. Cuando, por el contrario, el futuro se muestra al sujeto totalmente impredecible, de manera que éste se siente "obligado a abandonar la escena".

El suicidio es el efecto de la radicalización por parte del sujeto de la definición y extensión de la comprensión de la realidad y construcción de ésta. Así, el suicidio se manifestaría como una forma extrema de depresión, que bien subraya o bien rechaza en exceso la definición de la vida, reduciendo la amplitud del sistema al sujeto mismo, desechando lo externo a él mismo (Clemente y González, 1996).

Para Kelly, por tanto, en el suicida el sistema de construcción de la realidad está distorsionado por defecto o por exceso, y le provoca o bien abatimiento o bien aburrimiento. Además, Kelly introduce un elemento nuevo, la existencia de sujetos psicológicamente muertos, aunque estén biológicamente vivos, que son por estas razones expuestas inactivos social y psicológicamente.

Kelly propone los siguientes términos para explicar el suicidio (Clemente y González, 1996):

1. Dilación versus constricción: Hace referencia a la amplitud del campo de intereses de la persona.

2. Angustia: Entendida en términos de capacidad de predicción.

3. Amenaza: Supone que la persona prevé posibles cambios sobre su identidad y duda sobre su capacidad de control de los mismos.

4. Hostilidad: Aparece cuando el sujeto fuerza los acontecimientos para que éstos coincidan con sus predicciones.

5. Culpa: Aparece cuando el sujeto no es capaz de satisfacer las demandas del papel que desarrolla en un contexto social.

6. Postulado básico: Procesos psicológicos de una persona orientados por los parámetros de predicción, es decir, su capacidad de anticipar los acontecimientos.

7. Corolario de elección: Alternativas estratégicas de cada persona para resolver las situaciones y la eficacia de la alternativa elegida. 
En 1983, Neymeyer retoma la teoría de los constructos personales de Kelly y concluye que los constructos personales de los individuos suicidas cumplen las seis caracteristicas siguientes (González y cols., 1997):

1. Anticipación de fracaso, intimamente relacionado con la desesperanza frente al futuro.

2. Autoconstrucción negativa, que tiene mucho que ver con una baja autoestima.

3. Construcción polarizada o pensamiento dicotómico.

4. Aislamiento interpersonal.

5. Constricción en el contenido y aplicación de constructos.

6. Desorganización del sistema de constructos.

\section{Teoria de Rotter: La internalidad/ externalidad}

Para este autor, las conductas y actitudes generales ante la vida y el entorno son resultados de un proceso de elección o inhibición determinado por las propias atribuciones de logro y/o fracaso que las personas hagan sobre sus conductas, condicionadas por la interacción continuada con el medio ambiente y la realidad. Su principal aportación al tema del suicidio radica en su tesis que la experiencia continuada de ineficacia en el curso de la propia vida puede llevar al sujeto a un estancamiento y absorción de las propias limitaciones impuestas por el ambiente, rompiéndose el vínculo entre ambos por agotamiento, reificación de los significados, o simple inconformismo con el estatus y rol socialmente impuesto (Clemente y González, 1996). Por tanto, la teoria de Rotter expone dos de las maneras por las que se puede llegar al suicidio: por suspensión de la proyección social, al no poder realizar las expectativas propias y percibirse el sujeto como incapaz de controlar su vida y los acontecimientos que le suceden; o como alternativa aprendida como plausible ante la falta de realización de ciertas expectativas que le sirven de refuerzo vital.

\section{Teoria de Bachelor: Suicidios "para" y "a causa de"}

El modelo explicativo del suicidio de este autor se basa en parte en el modelo conductual de resolver problemas orientado a un objetivo (1980). Para ello usa "para" en contraste de "a causa de". 
Ofrece el ejemplo de que una persona abre el paraguas "para" no mojarse "a causa de" que le disgusta llevar la ropa húmeda. Las conductas autodestructivas se realizan para resolver una necesidad inmediata a causa de un sistema de creencias fuertemente aprehendido. La perspectiva del tiempo en estas dos ideas es importante; "Para" está relacionado con la conducta futura mientras "a causa de" está basado en las experiencias pasadas. Un cambio de la estructura temporal podría ser útil en el tratamiento de estos pacientes. Por consiguiente, el discurso del paciente acerca de la conducta suicida ("para") como método de conseguir reducir sus necesidades inmediatas requiere una intervención diferente de ("a causa de") las bases de sus sistemas de creencias. El primero, o problema para resolver, puede ser tratado por métodos más cognitivos de modificación de conducta mientras que el segundo o sistema de creencias precisa métodos más dinámicos (Proença, 2001).

\section{Teoria de Maris: La "carrera" suicida}

Maris (1981) realiza un estudio del suicidio integrando hallazgos sociológicos, psicológicos, psiquiátricos y existenciales. Maris usa el modelo de carrera suicida porque para este autor es relevante como reacciona la víctima a las diferentes crisis. Busca los conceptos clave que para este autor son: contingencias letales (letalidad del plan suicida), interacción negativa, relaciones traumáticas tempranas, transiciones malogradas de las distintas etapas de la vida, múltiples problemas en la familia de origen, abuso de drogas y alcoholismo, desesperanza, depresión y los significados de la muerte. Estos conceptos son identificados fácilmente en la historia individual del paciente (Proença, 2001).

Este autor relaciona sus hallazgos con los de la literatura y llega a cinco conclusiones básicas: el suicidio está directamente relacionado con la desesperanza y la depresión; el suicidio está inversamente relacionado con la satisfacción; la desesperanza, la depresión y la insatisfacción están directamente relacionados con métodos letales; la desesperanza está relacionada con la depresión, fracasos repetidos, e interacciones negativas prolongadas con aislamiento social; lo precedente está relacionado con traumas tempranos y problemas múltiples en la familia de origen.

\section{Modelo arquitectónico de Mack}

Aunque basado en el estudio del suicidio juvenil, Mack (1986) propone un modelo arquitectónico aplicable al problema general 
del suicidio que consta de los siguientes elementos (González y Ramos, 1997):

1. El macrocosmos: hace referencia a la influencia del sistema educativo en las epidemias de suicidio entre los escolares, así como a las influencias de la cultura, los factores sociopolíticos y la actividad económica sobre el suicidio.

2. La vulnerabilidad biológica, en especial los factores genéticos puestos de manifiesto en los estudios daneses sobre adopción.

3. Las experiencias tempranas.

4. La organización de la personalidad: fundamentalmente la que hace referencia a la dimensión narcisista, el desarrollo del yo y la autoestima.

5. Las relaciones del individuo: relaciones con los padres, el grado de separación respecto a ellos, las identificaciones, los lazos con otros adultos, y las relaciones con los amigos.

6. La psicopatología: especialmente la existencia de cuadros depresivos y el alcoholismo.

7. La ontogenia: en el sentido de la propia y particular relación con la muerte que tiene cada persona.

8. Las circunstancias vitales: factores precipitantes de tipo biológico (alcohol o drogas) y de índole sociofamiliar (traslados, desavenencias, fracaso escolar, etc.).

\section{Modelo basado en la mente de Bonner y Rich}

Consideran el fenómeno suicida como un proceso dinámico y circular, del que los individuos pueden salir o al que pueden volver a entrar, e incluyen las variables que influyen en éste en dos grupos: en primer lugar, el contexto socio individual que incluye aspectos del ambiente social y del entramado individual del sujeto y en segundo lugar el "estado mental suicida" (González y Ramos, 1997).

Dentro del ambiente social, los autores diferencian dos aspectos: 
1. Contexto social general: se refiere a los cambios sociales, la competitividad, la incomunicación, la valoración social del suicidio y los medios de comunicación.

2. Contexto social inmediato: son las características del entorno específico como los acontecimientos vitales estresantes, el grado de apoyo social, la presencia de conducta suicida en el entorno y las características sociodemógraficas.

En el entramado individual, los autores incluyen los aspectos bioquímicos, las enfermedades psiquiátricas, los factores cognitivos, evolutivos y de personalidad, así como el nivel de tolerancia al estrés y los modos de afrontamiento del mismo.

Por último, el término "estado mental suicida" hace referencia al conjunto de características psicológicos que rodean y acompañan al fenómeno suicida como son la depresión, desesperanza, baja autoestima, soledad, falta de razones para vivir y valoración positiva del suicidio como medio para la resolución de problemas.

\section{Modelo de trayectorias de desarrollo del suicidio de Silverman y Felner}

Silverman y Felner (1995) utilizan el concepto de vulnerabilidad personal, que sería la resultante de la exposición a los factores de riesgo y a los factores protectores. El modelo de trayectoria de desarrollo del suicidio seria equivalente a la historia evolutiva del trastorno, es decir, existirian una serie de procesos que conducen al suicidio y que se deben estar desplegando durante un determinado tiempo (González y Ramos, 1997). En cada etapa de la vida del individuo puede examinarse la presencia de condiciones de riesgo suicida, la adquisición de vulnerabilidades, y aquellos factores que incrementan la capacidad de reacción frente a las condiciones de riesgo.

\section{Teoria socioindividual de Shneidman}

Este autor, considerado en la actualidad uno de los mayores expertos en suicidiología del mundo, reconoce que sus maestros esenciales en el estudio de este fenómeno han sido Melville, Dostoievski y Thomas Mann.

Para este autor el suicidio estaria determinado por tres elementos básicos que son: el dolor, la perturbación y la presión. 
El "dolor" se refiere al dolor psicológico resultante de las necesidades psicológicas frustradas, la "perturbación" hace referencia a un estado alterado e incluye las distorsiones en la percepción y valoración de la realidad (constricción) y la impulsividad. Por último, la "presión" se entiende como los aspectos interiores y ambientales que mueven o afectan al individuo (González y Ramos, 1997). Estos tres elementos suponen un alto riesgo de suicidio que representa el "cese" de la conciencia, que llega a considerarse la mejor solución (Clemente y González, 1996; Proença, 2001).

Todo suicidio, según refiere el autor, tiene como objetivo lograr el fin de una situación cognitiva de sufrimiento inaguantable, provocada por un estresor cuyo origen está en las necesidades frustradas (o sea, es enfocado exclusivamente como un acto para resolver problemas). Además, presenta un sentimiento de aislamiento con respecto a los otros. El sujeto se estanca en una situación de indefensión y desesperanza, mermándose su capacidad de decisión y resolución por una situación de ambivalencia y desorientación cognitiva. Además, su capacidad de percepción se restringe, subrayando lo negativo. La forma de afrontar esta situación es la huida (el suicidio).

Las características comunes que Shneidman (1985) señala en todo acto suicida son (González y Ramos, 1997):

1. El propósito común del suicidio es buscar una solución.

2. El objetivo común es el cese de la conciencia.

3. El estímulo común es el dolor psicológico intolerable.

4. El estresor común es el dolor psicológico intolerable.

5. La emoción común en el suicidio es la indefesióndesesperanza.

6. El estado cognitivo común es la ambivalencia.

7. El estado perceptual común es la constricción.

8. La acción común es el escape.

9. El acto interpersonal común es la comunicación de la intención. 
10. El acto suicida es congruente con los patrones de afrontamiento a lo largo de la vida.

Por tanto, Edwin Shneidman propone una teoria socioindividual que sigue el patrón teórico de vulnerabilidad al estrés que incluye entre las variables que influyen en el suicidio factores del sujeto y de su entorno social. 


\section{c. Etapas en el proceso suicida}

El suicidio no suele ser un acto impulsivo sin premeditación ni planteamientos previos. Se considera que en la mayoría de los suicidios al menos los noventa días previos existe un proceso en su planteamiento con diferentes fases o etapas (Andress, 1996; Segarra y cols., 2001):

En un principio el individuo se plantea la posibilidad de quitarse la vida como solución a determinados problemas de base real o imaginaria. Se trata de una fase ideativa o fantasiosa, en la cual predominan los deseos de escapar ante una situación adversa.

Esta fase ideativa o fantasiosa se continúa con otra etapa, llamada de ambivalencia, en la cual predomina la lucha entre los instintos de vida (Eros) y de muerte (Tánatos). Normalmente es la más larga y se caracteriza por la agitación y falta de descanso. Durante este tiempo la persona lucha con las cuestiones morales y éticas que engloba el suicidio. Se pregunta si el suicidio es o no un pecado y las consecuencias que tendrá en sus familiares y amigos. Todo esto le origina una gran irritabilidad y agitación, que es percibido por las personas cercanas definiéndolo como un período de malhumor e impaciencia. No obstante, en esta lucha resulta fundamental el papel del yo individual como integrador del resto de las instancias psíquicas de la vida del sujeto. Si este yo se encuentra en una situación de debilidad a causa de una estructura de personalidad inmadura o inestable, de una enfermedad somática o mental o de los efectos tóxicos del consumo de drogas es posible que esta fase sea breve y culmine en un suicidio en cortocircuito, impulsivo y poco elaborado.

La siguiente etapa o etapa de resolución, en la que el individuo toma la decisión de suicidarse, es más corta que la anterior y el sujeto parece relajarse y librarse de un enorme peso. A nivel externo pueden identificarse signos indicativos de la misma como realizar o actualizar el testamento, intentos de reconciliación y de "despedida" de las personas próximas, etc.

En la siguiente fase o de planificación, el sujeto planifica el acto suicida y decide que método va a utilizar (dispararse, colgarse, precipitación, sobredosis, etc.) y donde lo hará: en el hogar o en otro lugar y si es en el hogar en que habitación. Piensa que sujeto 
encontrará el cadáver: familiares, amigos, policías, un camarero de hotel, etc. Una vez decididas estas cuestiones, el sujeto empieza a almacenar los objetos necesarios para este fin.

En la última fase o fase de aplazamiento la persona se encuentra más tranquila. Ya decidido, se calma y espera el momento propicio para realizar el acto suicida. Por este motivo, a menudo la familia se sorprende de que haya realizado en esa época el acto suicida "justo cuando estaba más tranquilo". 


\section{Estudios sociológicos sobre el suicidio}

\section{a. El estudio de Durkheim sobre el suicidio}

Sin lugar a dudas, la obra de Emile Durkheim llamada $E l$ suicidio (1897) supone el primer intento de estudiar el tema desde una base cientifica en Sociología, aunque los elementos iniciales para un estudio sociológico del suicidio aparecen ya en la obra de Morselli de 1879 (González y Ramos, 1997). Para ello el autor realiza un análisis estadístico-comparativo de diferentes variables y categorías sociales, tales como el matrimonio, la religión y las normas sociales, bajo la hipótesis de que las diferencias en estas variables explican actos individuales como son la tasa de suicidios en los diferentes países y clases sociales. Para este autor la sociedad es el marco, instrumento y modelo de desarrollo de los sujetos y directa e indirectamente orienta a los mismos hacia el suicidio cuando no es capaz de vincular a los sujetos a la vida a través de ella. La realidad de la sociedad se encuentra en sus valores, ideas, creencias, mitos que a su vez generan modos de conducta, creencias y valores.

Como consecuencia, la totalidad de los suicidios de una sociedad determinada sólo podrá ser explicado sociológicamente y no por motivaciones individuales. La estructura de la sociedad es la que determinará en función de sus características el que los individuos sean más o menos susceptibles al suicidio.

Aunque Durkheim admite la relación de los suicidios con trastornos mentales (a los que denominó factores extrasociales), considera que estos no explican por sí mismos el acto suicida. "Aunque la degeneración, bajo sus diferentes formas, constituya un terreno psicológico, fácil a la acción de las causas que pueden determinar al hombre a matarse, no es por sí misma una de estas causas. Se puede admitir que, en circunstancias idénticas, el degenerado se mate más fácilmente que el sujeto sano; pero no se mata necesariamente en función de su estado. La potencialidad que existe en él no puede traducirse en actos más que bajo la acción de otros factores, que es preciso investigar" (Durkheim, 1897).

Con un esquema de análisis muy sencillo, basado en el método estadístico de Quetelet refuta, además, otros factores considerados relacionados con el suicidio, como la herencia genética y la raza y halla que el suicidio está más extendido en los campos que en las ciudades, que predomina el sexo masculino y que en todos los países la tendencia al suicidio crece regularmente con la edad. 
Señala también la existencia de factores climáticos, considerando que las temperaturas extremas podría favorecer también su desarrollo.

Asimismo, realiza una tipología de los suicidios (que será expuesta en el apartado correspondiente) en función de las características sociales: suicidio egoísta, altruista, anómico y fatalista a los que se suman los tipos mixtos. Los distintos tipos de suicidio van a depender de dos variables: la integración social y la reglamentación social. La primera se refiere al grado en que el sujeto está integrado en la sociedad. Aquellos individuos muy integrados son propensos a los suicidios altruistas mientras que los que no lo están son vulnerables a los suicidios egoístas. La segunda variedad se refiere al grado de control impuesto por la propia sociedad en los fines y sentimientos del individuo. Aquellos que aceptan sociedades de control excesivo son proclives a los suicidios fatalitas mientras quienes rechazan totalmente el control lo son a los suicidios anómicos. La mayoría de las personas van a estar entre medias en ambas dimensiones y por lo tanto son menos proclives a suicidarse.

En resumen, la interpretación sociólogica del suicidio en Durkheim defiende que cada sociedad posee una inclinación específica al suicidio, en función de su estructura, sus características y circunstancias, lo que crea una mentalidad y un estado de ánimo colectivo, que asimilados por los individuos los predispone en cierto grado al suicidio, siendo éste en definitiva una expresión de la predisposición social.

Gibbs \& Martin (1964) amplían el estudio de las dimensiones de Durkheim y la teoría de la integración social. Estos autores consideran que las tasas de suicidio de una población varian inversamente a la estabilidad y permanencia de las relaciones sociales dentro de esta población (Proença, 2001).

Sociólogos como Goffman (1961), Douglas (1967), y Phillips (1974) hacen criticas a estos resultados en base a la variabilidad de los significados sociales entre grupo y grupo o entre época y época. Por ejemplo Goffman señala que las reacciones de la sociedad hacia los estigmatizados son por sí mismas factores que explican el suicidio. Douglas apunta que las personas socialmente integradas podrian camuflar las muertes por suicidio como accidentes. Phillips (1974) considera que la sugestionabilidad o imitación sí puede ser en ocasiones un factor explicativo del suicidio, en contraposición de las opiniones de Durkheim (Proença, 2001). 


\section{b. Otras teorias sociológicas}

\section{Teoria del suicidio de Farber}

Farber (1968) inicia su teoría con la premisa de que "las personalidades más dañadas psicológicamente e insertas en situaciones de deprivación son las que tienen más probabilidades de suicidarse". Posteriormente identifica y analiza cada componente de esta premisa. En el lado de la personalidad subraya en primer lugar el papel de la esperanza y la falta de ésta, relacionada con la sensación de aptitud personal. Por el lado de la deprivación, subraya la capacidad para ser socorrido en las demandas de apoyo interpersonal y la tolerancia para el suicidio dentro de la subcultura de la víctima. Para Farber los factores de personalidad juegan un doble papel: como actores del suicidio y como cerco social para otros actores. Un aumento de los tipos de personalidad vulnerables crearian un efecto multiplicador en el número de suicidas de una sociedad (Proença, 2001).

\section{$\underline{\text { Perspectiva psicosocial de Baechler }}$}

La postura del sociólogo francés Jean Baechler (1975) parte del presupuesto de que el suicidio es una conducta orientada a resolver un problema de forma positiva, o sea, para el sujeto el suicidio es la solución apropiada para una situación que le presiona y le provoca tensión.

Baechler critica a Durkheim por ser excesivamente "sociologista" $\mathrm{y}$ estudia el suicidio bajo presupuestos sociocognitivos y psicosociales, concibiéndole como el desenlace de un conflicto existencial del hombre. Baechler considera que lo que depende de la sociedad es el mito colectivo del suicidio mientras que el acto del suicidio es independiente de la sociedad (Ramírez, 1998). Para este autor el estudio del suicidio ha de ser más cualitativo que cuantitativo, o sea, ha de basarse más en las situaciones concretas que en las estadísticas, ya que los suicidios individuales no son equiparables los unos a los otros debiéndose considerar variables como senilidad, juventud, sexo... puesto que estas variables implican un status, un estilo de vida, unos roles, que son factores determinantes del suicidio y los elementos que mejor definen su realidad (Clemente y González, 1996). Por ejemplo, Baechler relaciona el aumento del suicidio con la variación en los grupos de edad: "el malestar suicida aparece entre los jóvenes cuando su grupo de edad tiende a durar más que la edad de transición, y 
tiende a instalarse por fuera del circuito que normalmente recorre la sociedad". Su hipótesis es que: "el Occidente contemporáneo es, por su naturaleza misma, la primera civilización que convirtió la juventud en un fenómeno social permanente, que la transformó en un grupo social"(en Ramírez O., 1998). Para Baechler, el suicidio tiene relación con la "noción de fracaso". Mientras en las sociedades tradicionales las personas hacían su balance frente a la muerte, en las modernas se adelantó ese momento a veces hasta la adolescencia. Ante los desafios y dificultades de la vida, algunos plantean una "estrategia de poder", o sea de vencerlos, y otros "una estrategia de dependencia", o sea la pasividad para conciliarse y acomodarse; cualquiera de estas actitudes puede llevar a la conciencia del fracaso total y al suicidio, o al semifracaso que aún deja una esperanza: en este caso se apela a la advertencia del intento suicida.

Además, Baechler crítica la equiparación de suicidio a enfermedad mental considerando estos casos no tanto un producto de la enfermedad en sí como de los efectos que tal situación tiene sobre el sujeto (vulnerabilidad ante los conflictos, mayor número de problemas para una menor capacidad resolutiva, debilidad vital, etc.)

\section{Estudios de Estruch y Cardús}

Joan Estruch y Salvador Cardús (1982), en su trabajo sobre la isla de Menorca inciden, como Baechler, en los aspectos cualitativos e individualistas de la conducta por encima de los cuantitativos y sociales confiriendo menor importancia a los factores sociales.

Defienden que el método estadístico es insuficiente para realizar una aproximación al suicidio: cada suicidio debe estudiarse en el contexto que se produce: y la explicación social del mismo expresa más la valoración social del mismo que la realidad (Clemente y González, 1996).

Los principios de los que parten y las conclusiones a las que llegan son (Clemente y González, 1996): no hay suicidio como forma unificada, sino suicidios, todos divergentes $y$ con características propias, efecto de unas situaciones concretas; el suicida previamente debe haber aprendido que el suicidio es una conducta plausible a unas circunstancias dadas; el suicidio es una solución para el que lo realiza y un problema para la sociedad, ya que obliga a replantearse el valor de la existencia; la actitud favorable puede estar incluido en la socialización de la persona, de 
donde provendría la propensión; suele darse un proceso de destrucción de la propia imagen y/o estigmatización; el suicidio no es un problema sociológico, sino que éste está en los factores sociales que pueden reforzar la actitud suicida individual.

Estos autores no conciben el suicidio por imitación sino como aprendizaje. En este proceso van a tener importancia tanto el que personas muy vinculadas afectivamente se hayan suicidado como la permisividad social del suicidio. Ambos refuerzan la aceptación del suicidio como alternativa válida para resolver ciertas situaciones.

Conciben al sujeto basándose en los principios de Interaccionismo Simbólico (Clemente y González, 1996), o sea, no como un simple miembro de la sociedad, sino como un elemento activo que se conforma y socializa en un marco y en unas condiciones concretas, de acuerdo con las cuales desarrolla su identidad, su individualidad y personalidad, haciendo hincapié en los aspectos de la interacción y experiencia como instrumentos de socialización y de modelado del carácter.

Por una parte, el suicidio se relacionaria con crisis de identidad o de imagen social y por otra con la predisposición a aceptar el suicidio como conducta plausible con su situación por los rasgos de carácter, la experiencia social, etc. 


\section{Factores de riesgo suicida}

Los factores de riesgo suicida son un concepto estadístico que relaciona determinadas variables de la persona y del ambiente con la frecuencia de aparición de un trastorno. Si esta relación es significativa, entonces se valora como factor de riesgo.

Los análisis estadísticos han mostrado que hay una diferencia significativa en la tasa de suicidios de algunos subgrupos de la población general que, aunque a veces es escasa, en otras ocasiones puede significar que entre el 10 y el 15\% de las personas que pertenecen a estas poblaciones consumarán el suicidio.

El suicidio es el resultado de la confluencia de múltiples situaciones y factores que se combinan entre sí y que generan un abanico de conductas suicidas que van desde la simple ideación ocasional hasta la consumación del suicidio. Las variables que intervienen en la conducta suicida son muchas e incluyen factores genéticos y biológicos, así como variables sociodemográficas, psiquiátricas y psicosociales.

Blumenthal y Kupfer (1986) (citado en Arranz Estevez, 1997) (2) proponen un modelo que explica las conductas autodestructivas en base a la interacción de múltiples factores de riesgo, agrupados en cinco ejes que constituyen esferas de vulnerabilidad: factores biológicos, rasgos de personalidad, trastornos psiquiátricos, factores familiares y genéticos y factores psicosociales entre los que se incluyen los acontecimientos vitales ("life-events"), los factores ambientales y las enfermedades médicas. La presencia de factores de riesgo pertenecientes a distintas esferas aumenta el riesgo de suicidio.

\section{a. Factores psicosociales, económicos y ambientales}

Dentro de estos factores, algunos autores como Adam (citado en Arranz Estevez, 1997) diferencian entre los de tipo macrosocial, relacionados con las tasas de suicidio de determinadas poblaciones (desempleo, estado civil, etc.), y los de tipo microsocial, relacionados con la producción de una personalidad vulnerable en un determinado individuo. Los factores sociales y ambientales pueden incidir sobre la conducta suicida de tres maneras diferentes: como factores predisponentes, responsables de una 
mayor o menor vulnerabilidad; como factores precipitantes de una conducta suicida en un sujeto predispuesto previamente o como un factor contribuyente que incrementa la exposición de un sujeto a otros factores predisponentes o desencadenantes.

\section{$\underline{\text { Edad }}$}

En general, a más edad mayor riesgo hay de consumar el suicidio. La máxima incidencia está en torno a los 75 años en el hombre y en torno a los 60 en la mujer (Domínguez, 1995; González y cols., 1997). En las últimas décadas se ha observado en los países industrializados un aumento del suicidio en las personas de 15 a 29 años, sobre todo en varones. En algunos países (entre los que se incluye España), el suicidio es la segunda o tercera causa de muerte en los grupos de 15-19 y de 20-24 años. Por tanto, el suicidio es una de las primeras causas de años potenciales de vida perdida (Conde y cols., 2001). Las tentativas de suicidio son más frecuentes en los jóvenes.

\section{Sexo}

Casi el $80 \%$ de los suicidios consumados corresponden a sujetos varones, los cuales presentan un riesgo de mortalidad por suicidio de dos a tres veces mayor que el de las mujeres. No obstante, es interesante mencionar que en el momento actual estamos asistiendo a un incremento paulatino de suicidios consumados entre las mujeres (González y cols., 1997). El número de tentativas de suicidio es siempre más elevado en la mujer, aunque no parece relacionarse estos intentos con el perfil hormonal de la mujer existiendo un bajo poder estadístico en el análisis de asociación entre el momento del ciclo y el intento autolítico (Baca García y cols., 1997).

\section{Orientación sexual}

Se considera que el riesgo es más elevado en homosexuales (Domínguez, 1995).

\section{Raza}

Entre los individuos de raza blanca, la frecuencia global de suicidio es aproximadamente el doble de la de otros grupos étnicos. Las tentativas son también más frecuentes en esta raza. En los 
últimos años, estas diferencias han ido disminuyendo en Estados Unidos, a expensas del aumento de suicidios de indios y negros norteamericanos de 15 a 34 años. En la actualidad, la mayor tasa de fenómenos suicidas de adolescentes en Estados Unidos la presentan los indios navajos (Martínez Rodríguez, 1995). En cambio, en estos grupos étnicos los suicidios consumados disminuyen con la edad. Estos datos sugieren que estas diferencias raciales podrian estar ligados a factores socioculturales como la mayor unión de los componentes de grupos étnicos y minoritarios (Arranz Estevez, 1997).

\section{Distribución geográfica}

Existe un aumento del número de suicidios en los países industrializados No se conoce con exactitud en que medio (rural o urbano) son más frecuentes. En las ciudades hay un mayor número de tentativas y las tasas más elevadas de suicidio aparece en los barrios más pobres. Un estudio japonés concluye que en ese país los suicidios son más frecuentes en el medio rural.

\section{Estado civil}

Los estudios epidemiológicos respaldan las observaciones realizadas por Emile Durkheim (1897) de que el estado civil influye decisivamente en la conducta suicida. El suicidio es más frecuente entre los divorciados y viudos, seguidos, a gran distancia, por los solteros y casados sin hijos, y finalmente, los casados con hijos. En la mujer el suicidio está menos influenciado por su estado civil. El riesgo de tentativa de suicidio es mayor en las personas que han sufrido la pérdida, por abandono o muerte, de la pareja o de un familiar.

\section{Situación laboral}

El desempleo y el paro se habían considerado factores de alto riesgo suicida, pero a medida que se han generalizado estas situaciones en la sociedad occidental, el riesgo de suicidio por estas causas ha disminuido. No obstante, se piensa que una situación de desempleo aumenta las probabilidades de suicidio en personas potencialmente vulnerables. 


\section{Profesión}

Los profesionales de la medicina presentan una prevalencia de suicidio superior a la de la población general, siendo el método más utilizado el medicamentoso (Sarró y de la Cruz, 1991). E1 peligro es mayor en psiquiatras, oftalmólogos y anestesiólogos. Otros profesionales con elevado riesgo suicida son músicos, agentes de seguro, abogados, farmacéuticos y dentistas. En las fuerzas armadas, policiales o personal de seguridad el riesgo es elevado, debiéndose tener en cuenta el fácil acceso a las armas de fuego. Además, hay profesiones que podrian ser consideradas suicidógenas como pilotos de competición, toreros, etc. (Arranz Estevez, 1997).

\section{Aislamiento social}

Entendido como falta de relación con otras personas, más que como separación física, es un factor de riesgo muy importante, ya puesto de manifiesto por Durkheim (1897). Existen numerosos estudios que ponen de manifiesto la gran frecuencia de aislamiento social (pocos amigos, poca relación con familiares, vida en soledad, etc.) en los suicidas. Se asocia al suicidio consumado y en menor medida a las tentativas, lo que algunos autores consideran que se explica porque los sujetos que realizan una tentativa tienen dificultades o problemas con su ambiente sociofamiliar, pero no están totalmente desconectados de él, mientras que los que consuman el suicidio han llegado a un grado más profundo de aislamiento y desconexión de su ambiente social (Arranz Estevez, 1997).

\section{Clase social y nivel cultural}

Los resultados son poco concluyentes y dispares: Parece que la mayor parte de individuos que realizan tentativas de suicidios pertenecen a clases inferiores y que cuanto mayor es el nivel educativo, mayor es el riesgo de suicidio y menor el de tentativa.

\section{Experiencias negativas en la infancia}

La asociación entre experiencias traumáticas infantiles y riesgo de intentos de suicidio a lo largo de la vida está bien documentada. En un estudio reciente realizado por Dube y cols. (2001) se concluye que el padecimiento de estas experiencias adversas tempranas incrementa el riesgo de intento de suicidio entre dos y 
cinco veces, en muchas ocasiones mediando en esta relación el alcoholismo, la depresión y el uso ilícito de drogas.

Además, en algunos estudios existe un aumento significativo de pérdidas parentales (por muerte, separación o divorcio) con respecto al grupo control, aunque en otros estudios no se aprecian diferencias entre ambos grupos. Se ha apuntado que la inestabilidad familiar podría ser la variable etiológica principal de la vulnerabilidad suicida. También se ha relacionado el riesgo suicida con las relaciones conflictivas con los padres y la presencia de padres con trastornos afectivos o que han realizado actos suicidas (Sarró y de la Cruz, 1991).

\section{$\underline{\text { Factores climáticos }}$}

Aunque el suicidio ha sido relacionado con factores como la temperatura, la humedad, los vientos, las fases lunares, etc., ya Emile Durkheim (1897) concluyó que estos factores no influían excepto las temperaturas extremas y la estacionalidad, encontrando una mayor frecuencia de suicidios en primavera y verano, resultado que se ha reproducido en otros estudios. Algunos autores señalan, en cambio, el mes de enero como un mes de alta incidencia de suicidios (González y cols., 1997).

\section{Religión}

Emile Durkheim (1897) destacó las diferencias de prevalencia entre católicos y protestantes europeos y consideró que la religión es un factor protector frente al suicidio por la integración social que proporciona al individuo que la profesa. Otros autores no han corroborado este carácter protector del catolicismo y judaísmo, considerándose actualmente que el factor protector de la religión sobre el suicidio es poco importante, al menos en los países occidentales. Para Castilla del Pino (1966) el temor a la condenación es una excusa utilizada ocasionalmente por los neuróticos para evitar el suicidio. En el melancólico, el suicidio deja de ser falta y no afecta nada en su relación con Dios.

\section{Régimen político}

No parece que el sistema político de un país tenga una influencia directa sobre su tasa de suicidios, al menos en la edad contemporánea. De hecho, países con tasas similares de suicidio tienen regímenes muy diferentes. 


\section{Guerras}

Desde hace un siglo (Durkheim, 1897) se sabe que las tasas de suicidio disminuyen en tiempos de guerra. Es un hecho que se ha verificado en las dos guerras mundiales y en la guerra civil española. Tras ésta, sin embargo, aumentaron el número de suicidios. En la distribución quinquenal del suicidio realizado por el Instituto Nacional de Estadística en España aparece una estabilización de las cifras oficiales del suicidio de 1906 a 1985. Esta estabilización se rompe, no obstante, en el decenio 1936-1945 a expensas, probablemente, de la elevación del número de suicidios existente en la postguerra (Conde y cols., 2001).

La prevalencia de la conducta suicida aumenta en los excombatientes o veteranos de guerra.

\section{Factores de sensibilización biográfica}

Son factores estudiados por Rojas (1978) desde un punto de vista fenomenológico más que estadístico y que inciden persistentemente en la historia del sujeto de forma crónica, paulatina y progresiva e influyen en el "quehacer" del hombre consigo mismo, cerrando toda posibilidad de proyecto vital auténtico. Son:

- El error existencial: que aparece cuando no se encuentra el sentido de la vida. Esto ocurre cuando no se consigue pasar de la inmanencia a la trascendencia, del ser-para-si al serpara-otros o cuando, como dice Castilla del Pino, se ha confundido un subproyecto con el proyecto existencial de la persona.

- Trabajo carente de gratificación.

- Pequeñas y continuas frustraciones: Al carecer de un proyecto vital auténtico estas frustraciones adquieren el relieve de algo insostenible, algo más fuerte que uno mismo que sobrecoge y domina.

- Problemas económicos encronizados, aunque es el que menos va a afectar nuclearmente al hombre. Como dice Castilla del Pino (1966), un fracaso económico para quien haya concebido la acumulación de dinero como único proyecto existencial significa el fracaso total. 


\section{"Cultura técnica"}

Para Rojas (1978) la cultura occidental, basada en la ciencia y la técnica, olvida la vida del hombre concreto, propiciando el suicidio. Los aspectos más relevantes en este sentido son:

- Civilización hedonista: que impulsa exclusivamente a la búsqueda de placer, evitando toda posible situación dolorosa. Pero en la vida hay adversidades que no son posible evitar y el hedonista se hunde en el suicidio como única salida.

- La deshumanización: que conlleva a la incomunicación y la soledad.

- La vida competitiva.

- La vida apresurada, el ritmo de vida y la prisa.

\section{El estrés y los acontecimientos vitales}

Existe una elevada incidencia de acontecimientos vitales estresantes de tipo negativo en los meses anteriores a la comisión de un suicidio o una tentativa. La decisión de suicidarse suele ser tomada bajo fuertes influjos exteriores, o por lo menos, bajo circunstancias con gran repercusión afectiva.

La prevalencia de acontecimientos estresantes es mayor en los varones suicidas que en las mujeres y también se correlacionan con la ideación suicida. Muchas veces el estrés es crónico y lentamente acumulativo. Pueden existir acontecimientos estresantes agudos que desencadenen la conducta suicida, pero la mayoria de los sujetos son capaces de tolerar las situaciones estresantes únicas y limitadas en ausencia de estrés crónico, sin recurrir al suicidio (Arranz Estevez, 1997). Para desencadenar el suicidio, estos eventos estresantes deben situarse en el contexto de una determinada estructura de personalidad y de vulnerabilidad del sujeto al estrés o su capacidad de adaptación al mismo.

Entre los varones los estresores más frecuentes son la enfermedad somática, los conflictos interpersonales y la separación mientras que en la mujer son la enfermedad mental, los conflictos interpersonales y la pérdida de un ser querido. En los suicidas jóvenes los estresores identificados más frecuentemente son la pérdida o el conflicto interpersonal, la separación, los problemas 
económicos y los problemas legales. En los ancianos los más frecuentes son la enfermedad somática y la jubilación.

Rojas (1978) en su estudio fenomenológico sobre el suicidio, resume las tres vertientes básicas sobre las que van a actuar los factores desencadenantes. Para esto, toma como punto de partida la estratificación de la afectividad de Max Scheler:

- Crisis somáticas (en relación con los sentimientos vitales o ser-para-la-vida): Las enfermedades somáticas graves, como el cáncer, pueden desencadenar el suicidio cuando son vivenciadas como una situación límite, en donde el hombre pierde apoyo y se hunde su firmeza, sintiéndose impotente. Para Rojas en este caso solo hay dos posibilidades: el suicidio y el salto existencial. En este último, el sujeto da a "esta experiencia singular un sentido existencial de cambio, de autenticidad, de madurez".

- Crisis ideológicas (en relación con los sentimientos anímicos o ser-para-sí): en las que la vida pierde su sentido, pueden delimitar un tipo específico de suicidio: el suicidio por balance existencial, típico de las depresiones existenciales de la involución. Se examina la existencia desde la sintomatología depresiva, la tristeza vital y los sentimientos de culpa distorsionan los recuerdos biográficos. Este balance también puede aparecer en jóvenes y hombres maduros.

- Crisis espirituales (en relación con los sentimientos espirituales o ser-para-otro): Incapacidad para comunicarse con los demás de forma auténtica, para amar.

Sobre estas dimensiones, determinadas circunstancias van a dar lugar a la conducta suicida. Estas pueden ser innumerables como disgustos familiares, problemas económicos, crisis políticas, problemas conyugales, infidelidad matrimonial, conflictos profesionales, embarazos no deseados, etc. 


\section{b. Factores biológicos}

Los estudios que detallan varios métodos no biológicos para prevenir el suicidio han sido casi universalmente negativos. Efectivamente, incluso los factores demográficos de riesgo expuestos previamente no permiten realizar previsiones certeras sobre quién puede cometer suicidio. Además, los programas organizados de prevención del suicidio con un enfoque psicoterapéutico y/o psicosocial no han tenido resultados positivos. Estos malos resultados en la valoración y prevención del comportamiento suicida han impulsado la búsqueda $\mathrm{e}$ identificación de factores biológicos implicados en la génesis de la conducta suicida. Los resultados biológicos en pacientes candidatos al suicidio parecen ser independientes del diagnóstico. Aunque una hipótesis reduccionista es inaceptable, la perspectiva biológica podría tener su puesto en la facilitación del acto suicida y no en la complejidad cognitiva y emocional subyacente (ideación suicida, deseo de morir y sentimientos de culpa, evitación del dolor, manipulación, etc.) (Ros Montalban, 1997)

\section{Factores genéticos}

\section{Estudios de riesgo familiar:}

En algunas familias se observa un alto índice de suicidio. Los familiares de primer grado de pacientes suicidas tienen un riesgo ocho veces mayor de suicidio que las familias controles normales. El 6\% de los sujetos que se suicidan tenían un pariente suicida, siendo esta tasa 88 veces mayor que en la población general (González y cols., 1997). Además, una historia familiar de suicidio incrementa el riesgo de una tentativa de suicidio violenta. Una historia familiar positiva de suicidio violento debería ser considerada como un fuerte predictor de conducta suicida en personas con trastorno depresivo mayor (Ros Montalbán, 1997). No obstante, estos fenómenos pueden ser explicados por otros factores de tipo psicológico, psicopatológico, sociocultural o de sensibilización a este tipo de muerte y pueden inducir a errores en la interpretación de una hipótesis genética. 


\section{Estudios en gemelos:}

La posible importancia de los factores biológicos del comportamiento suicida se sugirió a partir de estudios sobre suicidio consumado que demostraban una tasa de concordancia superior en los gemelos monozigotos respecto a los dizigotos, siendo estas diferencias estadísticamente significativas.

\section{Estudios de adopción:}

Estudios con familiares biológicos de sujetos adoptados que cometieron suicidio hallan una incidencia superior de suicidio en los primeros en relación con los parientes biológicos de un grupo control. Se encuentra una correlación altamente significativa en los estudios realizados para los sujetos que están relacionados sólo genéticamente (padres biológicos) que hayan cometido suicidio o que sufren algún trastorno depresivo. Dado que esta correlación es muy superior en las víctimas suicidas adoptadas con el diagnóstico de "reacción depresiva" se ha sugerido que el factor genético del suicidio podría traducirse en una inhabilidad para controlar las conductas impulsivas, independiente o adicionalmente a un trastorno psiquiátrico (Ros Montalbán, 1997).

\section{Estudio de la población Amish en EE.UU.}

Los amish constituyen un grupo religioso que se caracteriza por la no violencia, la abstención en el consumo de drogas, una elevada cohesión sociofamiliar y una concepción del suicidio como pecado final, con unas tasas muy bajas del mismo (González y cols., 1997). Se comprobó que 24 de los 26 suicidios a lo largo de cien años fueron consumados por sujetos diagnosticados de trastornos afectivos y pertenecientes a cuatro únicas familias.

\section{Factores neuroquímicos}

En la última década han proliferado muchos estudios que describen una exploración mucho más directa del funcionamiento neuroquímico de los pacientes suicidas. Aunque existen varios factores neuroquímicos implicados, la cuestión principal parece 
estribar en las alteraciones de la transmisión serotoninérgica en el sistema nervioso central.

\section{Estudios postmortem de las víctimas del suicidio:}

Los primeros estudios postmortem realizados en cerebros de víctimas del suicidio se realizaron para investigar los trastornos bioquímicos subyacentes en los pacientes deprimidos porque entonces se pensaba que todas las víctimas del suicidio tenían depresión. En general, se observa que la serotonina y su metabolito más importante, el 5-HIAA se hallan disminuidos en el tronco cerebral y en otros núcleos subcorticales. No obstante, no se hallan alteraciones de sus niveles en la región cortical (Gosh y Victor, 1995). Estos resultados pueden ser debidos en parte a algunas de las variables implicadas en la realización de estos estudios. Concretamente, los niveles reales de serotonina y 5-HIAA pueden estar influidos por factores como la dieta, la ingesta de drogas o alcohol, el lapso de tiempo transcurrido hasta el estudio postmortem y la toxicidad de algunas formas de suicidio como, por ejemplo, el envenenamiento por monóxido de carbono. Para subsanar estos posibles errores metodológicos, se han realizado posteriormente ensayos de unión a los receptores usando ligandos específicos con resultados en ocasiones discrepantes.

Cuatro de cinco estudios han demostrado una disminución de la unión a la imipramina no solo en el córtex, sino también en el hipotálamo, lo que sugiere una disminución de la transmisión serotoninérgica presináptica en personas que cometen suicidio. Mediante la utilización de ligandos como el espiroperidol marcado con $3 \mathrm{H}$, la ketanserina marcada también con $3 \mathrm{H}$ o el LSD marcado con 125I, es posible determinar los sitios de unión postsináptica de la serotonina. Varios estudios han encontrado un aumento en la capacidad de unión al receptor de serotonina 5-HT2 en el córtex frontal y prefrontal de las víctimas del suicidio. Estos hallazgos sugieren que existe una compensación postsináptica frente a la disminución global de la transmisión serotoninérgica en los pacientes suicidas (Gosh y Victor, 1995).

Estudios postmortem recientes realizados en víctimas del suicidio se han centrado en otros sistemas de neurotransmisión. En éstos se han descrito un incremento en la capacidad de unión a los receptores colinérgicos muscarínicos, aumentos en la unión a los receptores beta-adrenérgicos no solamente en el córtex prefrontal, sino también en el temporal, aumento en hipotalamo y en cortex frontal de la densidad y afinidad de los receptores $\alpha 2$ adrenérgicos, aumento de los receptores mu opiáceos en cortex frontal y temporal de jóvenes suicidas, disminución en los sitios de 
unión del factor liberador de la corticotropina (CRF) (Gosh y Victor, 1995; Ros Montalbán, 1997).

2. Estudios del líquido cefalorraquídeo (LCR) en suicidas frustrados:

Si bien puede argumentarse que el estudio de las aminas biógenas y de sus metabolitos en el LCR refleja de forma algo secundaria la transmisión neuronal real, se ha demostrado una correlación altamente positiva entre el 5-HIAA cerebral determinado en estudios autópsicos y el del LCR. Por lo tanto, los numerosos estudios sobre el 5-HIAA en el LCR pueden considerarse reflejo de su funcionamiento en el SNC (Gosh y Victor, 1995).

Los estudios iniciales del LCR en pacientes depresivos intentaron diferenciar diferentes formas de depresión desde el punto de vista bioquímico. Se observó de forma repetida que aquellos pacientes con intento de suicidio tenian niveles bajos de 5-HIAA, hallazgo de importancia no solamente porque permita distinguir, desde el punto de vista bioquímico, a este grupo de pacientes, sino también desde la perspectiva de prever el comportamiento suicida. Un estudio inicial de Asberg y col. en 1975 demostró que el $21 \%$ de los pacientes hospitalizados después de un intento y que habían presentado niveles bajos de 5-HIAA en el LCR, de hecho cometían suicidio en el año siguiente a la evaluación inicial. Estudios de otros autores corroboraron este hallazgo inicial de que los pacientes deprimidos cuyos niveles de 5HIAA en LCR estaban por debajo de la normalidad, tenían una mayor probabilidad de intentar suicidarse. En algunos estudios esta disminución solo aparece en los pacientes que recurrieron a métodos violentos y en otros, en los pacientes con trastorno bipolar, suicidas o no, no pudo realizarse tal distinción atendiendo a los niveles de 5-HIAA en el LCR. Este hallazgo, que contrasta con los resultados de los estudios previamente analizados en los pacientes con depresión unipolar, resulta dificil de interpretar, teniendo en cuenta la elevada tasa de suicidios en pacientes con trastorno bipolar. Algunos autores han postulado que si la disregulación serotoninérgica es el eje central de la génesis del trastorno bipolar, ésta puede enmascarar cualquier otra relación existente entre la hipofunción serotoninérgica y el suicidio en estos pacientes. Se ha visto, además, que la disminución del 5-HIAA en el LCR también diferencia aquellos pacientes esquizofrénicos que han intentado suicidarse de los que no, así como a aquellos pacientes suicidas con trastornos de la personalidad y pacientes alcohólicos con antecedentes de intentos de suicidio (Gosh y Víctor, 
1995; De Dios, 1995). Estos hallazgos también apoyan la idea de que el suicidio no constituye meramente el resultado final de una depresión clínica, sino que puede existir una disfunción serotoninérgica bajo el comportamiento suicida de pacientes con diferentes diagnósticos. El hecho de que los niveles bajos de 5HIAA pueden de hecho constituir un rasgo característico del trastorno también viene apoyado por la ausencia de relación temporal entre el intento de suicidio y los niveles de 5-HIAA del LCR. Los estudios en humanos y animales correlacionan la conducta agresiva con la hipofunción serotoninérgica. Dicha hipofunción puede no implicar una predisposición orgánica específica al suicidio, sino reflejar una disminución del umbral del comportamiento agresivo frente a los otros o hacia uno mismo. Aunque está establecido que los intentos de suicidio que se consuman, a menudo han sido cuidadosamente planeados y no son el producto de una pérdida momentánea del control de los impulsos, los métodos violentos de suicidio a menudo implican una programación todavía más elaborada. Por este motivo, es dificil determinar qué aspectos del comportamiento suicida se correlacionan específicamente con una disminución de los niveles de 5-HIAA en el LCR. Esta alteración, en conclusión, no parece expresar más que una "vulnerabilidad" adquirida a un riesgo de perturbación psiquiátrica y de conducta suicida por falta de control de la agresividad (De Dios, 1995). No obstante, niveles de 5-HIIA en LCR inferiores a la mediana en pacientes psiquiátricos con trastornos afectivos ingresados poco después de haber intentado suicidarse el riesgo de suicidio alcanza el $17 \%$ durante el año siguiente al intento fallido, según un estudio de Nordoström y Asberg (1999), en comparación al $7 \%$ de los pacientes en similar situación clínica con concentraciones de 5-HIIA en LCR superiores a la mediana.

Un estudio con sujetos que habían llevado a cabo un intento violento de suicidio demostró no solamente niveles más bajos de 5HIAA en el LCR, sino también un aumento de MHPG (3-metoxi-4hiroxifenilglicol) el metabolito más importante de la noradrenalina aunque este hallazgo no ha sido confirmado en otros estudios (Ros Montalban, 1997).

En otros estudios, pacientes con depresión y que han intentado suicidarse presentan una disminución de los niveles de ácido homovanílico (HVA), metabolito de la dopamina, en el LCR. En un estudio de seguimiento de 5 años realizado por Roy y cols., los pacientes que intentaron suicidarse por segunda vez después de la evaluación inicial, presentaban niveles significativamente menores de 5-HIAA y HVA. 
Considerando todos estos hallazgos conjuntamente se sugiere, en primer lugar, que es importante considerar no solamente los trastornos serotoninérgicos y, en segundo lugar, que el aumento en la sensibilidad y especificidad de posibles factores biológicos pronósticos de la conducta suicida implica el análisis de varias variables bioquímicas a la vez.

\section{Estudios en plaquetas y tests de provocación farmacológica:}

Se ha sugerido que la plaqueta puede ser un modelo periférico indicador de la actividad central de la neurotransmisión serotoninérgica: Algunos estudios han demostrado que en los pacientes suicidas existe un aumento en el número de receptores de 5-HT2 en las plaquetas; otros autores concluyen que existe una menor sensibilidad de los receptores 5HT-2 plaquetarios en pacientes con tentativas (Gosh y Víctor, 1995; Ros Montalbán, 1997). Algunos trabajos sugieren que una baja actividad de la MAO plaquetaria podría estar relacionada con la vulnerabilidad constitucional de algunas entidades psicopatológicas como el suicidio y las toxicomanías y con determinados rasgos de personalidad como impulsividad, evitación de monotonía, agresión e irritabilidad (Ros Montalbán, 1997).

Los tests de estimulación neuroquímicos se basan en el hecho de que numerosas hormonas pueden verse influidas por el funcionamiento neuroquímico. Uno de los métodos para comprobar la integridad del sistema serotoninérgico consiste en determinar la liberación de prolactina o cortisol en respuesta a agentes farmacológicos como la fenfluramina, precusores como el Ltriptófano o el 5-hidroxitriptófano, o antagonistas de los receptores de la serotonina como la m-clorofenilpiperazina o MK-212. La fenfluramina, agonista indirecto de la serotonina, dotado de una doble acción, ya que por una parte estímula la liberación de la serotonina almacenada en las vesículas sinápticas y por otra inhibe su recaptación por las terminaciones presinápticas, parece ser el estímulo más útil cuando se detectan conductas suicidas (Sáiz y cols., 1997). Algunos estudios han demostrado que existe una alteración en la respuesta de la prolactina frente a la flenfluramina en pacientes que han intentado suicidarse; también se ha demostrado un aumento de la respuesta del cortisol frente al 5-hidroxitriptófano, lo que puede reflejar un aumento de la sensibilidad en el receptor (Gosh y Victor, 1995). 


\section{Determinación de metabolitos neuroquímicos en orina}

La determinación de los metabolitos neuroquímicos en orina puede constituir otra valoración periférica de las diferencias biológicas que subyacen en los pacientes suicidas y no suicidas. Un estudio de 1965 de Bunney y Fawcett sobre los posibles marcadores biológicos del comportamiento suicida encontró un aumento de los 17-hidroxicorticosteroides en la orina de pacientes con depresión y que habían intentado suicidarse (citado en Gosh y Víctor, 1995). Estudios posteriores demostraron un aumento del cortisol urinario, especialmente en los pacientes que habian realizado un intento violento de suicidio (esto es, por ahorcamiento o con armas de fuego). También se ha hallado que los pacientes con depresión e intento de suicidio tenían niveles significativamente menores de dopamina, HVA y ácido dihidrofenilacético en comparación con pacientes deprimidos no suicidas. 


\section{Tipología del suicidio y de los fenómenos suicidas}

\section{a. Clasificación de los fenómenos suicidas de Enrique Rojas}

Rojas, en su magnífico ensayo Estudios sobre el suicidio (1978), realiza una ordenación exhaustiva de los tipos de suicidio basada en lo que considera puntos fundamentales de cualquier acción suicida: etiologia, forma, intencionalidad del acto, resultados, curso, gravedad, número de personas que realizan el acto, conciencia de éste y actitud del sujeto. Expondremos someramente cada uno de los tipos, ya que es una clasificación que engloba tipologias de otros autores e introduce conceptos previamente referidos o que se expondrán posteriormente.

\section{Según la etiologia:}

- Suicidio psicótico: Aquel que sucede en el curso de una psicosis. Incluyen las depresiones endógenas y por tanto es una de las causas más frecuentes de suicidio.

- Suicidio neurótico: A este grupo pertenecen la mayoría de los intentos de suicidio y chantajes suicidas. El autor considera que el factor "angustia-ansiedad" puede ser determinante para el paso al acto.

- Suicidio social: Donde incluye la tipología de Durkheim.

- Suicidio psicodisplásico: Donde se incluyen los suicidios realizados por personalidades psicopáticas o trastornos de la personalidad, según la terminología actual. El autor sigue la tipología de la personalidad descrita por Kurt Schneider, considerando que los actos autoagresivos son más frecuentes en los depresivos, los inseguros de sí mismos y los explosivos.

- Suicidio filosófico: En el que el sujeto no padece ninguna enfermedad psíquica, a lo más se trata de una personalidad extraña o extravagante, que por un proceso reflexivo "descubre" la falta de sentido de su existencia o de la existencia humana en general. Ya no se vive el futuro como anticipación, como expectación que forma parte del presente, 
sino que pierde su carácter ilimitado $y$ se reduce, enfocándose en la muerte.

\section{Según la forma:}

- Según la dinámica formal:

- Suicidio impulsivo (en cortocircuito): Aquel que se lleva a cabo súbitamente, sin avisos previos. Pueden aparecer en esquizofrénicos como resultado de sus pseudoalucinaciones psíquicas con voces que le ordenan quitarse la vida. También en distimicos con cambios bruscos de humor.

- Suicidio obsesivo: La idea de suicidio es intrusiva, sin que el sujeto pueda rechazarla.

- Suicidio reflexivo: Esta forma está en el polo opuesto del impulsivo. La idea de matarse pasa por la mente del enfermo con tal detenimiento, que éste pormenoriza el valor de su propia muerte desde la desesperación. Es típico de la depresión. En una primera etapa aparecen manifestaciones explícitas o implícitas de muerte en general con frases como "para vivir asi lo mejor es morirse" que terminan en la consideración de la posibilidad suicida. La idea de la muerte pasa de ser algo pasivo a ser algo activo. El segundo estadio es de ambivalencia, no saber que hacer, luchar con la vida y con la muerte. El tercero es el de las influencias informáticas en el que cualquier noticia, comentario o información actúa como dinamizador. Por último, la etapa de la decisión suicida, generalmente precedida los dias anteriores de una disminución de la angustia.

- Suicidio histriónico: se hace una representación de apariencia suicida con el fin de llamar la atención, conseguir la consideración de los demás, recobrar el amor perdido, etc. Son típicos en histéricos y en algunas adolescentes.

- Según la técnica:

- Suicidios de técnica suave: Más propio de mujeres, son la intoxicación medicamentosa y asfixia por gas.

- Suicidio brutal: Utilización de ahorcamiento, armas de fuego y arma blanca, precipitación desde la altura. 
- Suicidios de técnica intermedia: entre los dos grupos anteriores.

- Suicidios insólitos: Casos extravagantes y muy raros.

- Suicidios enmascarados: Por la técnica en sí misma asemeja más un accidente que un suicidio: accidentes de tráfico, etc.

- Suicidio social y moral: Técnicas autodestructivas no inmediatas, no se interrumpe la vida bruscamente, es como una muerte en vida.

\section{Según la intencionalidad:}

La idea de muerte y la idea de suicidio pueden ser manejadas con distintos fines, incluso muy alejadas de la aparente intencionalidad suicidógena.

- Suicidio con intención de morir: Si el suicidio no es consumado es por la intervención de otras personas o por desconocimiento de la técnica.

- Suicidio como huida de una situación insostenible: Es un deseo de escapar circunstancialmente de un momento conflictivo que alcanza ya un nivel tan alto, que el sujeto lo vivencia como superior a sus fuerzas.

- Conductas de riesgo: como búsqueda de riesgo innecesario o como acto de heroísmo. El riesgo y su permanente burla les ofrece una forma de compensación a sus sentimientos de inseguridad e insatisfacción (Castilla del Pino, 1966).

- Suicidio de intencionalidad ordálica: La acción autodestructiva se deja en manos del destino o se hace de ella una especie de juicio de Dios.

- Veleidad suicida: Variante de las dos anteriores o al menos relacionada con ellas; tiene un carácter de ligereza caprichosa, de inconsistencia, casi de antojo. Puede tener dos manifestaciones básicas, existiendo frecuentemente ambas, utilizándose el término de "gesto suicida":

- Carácter lúdico: el sujeto muestra una especie de juego con la muerte, solo o implicando a otras personas. 
- Intención catártica: gracias a la cual el paciente se siente liberado de sus tensiones internas, teniendo muchas veces un efecto profiláctico frente a otras acciones futuras similares.

- Chantaje suicida: Frecuente en personas con situaciones conflictivas que se han ido encronizando hasta alcanzar un punto en el que solo la manipulación de la idea de suicidio puede hacer recobrar el diálogo perdido con el entorno. Puede ser bastante teatral.

- Suicidio como revancha: como acusación a otras personas de haber tenido que llegar a esta situación. Esta intención a veces no es fácil de descubrir. Existe en él una agresión velada hacia otra persona, el deseo de herir a otra persona haciéndose daño él mismo.

- Suicidio por balance existencial: Hay personas, que en momentos avanzados de su vida, hacen un análisis de los resultados de su existencia. Si es negativo y lleva al suicidio frecuentemente es causado éste por una depresión, o sea, es un suicidio depresivo. Pero a veces no existe tal depresión. El autor pone de ejemplo "ciertos jóvenes adolescentes que, tras un fracaso amoroso o estudiantil, deciden suicidarse, desbordados por una impulsividad descontrolada que no puede ser encauzada hacia el exterior y que revierte hacia ellos mismos".

\section{Según la relación de integración con la sociedad:}

El autor incluye en este apartado los tres tipos de Emil Durkheim, que se expondrán en el siguiente apartado.

- Suicidio egoísta.

- Suicidio altruista.

- Suicidio anómico.

\section{Según los resultados:}

- Suicidio consumado: Es el suicidio por antonomasia, aquel que termina con la vida, materializando el propósito de morir. A veces se llega a esta situación sin una verdadera voluntad de morir, pero el desconocimiento de la técnica, la 
precipitación del momento del acto y sus circunstancias periféricas pueden dar lugar a la muerte.

- Suicidio frustrado: Con claros propósitos suicidas, pero que por determinadas circunstancias no acaba con la vida, por error de técnica o intervención de otras personas.

- Intento de suicidio: Aquella conducta autoagresiva que manipula con la idea de la muerte pero sin desear realmente morir. Hay en ella un posible peligro de muerte, ya que la técnica, aun siendo "suave", entraña unos riesgos. La idea de suicidio es tomada como medio y no como fin y busca un efecto social, un tipo especial de relación humana. Una de sus características esenciales es la incertidumbre en el resultado para la persona que lo realiza.

- Suicidio aparente: Una variante del intento de suicidio, pero en el cual las autoagresiones son tan pequeñas, ofrecen tan poca significación, que nunca hacen pensar en la búsqueda de la muerte.

- Equivalente suicida: Equiparado a lo que Menninger llama suicidio local, muestran conjuntamente tendencias autodestructivas y autopreservativas, existiendo en la personalidad de estos sujetos una personalidad paradójica. Son los siguientes fenómenos:

- automutilaciones: ataques deliberados autodestructivos. Según la naturaleza de las lesiones, se distinguen: heridas incisas, punzantes, por arma de fuego, quemaduras, erosiones y rara vez contusiones.

- fingimiento de determinadas dolencias para engañar a alguien con una finalidad ulterior. Emparentado con el suicidio aparente.

- accidentes intencionales y policirujía: Puede tratarse de renta o deseos inconscientes de autodestrucción o de inculpación.

- frigidez e impotencia sexual.

- Suicidio moral: o suicidio social, mediante el cual el paciente pretende una autodestrucción a largo plazo, llevando a cabo una forma de vida degradante y que le excluye de todo posible trato social. Es el caso de algunos alcohólicos y de forma más sutil otros casos como la pérdida de prestigio profesional, el descuido o desatención de las actividades sociofamiliares y laborales, la huida del trato con los demás, etc. 


\section{Según el curso evolutivo:}

- Suicidio único: Intento de suicidio que se efectúa una sola vez, ya que tiene efecto catártico, cambia el rumbo de la propia vida e inmuniza contra otras tentativas.

- Intento de suicidio reincidente: Aquel que se repite por diferentes motivos, desde el padecimiento de un trastorno depresivo mayor recurrente como en algunos trastornos de personalidad como los histriónicos.

\section{Según la gravedad:}

- Suicidio mortal: Suicidio consumado, bien por intención de muerte, bien intentos de suicidio que terminan en muerte por desconocimiento de la técnica, aunque en realidad no buscasen la muerte.

- Suicidio muy grave: Corresponde al suicidio frustrado y a ciertos intentos autolíticos.

- Suicidio grave: Las lesiones producidas tienen menor gravedad que en el caso anterior, pero existe aún un evidente peligro de muerte. Corresponde a ciertos intentos autolíticos de intencionalidad ambigua, ciertas conductas de riesgo y los equivalentes suicidas. También aquellos chantajes suicidas y suicidios histriónicos que ponen en peligro su vida por una sobredosis lesiva no buscada.

- Suicidio leve: Corresponde a ciertos intentos de suicidio y, sobre todo, chantajes, suicidios aparentes, gestos suicidas, veleidad, etc.

\section{Según el número de personas que participan en el acto:}

- Suicidio individual: Con mucho, el más frecuente.

- Suicidio doble: El pacto suicida es un acuerdo mutuo entre dos o más personas para quitarse la vida al mismo tiempo y, generalmente, en el mismo lugar. En un estudio realizado por Cohen (1961) en Inglaterra (citado en Sarró y De la Cruz, 1991) los suicidios dobles eran muy infrecuentes, de los que sólo un $10 \%$ eran jóvenes y el $72 \%$ eran parejas con una edad 
media de 60 años en el hombre y 56 en la mujer. En casos aislados eran padre o madre y un hijo o entre hermanos. En las parejas suicidas destacaba el aislamiento social, la dependencia hacia el otro, el desempleo y una enfermedad fisica grave. Las parejas estaban muy unidas, formaban una unidad social elemental, exclusiva, estaban encerradas en sí misma y sin contacto con el exterior. El equilibrio personal de cada miembro de la pareja dependía enteramente de la supervivencia del otro. Uno de los dos era el elemento activo que convencía al otro y planeaba y preparaba el suicidio.

- Suicidio ampliado: Forma de suicidio que supera la participación de dos personas. Una de las personas, bien por ciertas condiciones psicológicas o bien por un trastorno psicopatológico define la situación como insostenible, cuya única salida es el suicidio y consigue convencer a los demás de ello. Cabría distinguir entre el suicidio ampliado en el que se desea voluntariamente por el suicida la muerte de los otros de aquellos otros casos en los que ocurren otras muertes como consecuencia del acto suicida, siendo estas muertes no siempre previstas por la intención del suicida (Bousoño y cols., 1997).

- Suicidio colectivo: Es una variante del anterior, en el cual el numero de participantes es más numeroso. Relativamente frecuentes y actuales son los suicidios colectivos realizados por sectas religiosas como los miembros del templo solar en Suiza, Francia y Canadá, la secta "Hale-Boppers" de San Diego en marzo de 1997, los davidianos en Waco (Tejas) y algunas de las 914 personas de Jonestown (Guyana). Heuyer define distintas variantes:

- Suicidio colectivo racional: Realizado lúcidamente por ciertas personas con una concepción particular sobre la existencia.

- Suicidio colectivo en procesos pasionales: Más frecuentes que los anteriores. Muchas veces sigue la dinámica de adhesión mutua a esa o esas personas, existiendo por lo general un substrato patológico en el líder.

- Suicidio colectivo en el curso de un proceso delirante: Es el tipo más frecuente. El delirio depresivo, los contenidos mesiánicos o apocalípticos de ciertos esquizofrénicos, los delirios sensitivos de autoreferencia y perjuicio, etc.

- Suicidio colectivo en delirantes crónicos: Similares a los anteriores pero con la diferencia del curso evolutivo del delirio. 
- Suicidio colectivo en síndromes complejos en las cercanías de los desequilibrios afectivos: Comprende este grupo a los psicópatas y a los desarrollos neuróticos mal estructurados.

\section{Según la conciencia del acto:}

- Según la psicopatología de la conciencia:

- Suicidio consciente: Aquel que se realiza sin la participación de ningún trastorno de la conciencia. Se trata por lo general de un suicidio filosófico o metafísico, o bien de suicidios por balance existencial $\mathrm{o}$ en personalidades psicopáticas o desarrollos neuróticos.

- Suicidio realizado en el curso de un embotamiento de conciencia: No es muy frecuente. Puede ocurrir en el transcurso de una enfermedad orgánica cerebral o psicosis no endógena.

- Intento de suicidio en el curso de un cuadro confuso-onírico: El caso más frecuente es en el transcurso de un delirium.

- Intento de suicidio en un estado crepuscular: En trastornos epilépticos. Se presenta de forma automática, sin previo aviso.

- Según la intención consciente:

- Suicidio de intención consciente: La lucidez de la persona suicida abarca o puede abarcar distintas dimensiones: el efecto de sus manifestaciones explícitas e implícitas de cometer el acto sobre los demás, la conciencia de sentimientos heteroagresivos con un desbordamiento incontrolado de la agresividad latente que no es canalizada correctamente, lucidez para trazar las directrices principales del método a emplear, conocimiento de los resultados de la técnica, percatación de la posible explotación de este comportamiento con el fin de conseguir ciertos beneficios, su resonancia social, la posibilidad de rescate, etc.

- Suicidio de intención inconsciente: Al contrario del caso anterior, concurren una serie de factores de diversa indole: tristeza, desesperación, culpa, que arrastran hacia la autodestrucción. A veces una vida peligrosa, con una conducta permanente de riesgos, puede ser un exponente de este apartado. 


\section{Según la actitud del sujeto ante su vida:}

- Suicidio activo: El sujeto tiene una actuación práctica y concreta cuyo fin es la autodestrucción.

- Suicidio pasivo: Parece que el sujeto se deleita en su propia depauperación. No existe una búsqueda activa de la muerte sino que la persona permanece indiferente ante su vida, se va abandonando y se pone en situaciones comprometidas que poco a poco le llevarán a la muerte. Son ejemplos de ello el desinterés por vivir, las conductas de riesgo, el alcoholismo, etc. 


\section{b. Tipologia del suicidio de Emile Durkheim}

Emile Durkheim realiza en 1897 en su libro El suicidio la tipología más conocida sobre los suicidios, realizándola en función de las características sociales. Para este autor, la tasa global de suicidios es un hecho social que sólo puede ser explicado sociológicamente, $\mathrm{y}$ no por las motivaciones individuales al suicidio. Lo que le interesa son las variaciones en las proporciones de suicidios entre distintas sociedades, como algo que está en función de condiciones sociales; la unidad de análisis es la sociedad, no el individuo.

De un estudio comparativo en varias sociedades europeas, Durkheim infiere las siguientes categorias de suicidios: egoísta, altruista, anómico y fatalista; a los que hay que sumar tres tipos mixtos: ego anómico, anómico altruista y ego altruista. Los distintos tipos de suicidio van a depender de dos variables: la integración social y la reglamentación social. Aquellos individuos que están excesivamente integrados socialmente son propensos a los suicidios altruistas mientras que los que están aislados son vulnerables a los suicidios egoístas. La segunda variedad se refiere al grado de control impuesto por la propia sociedad en los fines y sentimientos del individuo. Aquellos que aceptan sociedades de control excesivo son proclives a los suicidios fatalistas mientras quienes rechazan totalmente el control lo son a los suicidios anómicos. La mayoría de las personas van a estar entre medias en ambas dimensiones $y$ por lo tanto son menos proclives a suicidarse.

El resultado, dice el autor, es que "no hay suicidio, sino suicidios"

\section{Suicidio egoista:}

Relacionado con el grado de desintegración de los grupos sociales de que forma parte el individuo, o sea, del grado de desintegración de la sociedad religiosa, doméstica y política. Por eso, son más frecuentes los suicidios en la Iglesia protestante que en la católica, ya que es una Iglesia integrada con menor fuerza. Es llamado "egoísta" porque, según el autor, al desintegrarse la sociedad, los fines propios son prioritarios con respecto a los colectivos, el yo individual se afirma con exceso con respecto al yo social. La característica principal de estas sociedades es la excesiva individualización y el egocentrismo. En las sociedades fuertemente integradas no se permite disponer del individuo a su antojo. En las 
sociedades desintegradas o cuando el individuo está poco integrado en el ámbito social, éste siente a la sociedad como algo ajeno a sí mismo, pierde su razón de ser en ella, lo que se traduce en una "especie de astenia colectiva", de malestar social, de "desencanto" generalizado, y una menor capacidad de tolerar las frustraciones y dificultades de la vida.

\section{Suicidio altruista:}

Propio de individuos excesivamente integrados y subordinados a la voluntad colectiva. La sociedad, de excesiva integración, tiene muy estrechamente bajo su dependencia al individuo. Es "aquel en que el yo no se pertenece, en que se confunde con otra cosa que no es él, en que el polo de su conducta está situado fuera de él, en uno de los grupos que forma parte" (Durkheim, 1897, p. 229). En el suicidio altruista el que se mata no lo hace en el ejercicio de un derecho, sino más bien en el cumplimiento de un deber. Pueden ser obligatorios o facultativos según la presión que haga la sociedad para su realización, o sea, si las normas sociales obligan a el suicidio o solo lo aconsejan y recomiendan. Este suicidio es frecuente en algunas sociedades primitivas, en especial en ancianos, viudas y servidores a la muerte de sus jefes. También forman parte de él los suicidios de militares derrotados en la sociedad occidental del siglo XIX. La aptitud de los militares para el suicidio es en Europa muy superior a la población civil de la misma edad y la causa es, según refiere Durkheim, que la moral militar es, en ciertos aspectos, una supervivencia de la moral primitiva, o sea, es una sociedad más integrada y menos individualizada.

\section{Suicidio anómico:}

Difiere de los tipos de suicidio previos en cuanto que depende, no de la manera de estar ligado los sujetos a la sociedad, sino del modo como ella los reglamenta. La propia sociedad realiza un papel moderador en los deseos de los individuos, ya que es el único poder moral superior al individuo y cuyo poder acepta éste. Este tipo de suicidio está intimamente relacionado con conceptos como "la necesidad de bienestar" y los "límites" socialmente impuestos. El suicidio anómico se produce, por una parte, en sociedades donde al hombre le falta proyección social tal y como está instituida la sociedad, a nivel de reglamentación moral, material e ideológica, no por la normativa objetiva; y, por otra, en aquellas situaciones en las que cambios sociales bruscos alteren tanto las situaciones como para deteriorar la autoridad social y hacer que la 
reglamentación social sea inoperante, perdiendo el sujeto los modelos de conducta y expectativas que encarrilan su motivación. Aparecen sobre todo en momentos de crisis económicas. Este suicidio aparece cuando la actividad de los hombres está desorganizada y por esta razón sufren. Por el contrario, el suicidio egoísta procede de que los hombres no perciben ya la razón de estar en la vida y el suicidio altruista de que esta razón parece estar fuera de la misma vida.

Para Durkheim, en la sociedad occidental actual (de sus palabras se deduce la similitud tan enorme que existe en la sociedad europea de hace un siglo y la de ahora), en la que "la industria, en vez de ser considerada como un medio al servicio de un fin que le sobrepasa, se ha convertido en el fin supremo de los individuos y las sociedades, Entonces ha ocurrido que los apetitos que pone en juego se han encontrado libertados de toda autoridad que los limite. Esta apoteosis del bienestar, al santificarlos, por decirlo así, los ha puesto por encima de toda ley humana. Parece que hay una especie de sacrilegio en ponerles diques... Se tiene sed de cosas nuevas, de goces ignorados, de sensaciones sin nombre, pero que pierden todo su atractivo cuando son conocidas. Entonces, al menor revés que sobrevenga, faltan las fuerzas para soportarlo. Toda esa fiebre cae, y se percibe cuan estéril era el tumulto, y como todas esas sensaciones nuevas, indefinidamente acumuladas, no han logrado construir un sólido capital de dicha, sobre el que se pueda vivir en los días de prueba. El prudente, que sabe gozar de los resultados adquiridos sin experimentar perpetuamente la necesidad de reemplazarlos por otros, encuentra en ello un asidero a la vida. Pero el hombre que siempre lo ha esperado todo del porvenir, que ha vivido con los ojos fijos en el futuro, no tiene nada de su pasado que le consuele contra las amarguras del presente, porque el pasado no contiene para él más que una serie de etapas atravesadas con impaciencia. Lo que le permitía cegarse sobre sí mismo, es que contaba siempre con encontrar más lejos la felicidad, que no había aún encontrado hasta entonces. Pero se le ha detenido en su marcha; desde entonces, ya no hay nada detrás ni delante de él, sobre lo que pueda descansar su mirada. La fatiga, por otra parte, basta por sí sola para producir el desencantamiento, porque es díficil no sentir, a la larga, la inutilidad de una persecución sin término" (pp. 273275).

Un subtipo de esta categoría es el suicidio anómico conyugal, fruto de la viudedad y especialmente del divorcio. El matrimonio, dice Durkheim (p. 293), "es una reglamentación de las relaciones de los sexos, que se extiende no sólo a los instintos físicos que este comercio pone en juego, sino también a los sentimientos de toda 
clase que la civilización ha injertado, poco a poco, sobre la base de los apetitos materiales". La pérdida de esta reglamentación, la ruptura del equilibrio doméstico del sujeto, de su entorno íntimo referencia en cuanto constructor próximo de la realidad individual, origina un incremento de suicidios de este tipo.

\section{Suicidio fatalista:}

A pie de página en el capítulo correspondiente al suicidio anómico, lo considera contrapuesto a éste. Es el que resulta de un exceso de reglamentación, en sujetos limitados por las sociedad en su porvenir y deseos. Aparece, dice, en los esposos demasiado jóvenes, en la mujer casada sin hijos, pero su importancia mayor es histórica, porque era el suicidio de los esclavos.

\section{Formas elementales de los diferentes tipos de suicidio:}

Tras explicar los diferentes tipos sociales de suicidio, Durkheim intenta realizar una descripción y clasificación de las formas individuales de los diferentes tipos de suicidio.

Dice el autor (p. 303): "Cada suicida da a su acto una huella personal, que expresa su temperamento, las condiciones especiales en que se encuentra, y que, por consecuencia, no puede explicarse por las causas sociales y generales del fenómeno. Pero éstas, a su vez, deben imprimir en los suicidios que determinan una tonalidad sui generis, una marca especial que las expresa. Esta marca colectiva es la que se trata de encontrar".

Esta clasificación es etiológica y morfológica y no tiene ninguna relación con el método elegido para la consumación del suicidio.

Es de gran interés para el estudio que estamos realizando por lo que no nos resistimos a transcribir literalmente gran parte de las descripciones hechas por Durkheim sobre estos tipos de suicidio.

El mismo autor realiza un esquema de estos tipos de la siguiente forma (p. 322): 
Clasificación etiológica y morfológica de los tipos sociales de suicidio

\begin{tabular}{|c|c|c|c|}
\hline \multicolumn{4}{|c|}{ FORMAS INDIVIDUALES QUE REVELAN } \\
\hline \multicolumn{3}{|c|}{ Carácter fundamental } & Variaciones secundarias \\
\hline \multirow{7}{*}{$\begin{array}{l}\text { Tipos } \\
\text { elemen- } \\
\text { tales }\end{array}$} & \multirow{2}{*}{$\begin{array}{l}\text { Suicidio } \\
\text { egoísta }\end{array}$} & \multirow[t]{2}{*}{ Apatía } & $\begin{array}{l}\text { Melancolía perezosa con complacencia } \\
\text { de sí misma }\end{array}$ \\
\hline & & & Sangre fría, desengañada, del escéptico \\
\hline & \multirow{3}{*}{$\begin{array}{l}\text { Suicidio } \\
\text { altruista }\end{array}$} & \multirow{3}{*}{$\begin{array}{l}\text { Energía } \\
\text { apasionada o } \\
\text { voluntaria }\end{array}$} & Con sentimiento tranquilo del deber \\
\hline & & & Con entusiasmo místico \\
\hline & & & Con valor apacible \\
\hline & \multirow[b]{2}{*}{$\begin{array}{l}\text { Suicidio } \\
\text { anómico }\end{array}$} & \multirow[b]{2}{*}{$\begin{array}{l}\text { Irritación, } \\
\text { hastío }\end{array}$} & $\begin{array}{l}\begin{array}{l}\text { Recriminaciones } \\
\text { vida en general }\end{array} \\
\text { violentas contra la }\end{array}$ \\
\hline & & & \begin{tabular}{l}
\multicolumn{2}{c}{ Recriminaciones violentas contra una } \\
persona en particular (homicidio o \\
suicidio)
\end{tabular} \\
\hline \multirow{3}{*}{$\begin{array}{l}\text { Tipos } \\
\text { mixtos }\end{array}$} & \multicolumn{2}{|c|}{ Suicidio ego-anómico } & $\begin{array}{l}\text { Mezcla de agitación y de apatía; de } \\
\text { acción y de ensueño }\end{array}$ \\
\hline & \multicolumn{2}{|l|}{ altruista } & Efervescencia exasperada \\
\hline & \multicolumn{2}{|c|}{ Suicidio ego altruista } & $\begin{array}{l}\text { Melancolía atemperada por una cierta } \\
\text { firmeza moral }\end{array}$ \\
\hline
\end{tabular}




\section{A. TIPOS ELEMENTALES}

\section{Suicidio egoísta}

Característica fundamental: apatía

1. Melancolía perezosa con complacencia de sí misma:

Tras considerar el Rafael de Lamartine el ejemplo fundamental de este tipo de suicidio, el autor realiza la siguiente descripción: "Lo que lo distingue es un estado de languidez melancólica, que afloja los resortes de la acción. Los negocios, las funciones públicas, el trabajo útil, hasta los deberes domésticos sólo inspiran al sujeto la indiferencia y el alejamiento. Le repugna salir de sí mismo. En desquite, el pensamiento y la vida interior ganan todo lo que pierde en actividad. Al desviarse de lo que le rodea, la conciencia se repliega sobre sí misma, se toma como su propio y único objeto y se da por tema principal observarse y analizarse. Pero con esta extrema concentración no hace sino profundizar el obstáculo que lo separa del resto del universo. Desde el momento en que el individuo se apasiona hasta tal punto por sí mismo, no puede sino desligarse más de todo lo que no sea él, y consagrar, al reforzarlo, el aislamiento en que vive. Al no mirarse más que a sí, no puede encontrar la persona razones de ligarse a ninguna otra cosa más que a ella. Todo movimiento, en cierto sentido, es altruista, porque es centrífugo y extiende al ser fuera de sí mismo. La reflexión, al contrario, tiene algo de personal y de egoísta, porque no es posible sino en la medida en que el sujeto se desprende del objeto, y se aleja de él para volver sobre sí mismo; y es tanto más intensa cuanto esta vuelta sobre ella sea más completa. No se puede obrar más que mezclándose al mundo; para pensar como, al contrario, es preciso tratar de confundirse con él, de manera que se le pueda contemplar desde fuera; con mayor motivo, es necesario para pensar como uno mismo. Aquél, cuya completa actividad se convierte en pensamiento interior, se hace más insensible a todo lo que le rodea. $\mathrm{Si}$ ama, no es para entregarse, para no unirse en una unión fecunda, a otro ser fuera de él; es para meditar sobre su amor. Sus pasiones son sólo aparentes, porque son estériles. Se disipan en vanas combinaciones de imágenes, sin producir nada que les sea exterior...

... Pero, por otro lado, toda vida interior toma de fuera su primera materia. No podemos pensar más que en los objetos o en 
la manera de concebirlos. No podemos reflexionar nuestra conciencia más que en un estado de indeterminación pura; bajo esta forma es impensable. Ahora bien, ella no se determina más que afectada por otra cosa que no sea ella misma. Si se individualiza, pues, más allá de cierto punto, si se separa demasiado radicalmente de los otros seres, hombres o cosas, se encuentra incomunicada con las fuentes mismas donde debía normalmente alimentarse y no tiene nada a que poderse aplicar. Al hacerse el vacío a su alrededor, ha hecho el vacío en ella, y no resta nada más que reflexionar que su propia miseria. Ya no tiene por objeto de meditación más que la nada, que está en ella, y la tristeza que es su consecuencia. Se complace en ello, se abandona a ello con una especie de goce malsano... Cuando uno experimenta tanto placer en no ser, no puede satisfacer completamente su inclinación, sino renunciando completamente a vivir. Esto es lo que hay de exacto en el paralelismo que Hartmann cree observar entre el desarrollo de la conciencia y el debilitamiento de la voluntad de vivir... Pero no hay que decir, como cree Hartmann, que la realidad sea, por sí misma intolerable, a menos de estar velada de la ilusión. La tristeza no es inherente a las cosas; ella no nos viene del mundo, y no es por el mundo sólo por lo que la pensamos. Es un producto de nuestro propio pensamiento. Somos nosotros quien la creamos por completo; pero para esto es preciso que nuestro pensamiento sea anormal. Si la conciencia hace muchas veces la desgracia del hombre, es solamente cuando alcanza un desarrollo enfermizo; cuando insubordinándose contra su propia naturaleza se considera como un absoluto y busca en sí mismo su propio fin. Tampoco se trata de un descubrimiento retrasado, de la última conquista de la ciencia, hubiéramos podido tomar del estado de espíritu estoico los principales elementos de nuestra descripción. El estoicismo enseña también que el hombre debe apartarse de todo lo que le es exterior, para vivir de sí mismo y para sí mismo. Sólo que, como la vida no encuentra entonces su razón de ser, la doctrina lleva al suicidio...

...Estos mismos caracteres se encuentran en el acto final que es la conciencia lógica de este estado moral. El desenlace no tiene nada de violento ni de precipitado. El paciente escoge su hora y medita su plan con mucha anticipación. Ni siquiera le repugnan los medios lentos. Una melancolía tranquila y que, muchas veces, no carece de dulzura, caracteriza sus últimos momentos. Se analiza hasta el fin...

... Esta pereza por la acción, este apartamiento melancólico resultan de ese estado de individualización exagerada, para el que hemos definido ese tipo de suicidios. Si el individuo se aísla, es que los lazos que lo unían a otros seres se han aflojado o roto, es que la 
sociedad, sobre los puntos por donde él se halla en contacto con ella, no está bastante fuertemente soldada. Estos vacíos que separan las conciencias y las hacen extrañas unas de otras, proceden precisamente del relajamiento del tejido social. En fin, el carácter intelectual y meditativo de esas especies de suicidios se explica sin esfuerzos, si se recuerda que el suicidio egoísta tiene por acompañamiento necesario un gran desarrollo de la ciencia y de la inteligencia reflexiva. Es evidente, en efecto, que, en una sociedad donde la conciencia esté normalmente necesitada de extender su campo de acción, está también mucho más expuesta a exceder esos límites naturales, que no puede traspasar sin destruirse ella misma. Un pensamiento que lo pone todo en discusión, si no es bastante fuerte para soportar el peso de su ignorancia, corre el riesgo de ponerse él mismo en discusión y de abismarse en la duda. Porque si no llega a descubrir los títulos que puede tener a la existencia, las cosas sobre las que se interroga $-y$ sería una maravilla si pudiera tan pronto profundizar tantos misterios -les negará toda realidad; el hecho mismo de que se plantee el problema, implica, ya que tiende a las soluciones negativas. Pero, al mismo tiempo, se despojará de todo contenido positivo y, no encontrando ya nada ante sí, que se le resista, sólo podrá perderse en el vacío de los ensueños interiores" (pp. 304-8).

\section{Sangre fría, desengañada, del escéptico}

Es una forma más vulgar de suicidio egoísta, menos elevada que la anterior.

Durkheim lo define así: "El sujeto, en vez de meditar tristemente sobre su estado, toma alegremente su partido. Tiene conciencia de su egoísmo y de las consecuencias que de él derivan lógicamente; pero las acepta por adelantado y se pone a vivir como el niño o el animal, con la única diferencia de que se da cuenta de lo que hace. Se impone, pues, como única tarea, satisfacer sus necesidades personales, hasta simplificándolas, para asegurarse más su satisfacción. sabiendo que no puede esperar nada de otro, no pide ya nada, completamente dispuesto, si se le impide alcanzar este fin único, a deshacerse de una existencia que no tiene razón de ser en adelante. Este es el suicidio epicúreo. Porque si Epicuro no ordenaba a sus discípulos apresurar la muerte, les aconsejaba el contrario, vivir, mientras en ello encontrarán algún interés. Sólo que, como él suponía muy bien que, si no se tiene otro objeto, se está a cada instante expuesto a no tener ninguno y que el placer sensible es un lazo muy frágil para sujetar al hombre a la vida, les exhortaba a hallarse siempre dispuestos a salir de ella, al menor llamamiento de las circunstancias. Aquí, pues, la melancolía 
filosófica y soñadora está reemplazada por una sangre fría escéptica y desengañada, que es particularmente sensible en la hora del desenlace. El paciente se mata sin odio, sin cólera, pero también sin esa satisfacción morbosa con la que el intelectual saborea su suicidio. Obra sin pasión y aún más que este último. No le sorprende la salida a la que se lanza; es un acontecimiento que preveía como más o menos próximo. Así, no se ingenia en largos preparativos; de acuerdo con su vida anterior trata solamente de disminuir el dolor. Tal es, especialmente, el caso de esos vividores que, cuando ha llegado el momento inevitable en que no pueden ya continuar una existencia fácil, se matan con una tranquilidad irónica y con una especie de sencillez" (p. 309).

\section{Suicidio altruista}

Característica fundamental: Energía apasionada o voluntaria

A diferencia del suicidio egoísta que se distingue por presentar síntomas depresivos, bien como languidez melancólica o bien como indiferencia epicúrea, el suicidio altruista tiene por origen un sentimiento violento y precisa de un despliegue de energía, que se pone al servicio de la razón y la voluntad. Son:

\section{Con sentimiento tranquilo del deber}

"El sujeto se mata porque su conciencia se lo ordena: se somete a un imperativo. Así, su acto tiene por nota dominante esta firmeza serena que da el sentimiento del deber cumplido: la muerte de Catón, la del comandante Beaurepaire son ejemplos históricos del mismo" (p. 309)

\section{Con entusiasmo místico}

En este caso el altruismo está en estado agudo, siendo más pasional e irreflexivo. Puede ser alegre o como medio expiatorio.

"Es un impulso de fe y de entusiasmo el que precipita al hombre a la muerte. Este entusiasmo mismo es unas veces alegre, y otras sombrio, según que la muerte sea concebida como un medio para unirse a una divinidad bien amada o como un sacrificio expiatorio, destinado a apaciguar una potencia temible y que se cree hostil. El fervor religioso del fanático que se hace aplastar con beatitud bajo el carro de su ídolo, no se asemeja al del monje atacado de tristeza o a los remordimientos del criminal, que pone fin a sus días para 
expiar su maldad. Pero, bajo estos matices diversos, los rasgos esenciales del fenómeno permanecen los mismos" (p. 309)

Sin lugar a dudas, la triste actualidad de los suicidios del terrorismo islámico podrían incluirse en este tipo definido por Durkheim.

\section{Con valor apacible}

Como los de los primitivos o de los soldados que se matan porque una ligera ofensa ha empeñado su honor o para demostrar su valor. Lo hacen tranquilamente pero no hay como en los vividores ironía, ni escepticismo, "ni esta especie de crispación involuntaria que el vividor que se mata no consigue jamás disimular completamente", sino que es una tendencia activa.

\section{Suicidio anómico}

Característica fundamental: Irritación, hastío

A diferencia de los suicidios egoístas es un acto pasional y a diferencia de los suicidios altruistas no son inspirados por pasiones como el entusiasmo, la fe religiosa, moral o política ni por virtudes militares, sino por la cólera y todo lo que de ordinario acompaña a la decepción.

El egoísta se queja de la vida de una manera doliente y ésta le oprime, pero no le irrita por disgustos agudos ni le inflige "sufrimientos positivos". No tiene arrebatos como el anómico.

Puede ser como recriminación violenta contra la vida en general o contra una persona en particular

En este grupo están los suicidios que son como el complemento de un homicidio previo: el hombre se mata después de haber matado a la persona que piensa que le ha arruinado la vida.

"La anomia, al franquear las necesidades de la medida que conviene, abre la puerta a las ilusiones, y, por consiguiente, a las decepciones. Un hombre que es bruscamente arrojado por debajo de la condición a la que estaba acostumbrado, no puede dejar de exasperarse al sentir escapársele una situación de la que se creía dueño, y su exasperación se vuelve naturalmente contra la causa, cualquiera que sea, real o imaginaria, a la que atribuye su ruina. Si él mismo se reconoce como el autor responsable de la catástrofe, la tomará consigo mismo; si no, con otro. En el primer caso, no 
tendrá más medio que el suicidio; en el segundo, podrá éste ser precedido de un homicidio o de alguna otra manifestación violenta. Pero el sentimiento es el mismo en los dos casos; solo el punto de aplicación varía. El sujeto se mata siempre en un acceso de cólera, haya atacado o no anteriormente a un semejante. Este trastorno de todas sus costumbres le produce un estado de sobreexcitación aguda, que tiende necesariamente a aliviarse con actos destructivos. El objeto sobre el que descargan las fuerzas pasionales, así producidas, es, en suma, secundario. El azar de las circunstancias es el que determina el sentido en que esas fuerzas se dirigen...

...No sucede de otro modo las distintas veces en que, lejos de caer por debajo de él mismo, el individuo es, por el contrario, arrastrado, pero sin regla ni medida, a sobrepasarse perpetuamente a sí mismo. Tan pronto, en efecto, como le falta el fin que se creía capaz de alcanzar, pero que, en realidad, excedía de sus fuerzas. Este es el suicidio de los incomprendidos, tan frecuente en las épocas donde no hay clasificación reconocida. Otras veces, después de haber conseguido, durante cierto tiempo satisfacer todos sus deseos y su gusto de cambio, viene a chocar de pronto contra una resistencia que no puede vencer, y se deshace con impaciencia de una existencia en la que se encuentra en adelante agobiado. Este es el caso de Werther, ese corazón turbulento, como él mismo se llama, que se mata por un amor contrariado, y de todos los artistas que, después de encontrarse colmados de éxitos, se suicidan por oír un silbido, por una critica un poco severa o porque su renombre cesa de aumentar...

...Aun hay otros que, sin tener que quejarse de los hombres ni de las circunstancias, acaban por cansarse de una persecución sin defensa posible, donde sus deseos se irritan en vez de calmarse. La toman entonces con la vida en general y la acusan de haberles engañado. Sólo que la varia agitación a la que se han entregado deja tras sí una especie de agotamiento, que impide a las pasiones decepcionadas manifestarse con la misma violencia que en los casos precedentes. Se hallan como fatigadas, a la larga, y así, resultan menos capaces de reaccionar con energía. El sujeto cae en una especie de melancolia, que, por algunos lados, recuerda a la del egoísta intelectual, pero no tiene su encanto lánguido. Lo que entonces domina es un disgusto de la existencia más o menos irritado" (pp. 311-3)

Durkheim aclara que aunque el sufrimiento existe tanto en el suicidio egoísta como anómico, éste no es de la misma forma. En el egoísta se debe a la inteligencia reflexiva hipertrofiada; en el anómico a la sensibilidad sobreexcitada e irregular. "En el uno, el 
pensamiento, a fuerza de replegarse sobre sí mismo, ya no tiene objeto; en el otro, la pasión, no reconociendo nuevos límites, carece de objetivo. El primero se pierde en el infinito del ensueño; el segundo, en el infinito del deseo"

\section{B. TIPOS MIXTOS}

Explica Durkheim que en un mismo suicidio pueden encontrarse características pertenecientes a distintos tipos, ya que las diferentes causas sociales del suicidio pueden actuar simultáneamente sobre el mismo individuo

\section{Suicidio ego-anómico:}

Característica fundamental: Mezcla de agitación y de apatía; de acción y de ensueño

Entre el egoísmo y la anomia existe una afinidad especial y generalmente estos dos factores no son más que dos aspectos diferentes de la misma realidad social. Por tanto, es frecuente que se encuentren en el mismo individuo. El egoísta suele tener cierta propensión a la irregularidad ya que al estar desligado de la sociedad, ésta no ejerce sobre él el suficiente dominio como para imponerle reglas. Si no se exaspera es porque, al estar por completo vuelto sobre sí mismo y no interesarle el mundo exterior, su vida pasional se languidece.

"Pero puede suceder que no sea ni un egoísta completo ni un puro agitado. Entonces se le ve desempeñar el papel de los dos personajes. Para calmar el vacío que siente en sí, busca sensaciones nuevas; es cierto que pone en ellas menor ardor que el apasionado propiamente dicho, pero también se cansa más pronto y este cansancio lo repliega de nuevo sobre sí mismo y refuerza su melancolía primera, e inversamente, la irregularidad va acompañada de un germen de egoísmo; porque no sería rebelde a todo freno social si estuviese fuertemente socializado. Sólo que donde prepondera la acción de la anomia no se puede desenvolver ese germen; porque al arrojar al hombre fuera de sí le impide aislarse en él. Pero, aunque sea menos intensa, puede dejar el egoísmo producir alguno de sus efectos. Por ejemplo, el límite contra el que viene a chocar el insaciado puede llevarle a replegarse en sí y a buscar en la vida interior un derivativo a sus pasiones decepcionadas, Pero como no encuentra nada en que pueda fijarse, la tristeza que le causa este espectáculo le determina a situarse de nuevo y aumenta, por consiguiente, su inquietud. Así se producen suicidios mixtos, en que el abatimiento alterna con la 
agitación, el ensueño con la acción, los arrebatos del deseo con las meditaciones del melancólico" (p. 315).

\section{Suicidio anómico-altruista:}

Característica fundamental: Efervescencia exasperada

La anomia puede asociarse al altruismo cuando hay una crisis que rompe el equilibrio entre el individuo y su medio y, al mismo tiempo, pone sus disposiciones altruistas en un estado que le conduce al suicidio. Son suicidios donde se dan la firmeza valerosa o exaltación pasional del suicido altruista $o$ bien el enloquecimiento exasperado de la anomia. A estos suicidios les llama "suicidios de obsesión". Un ejemplo es los suicidios en masa de los judíos al ser tomado Jerusalén ya que el hacerse súbdito de Roma amenazaba por una parte transformar su género de vida y por otra amaban demasiado su ciudad y su culto para sobrevivir al probable aniquilamiento de ambos. Otros ejemplos son el hombre arruinado que se mata tanto porque no quiere vivir en una situación de pobreza como por evitar a su nombre y su familia la vergüenza de la ruina o los militares que se retiran, que se suicidan no solo por el cambio súbito de su manera de vivir sino también por su predisposición a estimar poco la vida.

\section{Suicidio egoaltruista:}

Característica fundamental: Melancolia atemperada por una cierta firmeza moral

Aunque el egoísmo y el altruismo sean contrarios a veces pueden unir su acción. Esto aparece en épocas en que la sociedad está disgregada y no puede servir de objetivo a las actividades individuales. En esta sociedad existen individuos o grupos de individuos que aunque sufren el estado general de egoísmo, aspiran a otra cosa. "Pero, percibiendo bien que es un mal modo de huir de ellos, ir continuamente de unos en otros placeres egoístas y que los goces fugitivos, aún cuando sean incesantemente renovados, no pueden calmar su inquietud, buscan un objetivo duradero por el que puedan internarse con constancia y que dé un sentido a su vida. Sólo que, como no hay nada real que les preocupe, no pueden satisfacerse más que constituyendo por completo una realidad ideal, que pueda desempeñar este papel. Crean, pues, por el pensamiento un ser imaginario del que se hacen los servidores y al que se entregan de un modo tanto más exclusivo cuando más disgustados están de los demás, incluso de 
ellos. Es en sí mismos donde ponen todas las razones de ser que se atribuyen, puesto que nada más tiene valor a sus ojos. Viven, así, una existencia doble y contradictoria, individualistas para todo lo que está en relación con el mundo real, son de un altruismo inmoderado para aquello que concierne a este objeto ideal. Una y otra disposición llevan al suicidio" (p. 316).

Durkheim considera que esta es la naturaleza del suicidio estoico, ya que aunque tiene algunos rasgos esenciales del egoísta (ver arriba) al profesar la autosuficiencia y una independencia absoluta hacia el exterior, también tiene una dependencia estrecha con "la razón universal" y reduce al hombre a no ser más que un instrumento de ella. En él existe el egoísmo mezclado con el misticismo. Este misticismo egoísta es propio de las épocas de decadencia; en las sociedades jóvenes y en formación el misticismo proviene del impulso colectivo que arrastra en un mismo sentido todas las voluntades particulares, olvidándose los sujetos de si mismos para obrar por el fin común. 


\section{c. Otras tipologias}

\section{Tipologia del suicidio de Baechler}

Jean Baechler (1975) realiza un tipología sobre el suicidio partiendo de la información que había recogido sobre casos concretos. Cada tipo se divide a su vez en varios subtipos. Son:

1. Suicidio escapista: El sujeto busca evitar una situación. Dividido en:

- Huida

- Duelo

- Castigo

2. Suicidio agresivo: Supone que con la autodestrucción se daña a otro, dividido en:

- Venganza

- Crimen

- Llamada

- Chantaje

3. Suicidio oblativo: Supone la entrega de la propia vida por unos valores (personales, sociales, religiosos...). Se divide en:

- Sacrificio

- Transición

4. Suicidio lúdico: Supone que el sujeto más que precipitarse directamente a la muerte, lo hace mediante el juego. Sus formas son:

- Ordalía

- Juego 
Baechler estudia principalmente las causas por las que los enfermos mentales se suicidan. Según este autor, el suicidio en estas personas no es tanto producto de la enfermedad sino de las situaciones a las que ésta le conlleva. Para este autor los suicidios de los enfermos mentales son de dos tipos, atribuyendo a cada uno enfermedades y subtipos concretos. Esquemáticamente son (Clemente y González, 1996):

Tipo I: Escapista:

\begin{tabular}{|l|l|}
\hline ENFERMEDAD & CAUSA \\
\hline Esquizofrenia & Huida \\
\hline Depresión & Duelo \\
\hline Melancolía & Castigo \\
\hline
\end{tabular}

Tipo II: Agresivo

\begin{tabular}{|l|l|}
\hline ENFERMEDAD & CAUSA \\
\hline Delirios pasionales & Venganza, Crimen \\
\hline Histeria & Llamada \\
\hline Psicopatía & Chantaje \\
\hline
\end{tabular}

En la consumación del acto suicida en estos enfermos va a influir, según este autor, los siguientes apartados (en Clemente y González, 1996):

- La necesidad de escapar a la enfermedad y a los efectos que sobre la vida del sujeto tienen.

- Tendencia a responder exageradamente a conflictos que en principio parecen nimios.

- La aparición de depresión en el sujeto, que provocaría abulia frente a la realidad social, y un progresivo deterioro de la autoimagen.

- Algunas formas de paranoia y las alucinaciones auditivas o el deseo de escapar de ellas.

- Una reacción impulsiva e inconsciente ante una situación muy estresante. 


\section{$\underline{\text { Tipologia del suicidio de Jung }}$}

Jung realiza una proposición de estudio del suicidio basado en cuatro dimensiones fenomenológicas (colectivos-individuales, activo-pasivo, sincero-llamar la atención y planeado-impulsivo) y la siguiente tipología (en Clemente y González, 1996):

- El suicidio del héroe o mártir, provocado por un ideal.

- Dolor irreductible o angustia mental. La vida es insoportable, planteándose la muerte como una liberación.

- Reacción contrafóbica a la muerte. La muerte es tan temida, que la persona se la proporciona para no soportar más el temor a la misma.

- Búsqueda de libertad.

- Reunión con la persona amada.

- Deseo de reclusión. La persona se suicida con la intención de poner un "broche a la vida", siendo la muerte un medio de invaginación.

\section{$\underline{\text { Tipologia del suicidio de Hendin }}$}

Herbert Hendin, desde una perspectiva psicoanalitica, diferencia los siguientes tipos de suicidio (en Ey y cols., 1980):

- El suicidio como actitud de represalia o revancha tras un abandono: el suicida tiene la ilusión de poder controlar una situación de rechazo, experimentando una sensación de omnipotencia a través de la muerte.

- El suicidio como asesinato reflejo es un paso a la acción en forma exclusiva en un sujeto temperamentalmente violento, como expresión de la lucha interna contra el deseo de matar o agredir a los demás.

- El suicidio en el que la muerte se convierte en una reunión (tras la muerte de una figura paterna o de una relación muy importante)

- El suicidio en que la muerte es un renacer, variedad del precedente, en que la muerte borra los fracasos y aporta la ilusión de que va a recomenzar la reunión con el objeto 
- El suicidio en que la muerte es un castigo y que surge desde la culpa más intensa. Es un suicidio de inmolación al objeto, como única forma de recuperarlo, mecanismo frecuente en el melancólico y el delirante

- El suicidio en el que el paciente se creía estar ya muerto; esta "muerte emocional" típica del síndrome de Cotard es igualmente un mecanismo que aparece en la melancolía.

\section{Tipología de los fenómenos suicidas de Stone}

Geo Stone (1999), autor que ha realizado una polémica información en Estados Unidos sobre los métodos eficaces de suicidio, realiza una clasificación de los suicidios o tentativas según los motivos de las víctimas para suicidarse. El mismo autor reconoce que las categorias reseñadas son en parte arbitrarias y se superponen. No obstante, reproducimos su tipología tal como la expone en su libro, ya que es bastante clara y el autor la ilustra con numerosos ejemplos históricos y actuales. Su tipología es:

- Suicidio altruista/ heroico: Cuando alguien muere (más o menos) voluntariamente por el bien del grupo. El autor incluye los siguientes ejemplos: los griegos en Termopolis, los pilotos japoneses kamikace en la segunda guerra mundial, los esquimales ancianos Inuit que se matan para dejar más comida a su familia, la táctica de Gandhi de la huelga de hambre, llamada satyagraha habria pertenecido a esta categoría si las autoridades británicas no hubiesen accedido a sus demandas.

- Suicidio filosófico: Varias escuelas filosóficas, como los estoicos y los existencialistas, han defendido el suicidio en algunos casos.

- Suicidio religioso: Hay una larga historia de suicidios religiosos, normalmente bajo la forma de martirios. Fue muy frecuente los primeros años del cristianismo y en las distintas "herejias" que existieron antes y durante la reforma, contrareforma e inquisición. Ejemplos más recientes son los miembros del templo solar en Suiza, Francia y Canadá, la secta "Hale-Boppers" de San Diego en marzo de 1997, los davidianos en Waco (Tejas) y algunas personas de Jonestown (Guayana) y de aún más actualidad los terroristas suicidas del fundamentalismo islámico. 
- Escapar de una situación insoportable: Como puede ser una persecución, una enfermedad terminal o situación crónica de sufrimiento. Ejemplos de estos casos son:

- Las epidemias de suicidios entre los judíos en la Europa medieval (a veces se les daba a elegir entre convertirse al cristianismo o morir). Los esclavos indios y negros en América realizaron suicidios en masa para huir de tratamientos brutales. Según una leyenda, un propietario de esclavos paró estos suicidios entre los esclavos al amenazar con matarse él mismo, seguirles en la otra vida y tratarles aún peor allí.

- Hubo muchos suicidios durante las epidemias de peste en la Europa Medieval. Actualmente, el SIDA ha ocasionado una respuesta similar en muchas de sus víctimas.

- Hubo también una ola de suicidios entre sacerdotes y sus mujeres en 1705, cuando el Papa Gregorio VII ordenó el celibato en el clero, a los que previamente se les había permitido casarse.

- Un elevado número de asesinos realizan suicidio. El 4\% de 621 asesinos se mataron más tarde, y alrededor del 1,5\% lo hicieron tras el asesinato.

- Todos los ejemplos anteriores son valorados por la generalidad como situaciones más o menos "insoportables". No obstante, los adolescentes algunas veces llegan a considerar "insoportable" situaciones tan triviales como suspender un examen o fallar un gol.

- Abuso de alcohol y otras drogas: Como hemos visto anteriormente existe una elevada relación entre el alcohol y el suicidio, explicándose este aumento por distintas razones como son: el deterioro sociofamiliar y laboral que el alcoholismo produce, el alcohol y el suicidio pueden ser formas de responder a lo mismo, la depresión y la miseria, el alcohol aumenta los efectos de otras drogas sedativas, frecuentemente usadas en los intentos de suicidio, el alcohol puede aumentar las acciones impulsivas

- Suicidio romántico: Aunque los más famosos son del tipo de "Romeo y Julieta", durante el enamoramiento, son más frecuentes en personas que han vivido juntos muchos años cuando muere uno de ellos.

Los pactos suicidas (suicidio dual) constituyen de forma aproximada el $1 \%$ de los suicidios en Europa Occidental. Generalmente son realizados por personas de más de 51 
años, menos en Japón, donde el $75 \%$ de los suicidios duales son pactos entre enamorados.

- Suicidio de "aniversario": Se caracteriza por su realización por el mismo método o en la misma fecha que un ser querido muerto, normalmente un miembro de la familia. El suicidio "imitativo" es parecido al suicidio de aniversario por estar relacionado con una persona muerta, pero en una fecha o con un método diferente.

- Suicidio por contagio: Aquellos donde un suicidio parece provocar otros suicidios, suicidios "en racimo" o "en copia", más frecuentes en jóvenes. Es clásico el ejemplo de la cadena de suicidios coincidiendo con la publicación de Werther de Goethe, por el que estos suicidios por contagio se conocen aún como el "efecto Werther". Otro ejemplo mucho más reciente es el de Yukiko Okada, de 18 años, que había recibido un premio dias antes como la mejor cantante revelación de Japón y se tiró desde la ventana de su estudio, en el piso decimoséptimo. El trato que se dio a este suicidio por los medios de comunicación fue intenso. Treinta y tres jóvenes, uno de ellos de nueve años, se mataron en los dieciséis dias siguientes, veintiuno tirándose por la ventana. Ejemplos similares a éste existen en diferentes partes del mundo. El suicidio intensamente publicitado de una miss en un concurso de belleza fue seguido por una epidemia de suicidios de mujeres jóvenes que usaron el mismo método. En USA, hubo una racha de muertes por el método de la "ruleta rusa" tras la exposición de la película The deer hunter que presenta una escena de ruleta rusa de gran impacto, lo que indica que estos suicidios aparecen también tras suicidios de ficción. No obstante, otros autores niegan que exista relación entre artículos de periódicos y publicidad y suicidio, ya que tras el suicidio de una persona famosa, no siempre aparecen otros suicidios.

Aunque en general se acepta que la imitación y el contagio existen en el suicidio y que se manifiestan de forma esporádica, se cree que suelen coincidir con circunstancias y predisposiciones de la persona suicida.

- Un intento de manipular a otros: O sea: "si tú no haces lo que yo quiero, me mataré". De todas formas, la palabra "manipulativo" no implica que el intento de suicidio no sea serio, ya que intentos suicidas de fatal término son realizados a menudo por personas que esperan manipular o influir en los sentimientos de otros aunque no vivan para presenciar el 
éxito o fracaso de su actuación. No obstante, aunque en ocasiones la persona muera o se lesione con el intento, la intención es culpabilizar a la otra persona, y generalmente el intento no tiene resultados fatales.

- Pedir ayuda o enviar una señal de socorro: Es parecido al suicidio "manipulativo" con la diferencia de que no busca algo específico, sino que es una expresión de dolor y sufrimiento. Puede ocurrir en cualquier edad, pero es más frecuente en jóvenes. Los padres suelen minimizar o negar el intento.

- "Pensamiento mágico" y castigo: Relacionado con un sentimiento de poder y control total. Es la siguiente fantasia: "Lo sentirás cuando me muera". Un ejemplo es la costumbre del antiguo Japón de matarse en la puerta de alguien que le haya insultado o humillado. Es parecido al "suicidio manipulativo" pero lo que se busca es un resultado fatal. Se le llama también "suicidio agresivo". En una lucha de poder, si no gana por lo menos dice la última palabra al suicidarse.

- Aprobación cultural: La sociedad japonesa tradicionalmente ha aceptado o favorecido el suicidio en cuestiones de honor. Por ejemplo, el presidente de una compañia japonesa cuyos productos de alimentación fueron venenosos accidentalmente se mató como reconocimiento de su propia responsabilidad por el error de su compañía. En 1986, 275 directores de compañías se suicidaron en Japón por diferentes razones.

- Falta de un objeto exterior al que echarle la culpa del sufrimiento propio: J.F. Henry y A.F. Short sugieren que cuando una causa externa es el origen de la infelicidad de una persona, la respuesta extrema suele ser la ira y el homicidio; si no existe esta causa extrema, la respuesta extrema suele ser la depresión y el suicidio. Así, dicen estos autores, el matrimonio y los hijos se relacionan con una tasa de suicidios más baja, pero también se relacionan con una tasa de homicidios mayor. Al contrario sucede con las mejorias en la calidad de vida de tipo económico, que disminuyen los homicidios e incrementan los suicidios. También apoyaría esta hipótesis las bajas tasas de suicidios en los campos de concentración nazis, entre los afroamericanos y en los tiempos de guerra.

No obstante, los datos nacionales son contradictorios: hay países con bajas tasas de suicidio y homicidio (como Gran Bretaña y Grecia) y otros con tasas altas de ambos (Finlandia y Hungria). Además los actuales aumentos en múltiples 
naciones de las tasas de suicidio se acompañan de aumentos similares en las de homicidio. Por último, hay altas tasas tanto de suicidios como de homicidios en las prisiones.

- Otros: la mayoría de los suicidios van a tener múltiples causas.

Una vez expuestos los motivos, el autor concluye que las personas que intentan suicidarse pueden incluirse en uno de estos cuatro grupos:

1. Personas sin trastornos mentales con un problema irresoluble como una enfermedad crónica incurable o debilitante. Para este autor, el suicidio en estas personas es una alternativa válida y si la persona por su estado fisico fuera incapaz de consumarlo debería estar permitida su ayuda.

2. Personas impulsivas, frecuentemente jóvenes, realmente desdichados aunque de forma temporal, a veces bebidos, que seis meses más tarde seguramente no desearán suicidarse.

3. Personas con trastornos mentales, a menudo alcohólicos crónicos, esquizofrénicos o deprimidos

4. Personas que hacen un gesto autolítico como demanda de ayuda o demanda de atención

\section{Clasificación de las conductas suicidas de Maris}

Maris (1992) propone clasificar las conductas suicidas de una manera multiaxial, similar a los trastornos mentales de los DSM (Díaz y cols., 1997). En el eje I plantea incluir el tipo de conducta suicida: suicidio, tentativa, ideación (a los que subclasifica como escapistas, vengativos, altruistas, ordálicos y mixtos) o mixtos indiferenciados. En el eje II plantea clasificar las características secundarias de los mismos (certeza del evaluador, letalidad médica, intencionalidad, circunstancias, método, sexo, edad, raza, estado civil y ocupación) y por último, en el eje III incluiría la presencia o ausencia de conductas autodestructivas indirectas crónicas (alcoholismo, otras drogas, tabaco, automutilaciones, anorexia-bulimia, etc.) 


\section{Tipologias obtenidas por métodos estadisticos}

\section{$\underline{\text { Tipos de suicidios consumados de Bagley }}$}

Bagley y cols. en 1976 analizan estadísticamente diferentes variables de los suicidios consumados de 50 individuos en Brighton. De este estudio resulta la existencia, según los autores, de tres tipos diferentes de suicidios que son:

1. "suicidios en enfermos físicos": relacionados con enfermedades físicas y dolor crónico en personas mayores, de clase media que frecuentemente son viudos, viven solos, duermen mal y están deprimidos, y que utilizan los sedantes prescritos por su médico general para quitarse la vida.

2. "suicidios sociopáticos": caracterizados por la desorganización temprana de la vida familiar, mal ajuste laboral, rasgos sociopaticos, aislamiento social y parasuicidios previos

3. "suicidios depresivos": caracterizados por depresión crónica e intentos de suicidio previos en individuos que han estado en contacto durante tiempo con servicios de psiquiatría.

Este mismo autor, años después (Bagley, 1992), ha definido por análisis estadísticos los diferentes perfiles sociales de 130 suicidas jóvenes de 10 a 20 años desde 1978 a mitad de1981 y de mitad de 1981 a 1984. El autor considera que el aumento de las tasas de suicidio en los jóvenes en Canadá refleja factores sociales, ya que las enfermedades mentales a las que se han asociado tradicionalmente (depresión y esquizofrenia) han permanecido estables a lo largo del tiempo. Los perfiles tipificados por el autor en estos jóvenes suicidas son:

1. Tipo A (22 casos): típicamente, varón de diecisiete años o menos; método, disparo o ahorcamiento; intentos previos; contacto con servicios sociales en los seis meses previos; separación de los padres antes de los 16 años; tutela gubernamental actual o pasada; abandono de la escuela.

2. Tipo B (14 casos): típicamente, mujer de cualquier edad; método, sobredosis; intentos previos; contacto con servicios sociales los seis meses previos; separación de los padres antes de los dieciséis años; tutela gubernamental actual o pasada; abandono de la escuela.

3. Tipo C (33 casos): típicamente, varón de dieciocho a veinte años; método, disparo o asfixia por el tubo de escape del 
coche; reciente ruptura con la novia; abuso actual de drogas o alcohol; suicidio, enfermedad mental o alcoholismo en padres o parientes cercanos; existencia de trastorno de personalidad pero no de un trastorno mental formal.

4. Tipo D (10 casos): típicamente, varón de doce a catorce años; método ahorcamiento o disparo; historia de delincuencia; problemas escolares o abandono escolar actual; enfermedad mental o alcoholismo en padres; hogar conservado.

5. Tipo E (12 casos): típicamente, indios nativos; abuso de drogas, alcohol o disolventes; desempleo o abandono de la escuela; método, tiro; ausencia de contacto con servicios sociales.

6. Tipo F ( 29 casos): típicamente, de ambos sexos entre 15 y 20 años; diagnóstico de esquizofrenia o de depresión clínica actual; estudiantes; contacto con servicios sociales; ausencia de factores estresantes conocidos

7. Otros 19 casos no ha sido posible clasificarlos ni pueden ser interpretados clínicamente.

Los perfiles que aumentaron más en los últimos años del estudio son el Tipo A, C y D que representan varones en situaciones de estrés, y con familias desorganizadas y patológicas. Por el contrario, disminuyeron los suicidios de indios nativos, lo que quizás refleje el aumento de prosperidad y la disminución del alcoholismo en muchas de las reservas indias de la región de Canadá donde se ha realizado el estudio. El tipo F, correspondiente a suicidios relacionados con enfermedad mental ha permanecido estable en los diferentes períodos. Podría concluirse de este estudio que el aumento de suicidios en jóvenes podría reflejar cambios en la cantidad o grado de desorganización y patología familiar y en las reacciones o vulnerabilidad al estrés. Parece que los jóvenes son mucho más propensos actualmente a aceptar el suicidio como una forma aceptable de escapar a una situación insoportable.

\section{$\underline{\text { Tipos de parasuicidio }}$}

Henderson y Lance (1979) establecen seis tipos de parasuicidios, basándose en métodos estadísticos y no clínicos. Estos tipos son:

1. Grupo 1: Personas sin trastornos mentales, con motivaciones secundarias y extrapunitivas, no deprimidos, con bajo riesgo 
para la vida, elevada impulsividad, provenientes de familias desorganizadas, muchas veces los actos parasuicidas son conductas para demandar atención

2. Grupo 2: Personas "repetidoras": con trastornos mentales, deprimidos y como acto de evitación, han realizado otros actos parasuicidas de autolesión o autointoxicación y en este grupo es bastante probable que se repitan estas conductas, a veces con resultados mortales.

3. Grupo 3: Personas con actos de alto riesgo para la vida, deprimidos y en absoluto impulsivos. Sorprendentemente, en el estudio de seguimiento realizado durante dos años, ninguno se suicidó

4. Grupo 4: Parecido al grupo primero, pero son personas con trastornos mentales $y$ son realizados como forma de evitación.

5. Grupo 5: Personas con secciones en muñeca, con muy escasas motivaciones secundarias o extrapunitivas (dato contrario a las impresiones clínicas), en las que existe la influencia de un modelo y han realizado otras autolesiones previamente.

6. Grupo 6: Grupo indiferenciado, que es el más extenso y se caracteriza principalmente por atributos negativos, no es reconocible desde la clínica. Con baja proporción de trastornos mentales, baja motivación de evitación, no están deprimidos de forma severa y no presentan la influencia de modelos.

\section{Otros aspectos en la tipologia del suicido}

\section{Método utilizado}

Los métodos usados para suicidarse varian según los países, culturas, épocas y características demográficas, tales como la raza, el sexo, la edad y el medio rural o urbano. La elección del método también depende de la accesibilidad, la oportunidad y la aceptación sociocultural.

En general se puede afirmar que los varones prefieren métodos suicidas más "violentos", aunque éstos varian de unos países a otros. Por ejemplo, en EE.UU. el método empleado con más 
frecuencia son las armas de fuego, mientras que en España donde no es fácil acceder a ella, es el método menos usado (Saiz y cols., 1997). Las mujeres suelen usas formas más pasivas y menos violentas, como la ingesta de medicamentos.

En España los métodos suicidas más empleados son la precipitación y la suspensión, si bien hay que tener en cuenta que se observan diferencias importantes según la provincia, la edad, el sexo y el hábitat rural o urbano (Saiz y cols., 1997).

La elección del lugar donde suicidarse depende de varios factores. Generalmente, se realiza en la propia vivienda o en sitios habitualmente frecuentados por el suicida y en las localidades de diferentes países hay sitios utilizados tradicionalmente para el suicidio, como son la torre Eiffel en París, el viaducto de Madrid antes de realizar la protección, el río Neva en San Petesburgo, etc.

Schmitt y Mundt (1991) realizan una tipología del suicidio basado en un estudio de supervivientes a intentos autolíticos en Heidelberg según hayan empleado métodos suicidas "suaves" o "duros". Los métodos suaves (90\%) fueron principalmente intoxicaciones medicamentosas que precisaron ingreso en el Servicio de Medicina Interna, mientras que los métodos duros (10\%) precisaron el ingreso en Cirugia. Los pacientes que realizaron métodos duros presentaban mayor desintegración social, fueron más frecuentemente enfermos mentales, tuvieron una fase presuicida más corta (o sea, pasó menos tiempo desde que tomó el paciente la decisión de suicidarse y la realización del intento autolítico) y una autoestima más baja. Por el contrario, la agresividad fue baja en ambos grupos.

Se ha intentado relacionar el método utilizado con otras características, algunas curiosas, como el aspecto físico. En este sentido Lester (1987) estudia la razón ectomorfica (la altura dividida por la raíz cúbica del peso) en una serie de suicidios consumados. La única diferencia significativa que encontró fue que las personas que usaron como método la asfixia tuvieron puntuaciones ectomorficas más elevadas, o sea, eran más delgados que los que usaron otros métodos.

En lo que se refiere a las tentativas de suicidio, todos los autores están de acuerdo en manifestar que la intoxicación medicamentosa es el método más utilizado (Sáiz y cols., 1997). 


\section{$\underline{\text { Existencia de notas de despedida }}$}

En la bibliografia, la proporción de notas de despedida varía entre el 12\% y 35\% (Sarró y de la Cruz, 1991). La razón de su existencia es compleja y es considerada como una indicación de una intencionalidad realmente suicida. Se piensa que antes de morir se siente la tentación de escribir una nota para explicar los motivos o pedir perdón.

El incremento de éstas data del siglo XVIII, con el aumento del alfabetismo y la proliferación de periódicos que publicaban las "últimas palabras" de los suicidas a un público ávido de emociones. La publicación de estas notas ayudaron a mostrar el lado humano del suicidio.

Brierre de Boismont (1856) (en Sarró y de la Cruz, 1991) estudió el contenido de 1328 cartas de suicidio y las valoró como un documento personal válido, por ser su última comunicación y representar un acceso directo al suicida. Existieron notas de despedida en el $28,8 \%$ de los 4596 suicidios consumados estudiados por el autor, lo que llama la atención por el alto porcentaje en una época de alto índice de analfabetismo. Analizó sus contenidos siendo en todas ellas las "pasiones" las causas determinantes del suicidio y las clasificó en tres tipos:

- Las notas que contenían buenos sentimientos como honor, religión, amistad y arrepentimiento.

- Las notas que contenían malos sentimientos como venganza, reproches y falsedad.

- Las notas que contenian sentimientos mixtos.

La mayoria son escritas por mujeres y no indican el motivo concreto por el que se suicidan (Andress, 1996). Suelen dejar indicaciones sobre como liquidar sus bienes o disponer del cadáver. En general, las cartas de los suicidas se caracterizan por expresar hostilidad y autoreproches, pedir perdón a las personas significativas o a Dios, utilizar nombres concretos y usar con frecuencia los distintos significados de la palabra amor. Las palabras más utilizadas son "adiós" y "perdón". Cuando indican algún motivo para el suicidio, éste suele ser angustia y dolor físico o mental insoportable e inacabable. Los temas expresados en estas notas suelen ser la soledad, el desvalimiento y la desesperanza. 
B. F. DOSTOIEVSKI 


\section{Biografia de Fiodor Dostoievski}

Los datos reseñados en este apartado se han recogido esencialmente de los estudios biográficos sobre el autor realizados por E. H. Carr (1931), H. Troyat (1946), J. Frank (1984, 1986, 1993, 1997) y Cansino Assens (1982).

\section{a. Infancia y adolescencia (1821-1837)}

Sus padres contrajeron matrimonio en 1819.

El padre, descendiente de nobles e hijo de sacerdote, estudió medicina en contra de la voluntad de su familia. Ha sido definido como una persona de carácter irascible, autoritario, avaro y rígido, muy susceptible, que bebe demasiado, adolece de jaquecas y depresiones y sufre celos patológicos de su mujer. Trabajador y responsable.

La madre es hija de un comerciante de Moscú. Parece que fue una mujer resignada, débil, tierna, sensible, de carácter dulce y apagado. Para Carr (1931) su propia madre será el modelo de varias madres que aparecen en sus novelas, modelos de afecto y de inutilidad. Administradora eficaz, cien años después aún perduraba la leyenda sobre su indulgencia y compasión entre los descendientes de los campesinos de la finca que compró el matrimonio en Darovoe.

Fiodor Dostoievski nace en el Hospital de la Beneficencia Marinski de Moscú, donde su padre ejerce de médico, el 11 de Noviembre de 1821.

Es el segundo de ocho hermanos. Su hermano mayor, Miguel, nació un año antes. Después de Fiodor, vino Várvara y Andrei (cuyas memorias constituyen la fuente principal para reconstruir la infancia de Dostoievski); luego, tras un intervalo, Vera, Nicolás, Alexandra y una hermana gemela que murió a los pocos días.

La familia vive en un apartamento anexo al hospital y se caracteriza por llevar una vida urbana rutinaria y ordenada con lecturas vespertinas y paseos en verano. Es esencialmente una vida familiar solitaria, ya que a los hijos les estaba prohibido mantener relaciones con otros niños. Un papel significativo en la 
infancia de Dostoievski lo representa la nana Aliona Frolovna y sus relatos populares rusos.

Fiodor Dostoievski destacará en Diario de un escritor (1873, T.III, p.802) la formación religiosa y cultural de su familia: "Procedía yo de una familia rusa auténtica y temerosa de Dios. En cuanto alcanza mi memoria, recuerdo que me amaban mis padres. Desde la más tierna infancia estábamos en casa familiarizados con el Evangelio. Ya a los diez años conocía yo todos los acontecimientos principales de la historia rusa, según la obra de Karamzin, que nuestro padre nos leía por las noches. La visita al Kremlin y a las viejas iglesias de Moscú fue para mí siempre algo solemne".

A partir de los diez años, edad en que sale por primera vez de Moscú y en la que tiene su primer contacto con el campo, pasa los veranos en la Granja de Darovoe. De esta época data un incidente al que posteriormente Dostoievski otorgó gran importancia: un día se sintió atrapado por un lobo imaginario y se aterrorizó; un campesino llamado Marey le dio ánimos y le tranquilizó. Este incidente es narrado por primera vez en El Adolescente (T.II, P. III, C. IV, p. 1813), obra escrita en 1875. En 1876, en Diario de un escritor (El campesino Marey: 1876 febrero, Cap. I, III) lo convierte en una leyenda: Dostoievski refiere en este artículo que el recuerdo de esta experiencia le ayudó en su "regeneración moral" en Siberia al ayudarle a cambiar los sentimientos que presentaba hacia el pueblo y a la recuperación de su fe en éste como imagen humana de Cristo.

La enseñanza primaria corre a cargo de su padre primero y a partir de 1831 en la escuela privada de Souchard. En 1834 ingresa con su hermano mayor, Miguel, en el internado de Chemark.

En 1837 muere su madre de tuberculosis. En Mayo de este mismo año viaja con su hermano Miguel a San Petesburgo para ingresar en la Escuela Militar de Ingenieros. 


\section{b. San Petesburgo (1837-1849)}

Durante el viaje Dostoievski sufre una experiencia que le causó gran impacto y que relatará en Diario de un escritor (Enero 1876, p. 891; Agosto 1880, p.1453): cuenta como un cochero azota a su caballo como reacción a los golpes que le propina en la nuca su señor. Este incidente inspira un sueño de Raskólnikov en Crimen $y$ Castigo (T. II, P. I, C. V, pp. 55-59) y en sus apuntes para esta novela Dostoievski llama a este suceso su "primer ultraje personal".

En enero de1838 ingresa solo en la academia militar de ingenieria de Petesburgo. Su hermano Miguel es declarado no apto en la revisión médica. En la academia Fiodor se convierte en un joven solitario, buen estudiante, dócil y aplicado, que no disfruta con los bailes y las bromas de sus compañeros. Es descrito por un compañero como un muchacho de expresión triste y absorta, inquieto, orgulloso, de gran delicadeza moral y debilidad física y con tendencia al aislamiento. De esta época data su amistad con Shidlovshi, un joven poeta romántico que es su guía y tutor literario. Durante esta época lee a Shakespeare, Schiller, Hoffmann, Balzac, Goethe, Victor Hugo, Racine, Corneille, De Quincey, expresando habitualmente en su correspondencia con Miguel su admiración por estos autores románticos y su devoción hacia su amigo común Shilodvski.

En Julio de 1839 muere su padre asesinado por los siervos de Darovoe, aunque en los últimos años han aparecido algunas dudas sobre la autenticidad de este asesinato; otras fuentes consideran que murió de muerte natural, por una apoplejía (Bravo, 1987). Tras la muerte de su esposa, el padre de Dostoievski se había entregado totalmente a la bebida y habia aumentado notablemente su irascibilidad y excentricidad; miraba debajo de las camas de sus hijas buscando un amante oculto, hablaba solo con el fantasma de su mujer; perseguía a las campesinas jóvenes, llegando a tener un hijo con una de ellas, muerto al poco tiempo (Bravo, 1987).

Existe una leyenda familiar referida por la hija del autor, Liubov, aceptada por Freud, según la cual Dostoievski tuvo el primer ataque de epilepsia al conocer la muerte de su padre en el verano de 1839. Esta leyenda es desmentida por el propio Dostoievski en sus cartas de 1854 en las que menciona sus ataques como un fenómeno nuevo; además, ninguno de los compañeros de Dostoievski de la Academia Militar mencionan este ataque a pesar de que todos los que escribieron sus memorias lo hicieron cuando 
la enfermedad de Dostoievski era ya conocida públicamente. Parece improbable que este ataque fuera ocultado a sus compañeros en un régimen de observación y vigilancia constante en el que cien muchachos compartían la misma habitación.

Los meses siguientes se caracterizan por algo que será habitual a lo largo de casi toda su vida: la falta de previsión económica y la penuria crónica. Aunque recibe dinero de la herencia de su padre, Dostoievski lo despilfarra rápidamente, entre otras cosas, dando limosnas y jugando al billar y al dominó.

En 1843 obtiene el título de ingeniero del Ministerio de Guerra. Miguel se casa este mismo año. Lee apasionadamente literatura francesa (Lamartine, Victor Hugo, Paul de Kock) y empieza a concebir la literatura como forma de aumentar sus ingresos. Traduce a Balzac (Eugenia Grandet) y a G. Sand.

En 1844 dimite de su trabajo como ingeniero militar.

Durante 1844 y 1845 escribe Pobres gentes, que se publica en Enero de 1846, con gran éxito. Es protegido por las grandes figuras literarias de la época, como Belinski, quien le proclama el creador de la "novela social". Se relaciona con la aristocracia y entra a formar parte de los círculos literarios. De esta época data su primer encuentro con Turgueniev, con el que se enemistará más tarde, al igual que con el poeta Niekrasov, que se mofan de él y le apodan "el caballero de la triste figura".

De 1846 a 1849 escribe El doble, El señor Projarchin, La patrona, Una novela en nueve cartas, Plozúnvok, Corazón débil, El ladrón honrado, La mujer ajena y un hombre debajo de la cama, Un árbol de Noel y una boda, Noches blancas y Nietochka Nezvanova, esta última inconclusa. Todas ellas son desfavorablemente acogidas por la crítica.

En la primavera de 1846 comienza a presentar trastornos psíquicos. Dostoievski lo describe como "una grave postración de todo el sistema nervioso". Esta es una época de alto estrés social, tras el éxito de su primera novela y en la que sus siguientes obras son desprestigiadas por la critica. Sufre distintas somatizaciones: pulso rápido, cefaleas, se desmaya ante un cortejo fúnebre. Este desmayo no parece que presentase los sintomas de una crisis epiléptica habiéndose catalogado como una lipotimia originada por su situación psíquica. Padece insomnio causado por el temor a morir durante la noche, se muestra irritable y desconfiado. Según el doctor Yanovski, médico que le trata y del que se hace amigo 
íntimo, tenía alucinaciones y oía a alguien roncar a su lado por las noches. El tratamiento consistía en flebotomías y sanguijuelas.

Entra a formar parte de un grupo de jóvenes compuesto por funcionarios, estudiantes, periodistas, escritores y comerciantes cuyo líder es un funcionario del Ministerio de Asuntos Exteriores llamado Petrachevski, cuyo proceso pasará a la posteridad como "La conjuración de Petrashevski". En su casa se discuten las últimas noticias literarias y políticas. Defienden la liberación de los siervos, la libertad de prensa y el establecimiento de una comunidad ideal. La base principal de su ideología son las ideas de Rousseau. 


\section{c. La condena (1849-1859)}

El 22 de Abril de 1849 es arrestado acusado de conspiración y al día siguiente es trasladado a la fortaleza de Pedro y Pablo, donde pasará ocho meses en un aislamiento total. Para Fiodor este arresto, según confesó posteriormente a su mujer, le salvó de volverse loco. En su confinamiento, descubre la fuerza moral y resistencia del espíritu humano cuando es obligado a depender de sus propios recursos. Durante este período escribe El pequeño héroe.

El tribunal militar pide la pena de muerte que se conmuta el 19 de Noviembre, pero cuya decisión se mantiene en secreto. Realmente se le condena a cuatro años de trabajos forzados en Siberia, después de los cuales tendria que servir al ejercito ruso por tiempo indefinido.

El 23 de Diciembre de 1849 se realiza la parodia de ejecución en la plaza de armas del regimiento Semenóvski. Sus impresiones imborrables de este momento las relatará posteriormente en $E l$ Idiota (Tomo II, Parte I, Cap. V, p. 549) y en El Diario de un escritor (El ciudadano, T.III, p. 802).

Dos dias más tarde comienza el viaje al penal de Omsk, en Siberia. En Tolbosk es visitado por las mujeres de algunos supervivientes de la conspiración decembrista de 1825, quienes le regalan el Evangelio, único libro permitido en la prisión y que Dostoievski conservará durante toda su vida.

De 1850 a 1854 permanece como prisionero en este penal. Posteriormente recogerá sus experiencias del presidio en Memorias de la casa muerta (1856) y hará también referencias a ellas en el epílogo de Crimen y castigo, en Los hermanos Karamazov $y$ en Diario de un escritor (Febrero, 1876, p. 905 y 920). Fiodor Dostoievski considerará toda su vida los años de prisión como una etapa de salvación anímica, como el período de "regeneración de sus convicciones".

Los primeros meses que estuvo en prisión se caracterizaron por el desprecio de y hacia los compañeros de prisión. En este tiempo descubre la conciencia sociopolitica de los presos, que odian a los nobles como él. Dostoievski se muestra huraño, misantrópico e insociable. Considera que la prisión es un mundo de horror moral, donde las normas morales ordinarias han dejado de existir, todo está corrompido y degradado. En Memorias de la casa muerta relata su experiencia en estos años: Su horror primero, sus 
sentimientos de autocompasión masoquista, el odio de los prisioneros hacia él por ser noble. Refiere su primera fase negativa de regeneración de las convicciones que se caracterizó por la destrucción de la fe en la Humanidad (... "la tristeza de todo aquel año primero de presidio era insoportable y obraba en mí un efecto enervante, amargo...Entre los malignos y envidiosos camaradas de presidio, no notaba a los buenos...") (T.II, p. 1317) así como su regeneración posterior en la que aparecen sus primeras muestras de idealización del "pueblo" y ensancha las fronteras de la moralidad tradicional, considerando, al conocer a sus compañeros presidiarios, que más importantes que el crimen en sí son los motivos, la situación humana de la que emerge éste.

Aproximadamente en 1950, presenta su primera crisis convulsiva. Aunque hubo rumores sobre que el primer ataque epiléptico fue tras ser azotado, este hecho es desmentido por Yanovski y por un amigo íntimo suyo de la época de Semipalatinsk, Wrangel, quienes aseguraron categóricamente que nadie le causó jamás daño físico alguno. Sus compañeros de presidio tampoco lo nombran. El segundo ataque ocurrió en 1853 y posteriormente las crisis continuaron con un promedio de una vez al mes.

Rusia declara la guerra a Turquía en 1853 (guerra de Crimea).

El 15 de Febrero de 1854 sale de prisión siendo destinado a Semipalatinsk, para continuar el cumplimiento de la condena como soldado común. En Semipalatinsk permanece desde 1854 hasta 1859.

Durante este período lee la obra de Carl Gustav Carus, quien ha sido considerado repetidamente precursor del psicoanálisis.

De esta época data también el inicio de su amistad con el Barón Wrangel, procurador, que llega a Semipalatinsk en Noviembre de 1854 con veintiún años. Vivieron juntos a partir de la primavera de 1855 hasta el matrimonio de Fiodor.

En Semipalatinsk se enamora de María Dimitrievna, mujer casada con un alcohólico y madre de un niño de 8 años.

En Mayo de 1855 se traslada María con su familia a Kuznetsk existiendo una correspondencia apasionada entre ambos y cuyo tema principal son los celos de Dostoievski. En Agosto de este año muere el marido. 
Tras enviudar, María inicia relaciones con un maestro, que será un modelo real de situaciones triangulares que Dostoievski utilizará en sus obras, especialmente en Humillados y ofendidos.

En Febrero de1855 muere Nicolás I. Es coronado Alejandro II en 1856. Dostoievski hace a ambos odas laudatorias.

En el otoño de 1856 le ascienden a oficial lo que le permite una respetable posición en la sociedad y le proporciona ingresos aceptables. Se casa con María Dimitrievna el 7 de Febrero de 1857. Durante su noche de bodas sufre un ataque epiléptico que revela por primera vez a María Dmitrievna que se ha casado con un hombre enfermo.

Escribe El sueño del tito y La alquería de Stepanchikovo.

Le es concedida su petición para retirarse del ejercito por motivos de salud en Mayo de 1859.

En Julio de1859 se traslada a Tver con su mujer e hijastro Paul Isaev donde vive durante cuatro meses en los cuales presenta frecuentes ataques epilépticos y un agravamiento de sus hemorroides que le incapacita para trabajar. 


\section{d. La penuria (1860-1866)}

En diciembre de 1859, con treinta y nueve años vuelve a Petesburgo y en 1860 funda con su hermano el periódico Vremia ("Tiempo"), cuyo primer número aparece en Enero de 1861 y que será el periódico portavoz de la tendencia sociocultural de Dostoievski llamada "Pochennichestvo". Sus dos colaboradores principales serán Strajov (que será más tarde su biógrafo oficial) y Grigoriev. Sus principios principales son la búsqueda de una nueva sintesis cultural rusa que surja de la fusión del pueblo con la intelectualidad, siendo ésta para ellos una cuestión prioritaria con respecto a la mejora del destino del campesinado, que es la cuestión primordial para los radicales materialistas. Además, esta transición, según Dostoievski, debe hacerse pacíficamente. También de este movimiento surge la doctrina del "panhumanismo" ruso de Dostoievski, según la cual la idea rusa puede ser la sintesis de todas las ideas europeas en cada una de sus nacionalidades.

Su mujer, Maria Dimitrievna, enferma gravemente de tuberculosis y su temperamento se va haciendo cada vez más irritable e impetuoso. El matrimonio de Dostoievski resulta ser un matrimonio infeliz, siendo María un objeto de piedad para Dostoievski. Además, continúa agravándose su epilepsia con ataques epilépticos muy frecuentes.

En Febrero de1861 es abolida la servidumbre en Rusia. Los años posteriores son llamados "la época de las proclamas" con una situación de agitación abierta contra el régimen y propaganda antizarista de la intelectualidad radical. En Noviembre de este año estalla la revuelta antigubernamental de los estudiantes "nihilistas". Se cierra la universidad y el periódico Vremia apoya a los estudiantes. Aparecen los raznochintsy, jóvenes radicales de origen no aristocrático (hijos de sacerdotes, pequeños funcionarios, siervos) que han adquirido una educación y que sus idolos son Belinski y la figura central del libro Padres e hijos de Turgueniev, Bázarov, cuyos rasgos son los de los raznochinets (tono ofensivo, agresivo, con depreciación por el arte) y que es llamado en esta novela "nihilista" (que pasa a ser posteriormente la denominación general de esta tendencia). Su ideología está compuesta por una mezcla de utilitarismo inglés, socialismo utópico, ateísmo feuerbachiano y burdos materialismo y determinismo mecánico. Esta ideología y su crítica o repulsa será el tema sobre el que se basarán algunas de las obras mayores de Dostoievski 
En el primer número de Vremia publica Visiones petesburguesas en verso y prosa (los versos son de Mináev) donde hace un resumen de su pasado literario. También publica una serie de relatos de célebres procesos recientes por asesinato en Francia, entre ellos el del célebre Lacenaire que cometió un asesinato a sangre fría, escribió poemas y dejó sus memorias.

Traduce varios cuentos de Edgard Allan Poe, entre ellos un estudio de este autor, El gato negro, sobre la perversión y la inclinación a violar aquello que es Ley simplemente porque lo es. $\mathrm{Su}$ influencia en la dialéctica psicológica-filósofica de la primera parte de Memorias del subsuelo es obvia.

En 1861 escribe Humillados y ofendidos y publica Memoria de la casa muerta, obteniendo ambas novelas un gran éxito popular.

En Junio de 1862 realiza su primer viaje al extranjero. Pasa por Berlin, Dresde y Colonia, llegando a Wiesbaden, donde consigue una sustanciosa ganancia en el casino. Permanece dos semanas en París y posteriormente pasa ocho días en Londres, donde visita a Herzen. En Ginebra se reúne con Strajov y luego visita Turín, Génova y Florencia. En Florencia lee Los miserables de Víctor Hugo, novela que le apasiona más que la propia ciudad. Escribe sus impresiones sobre el viaje en Apuntes de invierno sobre impresiones del verano.

En Septiembre de 1862 vuelve a Petesburgo. Escribe Un asunto enojoso.

Tras el viaje inicia relaciones con Polina Suslova, veintidós años más joven que él y que es una mujer atea y feminista que preconiza el amor libre y la igualdad ante la ley.

En Enero de 1863 tiene lugar la revuelta polaca y en mayo de este año el periódico Vremia es suprimido por un artículo de Strajov sobre la cuestión polaca. En los meses previos el periódico había adquirido gran prestigio y un elevado número de suscriptores. Su cierre ocasiona grandes deudas a los hermanos Dostoievski.

En Agosto de 1863 Fiodor pide un préstamo al Fondo literario a cambio de los derechos de las obras ya publicadas a perpetuidad si no devuelve la deuda en Febrero de 1864. Con este dinero hace su segundo viaje al extranjero: Pasa cuatro días en Wiesbaden, donde pierde en el casino grandes cantidades de dinero. Va a París y se reúne con Polina, que mantiene relaciones en esa ciudad con un hombre español. Los dos continúan un tormentoso viaje "como 
hermanos", con una relación ambivalente de amor-odio. En Baden pierden prácticamente todo el dinero que les queda en el juego, y luego pasan por Ginebra, Turín, Génova, Roma y Nápoles, donde se separa de Polina. Para sobrevivir tienen que empeñar los objetos personales y pedir dinero prestado a familiares y amigos. Sigue su viaje, ya solo, a Turin y Hamburgo y en Octubre de este año vuelve a Petesburgo.

En Noviembre de 1863 se traslada con su mujer, gravemente enferma a Moscú. En los meses siguientes se ocupa principalmente del cuidado de María, que realiza tierna y piadosamente. Es un período marcado por el sufrimiento, al que se añade el agravamiento de las crisis epilépticas y de las hemorroides. Su penuria económica "crónica" se alivia al recibir una herencia de su tío rico de Moscú y proyecta con su hermano Miguel la edición de un nuevo periódico, Epojkha, cuyo primer número aparece en abril de 1864.

El 16 de Abril de1864 muere María Dimitrievna, su primera mujer.

Durante los meses que pasa en Moscú al cuidado de su mujer escribe Memorias del subsuelo, cuya primera parte finaliza en Febrero de 1864.

Tras la muerte de María, vuelve a Petesburgo. El 10 de Julio de 1864 muere Miguel Dostoievski de una enfermedad del hígado, en bancarrota, asumiendo Fiodor la obligación moral de atender a su familia. Mantiene económicamente a su hijastro, la familia legítima e ilegítima de Miguel y a su hermano Nicolás. Pide dinero a su rica tía Kumanin. Intenta continuar con la revista Epojkha, donde publica un cuento satírico inconcluso: El cocodrilo. Tras los dos primeros números de 1865, el periódico quiebra con una deuda aplastante.

A principios de 1865 aparecen otras dos mujeres en su vida: Ana Korvin y Marta Brown: Ana, procedente de una familia respetable rusa y Marta, humilde, de vida azarosa, enferma, cuyo sentimiento principal hacia Dostoievski es la gratitud y de Dostoievski hacia ella piedad. Estas mujeres quedarán inmortalizadas como Aglaya y Nastasia respectivamente en El Idiota.

En Julio de 1865 emprende su tercer viaje a Europa. En Wiesbaden se reúne con Polina Suslova, siendo abandonado luego por ésta. Adquiere más deudas aún en el casino, viviendo en condiciones de miseria. En Octubre pasa en Copenhague diez días donde visita a Wrangel y vuelve a Petesburgo; aquí se ve acosado 
por sus acreedores y se agrava su epilepsia y sus hemorroides. Empieza a escribir Crimen y castigo que se comienza a publicar en enero-febrero de 1866 y que tiene gran éxito.

E1 4 de Abril de 1866 un estudiante radical realiza un atentado fallido contra el zar Alejandro II.

En verano de 1866 va a la casa de campo de su hermana Vera en Lublina, donde conoce los modelos sobre los que se inspirará para algunos personajes secundarios de El eterno marido. 


\section{e. Residencia en el extranjero (1867-1871)}

El 4 de octubre de 1866 contrata una taquígrafa, ante la premura con la que le acucian sus acreedores, para dictar su nueva novela, El jugador. Esta taquígrafa es Ana Grigorievna, de veintiún años, con la que se casa el 15 de febrero de 1867. Su familia, y especialmente su hijastro, desaprueban este matrimonio.

En su segundo matrimonio, Dostoievski asume un papel pasivo. La actitud de Ana se basa en la admiración ciega hacia Fiodor por su genio literario, unida a una solicitud maternal y un afán de plena posesión. Durante los primeros meses de matrimonio las relaciones fueron dificiles por la falta de confianza de Dostoievski en sí mismo y la conciencia de sus propios defectos, junto con las dudas y temores en la duración del amor de Ana. Posteriormente se caracterizó por ser un matrimonio muy feliz y cuya influencia es fundamental para la creación de Dostoievski.

En Abril de 1867 empieza su cuarto viaje a Europa, que durará cuatro años, acompañado de su mujer Ana Grigorievna. Las razones de esta huida de Petesburgo son tanto las malas relaciones de Ana con la familia de Dostoievski como el acoso de los acreedores y la comprobada mejoría de su enfermedad epiléptica cuando reside en Europa. Pasan por Berlin y Dresde, desde donde va Dostoievski solo a Hamburgo con la intención de ganar dinero en la ruleta y donde lo pierde todo. En Junio se traslada, ya junto a Ana, a Baden, donde sigue jugando, teniendo el matrimonio que empeñar objetos como los abrigos y las alianzas. Aquí se encuentra con Turgueniev, con quien tendrá una agria disputa. Pasan un día en Basilea, donde el cuadro Cristo muerto de Hans Holbein, el joven, le ocasionará gran impacto. Este cuadro mantendrá en $\mathrm{El}$ Idiota un importante papel simbólico.

En la feria mundial de París en Mayo de 1867 hay un nuevo atentado fallido contra el zar Alejandro II, esta vez por un exiliado polaco, lo que ocasiona en Dostoievski una crisis epiléptica y un mayor encono aún hacia los polacos.

Llegan a Ginebra en Agosto de 1867. En Septiembre de 1867 asiste en esta ciudad al congreso por la Paz y la Libertad, en el que fueron oradores Garibaldi y Bakunin. Este congreso inspira el episodio de los nihilistas de El Idiota y es criticado duramente por Dostoievski. 
Durante el tiempo que permanecen en Ginebra, Dostoievski esporádicamente se acerca a Saxon-les-bains donde sigue jugando y perdiendo.

Durante 1867 y 1868 escribe El Idiota. Los siete primeros capítulos aparecen publicados en prensa en Enero de 1868, siendo recibido con indiferencia y desconcierto de la crítica.

El 5 de Marzo de 1868 nace su primera hija, Sonia. Dostoievski vive apasionadamente su paternidad. Posteriormente describirá en Los demonios las emociones que experimentó al nacimiento de su hija. La niña muere en Mayo de un resfriado lo que origina un inmenso desconsuelo al matrimonio.

A finales de Mayo de 1868 abandonan Ginebra y van a Vevey. En Septiembre de 1868 se instalan en Italia: Pasan dos meses en Milán y en Noviembre parten a Florencia donde permanecen hasta finales de Julio de 1869. En este mes salen rumbo a Praga pasando por Venecia, Bolonia, Trieste y Viena. No encuentran alojamiento en Praga.

Llegan a Dresde a mediados de Agosto de 1869 donde permanecen dos años. El 26 de Septiembre de 1869 nace su hija Lyubov.

En el otoño de 1869 escribe El eterno marido que tiene una buena acogida por el público y la crítica.

Proyecta escribir la novela Ateismo que en Diciembre de 1969 se transforma en La vida de un gran pecador y que planea dividir en tres o cinco noveletas separadas. Su proyecto es intentar representar como un hombre ruso encuentra su camino, después de sufrir mucho, desde los abismos de la corrupción, el ateísmo y la desesperación hasta la crisis moral y la regeneración de su fe. Escribe notas de gran parte de la primera novela que trata de la niñez y adolescencia del "gran pecador" y que luego utilizará en Los demonios y El adolescente. Al final relegará esta obra para escribir una novela que le parece de mayor actualidad, Los demonios, novela que escribe de Enero de 1870 a Julio de 1872.

El 19 de Julio de 1870 se declara la guerra franco-prusiana. En el período de Marzo a Mayo de1871 se establece la Comuna de París.

En la primavera de 1871 juega por ultima vez en Wiesbaden. Se apaga definitivamente la pasión de jugar que ha sufrido durante 
diez años. Probablemente la creciente dependencia de su esposa y el paso de los años disminuyeron la pasión por el juego.

En estos años en el extranjero se exacerba su patriotismo exacerbado e irracional y va aumentando su nostalgia de Rusia. 


\section{f. Años de bienestar (1871-1881)}

Vuelven a Petesburgo en Julio de 1871. Tres días después de su llegada nace su tercer hijo y primer varón, Fiodor.

Esta última etapa de su vida se caracteriza por la celebridad, la seguridad financiera (se encarga Ana de estos asuntos) y emocional, la tranquilidad y las actividades metódicas.

A finales de 1872 es nombrado redactor-jefe de El ciudadano y empieza a publicar artículos mensuales en esta revista, que continuará como una publicación independiente en 1876, 1877, 1880 y 1881: Diario de un escritor.

Es diagnosticado de enfisema pulmonar crónico: En el verano pasa unas semanas en el balneario alemán de Bad Ems en 1874, 1875,1876 y 1879.

Durante el invierno1874-1875 escribe El Adolescente en una casa de campo alquilada en Staraia Rusa, que es acogida favorablemente por la crítica.

Nace su hijo Aliosha en esta localidad en agosto de 1875, que morirá tres años más tarde en un ataque epiléptico.

Tras el nacimiento de Aliosha vuelven a Petesburgo y reanuda los artículos mensuales en Diario de un escritor. En Diciembre de 1877 anuncia que suspenderá temporalmente la edición de su periódico para realizar un nuevo libro (Los hermanos Karamázov).

Durante 1877-1878 tiene lugar la guerra ruso-turca.

En el verano de 1877 visita la granja de Darovoe, donde pasó su infancia.

Se afianza su amistad con Solobiev, un joven profesor de filosofia que conoció en 1873 y cuya amistad va madurando. En junio de 1878, tras la muerte de Aliosha, visitan juntos el monasterio de Optina Pustyn, donde conversan largamente con el Padre Ambrosius, modelo del stárets Zósima en Los hermanos Karamazov. Escribe este libro en el período de tiempo 1879-1880.

Es invitado en Mayo de 1880 a los festejos por la inauguración del monumento a Pushkin en Moscú. Estos festejos son aplazados a Junio por la muerte de la Emperatriz. Su discurso logra un rotundo éxito. El 10 de Junio abandona Moscú y vuelve a 
Petesburgo. Más tarde aparecen artículos reticentes a este discurso y contestaciones a éstos desde Diario de un Escritor (Agosto, 1880, p. 1448).

Muere el 28 de Enero de 1881 a los sesenta años de una hemorragia pulmonar. Comienza con las primeras hemorragias en la madrugada del día 26 de Enero. La madrugada del día 28 confiesa a Ana su convicción de que va a morir ese día. Se despide de su mujer e hijos y pide el Evangelio que le regalaron las mujeres de los decembristas en Siberia.

Es enterrado el día 31 de Enero de 1881 con gran afluencia de público.

El 1 de Marzo de este año será asesinado Alejandro II. 


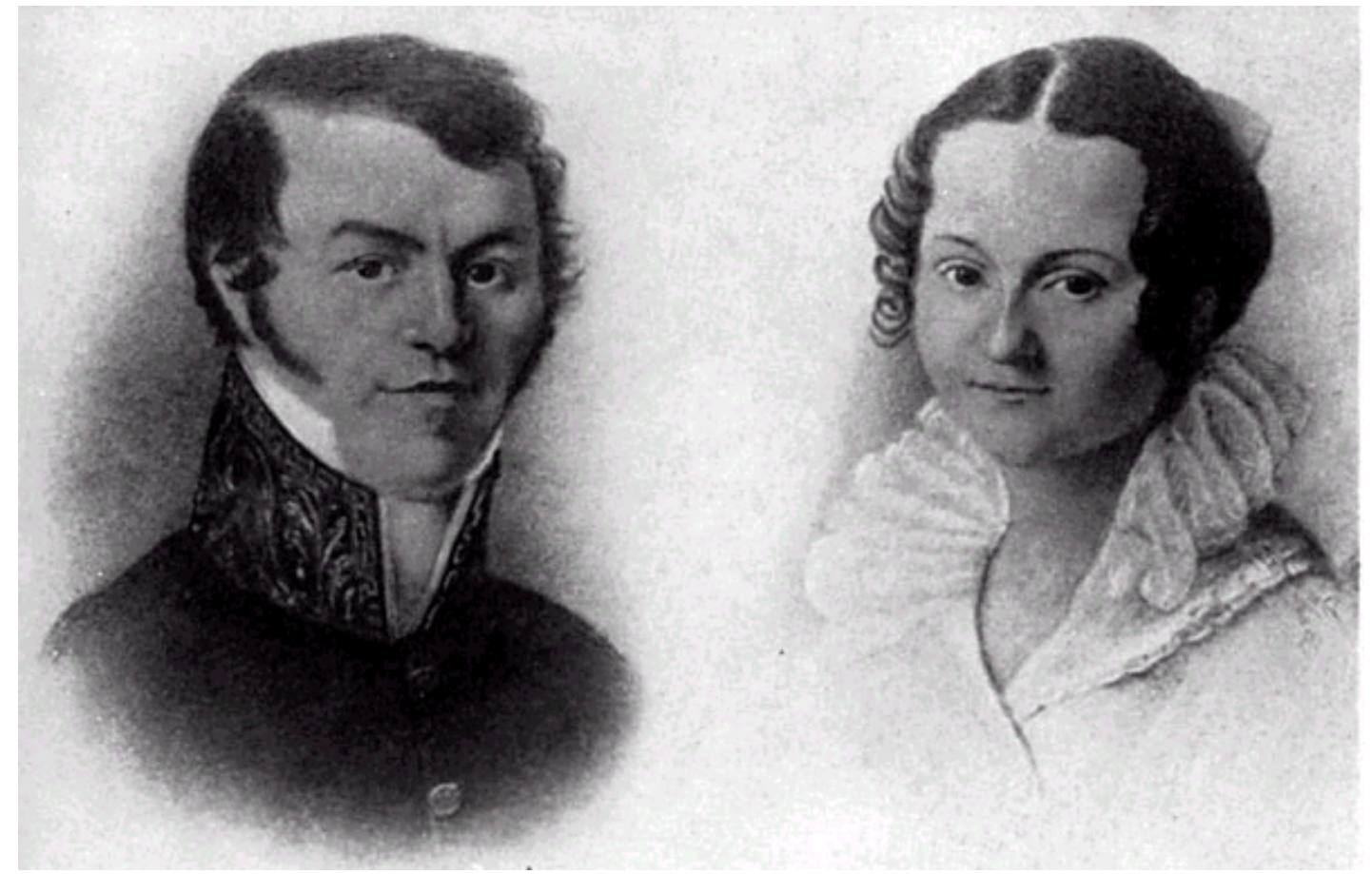

Los padres de Fiodor Dostoievski, el doctor Mikhail Andreyevich y Maria Fyodorovna Dostoevski

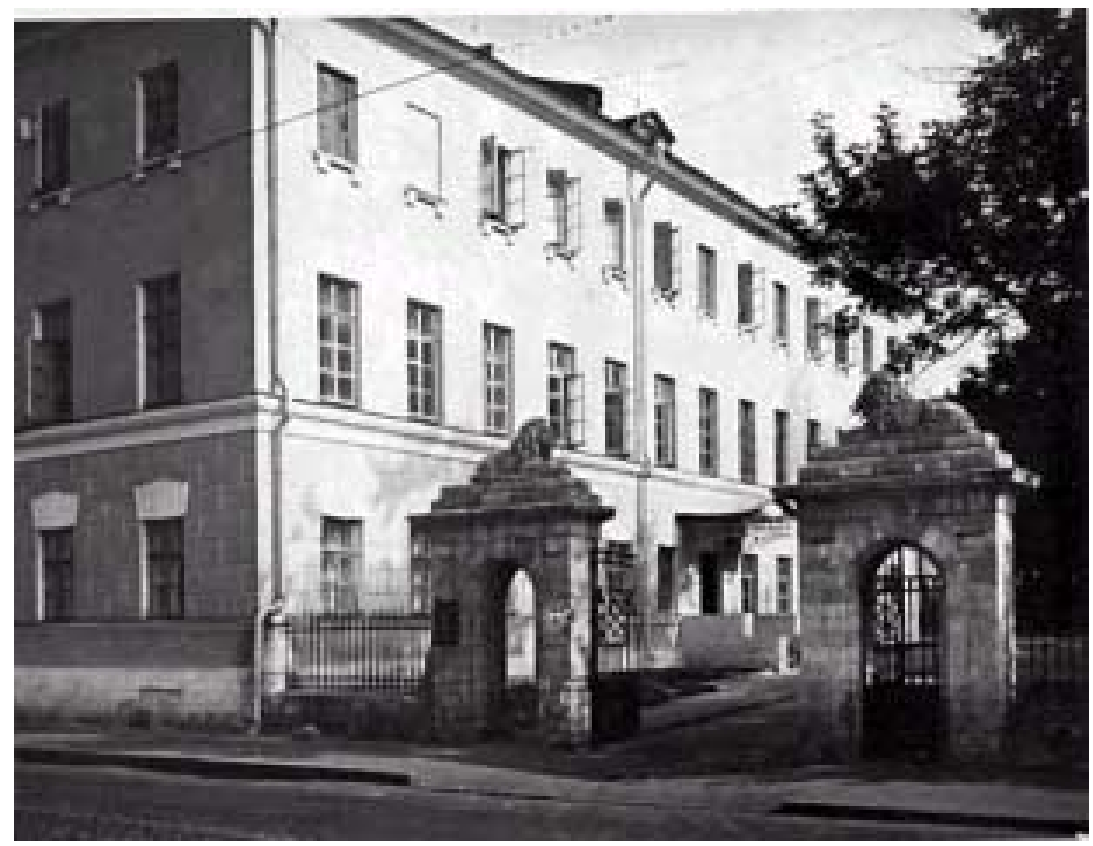

Hospital de la Beneficencia Marinski de Moscú, donde nació Dostoievski 


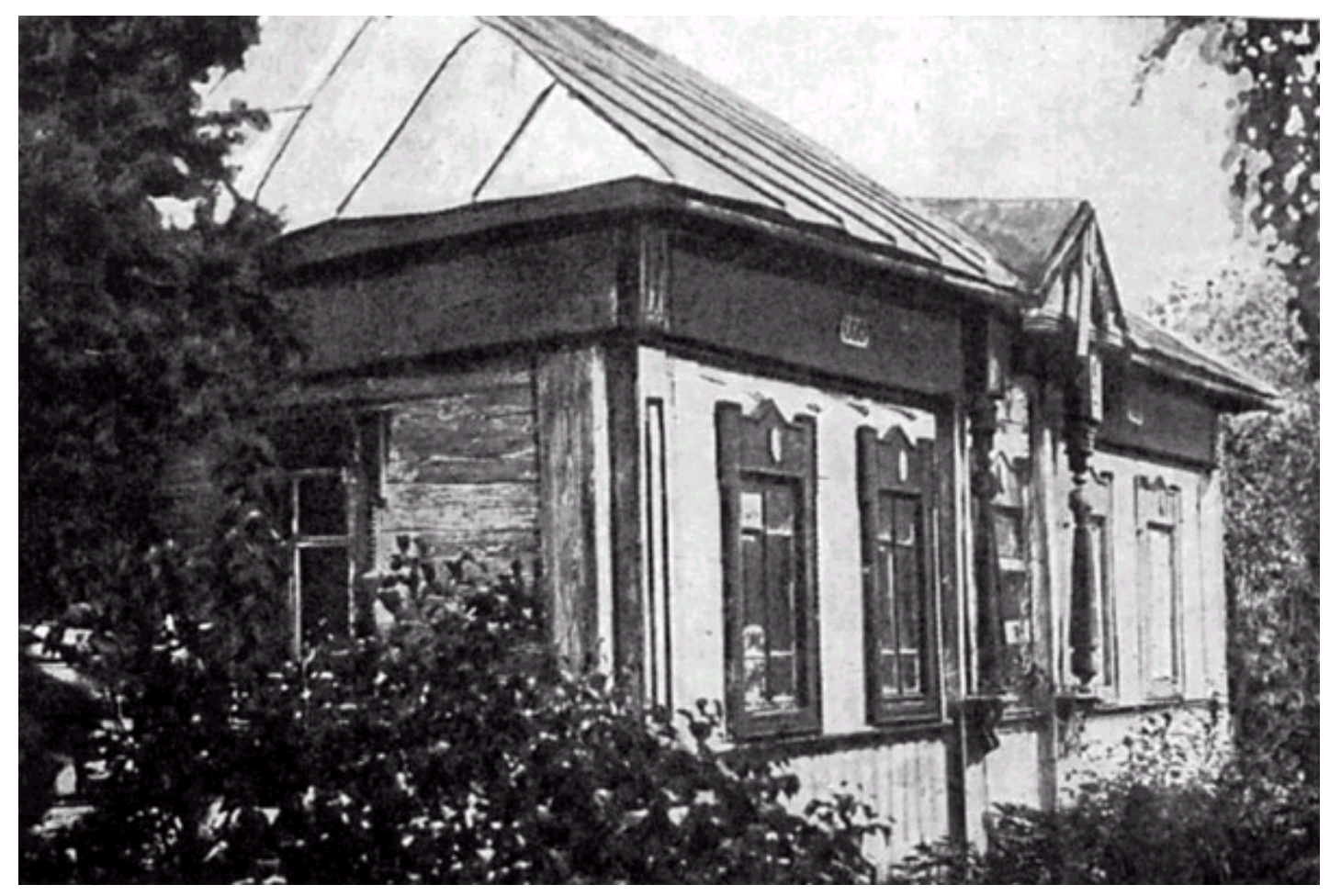

Granja de Darovoe, lugar donde Dostoievski pasó los veranos durante la niñez.

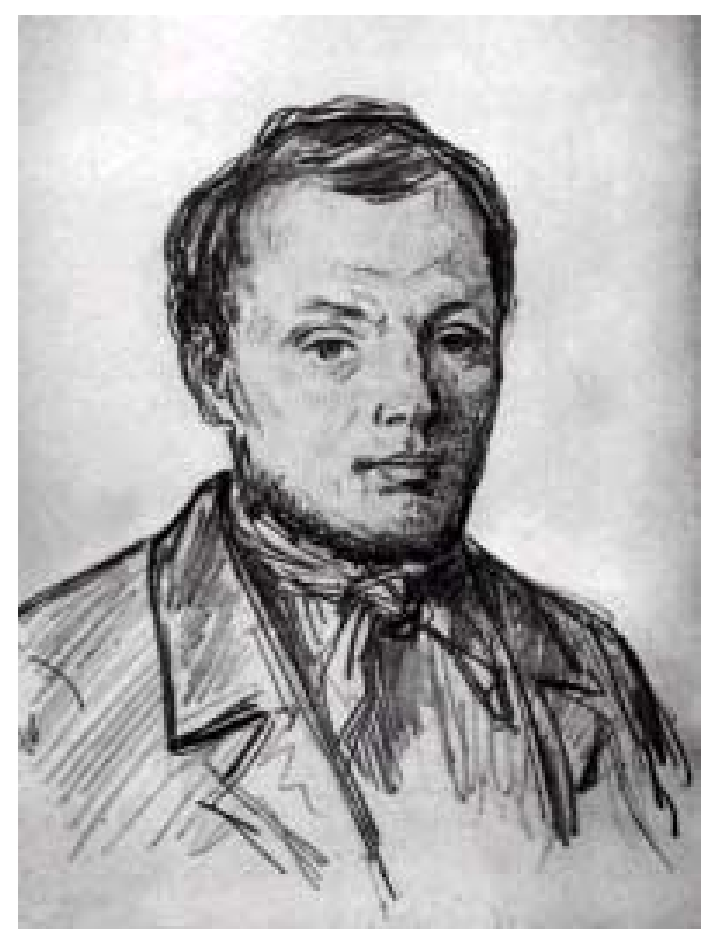

Retrato de Dostoievski de 1847 


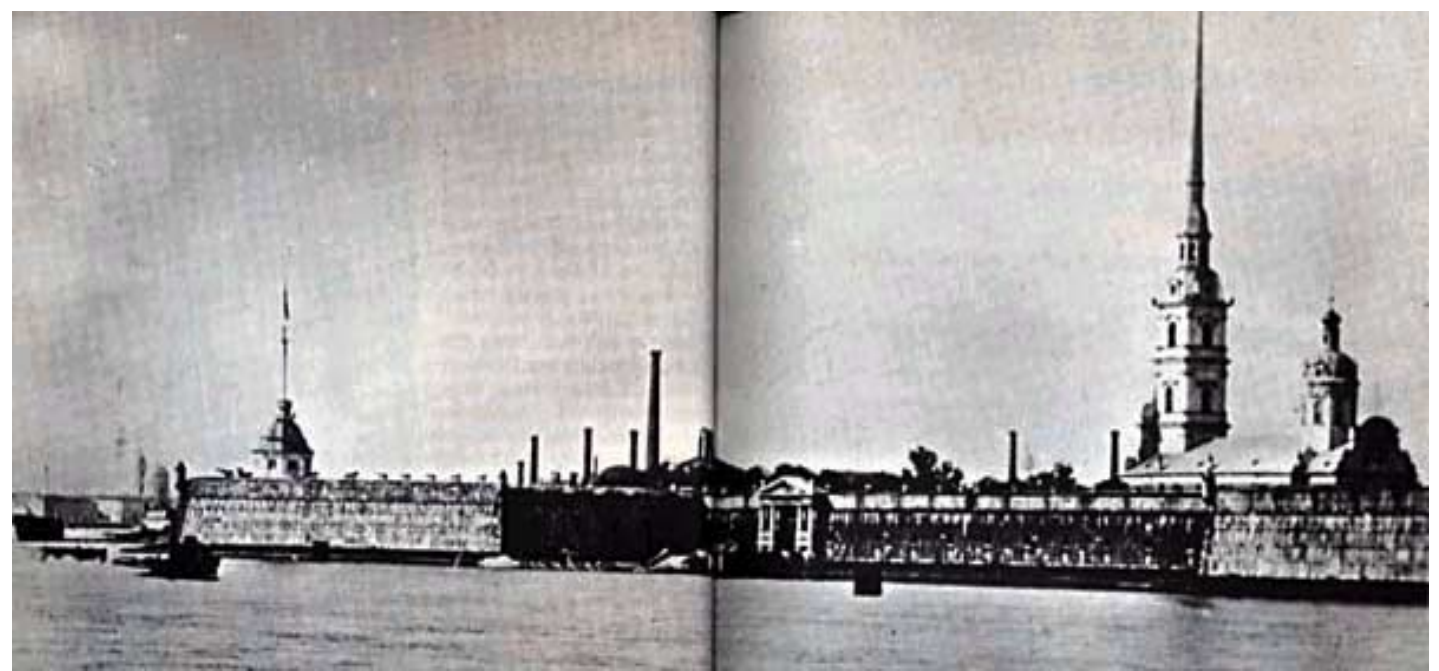

Fortaleza de San Pedro y San Pablo, en San Petesburgo

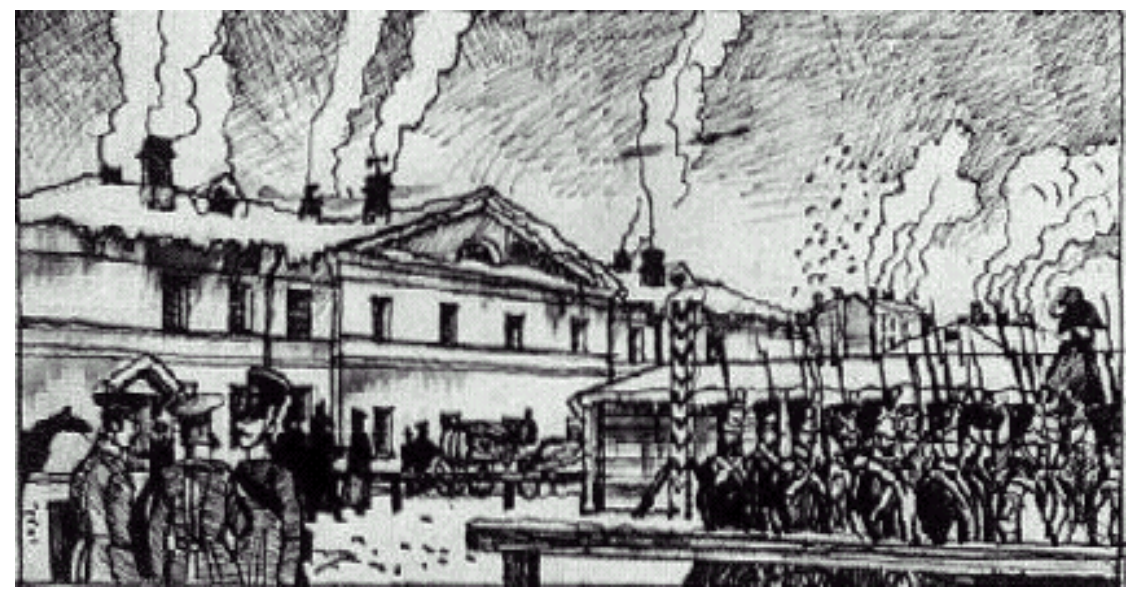

Parodia de ejecución en la plaza de armas del regimiento Semenóvski en San Petesburgo (1849) 


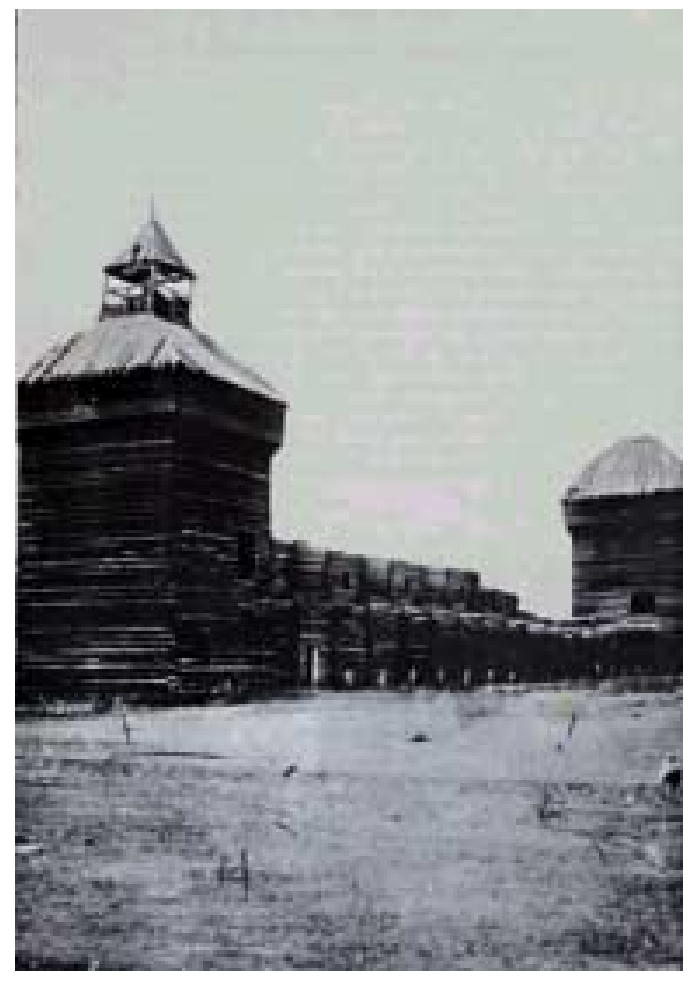

Penal de Omsk

Escultura de S.T. Konenkov "Dostoievski convicto"

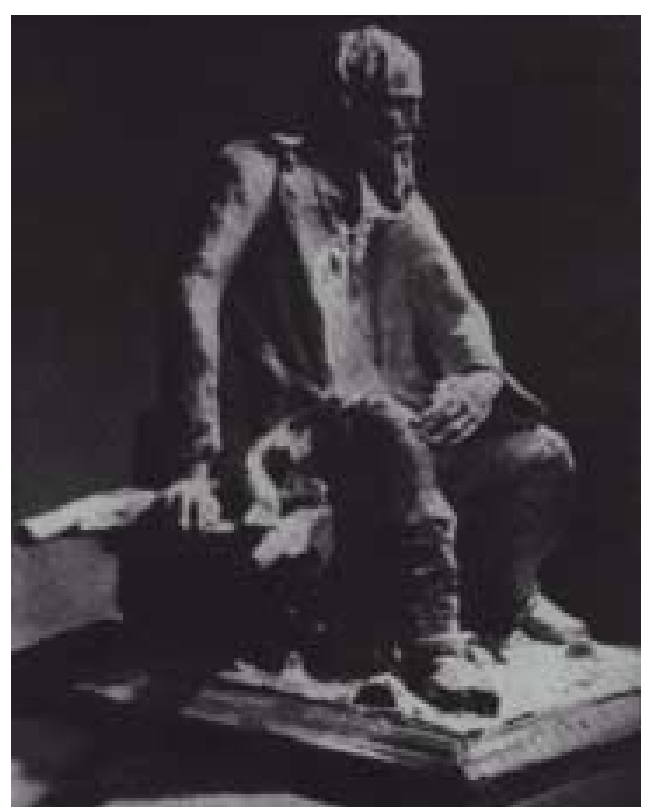




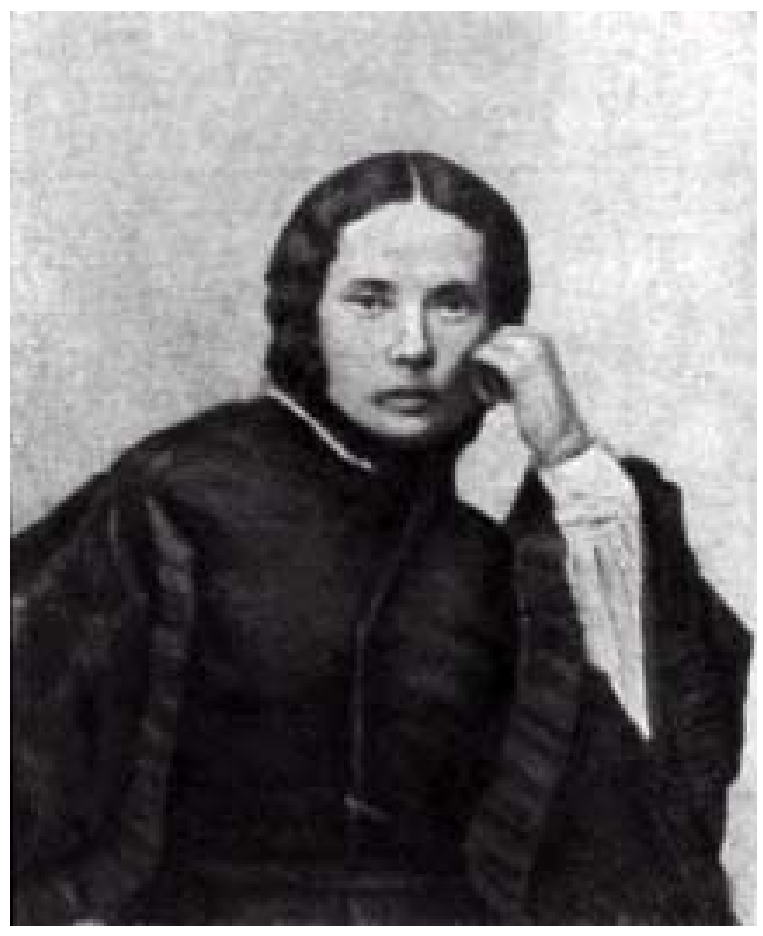

María Dimitrievna, primera mujer de Dostoievski

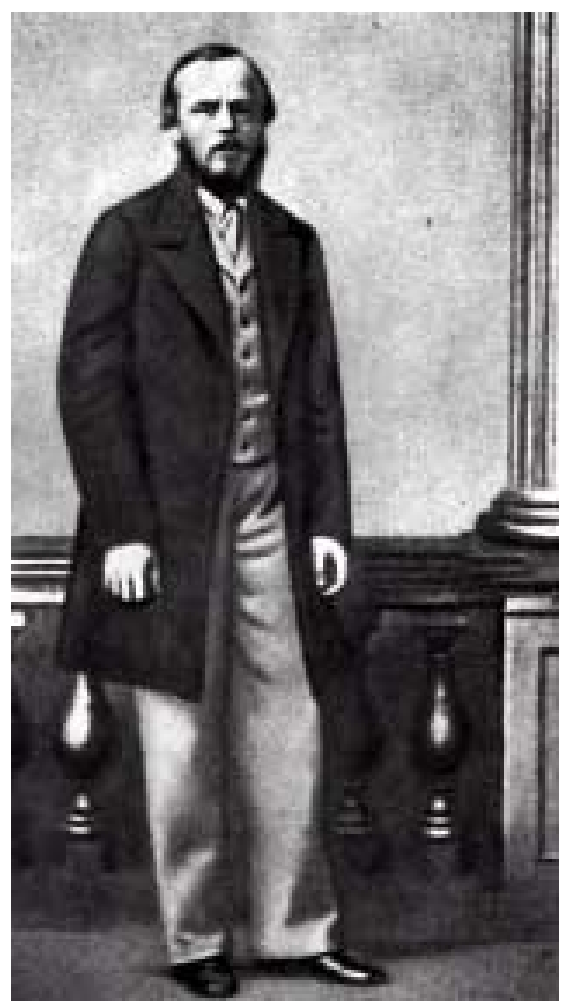

Dostoievski en 1860 


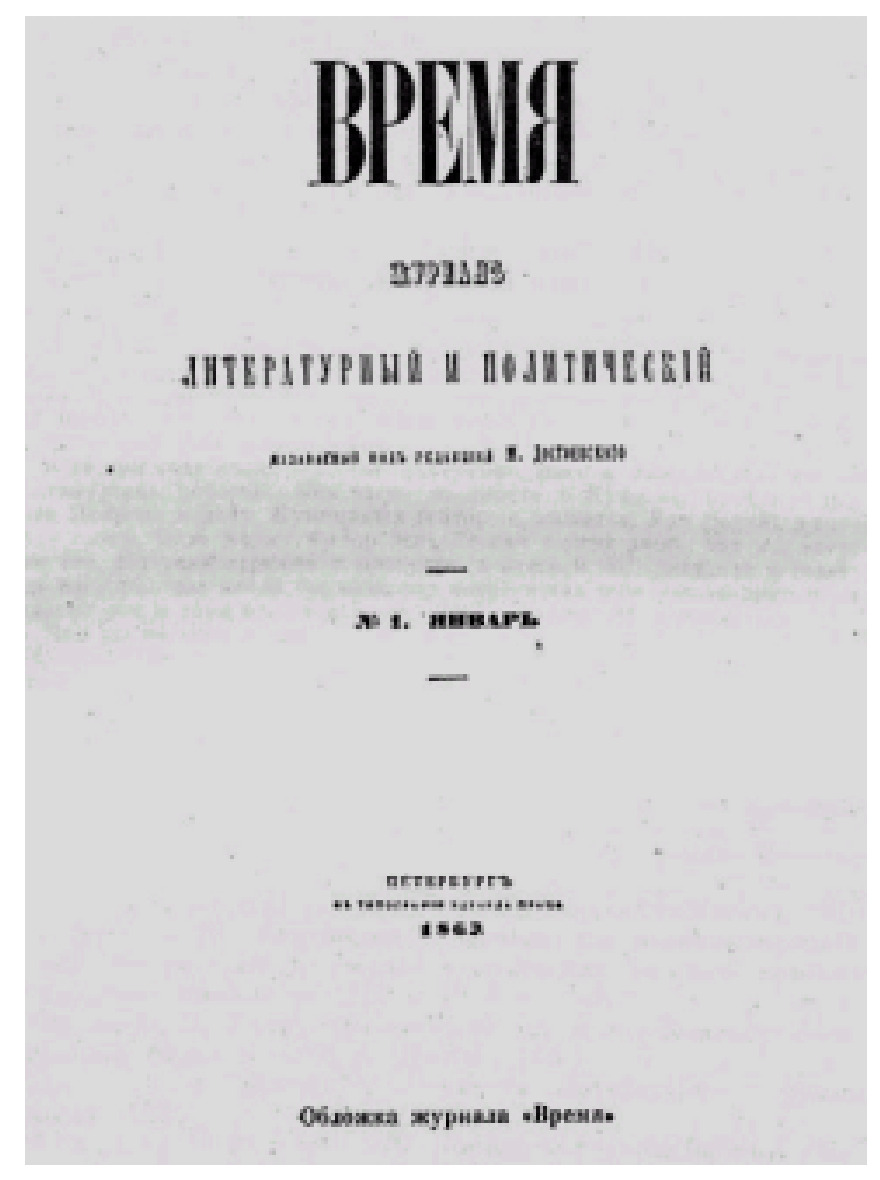

Primera edición de Vremia, periódico fundado por Fiodor y Miguel Dostoievski

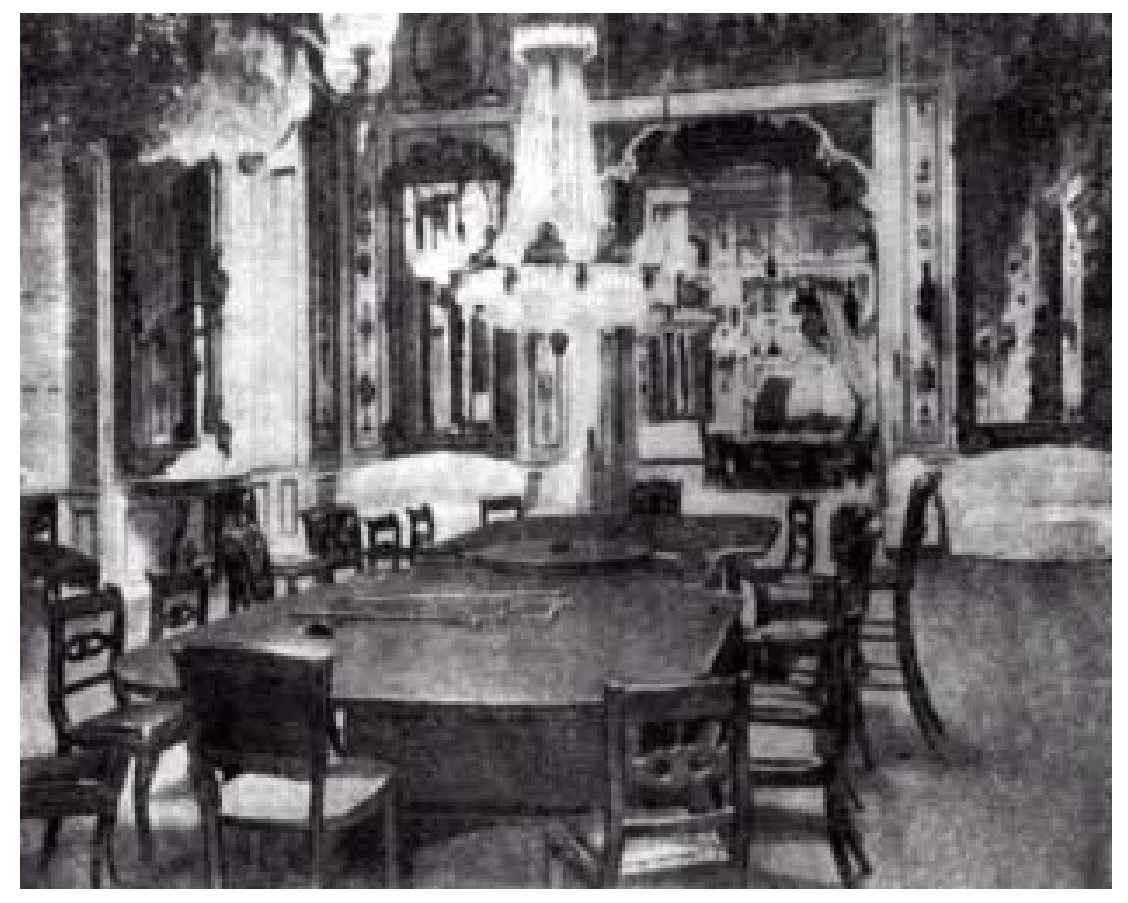

Casino de Wiesbaden 


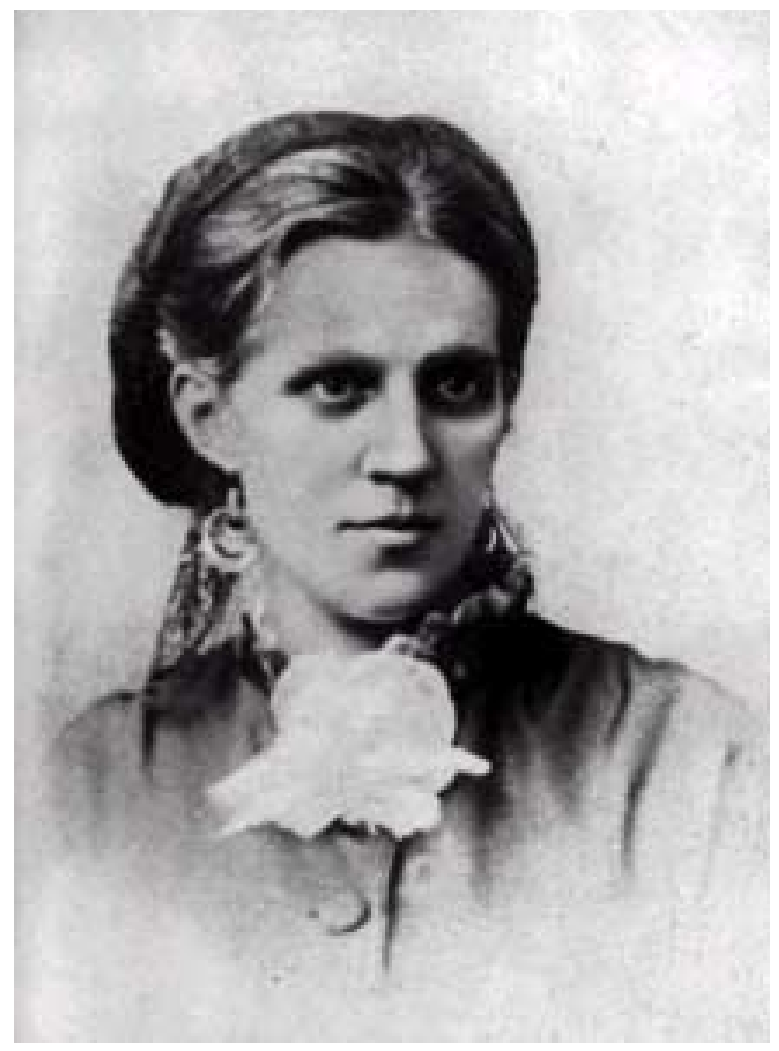

Ana Grigorievna, segunda mujer de Dostoievski

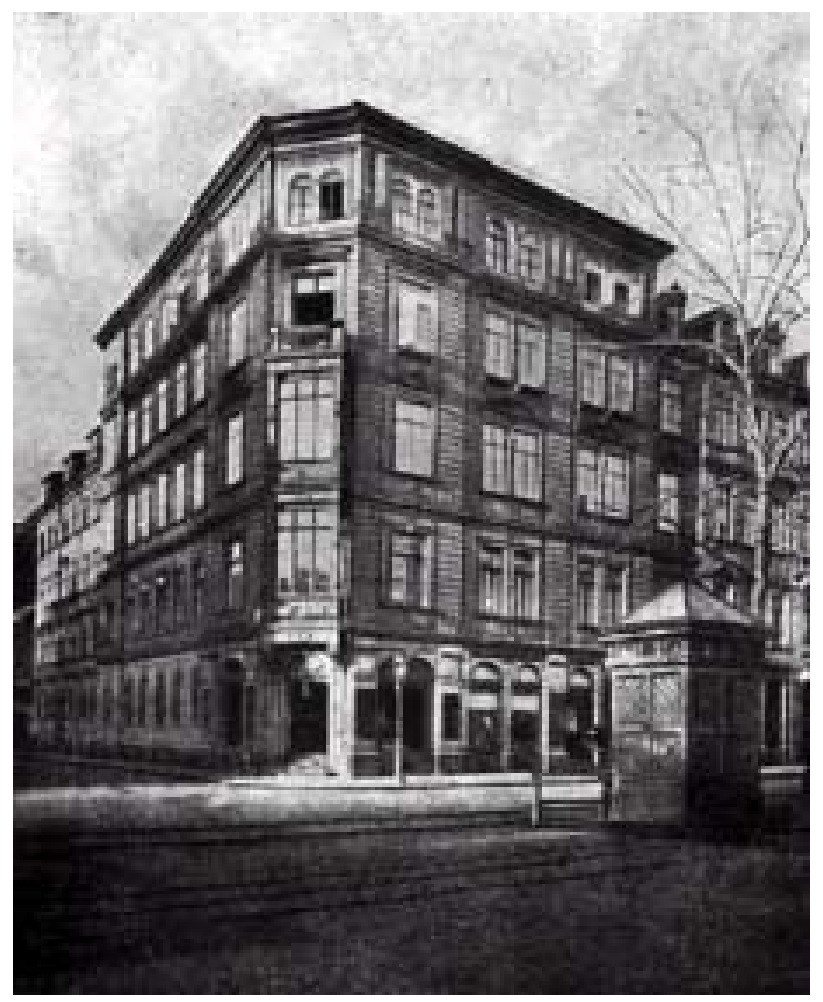

Edificio donde vivió el matrimonio en Dresde en 1870 y donde escribió Dostoievski Los demonios 


\section{Фёдор ММхаһ̆ловнЧ ДостоевскНИ}

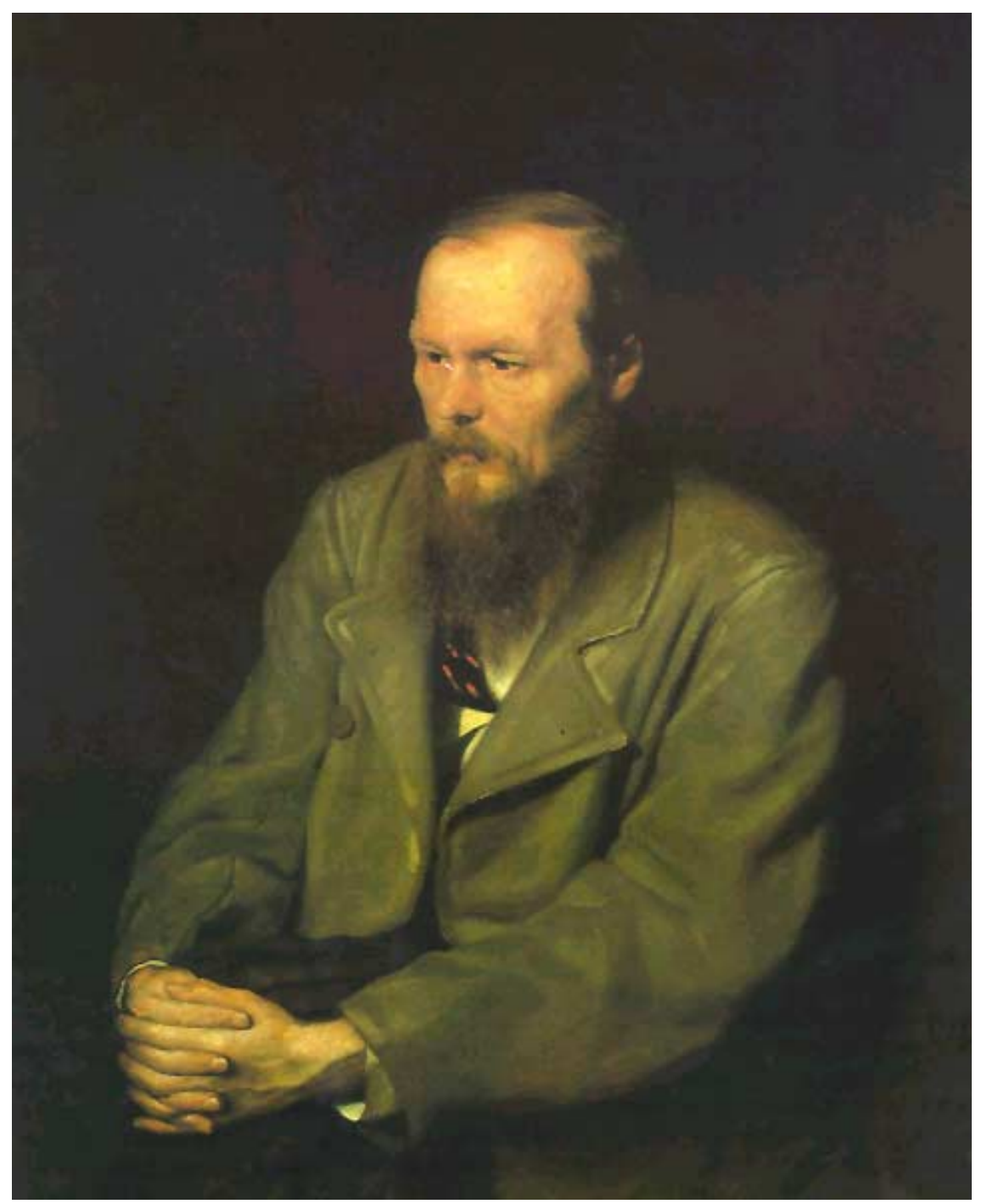

Fiodor Dostoievski en 1872

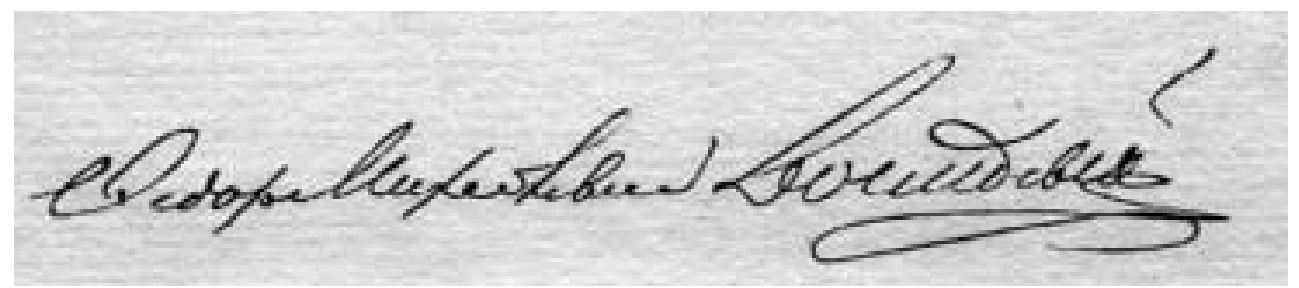

Su firma 


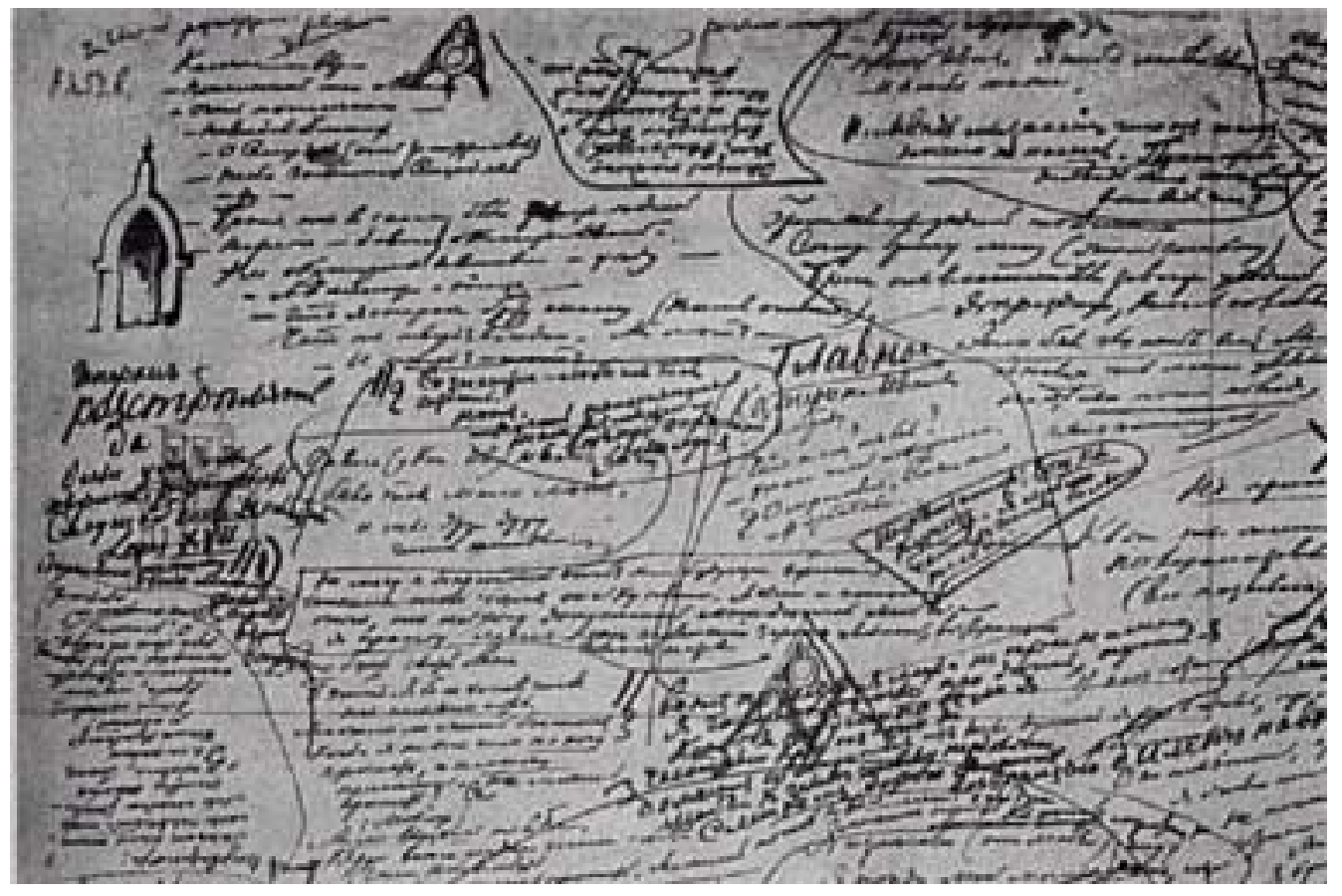

Apuntes de Dostoievski para Los hermanos Karamázov

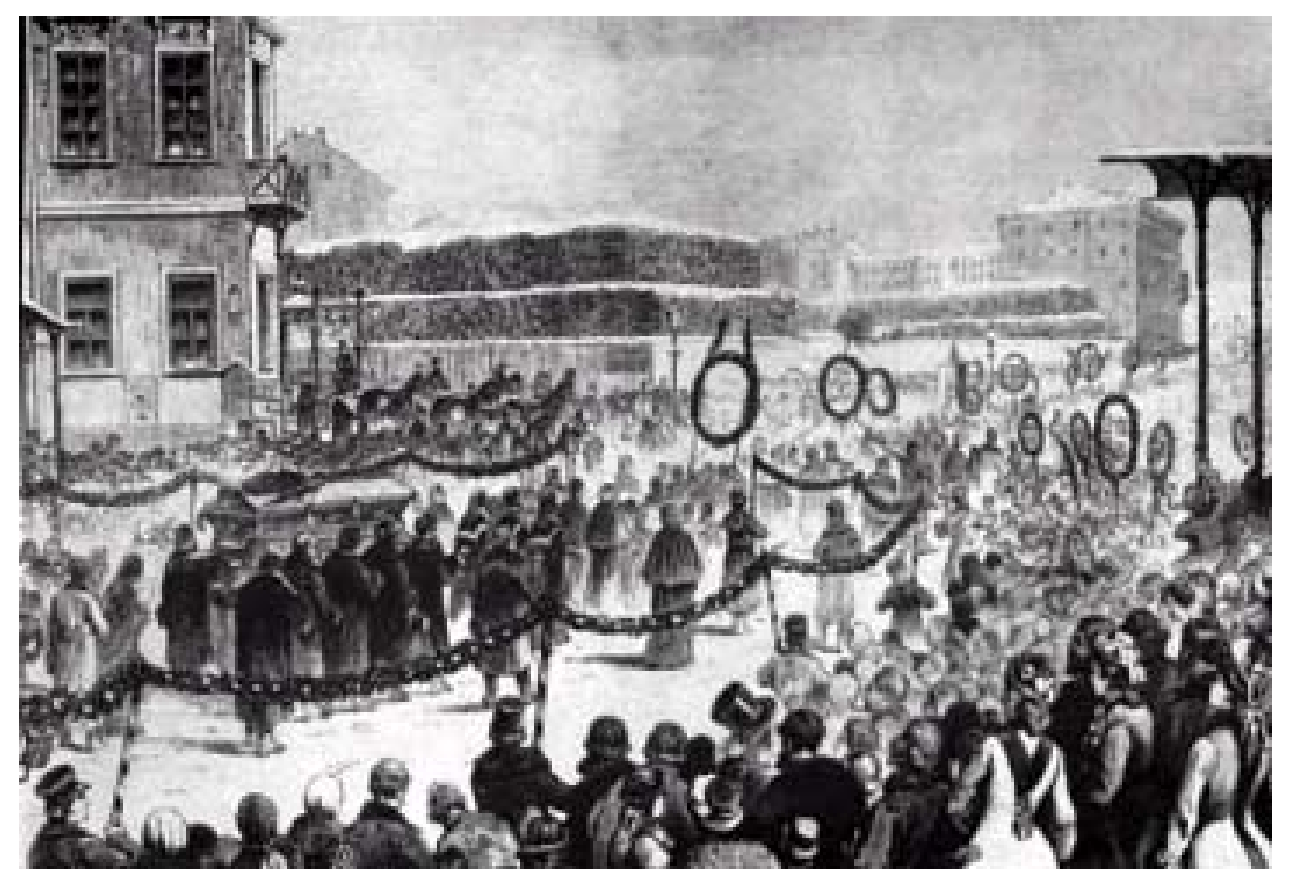

Entierro de Fiodor Dostoievski el 31 de Enero de 1881 


\section{Obras principales}

\section{Pobres gentes (1844-46)}

De gran éxito, Dostoievski fue proclamado por la crítica en esta primera obra el "creador de la novela social" y "el nuevo Gogol". Escrita en forma de epistolario, trata sobre la desgraciada historia de amor de un humilde funcionario estatal. Su espíritu innovador consiste en haber descubierto el complejo y rico mundo espiritual del individuo "insignificante", humillado por la vida, añadiendo la dimensión psicológica a la puramente narrativa, en su análisis de los conflictos del protagonista observándolos desde su propio interior.

\section{E1 doble (1845-1846)}

Continúa el estudio de los humildes burócratas estatales. Trata sobre la fundamental dualidad del ser humano, resultando una obra importante tanto desde el punto de vista psicológico como literario. En la época que se publico fue rechazada por el público y la critica. En Noviembre de 1877 dirá su autor sobre ella en Diario de un Escritor (T.III, p. 1378): "Esa novela me salió definitivamente mal; pero su idea no pudo ser más clara y jamás he producido en literatura nada que la aventaje en seriedad. Solo que la forma no se me logró en absoluto"

\section{El señor Projarchin (1846)}

Describe la psicología del avaro, tema que habrá de desarrollar posteriormente en otras obras (como en El jugador, en El Idiota y en El adolescente). Utiliza ya el nombre de Napoleón como forma de identificación simbólica del concepto de un egoísmo absoluto y centrado exclusivamente en el propio ser. Esta figura será utilizada con el mismo fin en El sueño del tito, Memorias del subsuelo y Crimen y Castigo. Como las siguientes obras de este periodo, será un rotundo fracaso. 


\section{La patrona (1847)}

Basado en La terrible venganza de Gogol, realiza el retrato de un "soñador" y un análisis de la personalidad masoquista. En el discurso del personaje de Murin se encuentran antecedentes de la leyenda del Gran Inquisidor, en su concepción de la incapacidad de la humanidad para soportar la "libertad".

\section{Una novela en nueve cartas (1845-1847)}

Trivial cuento cómico que, escrito en la forma de un intercambio de correspondencia, trata de una anécdota cómica relativa a los juegos de azar y timadores, en la que se utiliza el viejo recurso del "burlador burlado"

\section{Polzúnkov (1848)}

Primera caracterización del "bufón voluntario" que utilizará posteriormente en otras obras, y que se caracterizan por poseer una conciencia extremadamente lúcida de ser un inferior social y haber renunciado a luchar, aceptando su propia degradación y revelando la necesidad de ser aceptado, de ser sinceramente amado, como única solución a los tormentos de la humillación.

\section{Corazón débil (1848)}

Trata sobre un joven enamorado que descuida su trabajo, es despedido y se vuelve loco. El tema de fondo es el estudio de "el hombre incapaz de mantener su propia felicidad" por los sentimientos de culpa que padece por ser feliz. Coincide con lo que posteriormente Freud analizaría en sus artículos Los que fracasan al triunfar (O.C., III, 2416-2426) y Un trastorno en la memoria en la Acrópolis (O.C., III, 3329-3334) y llamaría "complejo de éxito". No obstante, mientras que Dostoievski lo atribuyó a factores sociales, Freud lo relacionó con el ambiente familiar de la infancia. 


\section{E1 ladrón honrado (De las memorias de un desconocido) (1848)}

Retrato sobre un alcohólico incurable con admirables cualidades humanas innatas que brillan por encima de toda la miseria de su vida.

\section{La mujer ajena y el hombre debajo de la cama (1848)}

Anécdota cómica tradicional sobre el tema siempre vigente de las aventuras extraconyugales.

\section{Un árbol de Noel y una boda (1848)}

Relato breve sobre una fiesta de Navidad, en que unos padres acaudalados pactan la boda de su hija con un hombre con prestigio que le dobla en edad.

\section{Noches blancas (1848)}

Primer estudio sobre las situaciones triangulares (dos hombres y una mujer) que posteriormente aparecerá en otras novelas.

\section{Netochka Nezvanova (1849)}

Obra inconclusa a causa del encarcelamiento de Dostoievski. En la primera parte describe el proceso de maduración emocional y moral de la protagonista como la superación del odio que siente hacia su madre - y de la culpa que ese sentimiento engendró merced a un desarrollo o ensanchamiento del ego, que permite identificarse con el sufrimiento ajeno. Analiza la influencia de un ambiente dañino en la infancia que fomente el egoísmo, la egolatría y la sensualidad con una moraleja moral: los que han sufrido a causa del egoísmo de otros deberían alimentar aversión hacia él y no buscar vengarse volviéndose a su vez en tiranos egoístas. En la segunda parte analiza el afecto apasionado y sadomasoquista (la dialéctica amor-odio) de dos niñas (Netotchka y Katia). 


\section{E1 pequeño héroe (1857)}

Escrito en 1849 en la prisión de San Pedro y San Pablo, utiliza la primera persona para relatar el despertar del instinto sensual en un niño y la atracción que este muchacho ejerce sobre una mujer casada.

\section{El sueño del tito (1859)}

Primera novela siberiana, es un lienzo de la vida provinciana, con sus eternas murmuraciones, calumnias y luchas para adquirir el dominio sobre naderías. Pasa desapercibida por el público y la crítica.

\section{La alqueria de Stepanchikovo y sus vecinos (1859)}

Segunda de las obras siberianas y más ambiciosa que la anterior, redactada de forma satírica, ya aparece el problema del bien y el mal. Relata cómo un charlatán llamado Foma Fomich, se introduce en casa de un coronel retirado, viudo, a quien dirige y tortura. Cuando el coronel le echa violentamente de su casa, éste vuelve confuso y reformado, consigue el matrimonio del coronel con una joven señora, y sigue dirigiendo la alquería, ahora mediante actuaciones bondadosas. Como la anterior novela, pasa desapercibida.

\section{Humillados y ofendidos (1861)}

Novela "folletín", de gran éxito popular aunque en realidad es una historia difusa, sentimental y melodramática, cuyo único interés consiste en que en ella se dibuja su obra posterior, muy superior en calidad.

\section{Memorias de la casa muerta (1861)}

Obtiene un gran éxito. De índole autobiográfico, reproduce la evolución psicológico-moral y de reevaulación por el que pasó Dostoievski en sus años de presidio. Es la obra menos 
"dostoievskiana" de todas, ya que a diferencia de las demás, se caracteriza por la objetividad apacible de la presentación, no hay un análisis minucioso de estados espirituales interiores y hay una gran descripción de paisajes.

\section{Apuntes de invierno sobre impresiones de verano (1862-63)}

Son las impresiones sobre su primer viaje al extranjero con una crítica vehemente de los países que visitó (Alemania, Francia, Inglaterra, Suiza e Italia). Su base principal es el embotamiento moral de Europa, la condena del socialismo racionalista y la aclamación del principio cristiano del autosacrificio.

\section{Una historia enojosa (1862)}

Es un corto relato contra las raíces autoindulgentes y egoístas del "humanitarismo" de los liberales.

En el apartado Obras estudiadas (III. A) de esta tesis doctoral se comentan en profundidad las siguientes obras, que son el objeto de este trabajo:

\section{Memorias del subsuelo (1864)}

E1 cocodrilo (1865)

Crimen y Castigo (1866)

E1 jugador (1866)

El Idiota (1868)

E1 eterno marido (1870) 
Los demonios (1870-1872)

El adolescente (1876)

Los hermanos Karamázov (1879)

Diario de un escritor (1872-1881) 


\section{Dostoievski según Freud}

Con fecha 19 de Octubre de 1920 Freud escribe una carta a Stefan Zweig agradeciendo el envio de un ejemplar de su libro Tres maestros; en ella manifiesta su desacuerdo con el tratamiento que hace del "réprobo ruso Dostoievski", añadiendo que, por el contrario, no tiene nada que objetar de los otros dos trabajos, que versan sobre Balzac y Dickens. En esta carta, Freud señala a Zweig que a Dostoievski "no se le puede entender sin el psicoanálisis" (Frank, 1984, p. 458).

Siete años más tarde, Freud realiza un artículo sobre la vida y enfermedad de Dostoievski desde el punto de vista psicoanalitico: Dostoyeuski y el parricidio. Este artículo, como todos los de Freud, pasó a ser artículo de fe durante años y en relación a él se han realizado trabajos con hipótesis más o menos descabelladas. Si bien Freud demuestra una vez más su genialidad indiscutible en elaborar teorias originales mediante la interpretación de los datos, es destacable el gran número de distorsiones, o al menos inexactitudes, entre la biografia real de Dostoievski y los hechos que él nos presenta. El mismo Freud, en correspondencia privada con Theodore Reik, definió este artículo como "una fruslería" (Frank, 1984, p. 457).

Freud comienza este artículo distinguiendo cuatro facetas en Dostoievski: el poeta, el neurótico, el moralista y el pecador. Si bien reconoce que como poeta su genio es incuestionable, considera que la faceta de moralista es más discutible, ya que Dostoievski alega "que solo quien ha atravesado los estratos más profundos del pecado puede alcanzar el culmen de la moralidad...Moral es quien reacciona ya contra la tentación percibido en su fuero interno y no cede a ella... Iván el Terrible no obraba de otro modo, y esta forma de conciliar la conducta personal con la moralidad, es un rasgo característico del alma rusa" Aparte de la licencia "etnológica" que se toma respecto a los rasgos "característicos rusos", la definición de moral de Freud es al menos cuestionable. Continúa Freud: "Tampoco el resultado final de la lucha moral de Dostoievski es nada loable...Acaba sometiéndose a la autoridad seglar y a la eclesiástica, venerando al zar y al Dios de los cristianos y propugnando un estrecho nacionalismo ruso, actitud a la que otros espíritus más deleznables han llegado con mucho menos esfuerzo". Define este resultado como un "fracaso" al que le ha llevado su neurosis. Que esta evolución sea un fracaso es, evidentemente, una opinión personal de Freud. Seguramente un gran número de personas no la denominarian así. 
Para Freud, la personalidad de Dostoievski está caracterizada por su extraordinaria afectividad, su sadomasoquismo y sus dotes artísticas. Refiere que Dostoievski es sádico hacia fuera en "las pequeñas cosas", como demuestra en "su irritabilidad, su gusto de atormentar y su intolerancia contra personas queridas" y en las cosas de más alcance, masoquista, "benigno, bondadoso y auxiliador". Pero esta situación es enturbiada por la coexistencia de la neurosis, que "es un signo de que el yo no ha logrado la sintesis y ha perdido, al intentarlo, su unidad".

Freud considera que la epilepsia de Dostoievski es una prueba de la existencia de esta neurosis: "lo más probable es que esta pretendida epilepsia fuera tan sólo un síntoma de su neurosis, la cual podriamos clasificar en consecuencia, como histeroepilepsia; esto es como una histeria grave". Aunque añade que esta aseveración no se puede asegurar con certeza, Freud considera que la epilepsia conduce al "rebajamiento progresivo de todas las funciones intelectuales y aparece frecuentemente acompañada de idiotez patente y de máximos defectos cerebrales". En los casos que esto no es así la "reacción epiléptica" se pone "indudablemente a disposición de la neurosis, cuya esencia consiste en derivar por el camino somático aquellas magnitudes de excitación que le es imposible manejar psíquicamente". Por tanto, Freud distingue entre una epilepsia orgánica y una epilepsia "afectiva", que se diferencian en que "quien padece la primera es un enfermo del cerebro, y quien padece la segunda, un neurótico". En el segundo caso, el ataque epiléptico es un síntoma de histeria.

A la luz de los conocimientos científicos actuales sobre epilepsia, este razonamiento, basado en la creencia errónea, propia del s. XIX, de la evolución clínica de las epilepsias genuinas hacia la demencia con el deterioro progresivo e inexorable de funciones superiores, es evidentemente falso. Además, Freud no menciona un dato de la biografia de Dostoievski esencial en este tema: la muerte de su hijo Alexei a causa de un ataque epiléptico en 1878, a los tres años de edad. Este dato sugiere de forma clara la existencia de un componente genético (orgánico) en la epilepsia de Dostoievski. La histeroepilepsia es una entidad aún reconocida. No obstante, sus características no coinciden en absoluto con las características de las crisis de Dosotievski. Las crisis en la histeroepilepsia suelen aparecer cuando hay espectadores (se interpreta como una búsqueda no consciente de atención), son provocadas por una contrariedad, es frecuente que se sigan de llanto y quejidos en vez de la confusión postcrítica y no suelen ocasionar daño físico; en Dostoievski las crisis aparecian fundamentalmente durante el sueño, está bien documentado el 
coma postcrítico y le produjeron en más de una ocasión lesiones (Cantrell, 1996).

Aunque se desconoce, dice Freud, la primera aparición y las oscilaciones posteriores de los ataques, "la hipótesis más verosímil es que los ataques comenzaron muy pronto, ya en la niñez representados por síntomas benignos y adoptando luego la forma epiléptica, cuando a los dieciocho años de edad sufrió el sujeto la conmoción de una terrible vivencia: el asesinato de su padre".

Los sintomas benignos infantiles tomaban la forma, según nos refiere Freud, de una melancolía repentina e inmotivada y un sentimiento de muerte inminente, así como de miedo a sumergirse en un estado letárgico similar a la muerte, motivo por el que Dostoievski dejaba notas antes de acostarse de que no le enterraran hasta pasados cinco días. Estos sintomas infantiles significan para Freud una identificación con un muerto o con una persona a la que se desea la muerte, generalmente el padre. Son un autocastigo por el deseo de muerte de éste.

Según Freud, por tanto, la epilepsia de Dostoievski corresponde a un deseo de autocastigo causado por el deseo de muerte de su padre y padeció ya "síntomas benignos" (como la melancolía y el temor a la muerte) en la infancia; ciertamente estos síntomas los padeció, pero sin ningún género de dudas fue en el período de tiempo 1846-1847, fecha en la que, como hemos visto, presentó diversos trastornos psiquiátricos. Estos datos fueron publicados por su hermano Andrés en 1881 sin duda alguna sobre su ubicación cronológica. También fueron relatados por el propio Dostoievski a su amigo Soloviev. Por tanto, son posteriores a la muerte de su padre y Dostoievski los sufrió cuando contaba más de veinte años.

Con respecto a la aparición de una crisis epiléptica tras la muerte de su padre, la casi totalidad de los biógrafos de Dostoievski desmienten tal crisis. El único dato que sustenta tal hipótesis es que Lyubov, la hija del autor, escribe en sus memorias que, según la leyenda familiar, la primera crisis epiléptica había aparecido en esas circunstancias. Esta leyenda es desmentida por el propio Dostoievski en sus cartas de 1854 en las que menciona sus ataques como un fenómeno nuevo. Además, ni los compañeros de la Academia de Dostoievski, ni su correspondencia en esa época aluden a este hecho en ningún momento.

Continúa Freud: "Sería muy adecuado que durante el tiempo de su encarcelamiento en Siberia hubieran remitido por completo los ataques; pero otros datos contradicen esta hipótesis". Esta 
posibilidad demostraría que los ataques eran su castigo y por tanto no los necesitaría mientras sufría el castigo de la prisión. En nota de pie de página Freud reconoce que la mayoria de los datos, entre ellos la propia manifestación de Dostoievski contradicen claramente esta afirmación. "Desgraciadamente" -comenta Freud"las manifestaciones autobiográficas de los neuróticos carecen de toda garantía de exactitud. La experiencia ha demostrado que su memoria incurre en falsedades encaminadas a desgarrar un encadenamiento casual". Todos los testimonios, excepto el de la leyenda familiar, están de acuerdo en afirmar que la epilepsia de Dostoievski no solo no remitió, sino que realmente empezó en Siberia y estos datos no corresponden sólo a los recuerdos posteriores de Dostoievski, sino también a sus cartas tras haber sido liberado y a los testimonios de sus compañeros de prisión; ni el más mínimo fragmento del material biográfico de Dostoievski apoya esta tesis de Freud.

Para Freud, en Dostoievski no existía solamente el normal complejo de Edipo, caracterizado por el sentimiento de culpabilidad engendrado por el deseo de poseer a la madre y suprimir al padre, reprimido por el miedo a la castración. Dostoievski presentaba también una fuerte tendencia bisexual, por la cual desea situarse en el lugar de la madre, adoptando un papel de objeto erótico para con el padre. Esta tendencia provoca igualmente un intenso miedo a la castración. Por tanto, refiere Freud, ambos impulsos, el odio al padre (complejo de Edipo) y el enamoramiento del padre (tendencia bisexual) sucumben a la represión. Freud asegura que Dostoievski presentaba esta disposición bisexual, como lo demuestra "la importancia que tuvieran en su vida las amistades masculinas (homosexualidad latente), en su conducta singularmente cariñosa para sus rivales en amor y en su excelente comprensión de situaciones sólo explicables por una homosexualidad reprimida, como lo prueban múltiples pasajes de sus novelas".

Aunque se desconoce exactamente a que amistades se refiere Freud, las amistades masculinas más "pasionales" que presentó Dostoievski fueron durante su adolescencia. Carr (1931) (p. 19) expone en su biografia una carta de Fiodor a Miguel correspondiente al invierno 1838-39 en que éste habla de sus sentimientos impetuosos hacia un compañero de estudios, Berezhetski. Sentimientos parecidos también expresó en esta época hacia su admirado Shilodvski. No obstante, el afecto hacia estas personas no parece distinguirse al que presentaria cualquier adolescente en esa época y en un internado de varones. En este sentido Frank (1984) cita el libro Memoirs of a Young Man de Herzen, en que relata con el mismo tono apasionado con el que Dostoievski escribe a Mijail sobre Berezhetski su amistad con 
Ogarev. Lo que, sin embargo, esta fuera de dudas es la importante relevancia que tuvieron las relaciones de Dostoievski con el sexo femenino a lo largo de su vida.

Con respecto a la actitud con sus rivales en el amor, Freud alude seguramente a los intentos de Dostoievski de "ayudar " al joven maestro Vergunov que fue su rival con respecto a su primera mujer. Esta actitud se ha explicado con interpretaciones muy diferentes, que pasan desde la teoría de Girard (1978) sobre el deseo mimético hasta plantearlo como una genuina preocupación por los posibles futuros aprietos económicos que sufriría una mujer a la que él amaba (Frank, 1984). Freud no menciona otros datos que podrían también tener interés en este asunto como son la insistencia en convencer a su primera mujer de la ventaja de elegir al propio Dostoievski como marido y los celos patológicos por su segunda mujer.

Por último, Dostoievski presenta en sus novelas una admirable comprensión de diferentes situaciones psicológicas; no sólo de aquellas "explicables por una homosexualidad reprimida", sino que lo que fundamentalmente realiza es un estudio de la ambivalencia y conflictos psicológicos subyacentes en las relaciones pasionales heterosexuales. Las situaciones de tipo homosexual sólo aparecen de forma sutil en las diferentes novelas: Así, la escena de El Idiota en el que permanecen Rogochin y el Príncipe Mischkin velando el cadáver de Nastasia, en la que las lágrimas de éste caen sobre las mejillas de Rogochin (T.II, P. IV, C.XI, p. 956), ha sido considerado por algunos autores bien la "culminación de la fantasía homosexual", bien la materialización del complejo de Edipo bisexual representado por la figura muerta de Nastasya (Cantrell, 1996). Girard (1978) explica de nuevo esta "homosexualidad latente" como una intensificación del deseo mimético, en el que el mecanismo mimético del sujeto tiende a apartarse del objeto designado para volverse al rival que designa el objeto.

Freud concluye que "la fórmula correspondiente a Dostoievski" es: "un sujeto de disposición bisexual particularmente intensa, que puede defenderse con singular energía su dependencia de un padre especialmente duro". Freud refiere que el padre de Dostoievski fue especialmente violento en la vida real. Realmente el padre de Dostoievski parece ser que fue un hombre irritable y despótico, pero no violento con sus hijos, como refiere Freud. Por ejemplo, se oponía a los castigos físicos en los niños como medio correctivo y nunca golpeaba a sus hijos, según se refiere en las memorias del hermano menor de Dostoievski, Andrei. 
Este cáracter de bisexualidad, continúa Freud, se transmuta en un superego sádico y en un ego masoquista y sus ataques epilépticos entrañan el sentido de una identificación punitiva con el padre ya que para Freud la disposición psíquica de Dostoievski entrañaba una intensa necesidad de castigo. En nota a pie de página Freud corrobora esta teoría por la comunicación del propio Dostoievski a su amigo Strajov de que "la irritabilidad y la depresión que le asaltaban después de sus ataques epilépticos tenian su origen en el hecho de que en tales periodos se aparecía a sí mismo como un criminal y no podía libertarse del sentimiento de haber echado sobre si una terrible culpa incógnita, haber cometido un terrible crimen que le agobiaba". Esta necesidad de castigo también justifica, según Freud, la aceptación inmediata por Dostoievski del castigo del zar aunque su condena como delincuente político fuera injusta e imprimirá su actitud ante sectores en que la relación paterno-filial da la norma como son la autoridad estatal y la creencia en Dios. En realidad, no existe ninguna prueba de que aceptase inmediatamente ese castigo del zar-padre, sino más bien al contrario, como demostró en su conducta durante los interrogatorios.

En Los hermanos Karamázov el parricida es epiléptico, "como si quisiera confesar que el neurótico y epiléptico que en él habia era un parricida". Para Freud en esta novela (y en todas en general) se aprecia claramente la simpatía que siente Dostoievski hacia los criminales basada "en la identificación de idénticos impulsos asesinos $\mathrm{y}$ en último término en narcisismo ligeramente desplazado", añadiendo que esta interpretación no anula en modo alguno su valor ético. Freud no menciona, en cambio, que esta novela fuera precursora de su teoria del complejo de Edipo, al menos en lo que respecta a la declaración de Iván Karamázov sobre el deseo universal de matar al padre: “¿Quién no desea la muerte de su padre?" (T.III, P.IV, L.XII, C.V, p. 530).

Para Freud también el juego era en Dostoievski un método de autocastigo. Tras perder todo, según refiere su segunda esposa, era cuando mejor resultaba su producción literaria. Freud interpreta este hecho de la siguiente manera: "Cuando su sentimiento de culpabilidad quedaba satisfecho por el castigo que él mismo se habia atraido, cesaba su incapacidad para el trabajo y se permitía dar unos cuantos pasos por el camino del éxito".

Freud termina este artículo analizando un relato corto de Stefan Zweig sobre un jugador en el que una mujer madura intenta salvar a un hombre joven del juego. Freud interpreta este relato como una fantasía del autor de que la madre misma inicie al adolescente en la vida sexual para liberarle de los temidos perjuicios del 
onanismo. En este relato el "vicio" de la masturbación estaría sustituido por la pasión del juego. Concluye Freud: "Si la pasión del juego, con sus vanos intentos de deshabituación y las ocasiones que ofrece para el autocastigo, es una reproducción de la obsesión masturbadora, no puede ya extrañarnos que conquistara un lugar tan importante en la vida de Dostoievski". Resulta sorpendente que Freud en su artículo no nombre ni diga una sola palabra acerca de cómo Dostoievski logró superar su ludopatía en la primavera de 1871 .

René Girard, en El crítico del subsuelo (1978, pp. 51-73) realiza la siguiente crítica a las repercusiones de este artículo algo tendencioso de Freud: "La idea de que Dostoievski tuviera algo que enseñar a Freud, la idea de que Dostoievski fuera más capaz de interpretar a Freud de lo que sería Freud de interpretarse a sí mismo es todavía considerada inconcebible por muchos...Se concede que Dostoievski tiene a veces "presentimientos" de una verdad que esencialmente permanecerá en manos de Freud. Freud siempre será el supremo árbitro y el punto de referencia absoluto...Para Freud, las obras de Dostoievski y la literatura en general son una masa homogénea, un sólido bloque de "represión" y "sublimación". Freud nunca admitirá que la obra de un escritor sea el fruto de una empresa intelectual como la suya, con sus inevitables yerros, sus experimentos fallidos y sus riesgos de fracaso definitivo, pero también con sus posibilidades de éxito a través del proceso de la prueba y el error. Freud nunca concede al escritor la capacidad de cultivar un pensamiento verdadero, de lanzarse a una aventura intelectual en el más puro y acabado sentido de la expresión." 


\section{OBRAS ESTUDIADAS Y MÉTODO}




\section{A. Obras estudiadas}

Hemos analizado todas las obras literarias de Fiodor Dostoievski posteriores a la muerte de su primera mujer, María Dimitrievna. Este periodo comprende las obras mayores de Dostoievski y se inicia con Memorias del subsuelo, la cual muchos autores han considerado como la primera obra de una nueva etapa en la evolución del pensamiento de Dostoievski (Carr, 1931; Girard, 1961). Así, se ha interpretado esta obra como el relato de la crisis espiritual que este autor atravesó en el invierno de 1863-1864 .

Para René Girard (1961), las Memorias del subsuelo es una obra de transición entre el romanticismo y la novela verdadera. En las novelas posteriores al "hombre del subsuelo" aparecerá, según Girard, la renuncia final del héroe a la autodivinidad. Esta renuncia a la divinidad, que significa una conversión auténtica, engendrará una nueva relación con el otro y una nueva relación consigo mismo. Dice Girard: "El Dostoievski que nos describe el subterráneo está a punto de salir; proseguirá su penosa ascensión de obra maestra en obra maestra hasta llegar a la paz y a la serenidad de Los hermanos Karamázov (p. 234). En este trabajo pretendemos realizar un estudio interpretativo sobre la temática suicida en las obras que corresponden a este período definido por Girard como "penosa ascensión de obra maestra en obra maestra".

\section{Memorias del subsuelo}

Esta obra está dividida en dos partes: La primera fue acabada en Febrero de 1864 y la segunda publicada en el número de Abril de ese mismo año en la revista Epojkha. En el momento de su publicación pasó desapercibido por la crítica.

La primera parte consiste en una exposición de la filosofía de la maldad y la segunda (A propósito de la nieve derretida) relata una serie de incidentes de la vida del supuesto narrador. En esta obra Dostoievski realiza su primera incursión en la filosofía y su influencia del cuento El gato negro de Poe es patente. En su primera parte trata por vez primera de analizar las consecuencias, para la persona, del intento de poner en práctica -con plena conciencia de todas sus implicaciones -las ideologias progresistas y radicales de los años cuarenta y sesenta. Expresa la convicción de que la naturaleza humana no es esencial ni fundamentalmente 
buena (al contrario que los materialistas y racionalistas que opinaban que el hombre era innatamente bueno y que, una vez ilustrado sobre cuáles eran sus auténticos intereses, con ayuda de la razón y la ciencia lograría construir una sociedad perfecta): Un hombre, siguiendo un aspecto de su naturaleza, puede escoger y desear el mal siendo consciente de que es el mal; Toda la historia de la Humanidad es, para Dostoievski, la historia de la irracionalidad humana. El hombre ama la construcción pero también la destrucción. Al hombre le gusta pecar contra sus propios intereses para liberarse a sí mismo de la tiranía de la razón. Así, el "hombre del subsuelo" reivindica la perversión y el propio capricho, aún en el extremo de actuar contra su propio bienestar y de practicar su propio egoísmo y voluntad, desmintiendo la idea de que se podría construir una sociedad perfecta con la base de individuos imperfectos.

El término "hombre del subsuelo" ha pasado a formar parte del vocabulario de la cultura contemporánea adquiriendo -como Hamlet, don Quijote, Don Juan y Fausto- la estatura de las grandes creaciones literarias arquetípicas. Ningún libro o ensayo que trate sobre la condición del hombre moderno estaria compelto sin una alusión a esta explosiva figura.

Según los diferentes autores, Memorias del subsuelo ha sido interpretado como autorrevelación psicológica de una personalidad patológica, como un grito de desesperación por los males de la "naturaleza humana", como declaración de la supuesta adherencia de Dostoievski a la filosofia nietzschiana del "amoralismo" y la voluntad de poder, como una desafiante afirmación de la personalidad humana contra todos los intentos de limitar sus inagotables potencialidades, etc. Todas estas interpretaciones, y muchas más, pueden ser apoyadas si seleccionan algunos de los textos y se colocan en primer plano, mientras otros son pasados por alto. Pero la intención de Dostoievski parece inclinarse más hacia una sátira que dramatiza los dilemas de un ruso de su época que trata de vivir de acuerdo con los códigos europeos de los años cuarenta y sesenta (romanticismo y materialismo).

El conflicto psicológico del hombre del subsuelo se va a repetir en las obras siguientes de Dostoievski con distintas matizaciones, y esta obra constituye una especie de introducción a la serie de sus grandes novelas. Aunque en esta obra no aparezca de forma explícita ninguna conducta suicida, consideramos que su análisis reviste gran importancia al ser "el hombre del subsuelo" el preámbulo de muchos de los personajes suicidas que aparecen en las obras posteriores. 
En el análisis de esta obra se ha seguido el estudio de J. Frank (1993, pp. 399-435)

\section{a. Primera parte}

- La dialéctica del determinismo: Cap. I-IV: Ya en el primer párrafo existe un claro conflicto entre un curso racional de la conducta (ir al médico ya que está enfermo) y un oscuro sentimiento ("malicia") por el que no lo hace. Luego nos refiere que fue un burócrata que trataba desagradablemente a sus clientes aunque en realidad no era malo sino que no consentia que los buenos sentimientos saliesen al exterior, o sea, eran reprimidos: "No solo no acerté a volverme malo, sino que tampoco logré llegar a ser nada" (T.I, C.I, p. 1456). Esta falta de carácter es atribuida a una conciencia demasiado lúcida que es capaz de reconocer lo bello y lo sublime, pero que cuánto más lo admira, más se degrada, y con esa degradación siente placer: "Es indudable que los más intensos placeres se los debemos a la desesperación, sobre todo si tenemos la conciencia lúcida de hallarnos en un callejón sin salida... Lo principal es que, por más que razone, siempre resulto el primer culpable: y lo que todavía me desespera más es el saber que lo soy, no adrede, sino por ley de la Naturaleza" (T.I, C.II, p. 1458) (Crítica al materialismo determinista). Por tanto, el hombre del subsuelo acepta el determinismo pero no es capaz de vivir con sus conclusiones: La razón indica al hombre del subterráneo que la culpa o la indignación es totalmente irracional y absurda; pero la conciencia y un sentido de la dignidad siguen existiendo como componentes consustanciales de la psique humana.

- El hombre de acción (Cap. V-VI): Es el interlocutor imaginario del hombre del subterráneo. El hombre subterráneo manifiesta su acuerdo con la convicción de que toda la conducta humana no es más que un producto mecánico de las leyes de la naturaleza, pero, al contrario que el hombre de acción, considera que esta teoria hace imposible, o al menos absurda, la conducta humana. La conciencia lúcida del hombre del subterráneo considera que el determinismo impide en forma estricta todo tipo de reacción moral. Insiste, por tanto, en la contradicción entre la aceptación intelectual del determinismo y el simultáneo rechazo de éste con todo el nivel intuitivo-emocional de la personalidad identificado con la conciencia moral. Su retórica es una ironía invertida que se vuelve contra sí mismo como medio de ridiculizar a su interlocutor, el hombre de acción ("...todos los hombres de 
acción son precisamente tales porque son estúpidos y de cortas luces...en virtud de la medianía, toman las causas segundas, las más inmediatas, por causas primeras, y al punto, y sin dificultad alguna, se convencen de haber encontrado un fundamento inmutable para su actividad, se tranquilizan, y eso es lo más importante...Yo me paro a reflexionar: tal causa, que me parece primera, me conduce a la anterior, y asi sucesivamente hasta lo infinito... Son, por tanto, leyes de la Naturaleza...Bajo el influjo de esas condenadas leyes de la conciencia mi maldad se descompondrá químicamente" (T.I, C. V, pp. 1462-63)

- La ventaja más ventajosa (cap. VII-VIII): Analiza la incongruencia entre los preceptos racionalistas y las normas de la experiencia humana: "¿No tienen valor alguno los millones de hechos que atestiguan que los hombres, a sabiendas, es decir conociendo sus verdaderos intereses les dan de lado y se arrojan a la ventura por otros senderos donde se exponen a riesgos y peligros, como si deliberadamente quisieran desviarse del buen camino para trazarse adrede otro más dificil y absurdo, que han de buscar a tientas?" (T.I,C. VII, p. 1464). La conclusión es que hay un interés más principal, pasado por alto en todas las teorías del racionalismo: la preservación del libre albedrío.

- El Palacio de Cristal (cap. IX): Símbolo de la utopía de la abundancia racionalista, el personaje lo rechaza porque no deja lugar al sufrimiento y no porque pretenda erigirse en defensor del sufrimiento, sino porque éste sirve como apoyo para mantener vivo el sentido de autonomía moral en un mundo privado de significación humana por el determinismo: "el sufrimiento es una duda, una negación, y ¿Quién podrá abrigar dudas en un palacio de cristal? Sin embargo, seguro estoy de que el hombre nunca dejará de amar el verdadero sufrimiento, la destrucción y el caos. El sufrimiento es la única causa de la conciencia... La conciencia, por supuesto, es infinitamente superior a esto de que dos y dos son cuatro" (T.I, C.IX, p. 1472)

- El Gallinero-palacio (cap. X): censurado en el original por lo que es poco entendible: El hombre del subterráneo no impugna el gallinero, sino que éste se tome por un palacio.

- Último capítulo: (cap. XI). Sigue oscilando entre el desafío y la desesperanza, afirmando y a la vez negando la vida, para expresar, por último, el deseo de algo distinto que le permita abandonar el subsuelo. 


\section{b. Segunda parte (A propósito de la nieve derretida):}

- El hombre del subterráneo narra en esta segunda parte sus experiencias de cuando tenía veinticuatro años (los años cuarenta): Sátira de los sentimentales románticos de esta época, denuncia del egoísmo y vanidad de estos intelectuales con su sueño de "beneficiencia universal" que descuidan sus más sencillas y obvias obligaciones morales.

- La dialéctica de la vanidad (cap. I): La vanidad del hombre subterráneo lo convence de su propia superioridad y desprecia a todos: pero como desea que tal superioridad sea reconocida por los demás, aborrece al mundo por su indiferencia y cae en el odio de sí mismo por su humillante dependencia. Esta vanidad corre paralela a la dialéctica del determinismo en la primera parte y tiene el mismo efecto de encerrar al ego en un mundo aislado de todo contacto humano, bloqueando el paso a toda fraternidad social: "Ninguno se parecía a mí, ni yo me parecía a ninguno. Yo soy uno sólo y ellos son todos" (T.I, p. 1477). Muestra los tormentos del hombre del subterráneo cuando intenta afirmar su existencia como ego que desea, ante todo, que alguien acepte su derecho a ser reconocido en una forma compatible con esa imagen de sí mismo absurdamente inflada. Relata el incidente del oficial: "Era aquello un verdadero suplicio, una insufrible y constante humillación mental, que al punto se trocaba en la sensación aguda, y directa de no ser más que un moscardón entre toda aquella gente... - más inteligente, desarrollado y generoso, ni que decir tiene -, pero un moscardón que cedía a todos el paso y al que todos ofendian y humillaban" (p. 1480-81). Esta humillación la entronca con el masoquismo relatado en la primera parte "Empezaba ya a sentir los ataques de voluptuosidad de que hablé en la primera parte" que le permite al ego afirmar su independencia y autonomía.

- Manfredo en una reunión (cap. II): El hombre del subterráneo adopta los rasgos del "soñador" romántico de los personajes de Dostoievski de sus primeras obras, cuyas fantasías literarias contrastan con las pretensiones sociomorales de la vida misma: No es un romántico puramente literario, sino se ha convertido en un romántico social, lleno de planes grandiosos de transformar el mundo, que al no ser capaz de realizarlo le hace refugiarse en "lo bello y lo sublime", en los sueños. Pero siente necesidad de mostrarse a sí mismo a los 
demás, aunque sus desorbitadas demandas de reconocimiento y necesidad de dominio le conducen invariablemente al rechazo “... anhelaba con ansias probarle a aquella gentuza que yo no era tan cobarde como me creían... soñaba yo con obtener la victoria, con vencer, con interesarles, y hacer que me tomasen afecto, siquiera en atención a mis altas miras y talento innegable" (p. 1490)

- Liza (cap. V-X): Aquí la comedia se convierte en tragedia. Revela el contraste entre el romanticismo social y sentimentaloide, autoglorificador, pagado de sí mismo e imaginario, y el auténtico acto de amor que brota del olvido de sí mismo. El sadismo del hombre del subterráneo, humillado que desea descargar su rabia sobre alguien más vulnerable aún que él, Liza. ("Me habían humillado y yo también quise humillar a alguien: me trataron como un pingo y quise hacer alarde de mi poder" p. 1518). Liza, en lugar de enojarse por sus palabras, le abraza: "De toda aquella jerizonga comprendió lo que una mujer comprende, antes que nada, cuando ama sinceramente: que yo era desgraciado" (p. 1519), pero la vanidad del "hombre del subterráneo" lo incapacita para responder espontáneamente y sin egoísmo a los demás "yo no podia ya amar, porque lo repito, amar, para mí, es sinónimo de tiranizar y dominar moralmente" ( $p$. 1520). Responde de una forma cruel hacia Liza ("cometí aquella crueldad por mi propio impulso, sin duda, pero no por mala sangre; únicamente por mi mala cabeza. Era una crueldad fingida, intelectual, forjada adrede, según los libros" p. 1521). Por tanto su crueldad no es por corrupción total de su sensibilidad moral, sino por su intelectualidad. Por último, ofrece su última vil racionalización, excusando su sadismo moral-espiritual como forma de purificación por el sufrimiento ("la afrenta no se borrará nunca de su memoria, y por mucho que se envilezca y por bajo que caiga, la afrenta la elevará y la purificará... Gracias al odio” p. 1522)

La conclusión es que al final, el hombre del subterráneo vuelve a la amargura de su soledad. Durante un momento tiene un atisbo de cómo escapar de la dialéctica de la vanidad: el absoluto desdén de Liza a su propia humillación, su capacidad de un amor sin egoísmo, el ideal de autosacrificio voluntario de la personalidad, a fuerza de amor. Dice el hombre del subterráneo: "Hemos perdido la costumbre de la vida hasta tal punto, que a veces sentimos una suerte de asco por la vida verdadera. Hemos llegado a considerar la vida viva como un trabajo, casi como un empleo, y todos somos en nuestro interior de parecer que es mejor vivir en los libros. ¿Y por qué nos afanamos, por qué hacemos locuras, qué es lo que 
pedimos? Ni nosotros mismos lo sabemos. Nos encontrariamos mejor si nuestros locos ruegos se cumpliesen...no he hecho sino llevar hasta el último límite en mi vida lo que vosotros, de puro cobardes, no osariais llevar a la mitad; y todavia consideráis vuestra cobardia como prudencia... Así que puede que yo esté más cerca de la vida que vosotros. ¡Pero mirad más de cerca la cosa! ¿No sabemos perfectamente donde vive lo que está vivo, en qué consiste y como se llama?. Dejadnos solos, sin libros, y al punto nos perderemos, nos embrollaremos, sin saber que hacer ni que pensar, sin saber lo que se debe amar y se debe aborrecer; igualmente ignorantes de lo que merece estima y de lo que sólo ha de inspirar desprecio. Hasta los propios semejantes nos resultarian insufribles; nos avergonzariamos del hombre verdadero, del que tiene carne y sangre...Nos empeñamos en ser un tipo de hombre corriente que nunca ha existido. Hemos nacido muertos, y hace mucho tiempo que nacemos de padres que ya no viven, y eso nos agrada cada vez más. Le tomamos el gusto. Dentro de poco querremos nacer de una idea" (pp. 1522-23). Por tanto, para Dostoievski la solución estaría en rechazar las ideologías artificiales occidentales y volver a la "tierra rusa", con la incorporación del ideal cristiano de amor desinteresado. 


\section{E1 cocodrilo}

En el último número de Epojkha, justo antes de su quiebra en 1865, Dostoievski publica la primera parte de este cuento satírico, inconcluso, como continuación de la polémica entablada por la revista con los liberales. En él no se hace ningún intento por dar verosimilitud psicológica; las relaciones entre los personajes son completamente superficiales y su idea principal consiste en narrar las reacciones estereotipadas de los personajes a un "incidente extraordinario". En un prólogo, que después fue omitido, Dostoievski compara este cuento con La nariz de Gogol.

Este "incidente extraordinario" concierne a un alto burócrata, solemne y presumido, y a su esposa, voluble y coqueta, que acuden junto con el narrador (un amigo que le tiene envidia) a ver a un cocodrilo que se exhibe en el Pasaje. Este burócrata se acerca demasiado al reptil, es devorado vivo y se instala confortablemente en la barriga del animal. Se puede oír con toda claridad su voz, que expresa gran satisfacción por lo ocurrido, decidiendo ocupar el tiempo libre en desarrollar sus altos ideales encaminados a la mejora de la humanidad. Su mujer, de gran belleza, se pregunta si pedir el divorcio, rechaza irse con su marido al interior del animal y se muestra muy sensible a las atenciones de otros hombres.

El tema de este cuento es, por tanto, la falta de humanidad a lo que es, después de todo, un hecho lamentable: un ser humano que es devorado por un cocodrilo. Nadie, salvo el narrador, se apena de la víctima. En él se hace una sátira de "los principios de economía", que impiden que al hombre se le saque de la barriga del reptil, ya que esto ocasionaria una gran pérdida económica al dueño del animal, que es alemán, y Rusia necesita capital extranjero para estimular su desarrollo industrial. El mismo burócrata devorado, de ideas progresistas, estará de acuerdo con la explotación económica del suceso. 


\section{Crimen y castigo}

Fue escrita por Dostoievski en el segundo semestre de 1865. Su publicación se inicia en enero-febrero de 1866 y tiene un gran éxito. El primer boceto es escrito como diario del protagonista, cambiándolo a tercera persona en noviembre de 1865 con un narrador que sostiene el punto de vista más cercano posible al protagonista. Es la primera de las cinco novelas que hacen a Dostoievski uno de los más grandes novelistas del mundo y algunos autores la consideran la obra más triste de la de la literatura universal, denominándola "la obra de la tristeza sin salida" (Bravo, 1987)

Crimen y Castigo es la historia de un joven estudiante llamado Raskolnikov que comete un crimen por unos principios. A partir de complejas motivaciones que él mismo encuentra difícil de analizar, mata a una vieja usurera, junto a su hermana, que, de forma inesperada, entra en la habitación en el momento del asesinato. Después de éste, se siente incapaz de hacer uso del dinero y de las joyas que ha tomado y las esconde. No hay ninguna prueba que lo relacione con el crimen; pero su ansiedad y su comportamiento extraño hace sospechar al policía encargado del caso. Antes de haber sido establecida su culpabilidad, el estudiante confiesa su crimen y es condenado a ocho años a Siberia, a donde le sigue una muchacha, Sonia, que ha estado prostituyéndose para ayudar a su familia. Raskolnikov marcha a Siberia arrepentido, no de haber cometido el crimen, sino de no haber sido capaz de mantenerse firme y haber confesado; pero después de una enfermedad sufrida en la prisión, se produce su "conversión" bajo la influencia de Sonia.

El tema del libro es, por tanto, el análisis de los motivos del crimen y las reacciones que éste produce en el asesino; y, con este tema, Dostoievski trata el problema de la libertad absoluta, la evasión de la sujeción moral y la posibilidad de traspasar su límite. Encontrará la solución mediante la redención por el sufrimiento voluntariamente aceptado y la humildad, con el consiguiente paso de la moral impuesta a la ética propia.

Así, Raskolnikov sueña con convertirse en el ídolo romántico por excelencia: Napoleón. Repudia los cánones normales de moralidad y busca otras verdades más allá de las fronteras del bien y del mal, tal y como son concebidos ordinariamente. Al principio, el crimen parece ser el resultado de su lógica utilitaria, puesta en movimiento por sus propias estrecheces económicas, por la desesperada situación de su familia y por un deseo de ayudar a los demás con el botín del crimen. Después aparece su justificación 
como el derecho de la "gente extraordinaria" a pasar por encima de la ley moral, con objetos de dar beneficios a la humanidad en general. En la escena de la confesión con Sonia, define su motivo como el deseo de obtener poder para sí mismo, tan solo para ver si tenía derecho a ocupar un lugar entre esos seres superiores que poseen el derecho innato a pasar por encima de la ley moral. Las razones de Raskolnikov para cometer el crimen eran demostrarse a sí mismo que era un superhombre, afirmar su derecho a transgredir las convenciones morales: "Yo necesitaba saber entonces, y saberlo cuanto antes, si yo era también un piojo, como todos, o un hombre. ¿Estaba facultado para transgredir la ley o no lo estaba? ¿Era osado a traspasar los límites y aprehender o no? ¿Era yo una criatura que tiembla, o tenía derecho?” (T.II, P.V, C.IV, p. 309). La cuestión fundamental de Crimen y Castigo es ¿Cae Raskolnikov únicamente porque es débil? ¿O porque existe algo especial en la esencia del hombre que le hace incapaz de encontrar plena satisfacción en la posición de un superhombre amoral?. En el Epílogo, Dostoievski insiste que en Raskolnikov no existe arrepentimiento sino una aplastante sensación de derrota. "Ved en lo que únicamente se reconocía el culpable: sólo en no haber persistido y haber ido a delatarse" (T.II, Epílogo, C.II, p. 349). Raskolnikov finalmente tiene un sueño que representa la universalización de su doctrina en el que todos se creen "hombres extraordinarios", como una plaga asiática, que lleva al desplome de todas las formas y valores comunes. Tras este sueño acepta su amor por Sonia, "refulgía ya la aurora de un renovado porvenir, de una plena resurrección a una nueva vida. Los resucitaba el amor, el corazón del uno encerraba infinitas fuentes de vida para el corazón del otro...En vez de la dialéctica, surgía la vida, y en su conciencia debía elaborarse algo totalmente distinto (T.II, Epílogo, C.II, p. 398). Dostoievski finaliza la novela con las siguientes palabras: "Pero aquí ya empieza una nueva historia, la historia de la gradual renovación de un hombre, la historia de su tránsito progresivo de un mundo a otro, de su conocimiento con otra realidad nueva, totalmente ignorada hasta allí. Esto podria constituir el tema de un nuevo relato... pero nuestra presente narración termina aquî" (p. 399).

Además de Raskolnikov, existen otros protagonistas en la novela que han sido considerados como el doble positivo (Sonia) y el doble negativo (Svridigáilov) de Raskolnikov. Sonia representa la máxima autosumisión y se caracteriza por la negación de sí misma. En ella aparecen los gérmenes de la doctrina de la salvación por medio del sufrimiento. Por el contrario, Svridigáilov, que acaba suicidándose, es el personaje que simboliza el hedonismo que predica la propia satisfacción individual como el supremo bien. 


\section{E1 jugador}

Novela fechada en Octubre de 1866, fue escrita en veintiséis días ante el requerimiento de cumplimiento de contrato de su editor. Considerada la novela más autobiográfica, está escrita en primera persona, en forma de confesión o diario y expresa la doble pasión de Dostoievski: su amante Polina y el juego. Puede considerarse esta obra como una condena de sí mismo y, al mismo tiempo, como una disculpa.

El protagonista, Aleksieyi Ivánovich, es un joven noble ruso, culto y muy inteligente, que trabaja como preceptor, para la familia de un general ruso que vive temporalmente en el extranjero. Aleksieyi cree estar enamorado de la hijastra del general, Polina. Estos amores, y la ludopatía del protagonista son las tramas fundamentales de la novela, Aleksieyi empieza a jugar, supuestamente como medio para conquistar a Pólina, pero de hecho más por una necesidad de autoafirmación propia que por un auténtico deseo de su amor.

En esta novela las escenas de juego son relatadas en un nivel nunca alcanzado previamente y nadie ha descrito de forma tan magistral como en esta novela la embriagadora pasión del juego: el juego permite caer en el dominio de la posibilidad total, del azar, es la primera experiencia de la libertad en el mundo, más allá de las leyes lógicas. El protagonista, Aleksei, así como todos los personajes rusos de la novela, actúa por sentimientos cuyas consecuencias pueden ser desastrosas pero que incluyen alguna pasión que transciende el espíritu práctico, al contrario de los personajes europeos de esta novela que van a actuar exclusivamente por motivos económicos.

En esta novela, Dostoievski analiza las características de la pasión del juego, y entre ellas su carácter exclusivo, que hace olvidarse de otros sentimientos y pasiones, como las de Aleksey hacia Polina y de la vieja tía hacia su sirvienta campesina Marfa. A medida que transcurre la novela, existe un paulatino eclipsamiento de la desgraciada historia amorosa entre Alexei Ivanovich y Polina. Durante buena parte de la novela las dos pasiones, el amor y el juego, se entrecruzan en la trama con similar importancia. Sin embargo, posteriormente, esto se convierte en imposible porque desde la óptica dostoievskiana la posesión pasional exige una atención exclusiva que excluye la intervención de fuerzas ajenas, por poderosas que éstas sean ("en el instante en que anoche estaba en la sala de juego y me embolsaba paquetitos de oro, mi amor (por Polina) parecía haber pasado a segundo plano" (T. II, C. XV, p. 485). La pasión amorosa es, por tanto, progresivamente 
sacrificada, de modo que la relación con Polina, fundamental al principio, palidece en la medida que se impone el vértigo del juego. A través de este proceso, Dostoievski va a exponer con una enorme precisión los mecanismos del comportamiento pasional. 


\section{E1 Idiota}

En Ginebra, en 1867, empieza Dostoievski a escribir esta novela. Los siete primeros capítulos aparecerán publicados en Enero de 1868, recibiéndola la crítica con indiferencia y desconcierto. La novela es acabada en Florencia, en 1869. En la actualidad se considera la más personal y original de todas sus obras mayores, en la que se reflejan sus convicciones más íntimas. No obstante, lo errático de la acción que acontece, en gran parte debida al dilatado tiempo que tardó en su terminación, con publicación de los artículos a medida que los iba escribiendo, hace que esta novela sea también la más desorganizada de las obras importantes de Dostoievski.

El protagonista, Mishkin, un antiguo príncipe de una casa rusa, sufre ataques epilépticos que se asemejan mucho a los padecidos por Dostoievski. Huérfano desde pequeño, se ha criado en el campo por unos viejos labradores que contrataron para él preceptores. Tras un agravamiento de su enfermedad es ingresado en una clínica suiza, donde permanece durante cinco años. Sale casi curado de la clínica y regresa a Rusia para tomar posesión de una herencia. Dos mujeres se enamoran de él, la hija menor de un general y la desdeñada amante de un rico comerciante. Medio enamorado de las dos, se dispone a casarse con la segunda por motivos de piedad; pero ella, para librarle del sacrificio, huye en el último momento con otro pretendiente, el cual, enloquecido por los celos, la mata. Y el príncipe y el asesino pasan una noche juntos velando el cadáver en estado de putrefacción. El asesino es condenado a Siberia; la hija del general se casa con un aventurero estafador que pronto la abandona. Y el príncipe regresa a Suiza en un estado de postración física y psíquica grave. Hay una trama secundaria, que trata de un joven de dieciséis años, Ippolit, mortalmente enfermo de tuberculosis, que intenta suicidarse tras exponer los motivos que le llevan a este acto.

Dostoievski confiesa a su sobrina que en el príncipe Mishkin intenta retratar al "hombre absolutamente bello". Lo compara con Cristo, Don Quijote y Jan Valjan de Los miserables. Este héroe encarna el ideal ético ruso, el ideal cristiano del amor. Según Dostoievski, el príncipe tiene una cualidad fundamental: es inocente. Esta inocencia se muestra en su candor, en su falta de toda vanidad social (que sería normal) y en su apasionada compasión hacia el sufrimiento humano. Supera la desconfianza inicial de los otros personajes por su evidente sinceridad e ingenuidad; y también hay un reconocimiento implícito de que su inocencia, que revela lo que otros se esfuerzan por ocultar, 
probablemente entrañe una sabiduría superior, a la manera de la tradición rusa del loco santo (yudorivi), el hombre sencillo cuya aparente locura confunde la sabiduría de los grandes. El ideal ético que se nos presenta en Mishkin es un ideal pasivo. Su virtud suprema es la palabra rusa "smirenie" (humildad incluyendo la idea de renuncia y paz espiritual) como oposición al término "hybris" (orgullo, presunción y rebelión espiritual). Representa la primitiva tradición cristiana de los Evangelios caracterizada por la concepción del pecado basada en el sentimiento y no en la acción.

El Idiota es, además, una novela de amor en el que su protagonista se desdobla ante dos tipos de amor diferentes: Amorpiedad (Nastasya) y amor-voluptuosidad (Aglaya). Este desdoblamiento del príncipe dramatiza el nivel más profundo de la idea temática de Dostoievski: por una parte, como heraldo de un amor cristiano que tiene que ser universal; pero además, también es un hombre, no un ser sobrenatural, un hombre que se ha enamorado de una mujer. Esta tensión insostenible hace al principe en los últimos capítulos perder todo contacto con la realidad $y$ al final cae definitivamente en una situación de embotamiento cerebral, estado que desde hacia mucho tiempo había temido que serian el precio de sus momentos de éxtasis en las auras epilépticas. 


\section{El eterno marido}

Escrita en Dresde durante el otoño de 1869, tiene una buena acogida por el público y la crítica. Está basada en parte en los apasionados amores de su amigo el barón Wrangel y los suyos propios con su primera mujer en la época de Semipalatinsk. Aunque técnicamente es una de sus novelas mejores, Dostoievski siempre la consideró un trabajo menor.

La acción de la novela transcurre nueve años después de que Pável Pávlovich Trusotskii, el "eterno marido", fuese engañado por su mujer y por el hombre a quien creía su amigo. Velcháninov, el amante, había tenido una aventura de todo un año con esta mujer, que corta con él al aparecer otro hombre en escena. La mujer muere pocos meses antes de que comience el relato, dejando intacta toda su correspondencia para que la lea su marido; así, éste se entera de sus relaciones y de que su adorada hija de ocho años, Liza, es en realidad hija ilegitima de Velcháninov. Poco después, Trusotskii llega con Liza a San Petesburgo, a la que maltrata desde que sabe que no es realmente su hija. En esta ciudad busca encontrarse con Velcháninov, con el que se relaciona, muriendo Liza poco después. Dos semanas después, los dos hombres se encuentran de nuevo y Trusotskii le invita a Velcháninov a ir con él a visitar a su nueva joven prometida. Allí, de nuevo, el primero es humillado y el segundo aclamado por la prometida y sus hermanos y amigos adolescentes. Esa misma noche Velcháninov se indispone y Trusotskii le presta auxilio, permaneciendo a su cuidado. En una de las ocasiones en que Velcháninov despierta, encuentra a Trusotskii con una navaja dispuesto a asesinarle. En los meses siguientes Velcháninov busca a Trusotskii, no encontrando más que la carta de la mujer de Trusotskii en la que relata de quién era hija Liza. Años después, los dos hombres se encuentran en una estación de ferrocarril y todo ha vuelto a ser lo que era: Trusotskii, el "eterno marido", se ha vuelto a casar y Velcháninov intenta de nuevo seducir a su joven mujer.

El eterno marido es una obra "clásica" en su construcción. La organización de los encuentros entre los dos personajes principales, con el gradual cambio de posición del uno al otro y, por último, su completa inversión, está brillantemente lograda. Ambos personajes se entregan a la típica lucha dostoievskiana entre el egoísmo y la conciencia y ambos están atrapados en la dialéctica del orgullo y la humillación. En esta novela Dostoievski muestra de nuevo las mutabilidades e indeterminaciones del carácter humano, ya que tanto el altivo y elegante Velchaninov 
como el dócil y engañado Trusotskii cambian momentáneamente de personalidad y muestran características del otro, bajo el peso de los acontecimientos. 


\section{Los demonios}

Escrita en el período transcurrido desde Enero de 1870 a Julio de 1872, es la novela con mayor proporción de caricatura satírica y parodia ideológica. Tiene, en el momento de su publicación, un gran éxito de la crítica y del público.

Está basado en un caso real: el asesinato de un estudiante por estudiantes universitarios "nihilistas" en 1869 (proceso Nescháyev). Dostoievski compagina este proceso con sus propias creencias para crear el argumento principal de la novela. En ella, retrata a un grupo radical que quiere derrocar al gobierno y erosionar a la Iglesia rusa para asumir la dirección del país. La fuerza del grupo radica en la clandestinidad, su inteligencia y la capacidad de cometer crimenes sin sufrir remordimientos. Sin embargo, en el punto álgido de sus acciones este grupo se desmorona.

En el número 50 de El ciudadano (1873), Dostoievski explica sus motivaciones para escribir esta novela. Dice: “...pretendí exponer la cuestión, y, además, en forma de novela, formular una respuesta clara a la pregunta: ¿Cómo en nuestra sociedad admirable... no solo podía darse un Nescháyev, sino muchos Nescháyeves, y de qué modo podía suceder que esos Nescháyeves pudieran reclutar secuaces?" Y continúa: "En mi novela he intentado exponer esos múltiples y diversos motivos con los que puede inducirse incluso a los hombres más sencillos y puros a cometer tan monstruoso crimen...se puede cometer la acción más vergonzosa y tremenda sin ser muchas veces un mal hombre" (T.III, pp. 795-800).

La novela transcurre en una pequeña ciudad a las afueras de San Petesburgo. El narrador no es testigo directo de todos los sucesos que ocurren; sin embargo, describe la historia como si hubiera participado en la trama o como si fuera un cronista al que le hubieran relatado los sucesos. Sabemos muy poco del narrador, excepto su estrecha amistad con Stepán Trofimovich, un idealista liberal del decenio de los cuarenta al que mantiene Varvara.

El Libro I es una presentación general de los personajes en la que se describe su pasado y personalidad. Dostoievski relata minuciosamente los sucesos ocurridos treinta años antes lo que permite al lector conocer mejor la situación actual de los personajes. Este primer libro tiene poca acción, simplemente desarrolla los personajes que van a tener un papel importante en la novela. Liza y Stravoguin comienzan una relación e, inevitablemente, surge el tema del matrimonio. Varvara se percata del interés de su hijo por Liza y considera que el matrimonio puede 
ser beneficioso para él. Sin embargo, este compromiso queda en suspenso cuando Varvara visita a Liza. Liza sospecha que Stavroguin y la criada de Varvara, Dasha, mantienen una relación sentimental. En vista de esto, Varvara decide casar a Dasha con Stepán Trofimovich y así asegurar el compromiso de Stavroguin y Liza. Stepán y Dasha acatan la decisión de Varvara debido a la relación de subordinación que mantienen con ella, aunque con gran malestar por parte de Stepán.

La escena crítica del libro I transcurre un día en casa de Varvara. Ésta sale de la iglesia y es abordada por la tullida María Timofóyevna, que la pide dinero. Sin pensárselo dos veces, Varvara lleva a María a su casa y Liza se une a ellas. Cuando llegan, Stepán, Shátov y el narrador están esperando. La presencia de la tullida altera la conversación y crea un sentimiento de incomodidad en la sala. La madre de Liza aparece en la escena y poco después, Dasha se une a ellos. El capitán Lebíadkin, hermano de Maria, se presenta con la pretensión de conseguir casarse con Liza. El capitán intenta impresionar a Liza y al resto de los personajes, pero al final queda en ridículo. Stavroguin, precedido por Piotr Stepánovich, entra en escena después de haber estado fuera de la ciudad durante algún tiempo. Niega estar casado con María, aunque la trata afectivamente y la acompaña a su casa. Piotr asegura que este matrimonio es verdadero y explica las razones de Stavroguin para negarlo. Además, trata de forma despectiva a su padre Stepán. Al volver Stavroguin, Shátov le abofetea. Stavroguin se contiene y no responde a la bofetada, yéndose Shátov. Liza presenta una crisis psicógena.

Al final del Libro I los personajes principales han sido presentados, aunque no se ha resuelto nada. Dostoievski usa esta tensión y confusión para desarrollar el Libro II. El libro I, típicamente dostoievskiano, sirve para presentar a los personajes, con los cuales posteriormente desarrolla una escena dramática y escandalosa. Además, origina una sensación de confusión que favorece el caos que viene a continuación.

El libro II contiene dos conversaciones opuestas sobre el concepto de Dios. Kirillov declara a Stavroguin su intención de matarse como forma de llegar a ser Dios al vencer el miedo a la muerte. Por otra parte, Shátov confiesa que desearía creer en Dios, pero que se siente incapaz a causa de su falta de fe. Su hostilidad hacia Stavroguin se debe al matrimonio secreto de Stavrogin y Maria y también al supuesto romance que mantuvo Stavroguin con la mujer de Shátov. 
Cuando Stavroguin sale de la casa de Shátov para ir al apartamento del capitán Lebiadkin y María, se encuentra con Fedka, un presidiario que fue un antiguo siervo de Stepán. Fedka le pide dinero, pero Stavroguin le trata groseramente y continua su camino. Cuando llega al apartamento, habla con Maria, a quien dice que quiere anunciar su matrimonio públicamente. María se enfurece y Stavroguin se va. De vuelta a casa, Fedka se aproxima de nuevo a Stavroguin. Stravoguin descarga su rabia en Fedka y le pega, arrojando luego dinero al aire. Fedka coge este dinero considerándolo como un anticipo del encargo para asesinar a Lebiadkin y a María.

Al dia siguiente Stavroguin es retado a un duelo con el hijo del hombre al que tiró de la nariz en el bar. Dispara al aire de forma intencionada con lo que consigue enfadar aún más a su adversario. Stavroguin sale fortalecido del duelo. Vuelve entonces a casa, donde Dasha le declara que ella le perdonará cualquier falta pasada o futura. Dostoievski en este momento desplaza el centro de atención de Stavroguin a Piotr.

Piotr empieza a ridiculizar al nuevo gobernador, mientras mantiene una relación amistosa con su mujer. Ésta está preocupada en los preparativos de una fiesta, lo que da a Piotr tiempo suficiente para dedicarse de sus asuntos personales. Convoca la primera reunión del grupo revolucionario en casa de Virguinskii. Este encuentro pone de manifiesto la incapacidad del grupo para realizar algo constructivo. Stavroguin llega tarde a la reunión y la abandona poco después, sin comprometerse a mantenerla en secreto, lo que desagrada a Piotr. La escena de esta reunión sirve de marco a Dostoievski para la sátira política $\mathrm{y}$ manifestar su desprecio hacia el movimiento revolucionario. Después, Piotr alcanza a Stavroguin y le manifiesta su intención de nombrarle el líder del grupo. Stavroguin se va sin decir palabra.

Como prometió al gobernador, Piotr proporciona datos a la policia sobre una posible revuelta en una fábrica. De forma anónima, acusa a su padre de ser el líder de este grupo. La policía va a casa de Stepán y le requisa los libros. Así, Piotr se venga de su padre y lo intenta aislar de la sociedad.

El Libro III empieza con la fiesta dada en beneficio de las institutrices. Desde el comienzo, la fiesta es un desastre que Dostoievski describe con su típico estilo dramático. La fiesta consiste en dos partes: los oradores durante el día y el baile en la noche. Los oradores son: el capitán Lebíadkin, Karamazinov, Stepán y un loco desconocido. Todos los discursos son un fracaso. El capitán Lebíadkin aparece borracho en el escenario, Liputin lee 
el ofensivo poema que había preparado Lebíadkin, Karamazinov (personaje que utiliza Dostoievski para caricaturizar a Turguéniev) aburre al público con su afectada conferencia llamada "Merci", el discurso de Stepán refleja su depresión y el último discurso, el del loco, es el remate final.

A pesar del fracaso de la mañana, Piotr convence a la mujer del gobernador para mantener el baile según estaba previsto. El baile tampoco tiene éxito, apareciendo muchas personas no invitadas y pocas de la alta sociedad. La fiesta finaliza con el aviso de que hay un fuego en el otro lado del río. El fuego ha sido intencionado y María y el capitán Lebíadkin han sido asesinados en su caseta, alquilada por Stavroguin para ellos. No se conoce quién ha sido el autor del crimen.

Stavroguin va a casa de Liza e intenta convencerla para marcharse juntos de la ciudad. Stavroguin dice a Liza que él tuvo en sus manos evitar el asesinato, pero no lo hizo. Liza, enajenada y arrastrando a su pretendiente, Mavrikii Nikoláyevich, detrás de ella, acude al lugar del asesinato encontrándose con la muchedumbre. Liza es identificada como "la mujer de Stavroguin" y es golpeada en la cabeza.

Se realiza la siguiente reunión del grupo, que está preocupado de que se les acuse del asesinato de los Lebíadkin. Piotr les tranquiliza ya que no existe ninguna prueba contra ellos, pero expresa el temor de que Shátov les traicione ya que desea abandonar el grupo. Shátov tiene la imprenta clandestina que podria utilizar como prueba de la existencia del grupo. De esta forma, Piotr convence a los demás de que es necesario asesinar a Shátov por la propia seguridad. Para ello, planean pedirle que lleve la imprenta a un lugar determinado donde le asesinarán. La culpa caerá sobre Kirillov, quien ha aceptado suicidarse y firmar cualquier documento que Piotr le presente.

En la sección siguiente, Dostoievski desarrolla el personaje de María Shátova, que es la figura en la que se representa el contraste entre el nacimiento y la muerte. Este personaje, innecesario en la trama principal de la novela, proporciona a Dostoievski la posibilidad de incluir otros temas. María es la exmujer de Shátov a la que no ha visto desde hace tres años y que llega a la ciudad con la intención de establecerse en ella. Está embarazada de Stavroguin y en su primera noche en la ciudad se pone de parto. Shátov, desesperado, busca una matrona por todas partes. Convence a la mujer de Virguinskii de que asista al parto, desarrollándose éste sin complicaciones. María confiesa que necesita a Shátov y planifican reanudar de nuevo su relación. Pero 
el grupo le asesina, como estaba planeado, y abandona el cadáver en un lago cercano, separándose después tras acordar mantener el silencio sobre esta acción. Uno de los miembros del grupo, Líamshin, enloquece y Piotr encarga a Tolkáchenko su custodia. Piotr va al apartamento de Kirilov para terminar de cumplir el plan. Después de una larga discusión, Kirilov firma una nota en la que se responsabiliza de la muerte de Shátov y después se suicida. Piotr se va a Petesburgo para buscar a Stavroguin, que ha partido.

Stepán inicia un viaje con destino a Spásov con el deseo de iniciar una nueva vida. Para a comer en una posada. Allí encuentra a una campesina, Sofia Matviéyevna, que vende Evangelios. Stepán cae gravemente enfermo. La campesina permanece con él a petición del enfermo, ya que no es capaz de abandonar a un hombre agonizante. Stepán muere en paz tras proclamarse creyente y rezar por el perdón de su alma. Varvara llega a la posada y al principio trata con descortesía a Sofia, pero luego le agradece su comportamiento.

El final de la novela es breve, pero trágico. María Shátova se despierta y al no encontrar a Shátov, sale a la calle a buscarle con su niño recién nacido. Pierde el conocimiento y muere tres días más tarde. El niño se enfría y muere antes que ella. Tolkáchenko abandona a Liamschim que escapa y confiesa todo a la policía. Él, Virguinskii, Erkel, Liputin, Tolkáchenko y Piotr son arrestados. Stavroguin envía una carta a Daria, pidiéndola que vaya a vivir con él. Ésta acepta el ofrecimiento y Varvara se une a ellos. Ambas van a buscar a Stavrogin, pero éste se ha ahorcado.

Un capitulo de la novela, Con Tijón, fue censurado y no se publicó durante la vida de Dostoievski, quien originalmente lo insertó tras el capítulo VIII de la Parte II. Dostoievski tuvo que realizar cambios de última hora en su obra, lo que hace algo menos coherente el libro, quedando Stavroguin como una figura mucho más enigmática y misteriosa de lo que inicialmente debía ser y faltando la aclaradora motivación filosófico-moral que Dostoievski se había propuesto darle. A pesar de esto, el capitulo es de alta calidad literaria y una de las más importantes obras de Dostoievski como filósofo. Stavroguin confirma estar más allá del bien y del mal. No siente remordimientos por sus acciones pasadas, actúa según sus propios deseos y no tiene deberes ni sigue normas morales. En este capítulo Stavroguin se enfrenta a Tijón, que representa al bien mientras que Stavroguin se retrata a sí mismo como un hombre diabólico. No sólo contiene la crucial revelación de toda la gama y profundidad de la depravación de Stavroguin (la confesión de haber violado a una niña de doce años) sino también su motivación, sus tormentos internos y su anhelo de 
redención. El final del capítulo expresa las fuertes creencias cristianas de Dostoievski. La confesión de Stavroguin resulta ser sólo otra y más extrema forma de su "sensualidad moral". Como dice Tijón su confesión "responde a la necesidad de un corazón mortalmente herido... Pero usted aborrece y desprecia ya por anticipado a todos cuantos hayan de leer lo aquí escrito y los provoca a la lucha" (T. IV, paralipómena de "Los demonios", p. 1591). Tijón discierne que Stavroguin, por sí mismo, jamás podrá alcanzar la verdadera humildad del auténtico arrepentimiento; su necesidad de sufrimiento y de martirio sólo puede llevarlo a provocaciones cada vez más espantosas. Tijón le sugiere se someta a la voluntad de un monje anciano y así se discipline a sí mismo mediante su total rendición a otro, pero Stavroguin rechaza esta sugerencia y se lanza a su perdición. Su figura es trágica, pues su incapacidad de creer en su propio renacimiento le lleva a su propia destrucción. Con Tijón es, sin duda alguna, un claro ejemplo del motivo por el que se considera a Dostoievski también un filósofo. 


\section{El adolescente}

Escrita durante el invierno de 1874-1875 en una casa de campo que alquila Fiodor en Stárava Rusa. La crítica la acoge favorablemente.

En Diario de un escritor, Dostoievski comenta sus intenciones al escribir esta novela. Dice: "Tomé un alma impecable, pero ya corroída por la terrible posibilidad de la corrupción, llegada por el odio a si insignificancia y casualidad y por esa amplitud en virtud de la cual un alma todavía pura acoge inconscientemente al vicio en su pensamiento, lo acaricia en su corazón y se recrea con él en sus todavía vergonzosos, pero ya osados y tormentosos sueños..., dejado en todo ello a sus propias fuerzas y a su discreción, amén de Dios, naturalmente. Son los abortos de la sociedad, miembros casuales de casuales familias" (1876 Enero C. I, II, p. 875)

En la mayoria de sus libros, Dostoievski se ocupa principalmente de los problemas de la vida y de la filosofia; en $E l$ adolescente, se ocupa de las reacciones psicológicas de los seres humanos en sus mutuas relaciones. Dada la indudable perspicacia de Dostoievski como psicólogo, esta novela en este sentido tiene gran importancia, aunque desde el punto de vista literario podría ser considerado un fracaso, siendo la obra más informe y peor trabada de las que escribió.

El personaje principal de esta novela es Arkadii Makárovich, hijo ilegitimo de Versílov y una sierva. Por esta condición sufre humillaciones de sus profesores y compañeros en un internado para la aristocracia. Ante estas vejaciones, Arkadii se humilla aún más, complaciéndose en su rebajamiento y encuentra placer en su aislamiento, en donde se regodea en su "idea" de "llegar a ser un Rothschild"; Para Arkadii, su motivo principal de orgullo estriba en esta idea secreta, que le sirve de acicate y le proporciona sentimientos de poder y de diferencia con los otros: "Con vuelos de corazón imaginaba, a veces, que cuando le expusiese a alguien $m i$ idea, ya, de pronto, no me quedaría nada y vendría a ser lo mismo que todos, y hasta era posible que desistiese de ella... Mi idea exige el rincón" (T.II, P.I, C.III, p. 1563). Este adolescente, además, presenta una relación ambivalente con respecto a su padre, Versílov, que desde la infancia le inspira una mezcla de amor y odio; el conocimiento paulatino de la personalidad real de su padre es el argumento principal de la novela. Arkadii se enamora de la misma mujer que Versílov, Katerina Nikoláyevna. Una carta comprometedora de esta mujer, en posesión primero del adolescente y luego de su padre, es el motor principal de esta 
novela. A medida que este adolescente va venciendo sus prejuicios y la crisis de la pubertad, su idea "de llegar a ser un Rothschild" deja de tener sentido para él.

El interés de esta novela no reside en su trama, sino en su cualidad de estudio psicológico. En ella, el tratamiento que se hace de la figura del padre es un claro precursor de la teoría psicoanalítica, con una descripción de los mecanismos psicológicos basados en la idealización, rivalidad e individualización de la adolescencia: Dice Arkadii a Versilov: "Yo necesitaría separarme de usted; usted me obliga a ello" (T.II, P.I, C.VI, p. 1601).

Por último, en esta novela se desarrolla extensamente la idea de la dualidad de la naturaleza humana. Para Dostoievski, esta dualidad es necesaria y hasta indispensable para la integración de la personalidad y su plena actuación: la parte inferior, lo subsconsciente del individuo es el impulso para la parte superior, racional. Esta idea del doble es elaborada y analizada de forma más exhaustiva en el personaje de Versílov, padre de Arkadii. 


\section{Los hermanos Karamázov}

Publicada en la prensa durante los años 1879-1880. A finales de 1880 , pocos meses antes de la muerte de Dostoievski, fue editada en libro. Es considerada por muchos autores la mejor novela de Dostoievski.

En la Parte I Dostoievski va a presentar a los principales personajes de la novela. Fiodor Karamázov, calificado de bufón, gorrón y corrupto es padre de tres hijos (legitimos): Dimitri, Iván y Aleksieyi. Desde el primer párrafo de la novela se sabe que Fiodor será asesinado y en las páginas siguientes se describe la vileza de este personaje: su crueldad, no sólo con sus dos esposas (ambas muertas), sino también con sus vástagos, de los que no se ha ocupado nunca y que han sido criados lejos. Se rumorea que Smerdiákov, su sirviente, es el hijo bastardo que tuvo Fiodor tras mantener relaciones sexuales con la retrasada mental del pueblo, Lizaveta, ya fallecida.

Los otros tres hijos, por diferentes razones, han vuelto a casa después de muchos años. Iván es un intelectual que cuestiona la fe y la religión. Dimitri se alistó en el ejercito y se ha convertido en un hombre tan sensual como su padre. Alíoscha habita en el monasterio donde sigue las enseñanzas del stárets Zósima. Tras una reunión del stárets Zósima con la familia Karamázov en la que Fiodor se comporta como un bufón, Zósima ordena a Alíoscha salir del monasterio y volver al mundo para llevar la luz del ideal cristiano.

Cuando el Padre Zósima presiente que llega la hora de su muerte, reúne a la congregación en su celda, en donde hace una larga disertación sobre sus creencias acerca de la humanidad y apela a la responsabilidad de todos los seres humanos en cada pecado individual. Posteriormente ordena de nuevo a Alíoscha que cumpla sus deberes hacia su padre y sus hermanos, es decir, que intervenga para decrecer la enemistad entre ellos. Alíoscha visita primero a su padre quien le confiesa que guarda un dinero para intentar seducir a Grúschenka, por la que está duramente enfrentado con su hijo Dimitri. Al salir de la casa, Alíoscha se encuentra con un chico, que más tarde es identificado como Iliuscha Sniéguiriov, que está tirando piedras a sus compañeros de clase. Este niño es hijo de un capitán al que Dimitri ha pegado y humillado. Alíoscha pasa por la casa de la señora Jojlákova, donde le ha citado Lise. Habla también con Katerina, quien le asegura que ella nunca abandonará a Dimitri, motivo por el que Iván ha decidido irse a Moscú. Además, Katerina le da a Alíoscha 
doscientos rublos para el capitán ofendido por Dimitri; al realizar este encargo es cuando Alíoscha se percata que el hijo del capitán es el chico que estaba tirando piedras. Finalmente, Alioscha vuelve al monasterio poco antes de que el stárets Zósima muera.

En la Parte III, se tratan dos temas importantes. En primer lugar, el cadáver del stárets Zósima empieza a putrefactarse y a oler casi inmediatamente después de su muerte, lo que se interpreta como un signo de posible corrupción del stárets. Esto origina una gran conmoción en el monasterio y en la sociedad religiosa, los cuales se dividen entre los que estaban a favor y los que estaban en contra del stárets mientras vivía. Para Alíoscha, la muerte y rápida putrefacción del cadáver tiene un profundo significado, que le origina una crisis de fe. Por este motivo, Alíoscha acude a casa de Grúschenka y acepta su vodka y embutidos, prohibidos en la Cuaresma. Ambos están una velada juntos y paulatinamente van forjando una relación más íntima, no exenta totalmente de sensualidad. El segundo gran tema de la Parte III es el anuncio del asesinato de Fiodor y el consiguiente arresto de Dimitri (del que sabemos que golpeó al criado de Fiodor, Grigori, pero desconocemos si participó en el asesinato de su padre). Dimitri es conducido a prisión donde en vez de mantener su inocencia, decide que de alguna forma él es culpable del asesinato de su padre. Aunque no sean directamente culpables, tanto Dimitri como Grúschenka y, más tarde, Iván se sienten culpables en parte de la muerte de Fiodor. Esta parte de la novela se engarza especialmente con las doctrinas del stárets Zósima previas a su muerte. Así, Dimitri se siente responsable de las acciones de otras personas. Grúschenka se siente culpable de haber deteriorado la relación entre el viejo Karamázov y Dimitri. Alíoscha entiende al fin que la fe no debe basarse en milagros, que no necesita de ellos. Por último, Lise siente la necesidad de sufrir y arrepentirse, y en un acto de fuerte autoagresividad se golpea los dedos con la puerta. Todos estos sucesos convergen en su significado; el sufrimiento es el único camino para la pureza espiritual.

En la Parte IV se relata fundamentalmente el juicio de Dimitri Karamázov, pero empieza con una historia independiente, que se utiliza como interludio para decrecer la tensión del argumento. La historia de un niño moribundo, Iliuscha, proporciona el sentimentalismo del que carecía hasta este momento la novela. Esta historia narra las enseñanzas de Alioscha y su influencia en la juventud. Volviendo a la trama principal, relata como Dimitri ha permanecido en prisión dos meses y el dolor de la mayoría de los personajes principales. Dimitri está convencido de que alcanzará su salvación mediante el sufrimiento. Smerdiákov, el verdadero 
asesino, se suicida tras confesar su crimen a Iván. Los remordimientos de conciencia atormentan a Iván cuando este se percata del papel decisivo que jugó en el asesinato del viejo Karamázov, y finalmente se confiesa totalmente culpable. Al final, Katerina enseña en el juicio una nota escrita por Dimitri que "prueba" que este es el responsable del crimen y así salva a su amado Iván de su implicación en esta muerte. Ella cree que Ivan, enajenado, sólo quiere salvar a Dimitri de ir a prisión a expensas de cargar él la culpa. Dostoievski, en esta Parte IV, no sólo finaliza la historia sino que también intenta guiar y aconsejar moralmente. Pero, al igual que en otros trabajos del autor, no le resulta igual de fácil prescribir soluciones que sacar a la luz problemas y tomar partido sobre ellas. En Los hermanos Karamázov la maldad humana es descrita con crudeza. La solución podría estribar, según Dostoievski, en amar a la humanidad y enseñarla a ser socialmente responsable. Sólo cuando el grupo tenga consciencia de su responsabilidad como sociedad la maldad podrá ser erradicada. Así, sirve el ejemplo de Alíoscha que intenta ayudar a su familia, a los niños y a todos los sujetos que entran en contacto con él. Si este concepto de culpabilidad social más que individual es la clave de la salvación entonces sería necesario defender una supraconsciencia humanitaria global.

En el epílogo Katerina pide perdón a Dimitri después de que éste acepte huir con Grúschenka a América (con la ayuda de Iván) durante algún tiempo y cargar con el peso del exilio. Alíoscha, que ha interpretado repetidamente la voz de la conciencia moral, es representado finalmente dando un paseo con los niños a los que, sin duda alguna, intentará moldear con las enseñanzas del stárets Zósima.

En esta novela se establecen, por tanto, dos polos opuestos: el problema de la sensualidad y el problema de la religión. Entre estos dos polos oscilan todos los personajes del libro: el viejo Karamázov está colocado en el polo de la sensualidad; el Padre Zósima, en el de la religión: entre ambos se sitúan en distintas gradaciones los hermanos Karamázov: Smerdiákov, Dimitri, Ivan y Aliocha.

Dentro de la novela es particularmente importante La leyenda del Gran Inquisidor narrada por Iván, que implica la defensa de la libre voluntad, no como proposición metafísica, sino como proposición moral así como la búsqueda de Ivan de una solución racional al sufrimiento de los niños inocentes.

Las intenciones de Dostoievski eran, según explica en el prólogo del libro, realizar una segunda parte de esta novela en la que 
Alíoscha sería el protagonista y la acción transcurriría treinta años después, es decir, en la década de los ochenta: Alíoscha se habría convertido en revolucionario y saldría de prisión tras haber cumplido condena por un delito politico. Para Dostoievski esta segunda novela, que no llegó a realizar, sería la principal, siendo esta otra una mera introducción biográfica del protagonista. 


\section{Diario de un escritor}

A finales de 1872 Dostoievski es nombrado redactor-jefe de $E l$ ciudadano y empieza a publicar articulos mensuales en esta revista a los que llama Diario de un escritor. Ante el éxito de estos artículos, Dostoievski decide continuar con ellos como publicación independiente durante los años 1876, 1877, 1880 y 1881, año en que fallece. En Diciembre de 1877, Dostoievski comunica la suspensión temporal de esta publicación para escribir una nueva novela (Los hermanos Karamázov). Con estos artículos, Dostoievski se vuelve la voz de la conciencia nacional. En ellos une la confidencia intima con los debates sobre politica extranjera, los temas eternos con las pequeñas preocupaciones del momento, los sucesos con las fantasías noveladas y frecuentemente se convierte en un periodista propagandístico de una política conservadora y agresiva.

El tema central en muchos de estos artículos es la idealización del pueblo ruso. Para Dostoievski, la peculiar santidad del pueblo ruso no necesita argumentación alguna sino que la presenta como un articulo de fe. Este culto no implica ningún conocimiento práctico del pueblo ni ningún interés por mejorar las condiciones en que vive. La idealización esta desprovista de toda preocupación humanitaria o reformista. Su interés está centrado en la moral, no en la política ni en lo social. Y además, adjudica al pueblo ruso un papel mesiánico, considerándole el salvador del mundo e identificándole con la religión. En sus diatribas, Dostoievski llega a justificar la guerra como guerra santa: "No siempre es la guerra un azote; a veces es hasta la única salvación". (Abril, 1876 p. 986; Abril, 1877 p. 1224)

Aunque el culto al pueblo ruso ocupa el lugar central de El diario de un escritor, hay otro tema también preponderante en el libro: el eterno contraste entre Rusia y Occidente. Según Carr (1931), la fórmula del credo ético-religioso-nacional de Dostoievski sería la siguiente: por un lado "egoísmo $=$ catolicismo $=$ anticristo $=$ Europa" y por el otro "fraternidad = ortodoxia $=$ Cristo $=$ Rusia". Existe una influencia fundamental del publicista Danilevski y su Tratado político en el asentamiento de estas creencias. Para este autor, mientras que en Europa predominan las cualidades individuales, en los países eslavos predominan las cualidades sociales y esto explica el hecho por el que un europeo desprovisto de su estatus social o nacional se cierra en su individualidad, mientras que el ruso degenera en la nada. Para Dostoievski esta falta de individualidad es la suprema cualidad de la virtud del pueblo ruso. 
Diario de un escritor no es solamente un manifiesto político, social y religioso. Contiene también varios artículos sobre procesos criminales, relata recuerdos de su infancia, habla de otros escritores y, especialmente para el tema que nos ocupa, dedica muchas páginas a reflexionar sobre el suicidio y comentar las noticias periodísticas sobre diferentes actos suicidas. Además, publicará una fantasía macabra, Bobók, que es un diálogo de los muertos en un cementerio y dos relatos cortos, La mansa y $\mathrm{El}$ sueño de un hombre ridículo.

La mansa (año 1876, Noviembre, pp. 1102-1131) es un relato compuesto en forma de monólogo interno. Muestra las cavilaciones de un marido que se pasea en todas direcciones en la habitación donde yace el cadáver de su esposa muerta, quien se suicidó arrojándose por una ventana, mientras aferraba un icono en la mano. El cuento se origina en un relato periodístico de un suicidio semejante referido por Dostoievski en el Diario en el artículo de Octubre. Frank (T. III, pg.373) lo relaciona con las reflexiones de Dostoievski ante el féretro de María. El marido es un prestamista de más de cuarenta años que conoce a la suicida, de dieciséis, cuando ésta va a la tienda a empeñar sus pobres pertenencias, entre ellas el icono con el que más tarde se arrojará por la ventana. La mujer es huérfana, sin recursos, y vive con sus tías; él le pide su mano y ella acepta. Al principio ella intenta amarle, pero él se muestra serio y silencioso con la intención de "parecerle un enigma" y demostrarle su superioridad moral. Para el protagonista, igual que para el hombre del subterráneo, los hombres le han echado con su despectivo silencio, le han causado una afrenta y le han separado de ellos. El quiere mostrarse ante ella duro y orgulloso, indicando que no necesita consuelo de nadie. Ella se rebela ante la actitud de él y para ello queda con un oficial, aunque no acepta mantener relaciones con él. Esa noche la mujer le apunta en la sien con su pistola cuando cree que está durmiendo. El la ve, pero finge que duerme profundamente. Ella no dispara y él piensa que en ese momento ambos han llevado a cabo una lucha terrible en la que él ha ganado. Durante el invierno siguiente el silencio se hace mayor aún entre ellos. Al fin, él decide mostrarle su amor, besarle los pies y confesarle su pasado; ella, tras asustarse mucho, confiesa que es una criminal, pero que intentará ser una buena esposa y quererle. En los cinco minutos que él sale ella reza al icono y se arroja con él por la ventana, ante la imposibilidad de corresponderle.

En el capítulo II de Abril del año 1877 de Diario de un escritor escribe Sueño de un hombre ridículo. Este relato narra el sueño de un hombre que decide suicidarse; sueña que se suicida y que es 
trasladado a un planeta idéntico a la Tierra pero paradisíaco, en el que todos son felices y reina la armonia: la naturaleza es acogedora; los seres humanos son buenos, alegres, sencillos y juiciosos. Pero con su llegada los hombres empiezan a aprender lo que es la mentira, y de ésta la voluptuosidad, la envidia y la crueldad; "conocieron el dolor y le tomaron gusto; lampaban por el sufrimiento y decian que la verdad solo se compra a precio del martirio... volvieronse todos tan celosos de su yo, que cada cual se afanaba por rebajar, oprimir y empequeñecer el yo del prójimo por todos los medios posibles" Algunos "soberbios voluptuosos" querían o todo o nada y si no conseguian nada con fechorias, quedaba el recurso del suicidio. Hasta "hubo religiones consagradas al culto del no ser y del propio aniquilamiento en aras del eterno reposo en la nada"; estos hombres proclamaron que "el dolor es belleza"; Tras este sueño que para el personaje le anuncia la verdad, este cambia profundamente; desde entonces intentará anunciar a todos la posibilidad de un paraíso en la Tierra, aún a riesgo de parecer ridiculo. 


\section{B. Método de estudio}

En este apartado hemos seguido el trabajo realizado por Dr. Gómez Bosque y Diez Blanco Antropología y Matemáticas incluido en el libro La matematización de la ciencia (Valladolid, 1964) y el estudio de Castilla del Pino realizado en su libro Introducción a la Psiquiatria en el apartado titulado Problemas generales (Madrid, 1982):

Max Scheler, en su obra Esencia y formas de la simpatía, distingue entre el centro vital y el núcleo personal o espiritual del hombre. El primero es aquel conjunto de anhelos que se orientan hacia la conservación de la vida y que se manifiestan muy especialmente en los impulsos tróficos, sexual y de validez o dominio; su forma de actuar es con frecuencia, la de los afectos y pasiones. El segundo está constituido por aquellos actos (intemporales y no objetivables en la conciencia íntima) que emanados de la persona se dirigen especialmente a la captación y realización de valores.

Gómez Bosque y Diez Blanco (1964) se basan en esta concepción de la persona humana de Max Scheler para establecer una división paralela de las ciencias antropológicas.

Así, la Psicología, tomada esta palabra en su amplio sentido se ocupa especialmente de los factores y de las fuerzas intimas que por su mutuo juego posibilitan la realización de las funciones de la "conciencia vital". En cambio, las Ciencias Culturales tienen como objeto propio el estudio de los actos espirituales del hombre y, sobre todo, de su evolución y desarrollo a lo largo del tiempo; por ello, la Historia constituye siempre el núcleo central de nuestro saber acerca de los fenómenos culturales. Ambos saberes, el psicológico y el histórico-cultural son auténticos dominios científicos. El método fundamental aplicable a estas ciencias del hombre es, según autores como Hengstenberg, Friedrich, Kraft, Seldmayr y Spranger, la "Hermenéutica".

La Hermeneútica es, por tanto, aquel método que intenta desentrañar los misterios de la conducta humana y que culmina poniendo de manifiesto el "sentido", más o menos oculto, de estas conductas. La Hermenéutica se dirige, pues, hacia algo eminentemente cualitativo, por lo que dificilmente puede darse un pensamiento matemático aplicable a este dominio.

En el plano que nos interesa, el plano "psicológico", en el nivel de "conciencia vital", la hermenéutica puede recibir la forma, por 
ejemplo, de las distintas técnicas de Psicologia profunda que han ido desarrollándose a partir del psicoanálisis. Esta hermenéutica vital considera a los fenómenos de conciencia como una mera fachada tras la que se oculta la dinámica y el juego mutuo de las diversas "pulsiones"; el "sentido" de la conducta humana sólo se desentraña cuando tal conducta es puesta en relación con los oscuros "móviles" que yacen en la "sima" o "profundidad" del alma; a esto se llama "comprender" el hombre.

En este terreno la poesía se adelantó a la ciencia: cuando la psicología empírica oficial de finales del siglo XIX y principios del siglo XX estaba reducida a una simple psicofisica o a una vacua psicología asociacionista, la literatura dramática, poética y narrativa estaba ya cargada de una profunda sabiduría sobre las motivaciones personales. Dentro de esta literatura estos autores destacan los dramas de Schiller, los aforismos de Nietzsche y las novelas de Dostoievski.

Castilla del Pino en su Introducción a la Psiquiatría (1982) estudia la doble dimensión de esta ciencia: en el nivel científiconatural, los métodos usados en Psiquiatría no difieren de los que se utilizan en los otros sectores de la Biología: la observación, espontánea y experimental y la explicación. Por el contrario, si se considera a la Psiquiatría como ciencia humana, el acto de conducta no es considerado meramente como síntoma, al modo como se procede en la Psiquiatría cinetíficonatural, sino como signo, en tanto la conducta tiene un sentido, propósito, intencionalidad o significación. Si se acepta esto último, que la conducta tiene sentido, las hipótesis que hayan de construirse acerca de la conducta observada no serán explicativas, sino interpretativas, es decir "hermenéuticas".

También este autor considera que, hasta Freud, la psicología que precisaba el psiquiatra, la que le podía acercar a la intelección de la vida del hombre al que se califica en sentido amplio de enfermo, no estaba en los tratados de Psicología sino en las intuiciones de los grandes literatos de todas las épocas. La Psicología de esta época, en su afán de hacerse "científica", adoptó el modelo de ciencia que había resultado tan provechoso en el campo de la Fisiologia, el cual a su vez se extrajo de la Física y concretamente de la Mecánica. Así, el fenómeno psíquico quedaba subsumido en un determinado tipo funcional, sin considerar las motivaciones o sentido de las conductas. Dice Castilla del Pino (p.50): "Esquilo, Sófocles, Cervantes, Shakespeare, Dostoievski, Sthendal, entre otros muchos, ofrecian una imagen del hombre actuando en determinada situación, y por tanto, aportaban conocimientos asistemáticos de lo que en un amplio sentido se 
denomina "la vida humana". A partir de Freud, la psicología toma también, como objeto, esa vida humana"

En este trabajo hemos investigado, utilizando el método hermenéutico, los fenómenos psicológicos, sociológicos y psicopatológicos que Dostoievski engloba en las distintas conductas suicidas de sus personajes y en sus reflexiones sobre el suicidio. También hemos cotejado estos hallazgos con las diferentes teorias, tanto clásicas como actuales, sobre la génesis y el desarrollo de los diferentes actos suicidas.

Para ello, hemos recogido en las obras reseñadas todas las alusiones, directas o indirectas, sobre el suicidio, entendiendo como tal no solo las conductas con las que el sujeto acaba con su vida, sino también aquellas en las que el sujeto busca su muerte pero no consigue su fin y aquellas en las que el individuo, con la idea de la muerte propia, busca otros fines diferentes. Por tanto, incluimos en este estudio no solo los suicidios consumados, sino también los suicidios frustrados, los intentos de suicidio, las ideas de suicidio y las amenazas suicidas de los personajes de las obras estudiadas.

Una vez entresacados estos datos, hemos procedido a su valoración intentado interpretar cuales eran las características de las diferentes conductas suicidas. En los personajes implicados se ha valorado principalmente la existencia o no de psicopatología, los rasgos de personalidad, la intencionalidad del acto, la impulsividad o reflexión de este acto, las motivaciones, las influencias sociales y ambientales y el sentimiento básico que empuja a su realización.

Para finalizar, en un último apartado, hemos incluido las reflexiones del propio autor sobre el fenómeno suicida realizados, bien directamente en los artículos periodísticos de Diario de un escritor, o indirectamente puestos en boca de los personajes que Dostoievski creó como encarnación de la sabiduría y de la bondad, que se presupone son la expresión de los conceptos que Dostoievski considera como verdaderos. 
IV. RESULTADOS Y DISCUSIÓN 


\section{A. Listado de fenómenos suicidas en las obras estudiadas}

A continuación enumeramos los fenómenos suicidas recogidos en cada una de las obras estudiadas, especificando el personaje que lo protagoniza, el método empleado para el acto suicida (cuando ha sido señalado por el autor) y el tipo en el que se encuadra en este estudio.

\section{Crimen y castigo}

1. Intento de suicidio: Nikolai Dementiev, ahorcamiento (T.II, P.II, C.III, p. 113) (Suicidio como forma de renacer).

2. Intento de suicidio: Afrosiniuschka, inmersión (T.II, P.II, C.V, p. 136) (Suicidio en el alcoholismo).

3. Ideas de suicidio: Raskólnikov, inmersión (T.II, P.II, C.V, p. 137) (Suicidio como forma de renacer).

4. Suicidio consumado: Marmeládov, atropellamiento (T.II, P.II, C.VI, p. 140) (Suicidio en el alcoholismo).

5. Suicidio consumado: Niña sordomuda víctima de abuso sexual, ahorcamiento (T.II, P.IV, C.II, p. 224) (Suicidio infantil).

6. Suicidio consumado: el "tío Philipp", ahorcamiento (T.II, P.IV, C.II, p.224) (Suicidio como huida).

7. Suicidio consumado: Niña víctima de abuso sexual, inmersión (T.II, P.VI, C.VI, p.370) (Suicidio infantil).

8. Suicidio consumado: Svridigáilov, disparo (T.II, P.VI, C.VI, p. 373) (Suicidio en el narcisismo maligno).

\section{E1 Idiota}

1. Suicidio consumado: Kapitón Aleksiéyich Radomskii, disparo (T.II, P.III, C.II, p. 764) (Suicidio por sentimientos de culpa). 
2. Intento de suicidio: Ippolit, disparo (T.II, P.III, C.VII, p. 817) (Suicidio "lógico").

3. Fantasías suicidas: recuerdos de la infancia de Aglaya, envenenamiento (T.II, P.III, C.VIII, p. 820) (Suicidio infantil).

\section{E1 eterno marido}

1. Suicidio consumado: comisario, ahorcamiento (T.II, C.VIII, p. 1004) (Suicidio en el juego patológico).

2. Gesto suicida: Pável Pávlovich Trusotskii, ahorcamiento (T.II, C.VIII, p. 1005) (Amenazas suicidas).

3. Intento de suicidio: Liza, precipitación (T.II, C.VIII, p. 1005) (Suicidio infantil).

\section{Los demonios}

1. Gesto suicida: Stepán Trofimovich, ahorcamiento (T.II, P.I, C.II, p. 1117) (Amenazas suicidas)

2. Suicidio consumado: forastero, ahorcamiento (T.II, P.II, C.V, p. 1286-7) (Suicidio en el juego patológico).

3. Suicidio consumado: Kirillov, disparo (T.II, P.III, C.VI, p. 1482) (Suicidio "lógico")

4. Suicidio consumado: Stavroguin, ahorcamiento (T.II, P.III, C.VIII, p. 1515) (Suicidio en el narcisismo patológico)

5. Suicidio consumado: Matryosha, ahorcamiento (T. III, paralipónema de Los demonios, pp. 1582-7) (Suicidio infantil).

\section{E1 adolescente}

1. Suicidio consumado: Lidia Almákova, envenenamiento (T.II, P.I, C.IV, p. 1573) (Suicidio "romántico"). 
2. Suicidio consumado: Kraft, disparo (T.II, P.I, C.VIII, p. 1636) (Suicidio "lógico").

3. Suicidio consumado: Olia, ahorcamiento (T.II, P.I, C.IX, pp. 1648-53) (Suicidio en trastorno psicótico).

4. Ideas de suicidio: Principe Sokolskii joven, disparo (T.II, P.II, C.VII, p. 1738) (Suicidio por sentimientos de culpa).

5. Suicidio consumado: Relato de Makar sobre un soldado licenciado, ahorcamiento (T.II, P.III, C:III, p. 1794) (Suicidio por sentimientos de culpa).

6. Suicidio consumado: Relato de Makar sobre un niño maltratado, inmersión (T.II, P.III, C.III, pp. 1801-2) (Suicidio infantil).

7. Intento de suicidio: Versílov, disparo (T.II, P.III, C.XII, p. 1913) (Suicidio violento).

8. Suicidio consumado: "le grand dadais", disparo (T.II, P.III, C.XIII, p. 1916) (Suicidio en el alcoholismo).

\section{Los hermanos Karamázov}

1. Suicidio consumado: "Señorita de la pasada generación", precipitación (T. III, P.I, L.I, C.I, p. 23) (Suicidio “romántico”).

2. Intento de suicidio: Sofia Ivánova, ahorcamiento (T.III, P.I, L.I, C.III, p. 28) (Suicidio en trastorno psicótico).

3. Intento de suicidio: padre de Katerina Ivánova, disparo (T.III, P.I, L.III, C.IV, p. 105) (Suicidio por sentimientos de culpa).

4. Intento de suicidio: Grúschenka, ahorcamiento (T.III, P.I, L.III, C.X, p. 133) (Suicidio "romántico").

5. Ideas de suicidio: Dimitri, ahorcamiento (T.III, P.I, L.III, C.XI, p. 136) (Suicidio por sentimientos de culpa).

6. Ideas de suicidio: caballero amigo de Zósima en la juventud (T.III, P.II, L.VI, C.II, p. 250) (Suicidio por sentimientos de culpa). 
7. Ideas de suicidio: Dimitri, disparo (T.III, P.III, L.VIII, C.VIII, p. 346) (Suicidio por sentimientos de culpa).

8. Suicidio consumado: Smerdiákov, ahorcamiento (T.III, P.IV, C.X, p. 504) (Suicidio por sentimientos de culpa)

\section{Diario de un escritor}

1. Suicidio consumado: Campesina maltratada, ahorcamiento (T.III, 1873, Artículos en El ciudadano, III, p. 713) (Suicidio como huida).

2. Suicidio consumado: joven que deja nota de despedida a su padre, disparo (T.III, Enero 1876, p. 873) (Suicidio anómico).

3. Suicidio consumado: hombre que no puede pagar la pensión de su querida (T.III, Enero 1876, p. 873) (Suicidio anómico).

4. Suicidio consumado: asesino de la burguesa Perova (T. III, Enero 1876, C.I, p. 875) (Suicidio violento).

5. Suicidio consumado: chica que estudia para comadrona, envenenamiento (T.III, Mayo 1876, C.II, p. 996) (Suicidio anómico).

6. Suicidio consumado: Hermano de la Kairova, disparo (T.III, Mayo 1876, C.I, p. 980) (Suicidio en el alcoholismo).

7. Suicidio consumado: Hija de emigrante famoso, inhalación de cloroformo (T.III, Octubre 1876, C.I, 1087).

8. Suicidio consumado: Costurera, precipitación (T.III, Octubre 1876, C.I, p. 1088) (Suicidio como huida).

9. Ideas de suicidio: suicida materialista (T.III, Octubre 1876, C.I, p. 1088-90) (Suicidio "lógico").

10. Suicidio consumado: La mansa, precipitación (T.III, Noviembre 1876, p. 1128) (Suicidio como huida).

11. Suicidio consumado: Niño castigado en la escuela, ahorcamiento, (T.III, Enero 1877, C.II, pp. 1173-4) (Suicidio infantil). 
12. Ideas de suicidio: "un hombre ridículo", disparo (T.III, Abril 1877, p. 1231) (Suicidio egoísta).

13. Suicidio consumado: General Hartung, disparo (T.III, Octubre 1877, p. 1361) (Suicidio por sentimientos de culpa).

En las obras Memorias del subsuelo, El cocodrilo y El jugador no aparece ningún fenómeno suicida. 


\section{B. TIPOS DE PERSONAJES SUICIDAS}

Los personajes de las obras de Dostoievski que realizan actos suicidas se engloban en los siguientes tipos:

Aquellos personajes que realizan el suicidio tras sufrir una situación adversa, caracterizados por su inocencia, cuyo suicidio es consecuencia de la maldad y de la injusticia humana. Dentro de este grupo se encuentra:

- El suicidio infantil

- El suicidio como huida: Víctimas adultas de la humillación y la miseria

Aquellos personajes cuyo suicidio es consecuencia de un trastorno mental. Los tipos de suicidio pertenecientes a este grupo son:

- El suicidio en trastornos psicóticos

- El suicidio en el juego patológico

- El suicidio en el alcoholismo

Aquellos personajes cuyos rasgos de personalidad son definidos por el propio autor como personajes tipo "Cleopatra" y que, víctimas de su acedia, terminan suicidándose:

- El suicidio en el narcisismo maligno

Aquellos personajes cuyo suicidio se debe fundamentalmente a un inteligencia reflexiva hipertrofiada:

- El suicidio "lógico" 
Aquellos personajes cuyo suicidio es producto de una situación pasional, pudiéndose acompañar o no de violencia. Son:

- El suicidio violento

- El suicidio "romántico"

Aquellos personajes en las que el suicidio es producto de sentimientos de culpabilidad por una acción valorada como reprobable. En el primero de estos grupos, la falta de consumación del suicidio tiene una función catártica:

- El suicidio como forma de renacer

- El suicidio por sentimientos de culpa

Aquellos personajes que aparecen en Diario de un escritor cuyo suicidio está relacionado para Dostoievski directamente con la occidentalización de la sociedad rusa:

- El suicido egoísta

- El suicidio anómico

Aquellos personajes cuyos actos suicidas son exclusivamente un intento de manipular los sentimientos de otro:

- Amenazas suicidas 


\section{El suicidio infantil}

\section{Crimen y Castigo}

1. Una niña, víctima de la lujuria de Svridigáilov: En el capítulo II de la parte IV (p. 224) Luchin relata a Razúmijin, Raskólnikov, Dunia y la madre de éstos últimos el sucio pasado de Svridigáilov. Hace siete años éste es denunciado tras el ahorcamiento en su guardilla de la sobrinita de una amante suya, sordomuda, de catorce o quince años; se sospechaba que esta niña, que era odiada y maltratada por su tía, había sido ultrajada por Svridigáilov. Gracias al dinero de su mujer la denuncia fue retirada y todo quedó solo en un rumor.

2. Horas antes de su muerte, Svridigáilov sueña con una chica que se ha suicidado ahogándose: Esta chica suicida con la que sueña Svridigáilov podría ser otra víctima real de éste o un desplazamiento del suicidio de la niña sordomuda: "Aquella joven se había suicidado ahogándose. Parecía tener no más de catorce años; pero ya tenía desarrollado el sentimiento y se había perdido a sí misma, ofendida por una afrenta, que había henchido de espanto y de asombro su tierna, infantil conciencia, colmado de inmerecido sonrojo su alma de angelical pureza, y arrancándole un supremo grito de desolación que nadie había oído..." (T.II, P.VI, C.VI, p.370)

\section{E1 Idiota}

1. Tras el intento frustrado de suicidio de Ippolit, Aglaya confiesa al príncipe sus fantasias sobre el suicidio en la infancia: "¿Sabe usted que yo misma he pensado treinta veces, cuando era una chica de trece años, envenenarme, y así lo dejaba escrito en una carta dirigida a mis padres y también imaginaba que me pondrian el féretro $\mathrm{y}$ todos vendrian a llorarme y se acusaban de haber sido poco cariñosos conmigo?” (T. II, P. III, C. VIII, p. 820) 


\section{El eterno marido}

1. En esta novela aparece un suicidio frustrado en el personaje de Liza, de ocho años, a quién Trusotskii maltrata desde que se ha enterado que en realidad Liza no es hija suyo, sino fruto de las relaciones que mantuvo su mujer, ya fallecida, con Velcháninov. La patrona de la casa donde viven padre e hija cuenta a Velcháninov que una vez, a no ser por su intervención, Liza se habría tirado por la ventana (T.II, C.VIII, p. 1005). Liza morirá por enfermedad días después.

\section{$\underline{\text { Los demonios }}$}

1. Matryosha, personaje que aparece en el capitulo Con Tijón, en el que se inserta la confesión de Stavroguin. Este capitulo, escrito originalmente para Los demonios, fue censurado y no se publicó en vida de Dostoievski. En su confesión Stavroguin relata la seducción de esta niña de doce años. Matryosha era víctima de malos tratos por parte de su madre y "era rubia y barrosa, una cara vulgar la suya, pero muy infantil y plácida, de una desusada mansedumbre" Tras forzarla, Stavroguin sostiene que Matryosha pensaba que había cometido "un crimen terrible, digno de pena capital, que habia matado a Dios". A los pocos días, tras alzar "su puñito" y amagar a Stavroguin con él, se ahorca (T. III, paralipómena de Los demonios, pp. 1582-7).

\section{$\underline{\text { El adolescente }}$}

1. Makar Ivánovich, marido legal de la madre de Arkadii, cuenta la historia de un niño de ocho años, hijo de una viuda muy pobre, al que un comerciante borracho y tirano se encarga de educar severamente y al que maltrata. El niño, tras romper accidentalmente una porcelana en casa del comerciante, se tira al río. El comerciante, tras esta tragedia, se casa con la madre del niño, se vuelve compasivo y generoso y construye 
una iglesia en recuerdo del niño. Posteriormente, cede todos sus bienes a su mujer y se vuelve peregrino.

\section{Diario de un escritor}

1. En el capítulo II de Enero de 1877 de Diario de un escritor Dostoievski relata el suicidio por ahorcamiento en la escuela de un chico de doce o trece años, tras ser castigado por el profesor a permanecer después de clase en el colegio hasta las cinco de la tarde: "Resultaba ser el muerto un chico de buena y pacífica conducta, sólo que de algún tiempo a esta parte había merecido algunas notas poco satisfactorias, por lo que le habian castigado. Dicen que también el padre del chico es hombre muy severo, y que precisamente ese día el niño celebraba su santo. Puede que en su exaltación infantil pensase el chico en el recibimiento que iban a hacerle en su casa sus padres, hermanitas y hermanitos. Y he aquí que me lo dejan solo, muerto de hambre, en una casa desierta, y recapacitando en la terrible cólera del padre, con quien tendría que habérselas, lleno de pena, de vergüenza y también, acaso de miedo ante el inminente castigo. No ignoraba la posibilidad de poner fin a su vida. ¿Qué niño la ignora hoy?... ¿ंNo habrá demasiados formulismos y seca falta de cordialidad en el modo como tratamos aquí este problema de la educación?" (pp. 1173-4)

Dostoievski no cree que este chico se matase solo por rabia y temor, ya que estos sentimientos pueden encontrar desfogue rápidamente. Dice: "debió de mediar aquí un sentimiento mucho más complejo... es decir, cuestiones infantiles reprimidas, aún no conscientes, fuerte sensación de una indignante injusticia, la noción prematura y enconada de la propia insignificancia y el problema morbosamente enconado. “¿Por qué a mí nadie me quiere?" Anhelo apasionado de obligar a los demás a compadecernos, lo que vine a ser igual que anhelo apasionado de que todos nos quieran, $\mathrm{y}$, además, también irremisiblemente, muchedumbre de otros matices y notas;... El chico aristocrático de la historia de Tolstoi (de Infancia y adolescencia) podia soñar en que ellos entraban y le hallaban muerto, y se ponían a quererlo y compadecerlo y a culparse a sí mismos. Hasta podía soñar con el suicidio; pero sin pasar de eso, de soñarlo; la recia estructura de la familia noble de histórica cepa habriase resistido a ello, aún en un niño de doce años y no lo 
habría dejado pasar del sueño a la realidad, mientras que en el caso a que nos referimos, el niño lo soñó y lo hizo. Por lo demás, al hacer esta observación no hablo tan solo de una actual epidemia de suicidios. Siente uno que aquí media, además, otra cosa: que parte enorme de la vida rusa se ha mantenido enteramente inadvertida y sin historiador. Cuando menos está claro que la vida de nuestra clase media noble, viene a ser ya un rinconcillo harto insignificante y particular de la vida rusa ¿Quién será el historiador de los demás sectores, que, según parece, son terriblemente numerosos?... Aquí, indiscutiblemente, tenemos la vida descompuesta, y descompuesta, por ende, la familia. Pero es indispensable asentar de nuevo la vida sobre nuevos principios. Ahora, que ¿quién nos indicará cuáles han de ser esos principios? ¿Quién, por poco que fuere, podría definir y enunciar las leyes de esa descomposición y de la creación nueva?" (pp. 1174-5).

\section{Discusión}

Aunque la tendencia a negar la existencia del suicidio en la infancia y adolescencia ha dado lugar a un número escaso de publicaciones hasta hace poco, ya en el siglo XIX aparecen en la literatura científica algunas referencias al suicidio de los niños (Mardomingo, 2000): Wislow relata en su obra The anatomy of suicide que el suicidio se da en menores de doce años y señala como motivo desencadenante la riña de sus padres. Esquirol (1845) subraya la rareza del suicidio en la infancia, aunque reconoce su existencia y lo atribuye a una educación equivocada que transmite la idea de que quitarse la vida es legítimo cuando la vida ha perdido su sentido. Duran-Farel en su estudio Etude sur le suicide chez les enfants (1855) da gran importancia a los sentimientos de los niños y a la atención afectiva que reciben de los padres.

Freud, en sus Contribuciones al simposio sobre el suicidio (1910) vincula el suicidio de los adolescentes a los traumas que encuentran en la vida. En esa perspectiva, Freud considera como una función ética de la familia y la escuela el ser soporte de los sujetos y de empujarlos hacia el placer del vivir. Ante la vida implacable, dice, la escuela debería ser una alternativa de juego y escenificación de la misma, quitándole su carácter traumático y debería encaminar el sujeto hacia un despertar del interés por la vida y por el mundo exterior. 
El concepto que el niño tiene de la muerte como algo inevitable, irreversible y universal es muy complejo y va madurando con la edad. Según Speece y Brent (1984) (citado en Sarró y de la Cruz, 1991) el niño a partir de los siete años ya comprende el concepto de la muerte. Otros autores distinguen tres etapas en el concepto de muerte en el niño a partir de los cinco años (edad en que el niño no considera la muerte) (Gastanmiza y cols., 1997):

- La muerte es concebida como una desaparición provisional, temporal, no irreversible entre los cinco y nueve años. A esta edad la muerte se personifica.

- Entre los nueve y trece años aparece el concepto de muerte como algo irreversible y capaz de afectar primero a personas neutras y luego a las próximas.

- A partir de los trece años se adquiere con el pensamiento abstracto el pleno concepto de muerte como final de la vida, irreversible y biológico.

Los estudios epidemiológicos sobre el suicidio en niños y adolescentes son en general poco fiables por la tendencia a la ocultación de los suicidios infantiles denominándoles muertes accidentales. Las cifras reales de suicidios infantiles son muy superiores seguramente a las publicadas.

No obstante, los intentos de suicido en adolescentes se han triplicado en los últimos veinte años y los suicidios han pasado a ser la segunda o tercera causa de muerte en grupos de población con edades entre trece y dieciocho años, después de los accidentes de tráfico. Según datos del Instituto Nacional de Estadística, en comparación con otros países del entorno se puede concluir que España registra una de las tasas de suicidio de adolescentes más bajas de Europa.

Las creencias erróneas más frecuentes sobre las conductas suicidas en los niños son: considerar que no existen suicidios antes de los seis años y que estos son raros en el período de latencia; que no es posible a nivel psicodinámico o evolutivo que aparezca una depresión grave en la infancia; que el niño no entiende que la muerte es irreversible y por tanto no se puede considerar un suicidio propiamente dicho; que los suicidios en los niños son impulsivos y no el fruto de preocupaciones duraderas; que durante la infancia no puede planearse a nivel cognitivo ni físico un acto suicida seriamente; que la mayoría de los actos suicidas en la infancia son manipulativos y poco agresivos; que las 
amenazas de suicidio en los niños no deben ser tomadas en serio aunque sean frecuentes; que los niños no tienen métodos al alcance de la mano para matarse y que los actos autodestructivos son respuestas a desencadenantes inmediatos (Sarró y de la Cruz, 1991).

Los métodos utilizados por adolescentes son similares al del adulto siendo en España los más frecuentes la precipitación seguido por el ahorcamiento en varones e intoxicación en mujeres. Los niños, a diferencia de los adolescentes, utilizan preferentemente métodos violentos en el $66,6 \%$ de los casos (precipitación, arma blanca) siendo el método utilizado por los niños tanto más violento y traumático cuanto menor es su edad (Gastanmiza y cols., 1997).

La conflictividad familiar es una de las circunstancias biográficas más frecuentes en los niños y adolescentes que quieren suicidarse, de tal forma que la desestructuración y desorganización de la familia, junto con las pautas anómalas en la interacción familiar constituyen uno de los factores de riesgo fundamentales. Otra circunstancia biográfica muy frecuente de conductas suicidas es el fracaso escolar (Conde y cols., 2001).

Según la recopilación de Brooksbrank de 1985 (citada en De la Gándara, 1995) otros factores precipitantes de elevada importancia numérica en las conductas autolíticas fueron el abuso psíquico, físico o sexual (20\%), el aislamiento social por absentismo escolar $(57 \%)$, los problemas de salud somática $(50 \%)$ y los problemas de salud mental (20 a $56 \%)$.

Aproximadamente el $50 \%$ de los adolescentes que comete un intento de suicidio refiere una situación conflictiva familiar de meses o años; un $50 \%$ señala como desencadenante del intento una discusión con los padres; le sigue en frecuencia el temor al castigo y el miedo a la separación de los padres después de una disputa entre ellos (Mardomingo, 2000). La falta de apoyo emocional y personal de la familia es una característica propia del $80 \%$ de los niños que intentan suicidarse: Las relaciones conflictivas con los padres, la falta de comunicación de los padres con el hijo, la falta de atención y el desinterés por los problemas del niño, las críticas persistentes a su conducta, la frialdad afectiva, la falta de amor, un método educativo basado en los castigos y el aislamiento social de la familia son muy frecuentes.

El alcoholismo del padre se da en el 33\% de los casos, frente al $2 \%$ en el grupo control; el $62 \%$ de los niños tiene relaciones conflictivas con su padre y en el $33 \%$ el padre no vive en el medio 
familiar, por lo que se considera que la figura del padre parece fundamental en la génesis y desarrollo de las conductas suicidas (Mardomingo, 2000). Las agresiones violentas también aumenta el riesgo suicida, siendo los intentos autolíticos seis veces más frecuentes en los niños maltratados.

Además de los factores de riesgo en el medio familiar se han descrito algunas características temperamentales y de personalidad que son más frecuentes en los adolescentes y jóvenes que quieren suicidarse como son: impulsividad, reacciones emocionales intensas, escasa tolerancia a la frustración, sentimientos de cólera, dificultad para demorar la gratificación, estilo cognitivo rígido, escasa flexibilidad ante las demandas ambientales y deficiente autoimagen. Además, y como factores claves en su génesis, aparece sentimientos de desesperanza y desvalimiento en el $93 \%$ de los casos y muy frecuentemente, sentimientos de soledad e incomunicación y de incapacidad para encontrar soluciones alternativas a los problemas de la vida cotidiana (Mardomingo, 2000).

En algunas ocasiones, la exposición al suicidio va a ser también un factor importante: en determinados adolescentes, la experiencia del suicidio de un miembro de su familia o de un amigo, parece que va a hacer este acto más posible o permisible (Gosh y Victor, 1995). Otros desencadenantes significativos son los conflictos escolares y el contagio informativo.

Gould propone la siguiente clasificación de las conductas suicidas en la infancia y adolescencia (en González y cols., 1997):

1. Suicidio motivado por el deseo de conseguir apoyo y fuerza a través de la unión con un poderoso objeto amado perdido.

2. La muerte como evitación del abandono o la amenaza del abandono.

3. Conducta suicida como manipulación para obtener el amor o la atención y castigar al otro.

4. Búsqueda de la redención de los pecados por la muerte.

5. Autoasesinato. Cuando la rabia hacia otro es de gran intensidad y por alguna razón no puede expresarse, puede volverse hacia uno mismo y representar de forma simbólica el asesinato del otro. 
6. Suicidio por desintegración de la personalidad, en el curso de un proceso psicótico activo.

7. Un último grito de ayuda. Una tentativa de suicidio puede ser una señal de socorro enviada de modo difuso y al azar con la esperanza de que alguien la recoja.

Actualmente se cree que la tendencia hacia la conducta suicida del adolescente y adulto se forma durante la infancia (Sarró y de la Cruz, 1991). En el acto suicida del niño hay aspectos muy similares a los del adolescente como la planificación, los métodos, la depresión y percepción de muerte.

En Diario de un escritor (Diciembre 1876, C.I) Fiodor Dostoievski define el suicidio infantil como una consecuencia de la educación otorgada por las familias, basada en el materialismo. Para este autor, el suicidio infantil es una consecuencia más de lo que él considera causa última del suicidio en el adulto: la falta de orientación hacia un sentido superior de la existencia; esta concepción chata de la vida, transmitida a los hijos, es la que hace posible la existencia del suicidio en el niño. Por tanto, Dostoievski hace una interpretación del suicidio en el niño y en el adolescente similar a la que hace Freud: para ambos autores, en estos casos hay un fallo en la función de soporte y de protección del instinto de vida en la familia y en la escuela. Pero, mientras que para Freud este fallo está en la función ética de la familia, para Dostoievski radicará en la falta de una correcta educación religiosa y moral.

Dice Dostoievski en el artículo citado: “...en los tiempos actuales se suicidan hasta niños, jóvenes de una edad tierna, que aún no tienen experiencia de la vida. Pero yo tengo la convicción secreta de que nuestra juventud sufre y tiene nostalgias de una finalidad más alta de vivir. En nuestras familias apenas hay quien pare mientes en las altas finalidades de la vida de la vida, y en la idea de la inmortalidad, no sólo no piensan, sino que es frecuente que hasta la hagan objeto de burla, y esto delante de los niños, desde su más tierna infancia, y hasta, si a mano viene, con toda intención" ( $\mathrm{p}$. $1142)$.

Por otra parte, Fiodor Dostoievski representa en sus obras una y otra vez la tragedia del abuso sexual infantil y sus consecuencias en una época en que este tema era silenciado. Su interés por los abusos sexuales infantiles fue malinterpretado por personas cercanas a él. Así, poco después de la muerte de Tolstoi, en 1910, se publicó una carta que Strajov le había escrito a éste en Noviembre de 1883. En ella dice acerca de Dostoievski, ya muerto: "Él se sentía inclinado hacia la corrupción y se mostraba orgulloso 
de ello. Viskotakov me contó una vez que él se había jactado de haber fornicado con una niña que le había entregado su institutriz. Observa que en lo que se refiere a esto, a su sensualidad animal, no tenía ningún gusto, ningún sentimiento hacia el encanto $\mathrm{y}$ belleza femeninas. Eso puede verse también en sus novelas. Los personajes que más se parecen a él son el protagonista de Memorias del subsuelo, Svridigáilov de Crimen y castigo y Stavroguin de Los demonios" (Carr, 1931, p. 95). Esta historia puesta en boca de Viskotákov es más que dudosa. Los dos últimos personajes citados protagonizan, como hemos visto, escenas de abuso de niñas. También en Los hermanos Karamázov aparece la violación de Lizaveta, débil mental, por el viejo Karamázov. El fruto de esta violación será Smerdiákov. Una información reciente publicada por Frank (1997, p. 39) relaciona el interés de Dostoievski por estos temas como el resultado de una experiencia de su infancia en el Hospital de la Beneficencia (donde vivia) en que una amiga suya de nueve años fue violada por un borracho y murió desangrada. Dostoievski refirió una vez que "el pecado más aterrador es violar a una niña por el cual no hay ni puede haber perdón", lo que contradice totalmente las suposiciones previamente referidas. Este horror ante el maltrato a los niños es la causa principal que esgrimirá Iván Karamázov en su negación de Dios: Iván afirma que no cabe, bajo ningún precio, redimir ni justificar lo injusto de los sufrimientos que padecen niños. Y considera que si es imposible lograr una armonía general, si "las lágrimas del niño son inevitables", la conclusión lógica es la negación del mundo y por tanto "todo está permitido": el egoísmo y hasta el crimen no sólo debe estarle permitido al hombre, sino hasta considerarle su salida más noble en su situación. Ante el sufrimiento de los inocentes Iván se rebela: "No es que no acepte a Dios, Alioscha; pero le devuelvo con el mayor respeto mi billete" (T.III, P.II, L.V, C.IV, p. 203). Ivan Karamázov, por tanto, no niega la existencia de Dios, sino que la refuta en nombre de un valor moral ante la permisividad del sufrimiento infantil.

Dostoievski se anticipa a los estudios realizados en niños que han sufrido abuso sexual. Los niños con mayor riesgo de abuso sexual son niños que aún no han adquirido la capacidad de lenguaje, niños con discapacidades psicomotoras o niños socialmente aislados (Delgado, 1996). Así, en las novelas analizadas de Dostoievski, una niña es sordomuda y otra estaba socialmente aislada. Entre los sintomas que más frecuentemente sufren los niños víctimas de abuso sexual se encuentran las tendencias suicidas $\mathrm{y}$, en general, el comportamiento autodestructivo e impulsivo (Arechederra, 1997; Delgado, 1996). Otros síntomas que aparecen son: sintomas disociativos, molestias somáticas, sentimientos de inutilidad, vergüenza, desesperación o 
desesperanza, sensación de perjuicio permanente, perdidas de creencias anteriores, hostilidad, retraimiento social, sensación de peligro constante, deterioro de las relaciones con los demás, y alteraciones de las características de personalidad previa (DSM-IV, 1995; Gómez Bosque, 1999). Dostoievski nos cuenta poéticamente los sentimientos de vergüenza (el "inmerecido sonrojo de su alma") y desesperación ("supremo grito de desolación") de una de ellas y los sentimientos de culpabilidad de Matryoscha: pensaba que había cometido "un crimen terrible, digno de pena capital, que había matado a Dios". En estas novelas las víctimas de abusos sexuales acabarán casi invariablemente suicidándose, resultado relativamente frecuente en estas personas tanto a corto como a largo plazo. Actualmente se considera que las experiencias traumáticas en la infancia, y de forma específica el abuso sexual, están fuertemente asociadas con el riesgo de intentos de suicidio a lo largo de la vida (Dube y cols., 2001). Este riesgo aparece tanto en adultos como en niños y adolescentes.

Uno de estos suicidios infantiles, como hemos referido previamente, corresponde a un sueño de Svridigáilov horas antes de cometer él mismo su suicidio. Este sueño, además, va a ser muy rico en motivos folclóricos rusos (Ivanits, 1992): Es el día de Trinidad, la joven yace vestida de tul blanco con sus cabellos mojados, alborotados, con una corona de rosas que le ciñe la frente. Estos detalles sugieren que la chica es comparada con una rusalka, ninfa acuática, que a menudo toma el espíritu de una doncella ahogada y que es especialmente peligroso en la semana de la Trinidad. Este sueño es el preludio del suicidio posterior de Svridigáilov.

En las obras de Fiodor Dostoievski se aprecia reiteradamente su preocupación por los derechos de los niños, y condena, especialmente en Diario de un escritor, los castigos brutales a los que son sometidos. Este tratamiento del maltrato infantil es totalmente contrario a la cultura popular rusa: el Domostroi, una guía tradicional de la administración del hogar ruso utilizada en la época de Dostoievski y que había sido compilada por eclesiásticos en el siglo XVI, aconsejaba a los padres no sonreír ni jugar con los niños y castigarles con severidad: "la vara no les matará sino que les hará bien" (Torrecilla Hernandez, 1998). Así, Dostoievski se pregunta: “¿No habrá demasiados formulismos y seca falta de cordialidad en el modo como tratamos aquí este problema de la educación?" (T.III, Diario de un escritor, Enero 1877, C.III, p. 1174).

Además de las víctimas de abuso sexual de los personajes libidinosos de sus obras, Dostoievski da importancia como génesis del suicidio infantil el temor al castigo, tal como aparece en el 
relato de Makar de El adolescente y en el caso entresacado de los sucesos del periódico de Diario de un escritor. En este último caso, el autor investiga más a fondo este suicidio: en él no sólo existe, dice, el miedo a un padre excesivamente severo y colérico, sino también el sentimiento de carencia de afectividad y, sobre todo, la incapacidad de fantasear sobre ello, que Dostoievski atribuye a factores sociales: mientras los niños de clase aristócratica (como el niño de la novela de Tolstoi y Aglaya, de El Idiota) pueden fantasear sobre su suicidio y las reacciones de los seres queridos ante éste, el niño de ambiente rural pasa al acto.

Dostoievski se anticipa aquí una vez más al psicoanálisis: según Ajuriaguerra y Marcelli (1982), por buena que sea la crianza del niño, no existe un niño sin fantasía agresiva, pero existe una clara oposición entre fantasías agresivas y fantasmas agresivos y destructores. Cuando estos fantasmas invaden excesivamente el mundo del niño, éste no puede expresar fantasías agresivas y suele presentar un aspecto inhibido y angustiado que alterna en ocasiones con conductas actuantes bruscas e imprevisibles, dirigidas contra los demás o contra sí mismo. Por el contrario, un niño que presenta una organización lúdica y una ensoñación fantasiosa puede experimentar sus fantasias sin ser destructor para los otros ni destruido por ellas. Nos encontramos aquí con la oposición proceso primario/proceso secundario; los fantasmas agresivos corresponden al dominio más arcaico y el niño no puede elaborarlos, mientras que las fantasías agresivas se integran en su personalidad y en su yo. El niño aristocrático de Tolstoi y Aglaya pertenecerian a este segundo tipo, mientras que el niño que se suicida en la escuela al primero.

Como curiosidad destacamos que este suicidio infantil citado en Diario de un escritor acaeció el día del santo del niño, habiéndose señalado en la literatura médica que una cuarta parte de los suicidios infantiles acontecen en la semana posterior al cumpleaños (De la Gándara, 1995). 


\section{El suicidio como huida: victimas adultas de la humillación y la miseria}

\section{Crimen y Castigo}

1. El "tío Filipp", sirviente de Svridigiálov, se ahorcó a causa de la persecución y vejamen al que su amo le sometía. Según había oído Dunia "el tal Filipp era un hipocondríaco, una suerte de filósofo de andar por casa, del cual decian las gentes que habia leido demasiado y que se habia ahorcado más bien por efecto de las burlas que de los golpes del señor Svridigáilov" (T.II, P.IV, C.II, p.224). Svridigailov refiere como el fantasma de Filipp se le apareció poco después de muerto, quizás para vengarse, pero él le recriminó tranquilamente por presentarse con los codos rotos y el fantasma nunca volvió ( $\mathrm{p}$. 217).

\section{$\underline{\text { Diario de un escritor }}$}

1. En el artículo El Medio, publicado en el número dos de El ciudadano (1873) relata el suicidio de una campesina maltratada por su marido. Hecho real publicado en los periódicos durante el tiempo que Fiodor Dostoievski estuvo en el extranjero, el marido fue declarado culpable, pero digno de benevolencia, por lo que la pena fue inferior a ocho meses en prisión. Dostoievski relata el suceso: Desde hace años el campesino maltrata a la mujer, la insulta. El marido es alto, recio, fuerte, de carácter cruel, le divierte colgar las gallinas por las patas y pegar a su mujer y matarla de hambre; no sabe por qué la maltrata, seguramente por el mismo motivo que cuelga a las gallinas. Al final también cuelga a la mujer, que Dostoievski imagina pequeña y flaca, mansa y sufrida, ya que tardó en atentar contra su vida. "Se ahorcó en Mayo, una mañana clara de primavera. La víspera la habian visto muy decaída, como lela. Antes de suicidarse fue a quejarse a la Justicia; pero la despacharon, diciéndole: “iLlevense mejor!". Al ahorcarse la cuitada y lanzar un estertor, la niña, desde su rincón, gritóle: "Mamá ¿por qué te cuelgas?". Luego acercóse tímida, miró a la suicida, y varias veces acercóse a mirarla" (T.III, Artículos en el ciudadano III, p. 713). Al marido le trata 
el jurado con benevolencia porque el abogado considera que esto es consecuencia de la falta de ilustración, de la estupidez, del medio. Dostoievski critica este veredicto ya que campesinos hay a millones y no maltratan todos a sus mujeres y el hombre culto también se ahorca. Termina el capitulo con un "Basta de hacer piruetas, señores abogados, con el famoso medio" (p. 714).

2. En el apartado del capítulo I de Octubre del año 1876 de Diario de un escritor comenta el caso de un suicidio, publicado por todos los periódicos: una pobre muchacha, costurera, que se tiró por la ventana, desde un cuarto piso, "porque no hallaba trabajo para mantenerse". Se arrojó "llevando en la mano una imagen sagrada". Dice Dostoievski: "Ese es ya un suicidio manso, resignado. Ahí, por lo visto, no hubo protesta ni recriminación; sencillamente, que se le hizo imposible la vida. "Dios no lo quiere.." y se fue al otro mundo después de rezar sus oraciones... Esa alma mansa, que se suprime de ese modo, nos inquieta involuntariamente". Este suceso inspirará el relato La Mansa escrito en el número correspondiente a Noviembre de ese año (p. 1088).

3. La mansa: Relato compuesto en forma de monólogo interno, inserto en Diario de un escritor en el mes de Noviembre del año 1876 (T.III, pp. 1102-1131). Muestra las cavilaciones de un marido que se pasea en todas direcciones en la habitación donde yace el cadáver de su esposa muerta, quien se suicidó arrojándose por una ventana, mientras aferraba un icono en la mano. El cuento se originó, como ya hemos dicho, en el relato periodístico de un suicidio semejante.

El marido es un prestamista de más de cuarenta años que conoce a la futura suicida, de dieciséis, cuando ésta va a la tienda a empeñar sus pobres pertenencias, entre ellas el icono con el que más tarde se arrojará por la ventana. La mujer es huérfana, sin recursos, y vive con sus tías; él le pide su mano y ella acepta. Al principio ella intentó amarle, pero él se mostraba serio y silencioso, ya que quería "parecerle un enigma". Ella oía cotilleos en la calle referentes a él, como que era tacaño y cobarde (fue expulsado del ejercito por negarse a aceptar un desafio). Pero él no justificaba nada: "yo soy orgulloso. Yo quería que ella misma comprendiese sin que yo le ayudase, pero no haciendo caso a las habladurias de la gente chismosa, sino que adivinase a este hombre y lo comprendiese. Al traerla yo a mi casa, le exigí la plena 
estimación de mi persona. Quería que ella me idolatrase por mi pasión y era digno de ello" (p. 1111). El quería mostrarse ante ella duro y orgulloso, que no necesitaba consuelo de nadie. Ella se rebeló ante la actitud de él y para ello queda con un oficial, aunque no acepta mantener relaciones con él. El marido oye todo detrás de una puerta: "sólo por odio a mí, por odio a aquél que creía poder haberla engañado, había podido lanzarse a aquella cosa extraña, a aquel rendez-vous" (p. 1116). Esa noche la mujer le apunta en la sien con su pistola cuando cree que está durmiendo. Piensa el marido: "Dicen que quien llega a una cumbre siéntese involuntariamente atraído por el abismo; yo creo que muchos suicidios y crímenes se cometieron únicamente por tener ya en mano el revólver. Viene a ser también éste un abismo, una pendiente de cuarenta y cinco grados, y nos vemos impelidos a bajar esa sima, y hay algo que nos obliga con fuerza irresistible a apretar el gatillo" (p. 1118). Ella no dispara, él piensa que en ese momento ambos han llevado a cabo una lucha terrible en la que él ha ganado. Durante el invierno siguiente el silencio se hace mayor aún entre ellos. Él se siente feliz con su victoria, y aunque la humillación de ella a veces le inspiraba compasión, también le resultaba grata por la desigualdad que mostraba entre ambos; al fin, al oírla cantar un día, había olvidado que él estaba en la casa, él decide mostrarle su amor, besarle los pies y confesarle su pasado; ella, tras asustarse mucho, confiesa que es una criminal, pero que intentará ser una buena esposa y quererle. En los cinco minutos que él sale ella reza al icono y se arroja con él por la ventana. El marido se pregunta: “¿por qué se ha matado ella? Siempre quedará por resolver esa cuestión. Mi amor le asustó; ella se preguntó concienzudamente: “¿Debo o no debo aceptarlo?, y no pudo sufrir esta pregunta y optó por la muerte... había prometido demasiado, se asustó; temió no poder cumplirlo... No quería engañarme con un amor a medias o con una cuarta parte de amor, haciéndomelo pasar por amor verdadero" (pp. 1128-9) "Yo la atormenté hasta causarle la muerte; esto es todo" (p. 1130).

\section{Discusión}

En todos estos casos el suicidio podría ser considerado una forma de escape ante una situación considerada por el sujeto como insostenible: esta situación puede derivar de un estado bien de miseria, bien de humillación o por una mezcla de ambos. Estos suicidios han sido descritos por autores como Baechler, Jung y 
Stone. La situación insoportable a la que es incapaz de enfrentarse el suicida será diferente en cada uno de los personajes analizados.

En el primer caso, el "tío Filipp" de Crimen y Castigo, este suicidio sirve para indicar una vez más las consecuencias de sufrimiento y desolación que conllevan las actuaciones de uno de los personajes principales de la novela, Svridigáilov, el cual a su vez terminará suicidándose. El tío Filipp es siervo de Svridigáilov y su esclavo, ya que se suicida antes de la abolición de la servidumbre en 1861. Svridigáilov le humilla y se burla de él. No obstante, según comenta Dunia, parece ser menos importante las vejaciones fisicas que sufre que la injuria narcisística que las burlas de Svridigáilov le producen. Porque el tío Filipp es hipocondríaco (en el sentido popular del término, o sea, melancólico), "una especie de filósofo que lee mucho". Con esto, Dostoievski parece querer indicarnos que el tío Filipp se ha empapado de la lectura en boga en esos años en Rusia, la literatura romántica francesa que difundía principalmente ideas humanitarias y socialistas. El conocimiento de estas ideas, que ensalzan los derechos y la igualdad del hombre, y la disonancia que estas ideas tienen con la situación de esclavitud y humillación de Filipp, parecen haber sido el acicate para cometer el suicidio. Pero Dostoievski quiere dejar claro que el responsable de la situación insostenible que lleva a Filipp al suicidio es Svridigáilov, el amo, motivo por el cual el fantasma de Filipp se le aparece para vengarse.

En Diario de un escritor Dostoievski nos relata el suicido, entresacado de las noticias del periódico, de una mujer campesina maltratada por su marido. Es interesante destacar que, aunque Dostoievski denuncia este hecho en 1873 , en esa época el maltrato conyugal era defendido y aprobado de forma generalizada. En Estados Unidos, el derecho del marido a golpear a su esposa constaba en la ley escrita hasta 1874 (Sadock, 1995). El suicidio es la única forma de escape que encuentra la víctima a la terrible vida que lleva, una vez que, denunciado el hecho a la policía, ésta no pone ningún remedio y hasta ironiza sobre la situación.

Otra situación similar es la de la costurera que se arroja por la ventana con un icono en las manos. En este caso de lo que escapa es de la penuria material en que está. Dostoievski lo dice claramente, se le hizo imposible la vida. "Dios no lo quiere.." y lo denomina suicidio manso, resignado.

El hecho anterior da pie al relato La mansa, publicado en Noviembre del mismo año y que Frank (T. III, p. 373) relaciona con las reflexiones de Dostoievski. ante el féretro de María, su primera 
mujer. En este caso, Dostoievski realiza una compleja narración de los motivos que inducen a una joven huérfana y pobre a suicidarse. Casada con un hombre mucho mayor que ella, un prestamista, la arrogancia y altanería del marido van propiciando la caída de la joven. Este hombre, al igual que el "hombre del subterráneo", considera que los hombres le han echado con su despectivo silencio, le han causado una afrenta y le han separado de ellos. Como el protagonista de las Memorias del subsuelo, él intenta afirmar su existencia como ego que desea, ante todo, que alguien acepte su derecho a ser reconocido en una forma compatible con esa imagen de sí mismo absurdamente inflada "Al traerla yo a mi casa, le exigí la plena estimación de mi persona. Quería que ella me idolatrase por mi pasión y era digno de ello" ( $\mathrm{p}$. 1111). En el marido su incapacidad de amar se convierte en sadismo ante alguien más vulnerable aún que él. La reacción de la mujer es en un principio de rebelión y rabia: intenta vengarse siéndole infiel, pero su condición noble le impide llevarlo a cabo. Situación parecida se vive esa misma noche, cuando la mujer apunta con el revolver la sien del marido que cree dormido, pero es incapaz de disparar. El resultado es la sensación de triunfo del marido, la desolación de ella que le lleva a enfermar y el incremento del silencio entre ambos. Pero cuando el marido le abre su alma y le expresa su amor, ella no puede soportarlo: se siente culpable del odio almacenado durante tiempo contra su marido, de sus deseos de asesinarle, del desprecio que siente hacia él y de su incapacidad para corresponderle. Y la mansita, tras rezar sus oraciones, se suicida. El marido se pregunta ante el cadáver cuales fueron las causas de este suicidio: si enajenación mental transitoria, si su incapacidad para amarle, si los tormentos que él le habria infringido o el azar que hizo que él se retrasase cinco minutos.

Aunque en este suicidio los sentimientos de culpa parecen haber sido el factor precipitante, creemos que en su génesis juega el papel principal la humillación reiterada causada por su marido, quién solamente es capaz de relacionarse desde la tiranía y la dominación. En este sentido, Dostoievski hace hincapié, ya con el título del relato, en la mansedumbre de la suicida, y destaca su incapacidad para la agresión y la venganza, aún en plena rebelión.

Tanto en el caso de La mansa como en el caso del tío Philipp en Crimen y castigo, Dostoievski hace referencia al deseo de matar a la persona causante de la humillación, anticipándose a las teorías psicoanalíticas de Freud y Menninger en las que el suicidio estaría relacionado con la agresión introyectada. En estas teorías se considera que en la base de la génesis del suicidio está el deseo de matar a otro, lo que provoca un sentimiento de culpabilidad que 
lleva a dirigir hacia sí mismo la agresividad, matándose a sí mismo. Esta visión del suicidio como un homicidio frustrado o agresividad interiorizada ya había sido expuesta por Stekel en 1910 en el simposio sobre el suicidio realizado por la Sociedad Psicoanalítica de Viena. En el caso de La mansa, el homicidio frustrado es relatado minuciosamente, cuando la protagonista apunta con una pistola en la noche a la sien de su verdugo. El tío Philipp, al contrario, se intentará vengar como fantasma, una vez muerto. No obstante, Svridigáilov, parece indicarnos Dostoievski, es más poderoso que los fantasmas de los siervos, humillando de nuevo a éste y no permitiendo su reaparición. En ambos casos, y seguramente también en el caso de la mujer del campesino maltratada aunque el autor no lo explícita, se confirma la teoría que expondría Menninger en 1938: en los suicidios aparecen siempre elementos de por lo menos dos de los siguientes orígenes, y posiblemente tres: los impulsos derivados de la agresividad primaria que se cristaliza como un deseo de matar (al objeto que ha sido introyectado), los impulsos derivados de una modificación de esta primitiva agresividad al actuar la conciencia (provocando sentimientos de culpabilidad) que se cristaliza como deseo de ser matado y el deseo de morir, que determinará la consumación del suicidio, debiendo sumarse a la intención consciente de morir el deseo inconsciente de morir.

Por tanto, en aquellos suicidios que aparecen en las obras de Dostoievski, en que la motivación principal parece ser la huida de una situación insostenible, y especialmente si esta situación deriva de la tiranía y humillación causada por otro, parece confirmarse las primeras teorias psicoanalíticas que consisten en considerar el suicidio como un homicidio frustrado. 


\section{Suicidio en trastornos psicóticos}

\section{E1 adolescente}

1. Olia: Natural de Moscú, acude con su madre viuda a Petesburgo en busca del dinero que un comerciante les debe. Es una joven agraciada, de veinte años, flaca y pelirroja, de aspecto enfermizo. Su madre expone tras su muerte su carácter y su historia: "era muy orgullosa, se indignaba. Y así fue siempre, mientras vivió, incluso de pequeña: jamás se quejó, jamás lloró..." El comerciante se niega a satisfacer la deuda y le ofrece dinero a Olia a cambio de "sus favores", lo que ésta rechaza furiosa. Cada vez más necesitadas madre e hija, ponen un anuncio en los periódicos para dar clases de Ciencias y Aritmética. Una señora le ofrece trabajo "para su sobrinita" y cuando llegan a la dirección señalada resulta ser una casa de citas. La noche siguiente Olia delira y tiene fiebre. Cuatro dias más tarde aparece Versilov y les ofrece su apoyo y su dinero. Aceptan el dinero, comentando Olia que esto prueba la delicadeza de ellas al confiar en él. Al día siguiente Olia asegura a su madre que Versílov es un villano que ha querido ofenderla. Su madre se percata de que Olia ha perdido el juicio "Desde que en aquella infame casa la insultaron, se le trastornaron el corazón y el juicio". Olia devuelve el dinero a Versílov y esa misma noche se ahorca aprovechando que su madre duerme (T.II, P.I, C.IX, pp. 164853). Deja a su madre la siguiente carta de despedida escrita a lápiz en renglones desiguales: "Mámenka, rica: Perdóneme usted por abreviar mi début en la vida. La que tantos disgustos le ha dado. Olia". Esta carta es considerada por Arkadii como humorística mientras que para Versílov aunque el lenguaje no se ajuste al tono de la situación y aunque pueda pertenecer al lenguaje de los compañeros del Gimnasio o haberlo tomado de algún folletín, es empleado con toda sencillez y seriedad (T.II, P.I, C.X, p. 1655).

\section{Los hermanos Karamázov}

1. Intento de suicidio de Sofía Ivánova, segunda mujer de Fiodor y madre de Iván y Alíoscha. Huérfana desde niña, su madrina y protectora era una generala. "Ignoro pormenores -dice el 
narrador de la novela - habiendo oído únicamente que a la ahijada, sencilla, dócil e inconsciente, la había descolgado una vez del lado con que quiso ahorcarse, atándolo a un clavo en el desván, lo que indica hasta que punto se le hacía penoso aguantar las extravagancias y eternos reproches de aquella vieja, que, desde luego, no era mala, pero se había vuelto insufriblemente voluntariosa por efecto de la ociosidad" (T.III, P.I, L.I, C.III, p. 28). Era muy bella e inocente, motivo por el que se casa el voluptuoso Fiodor con ella. Con motivo de las orgias que realiza su marido en su presencia, Sofia contrae una enfermedad nerviosa, que consiste en "unos ataques histéricos terribles y pérdida de la razón a temporadas". A estas enfermas, dice el narrador, se les llama endemoniadas en las aldeas. Murió cuando Aleksieyi tenía cuatro años.

\section{Discusión}

El caso de Olia, personaje de El adolescente, es característico de un trastorno paranoide: Huérfana de padre desde hace tiempo, con estudios, acude con su madre a San Petesburgo para cobrar una deuda pendiente. Alli, es humillada y engañada una y otra vez, mientras que la situación económica se va agravando progresivamente. En ese momento aparece su benefactor, Versílov, que desinteresadamente le ofrece su dinero. Pero Olía es incapaz de confiar en él y ante esta situación enloquece y se suicida. Así, Dostoievski relata en pocas líneas un caso clinico de un trastorno paranoide agudo. Nos cuenta su personalidad previa: orgullosa, desconfiada y suspicaz, vigilante y combativa, restrictiva en la expresión de emociones cálidas, con una gran necesidad de ser autosuficiente y de parecer invulnerable; acude con su madre a una ciudad desconocida, en dónde realmente es engañada. En una situación de carencia económica y afectiva importante, aparece un hombre "que podría ser su padre" (p. 1650) que representa el cese de estas carencias. Pero su personalidad previa y las vivencias terribles que ha sufrido le impiden confiar en él. Interpreta su acción como una ofensa $y$, ante esta situación que le resulta insoportable, se suicida tras dejar una breve nota de despedida a su madre. Clínicamente este personaje podría corresponder a un trastorno paranoide de la personalidad que sufre un trastorno psicótico breve con ideación paranoide ante un estrés grave. Este trastorno conlleva, según el DSM-IV (1995) un riesgo especialmente alto de suicidio. 
Entre los antecedentes personales de Sofia Ivánova, personaje de Los hermanos Karamázov, está un intento de suicidio frustrado. E1 desencadenante de este intento suicida es, según nos relata Dostoievski, los reproches y exigencias de su madrastra. Él nos describe a Sofia, la segunda mujer de Fiodor y madre de Iván y Alíoscha, como una joven muy bella de aspecto inocente, muy dócil, sencilla e inconsciente. Su matrimonio con Fiodor es su forma de escapar de las extravagancias de su protectora. Sofia tiene una personalidad muy débil, que ante las humillaciones a las que le somete su marido, enloquece. Dostoievski llama a su trastorno "ataques histéricos", aunque dada la personalidad previa de Sofía y sus síntomas, así como la denominación de "endemoniada" por la gente de la aldea, parece corresponderse más bien su patología con una posible esquizofrenia. Además, el autor nos deja bien claro que la madrastra, aunque de fuerte carácter y dominante, es una buena persona, por lo que el intento de suicidio de Sofia podría ser una consecuencia más bien de su frágil personalidad que de el maltrato de aquella. 


\section{El suicidio en el juego patológico}

\section{El eterno marido}

1. La patrona de la posada donde se alojan Pável Pávlovich y su hija Liza cuenta a Velcháninov el siguiente suceso: un comisario se ahorcó en su casa. La niña, Liza, vio el cadáver suspendido y su padre, Pável Pávlovich, la amenazaba con ahorcarse él también: "Hace poco, aquí, en el patio, hubo unas desgracia; un comisario, o algo así, según decía la gente, tomó una habitación en la fonda para pasar la noche, y a la mañana fue y se ahorcó. Según decian, se había jugado unos dineros" (T.II, C.VIII, p. 1004).

\section{$\underline{\text { Los Demonios }}$}

1. En la parte II de Los demonios se relata la expedición que hacen los jóvenes nihilistas para ver a un beato y profeta de la región. Durante el camino se acercan a ver a un forastero que acaba de suicidarse en una fonda. Una de las damas justifica esta acción ya que "se aburre una tanto, que no hay que andar con remilgos con las distracciones". El suicida "era joven, un chico de unos diecinueve años nada más, bastante guapo, con rubio y abundante pelo, con un rostro en óvalo regular y una frente despejada, bellisima... Encima de la mesa había una esquela, de su puño y letra, pidiendo que no se culpara a nadie de su muerte y explicando que se mataba porque había tirado cuatrocientos rublos". Según cuenta un vecino suyo, estos rublos eran los ahorros de su familia para comprar el ajuar de su hermana mayor. El chico, hasta entonces, era juicioso y prometía llegar a ser algo. Llegó a la ciudad tres días antes y buscó un sitio donde jugar y la última noche pidió una chuleta, una botella de Château d'Iquem, uvas, papel, tinta y la cuerda. Los comentarios de los jóvenes son los siguientes: "Uno observó que aquella habia sido la mejor salida y que nada más acertado había podido ocurrírsele al joven; otro concluyó que aunque hubiese sido sólo por un rato, se había dado la gran vida. Un tercero soltó de pronto "¿Por qué entre nosotros es tan frecuente perder la cabeza y pegarse un tiro, como si se nos 
fuese a todos el suelo de debajo de los pies?" Al razonador lo miraron con malos ojos..." (T.II, P.II, C.V, p. 1286-87)

\section{Discusión}

Ambos suicidios son utilizados por Dostoievski para estudiar las reacciones de personajes de la novela ante ellos. Por tanto, en los dos casos, Dostoievski no entra en las motivaciones psicológicas de estos personajes, totalmente ajenos a la trama de la novela, siendo la causa la pérdida de dinero en el juego. Es llamativo que Dostoievski, que padeció una ludopatía que le originó graves problemas y que ha descrito la pasión del juego en varias novelas suyas, solo describa este final trágico de personajes jugadores de forma tan superficial.

Por el contrario, en los personajes ludópatas bien caracterizados de este autor, Aleksieyi Ivánovich en El jugador y Arkadii en $\mathrm{El}$ adolescente, no se hace ninguna referencia a la posibilidad del suicidio. Mientras que en el caso de $E l$ adolescente el personaje muestra principalmente los sentimientos del ludópata en la primera fase evolutiva del juego o fase de ganancia, Aleksieyi en $E l$ jugador sufre tanto esta fase como la siguiente o fase de pérdida. Esta termina con el propósito del personaje de regenerarse y resucitar, pero no ese mismo día, sino al día siguiente (" $\mathrm{i}$ Mañana, mañana se termina todo!") (T.II, C.XVII, p. 499) y con sus pensamientos recurrentes sobre el juego, lo que indica que el personaje seguramente continuará en la loca y pasional carrera de la ludopatía.

Los personajes suicidas referidos en este apartado, superfluos en la trama de la novela, personificarian la tercera fase o fase de desesperación, en la que los intentos de suicidio y los suicidios consumados son frecuentes. Esta tercera fase suele finalizar, bien con la petición de ayuda para superar el problema, bien con el encarcelamiento por los delitos cometidos como medio para conseguir dinero para continuar jugando o por las deudas adquiridas o bien con el suicidio.

La conducta suicida es un final frecuente en los jugadores patológicos. Las tasas más elevadas de suicidio en Estados Unidos se encuentran en Las Vegas (Nevada) ciudad mundialmente conocida por sus casinos. Según el DSM-IV (1995), el 20\% de las personas en tratamiento por juego patológico han realizado en 
alguna ocasión un intento de suicidio. McCormick y cols. (1984), en un trabajo realizado sobre la incidencia de trastornos afectivos en jugadores patológicos en tratamiento, refieren que el $12 \%$ de los ludópatas que entraron en el estudio habian realizado un intento autolítico potencialmente letal, el $12 \%$ había hecho preparativos para un intento serio, el $6 \%$ refería un plan concreto, el 18\% había pensado en un método específico de suicidio, el $22 \%$ había tenido pensamientos recurrentes de suicidio sin incluir un método en particular y el $10 \%$ tenía deseos de muerte sin concretar éstos en ideación suicida.

Esta relación ludopatía-suicidio es bien conocida por Dostoievski $\mathrm{y}$ es un recurso que utilizará, por tanto, para introducir en la novela suicidios de los que no desea explayarse en sus motivaciones, sino con la intención de elaborar las repercusiones y reacciones de los personajes principales ante el hecho del suicidio. Con este mismo fin también aparecen en las novelas suicidios de personas alcohólicas.

Dostoievski conocía muy bien el problema del juego patológico, que sufrió en sus propias carnes, y que le llevó a situaciones de extrema penuria durante largos periodos de su vida. Sufrió este problema de forma acuciante desde 1862 a 1871, fecha en que jugó por última vez. Tanto el autor como su segunda mujer, Ana, separaban el vicio del juego de la personalidad moral de escritor y lo consideraban ajeno a su propio carácter. Así, expresa Ana en sus memorias su concepción del juego como enfermedad, concepción que hoy en día es ampliamente aceptada. Dice: "debe considerarse que la pasión del juego es una enfermedad para la cual no hay cura" (en Frank, 1997, p. 239).

Para Dostoievski, el juego estuvo ligado siempre a sus incursiones a Europa. En su primer viaje en 1862 ya para en el casino de Wiesbaden donde gana cierta cantidad de dinero. En su segundo viaje se inicia realmente su ludopatía, que aparece cada vez que viaja a Europa. Aunque la causa de que sólo jugara fuera de Rusia podría ser simplemente que Europa le brindaba posibilidades inexistentes en su país, algunos autores como Leatherbarrow (1999) (p. 29) consideran que esa atracción por los casinos europeos, que él veía como una forma de posesión, tuviese algo que ver con el significado metafórico que adscribe al juego en su novela El jugador, en la que el acto de jugar llega a ser una afirmación consciente o inconsciente de la falta de sentido del universo, enmarcando este acto en su visión del colapso cultural europeo. 
Aunque Freud en su artículo Dostoyevski y el parricidio (1927) considera el juego como un sustituto de la masturbación, esta interpretación está actualmente desechada hasta en el ámbito psicoanalítico.

Para Otto Fenichel (en Frank, 1993) el juego es, en esencia, una provocación al destino, que se ve obligado a tomar su decisión a favor o en contra de la persona. El jugador obliga al destino a tomar una decisión acerca de él, esperando su perdón; pero hasta perder le parece preferible a continuar sufriendo la intolerable presión del superyo. Según esta hipótesis, el juego en Dostoievski podría estar relacionado con sentimientos de culpabilidad (que seguramente sentiría cuando salia a Europa, ya que abandonaba a los suyos y especialmente en su segundo viaje en el que lo hacia para reunirse con su amante). Obviamente, Dostoievski esperaba ganar y asi expiar su culpa compensando a quienes había abandonado y traicionado (Miguel y Maria en los primeros viajes y Ana en el último). Sin embargo, lo que habitualmente sucedió fue padecer una mayor humillación al perder. Esta "provocación al destino" aparece explicitamente expuesto en algunos pasajes de $E l$ jugador. "En aquel momento debería haberme retirado; pero hubo de acometerme cierta sensación extraña, algo así como un prurito de retar a la suerte, como un antojo de gastarle una broma, de sacarle la lengua" (T. II, C. IV, p. 417)

En boca de este mismo personaje, Aleksey, Dostoievski pone la siguiente afirmación al recordar la pasión en el momento del juego: "Recuerdo bien que, efectivamente, sin que interviniera para nada el amor propio, me acometió de pronto una espantosa ansía de peligro. Es posible que, al pasar por tantas sensaciones, el espiritu, lejos de rendirse, se excite más aún y exija sensaciones cada vez más fuertes, hasta su definitiva inercia” (T. II, C. XIV, p. 479). Por tanto, Dostoievski expresa su conocimiento de que el juego patológico implica una carrera desenfrenada y sin limites cuyo fin no es otro que la nada.

No obstante, Dostoievski consiguió liberarse de este trastorno antes de llegar a la última y desesperada fase en que la búsqueda de esa "definitiva inercia" mediante el suicidio es tan frecuente: En Wiesbaden, durante la primavera de 1871, prueba suerte en el juego por última vez. Nunca más volverá a jugar a partir de esa fecha. Algunos autores han sugerido que la causa del abandono del juego fue porque en los cuatro últimos viajes que hizo a Alemania, para cuidar su salud, los casinos estaban cerrados. Pero esta hipótesis es poco satisfactoria, ya que si Dostoievski no hubiera vencido su adicción, le habría sido fácil dirigirse a donde los casinos seguian abiertos; antes, la distancia nunca le habia 
impedido ceder a su tentación. La última vez que juega, como en tantas otras, tras perder todo su dinero, Dostoievski asegura a Ana en sus cartas que nunca más volverá a jugar. Pero además refiere: "Dentro de mí ha ocurrido algo grande, una vil fantasía que me ha atormentado desde hace diez años se ha desvanecido. Durante diez años (o mejor dicho desde la muerte de mi hermano, cuando de pronto me vi abrumado de deudas) no dejé de soñar en obtener ganancias" Continúa Dostoievski refiriendo que había sufrido la noche anterior pesadillas terribles con su padre. Y que estas pesadillas habían sido similares a las padecidas en otras dos ocasiones y que le habían anunciado desastres inminentes. En la misma carta Dostoievski narra que ese mismo día había ido a buscar un sacerdote ruso y confundió una iglesia judía con una rusa: "Fue como si me echaran un balde de agua fría". Según Frank (1997), posiblemente Dostoievski considerara que su error le indicaba, mediante una señal desde lo alto, que su manía del juego estaba llevándole a una degradante proximidad al pueblo que Dostoievski despreciaba por estar tradicionalmente relacionado con el sucio afán de lucro. Y esta premonición, junto con las pesadillas sufridas el día anterior, habrian influido decisivamente en que Dostoievski decidiera de forma determinante acabar con su ludopatía y se liberara con éxito de ella. 


\section{El suicidio en el alcoholismo}

\section{Crimen y Castigo}

1. Afrosiniuschka intenta suicidarse tirándose al río en presencia de Raskólnikov. Es salvada por un guardia que se lanza al agua. Es "una mujer alta, con pañuelo a la cabeza, el rostro amarillento, alargado, demacrada, y los ojos ribeteados, hundidos" (T. II, P. II, C. V, p. 136). Según refiere una vecina suya que presencia el acto, bebe mucho y ya ha intentado en otra ocasión colgarse, habiéndole descolgado de la cuerda "iBorracha perdida estaba, padrecitos; borracha perdida!". Raskólnikov duda entre imitarla, "también eso puede ser una salida", o acudir a la comisaria a confesar su crimen.

2. Marmeládov es el alcohólico padre de Sonia que ha llevado a su familia a la pobreza. Muere atropellado por un coche de caballos y en varias ocasiones se sugiere que podría haber sido intencionado, como por ejemplo, con las palabras del cochero: "él vino derechito a meterse entre las patas de los caballos y cayó al suelo. No parece sino que lo hizo adrede o que estaba muy borracho" (T.II, P.II, C.VI, p. 140), y las recriminaciones al moribundo de su mujer, Katerina Ivanova, en el sentido de que por fin lo había logrado.

Se nos presenta a Marmeládov como un hombre con facha de funcionario jubilado, sucio, de unos cincuenta años, "de mediana estatura y de constitución recia, algunos pelos canosos en el cráneo mondado; una cara con pintas amarillas y hasta verdosas, por efecto de la bebida, y los pómulos salientes, por debajo de los cuales fulgian unos ojillos pequeñines como rendijas y que lanzaban miradas llenas de vivacidad y rojizas" (T.II, P.I, C.II, p. 24).

A Raskólnikov le llama la atención desde el primer momento en que le ve en una taberna: "en sus miradas resplandecia también cierta como solemnidad -no le faltaban, en efecto, idea y alma -, y al mismo tiempo, sin embargo, dejaban traslucir algo de locura". Marmeládov inicia una conversación con Raskólnikov, que causa hilaridad a las personas presentes, ya que conocen su inclinación a los discursos oratorios. Dice el narrador: "Ese hábito llega a 
convertirse para algunos borrachos en una necesidad, y probablemente para aquellos a los cuales los tratan mal en casa y los echan de allí. Por lo que, en compañia de otros bebedores, se esfuerzan siempre por justificarse y, a ser posible, granjearse también algún respeto" (p. 25).

En esta conversación Marmeládov cuenta su vida y expresa su dolor por su degradación ("Cuando el señor Lebeziátnikov, hace un mes, le pegó a mi señora con su propia mano, y yo estaba acostado con la borrachera. ¿acaso no sufría?"), su miseria económica, los gastos ocasionados por la bebida incluida la venta de las pertenencias y ropas de su mujer, la enfermedad de su mujer. Refiere que tras casarse en segundas nupcias con Katerina Ivánova estuvo un año sin beber, aunque ni en este periodo de abstinencia pudo contentar a su mujer. Tras cesarle en su trabajo por cambio de personal, reinició el consumo. Ya en Petesburgo, pierde otro empleo a causa de la bebida y su hija Sonia, ante la pobreza de la familia con sus tres hemanastros pequeños y por sugerencia de su madrastra Katerina empieza a trabajar como prostituta. Es readmitido por compasión en su antiguo empleo, pero cuando gana su primer sueldo (hace cinco días), se lo bebe y deja de ir a trabajar.

\section{$\underline{E 1 \text { adolescente }}$}

1. Nikolai Semíonovich Andréyev, apodado "le grand dadais" (cuya traducción es "el gran papanatas"). De él se dice al final de la novela escuetamente que se pegó un tiro. Es descrito como muy alto y flaco, con una cabeza muy pequeña para su cuerpo, muy mal vestido, desastrado y sucio, "sus ojos miraban con excesiva atención y con cierta innecesaria y superflua energía" (T.II, P.III, C.V, p. 1825). Inseparable de Trischátov, vive del dinero que extorsiona a Lambert, a quien amedrenta ridiculizándole. Trsichátov habla a Arkadii sobre él: "Yo le quiero mucho -empezó con aire de franqueza, cual si siempre hablase de eso conmigo -. No podrá usted creer lo desdichado que es Andréyev. Se comió y se bebió la dote de su hermana, y además, todo lo que tenía se lo comió y se bebió en un año, el año que estuvo sirviendo, y ahora veo yo que padece. Y eso de que no se lave lo hace de puro desesperado. Y tiene unas ideas la mar de raras; de pronto, va y le dice a usted que eso de ruin y de honrado viene a ser lo mismo, sin que exista entre ambas cosas diferencia alguna; 
y que no hay que hacer nada, ni bueno ni malo, y que lo mejor de todo es estarse tumbado, sin quitarse la ropa en un mes, beber, comer y dormir, y nada más... si hace ahora esas fanfarronadas, es porque quiere acabar con Lambert. Ayer mismo lo decía. ¿Querrá usted creer que algunas veces, de noche o cuando está largo rato solo, se echa a llorar? Y mire usted: cuando llora lo hace de un modo particular, como no llora nadie; da rugidos, unos rugidos terribles, así que vea usted: inspira todavía más lástima" y dice un poco después "yo, sinceramente, quiero ser honrado... pero él, mucho lo temo, se ahorcará. Irá y no se lo dirá a nadie. El es así. Ahora todos se ahorcan" (T.II, P.III, C.V, p. 1831-32)

\section{Diario de un escritor}

1. En el capítulo I de Mayo de 1876 de Diario de un escritor, Dostoievski comenta el juicio de una mujer que intentó matar a la mujer legal de su amante. Esta mujer, que es llamada la Kairova, es una mujer marginal, con múltiples antecedentes familiares de alcoholismo, entre ellos el de un hermano que "había perdido la razón por efecto de la bebida, y terminó pegándose un tiro" (T. III. p. 980).

\section{Discusión}

El riesgo de suicido es 60 a 120 veces más alto en personas con problemas de alcoholismo que en la población general. Se calcula que un $25 \%$ de todos los suicidios están relacionados con el alcohol y entre 5-27\% de todas las muertes en alcohólicos son debidas al suicidio. Dostoievski también ha relacionado la patología derivada del consumo perjudicial del alcohol con el riesgo de suicidio. En el caso referido en Diario de un escritor, el suicidio del hermano de la mujer juzgada por intento frustrado de asesinato, la Kairova, Dostoievski no hace más que transcribir los datos referidos por la prensa en el relato del juicio, que "había perdido la razón por efecto de la bebida, y terminó pegándose un tiro". Por tanto, en este caso, la relación del suicidio con el consumo del alcohol y con el trastorno mental (en este caso, no especificado), no parece haber sido realizada por el autor, sino que 
sólo se hace eco de una opinión expresada durante el proceso y que es considerada como algo conocido y sin necesidad de mayor explicación. Y esta circunstancia, la conocida relación del consumo abusivo del alcohol con el suicidio, es utilizada por Dostoievski en Crimen y Castigo como elemento dramático en el caso de Afrosiniuschka, para introducir las reflexiones de Raskólnikov sobre la posibilidad del suicidio. Algo muy similar hace Dostoievski con la ludopatía en otras novelas; podriamos concluir que tanto ésta como el alcoholismo, para el autor, son trastornos cuya relación con el suicidio son ampliamente conocidas por el público y Dostoievski las utiliza cuando desea introducir un suicidio en las novelas sin explayarse en las motivaciones psicológicas que inducen a ello.

Marmeládov, por el contrario, es un personaje de mayor importancia en la novela; padre de Sonia, la heroína de la obra, es para algunos autores (Dilman, 1984) un acicate fundamental en Raskólnikov para la consumación del crimen. Tras recibir la carta de su madre en la que refiere que su hermana Dunia se casará con un hombre adinerado para salvarle de la miseria, Raskólnikov asemeja esta boda a la prostitución de Sonia. De forma implícita se compara con quién considera una persona insignificante y débil, Marmeládov, y esta comparación va a influir decisivamente en la realización del crimen como forma de probarse a sí mismo que no se asemeja a él, sino que pertenece a la clase de "hombres extraordinarios".

Marmeládov es el prototipo de alcohólico cuyo deterioro físico, psicológico, social, laboral y familiar va agravándose paulatinamente hasta llegar al derrumbe total. Dostoievski remarca su aspecto físico, en el que se ven los estigmas de su alcoholismo: "una cara con pintas amarillas y hasta verdosas, por efecto de la bebida" y los pómulos salientes, típica fascies alcohólica con chapetas malares, hipertrofia de las glándulas parotideas y tinte ictérico (en Afrosíniuschka también recalca el tono amarillento de su rostro). Y refiere una historia típica del paciente alcohólico: los problemas de relación con su pareja, el deterioro laboral que le incapacita para continuar cumpliendo en el trabajo tras ganar el primer sueldo, la falta de control sobre la bebida, las dificultades monetarias y el relevo por su hija de la función de sustentación económica, su degradación y sentimientos de inutilidad. El final de Marmeládov también es muy frecuente en los pacientes alcohólicos: un accidente de "tráfico" del que no se sabe con seguridad si realmente ha sido un accidente causado por el grave estado de intoxicación en que se encuentra o un suicidio. 
En el personaje de El adolescente, Nikolai Semíonovich Andréyev, su situación psicopatológica no está bien definida: no aparece tan claramente descrito su problema de alcoholismo, aunque Dostoievski en varias ocasiones comenta que este personaje se come y bebe todo el dinero que consigue ("en ostras y champaña" dice Lambert); no obstante, lo más destacado de este personaje es su aspecto desastrado y sucio, su falta de compostura social y de intereses y su continua utilización del francés. Por esto último y por su peculiar aspecto es apodado "le grand dadais". Y Trischátov, su amigo intimo, da las claves de este personaje. Le comenta a Arkadii su apatía, su desinterés, la clinofilia que presenta, sus sentimientos de culpabilidad, su desesperación y tristeza. Todos estos síntomas podrian encuadrarse en el diagnóstico de trastorno depresivo mayor en un personaje con, al menos, un abuso de alcohol. Como se sabe, la comorbilidad de estos dos trastornos es muy frecuente y resulta especialmente fatídica para la consumación del suicidio. Existen diferentes teorias sobre la coexistencia de depresión y alcoholismo, ya que las tasas mayores de comorbilidad de lo que puede explicarse solo por azar indican una relación etiológica entre ambas entidades. Una de las hipótesis es que la utilización del alcohol por los pacientes depresivos podría ser una forma de aliviar los efectos disfóricos de la depresión. Otra, que el consumo crónico y elevado de alcohol sea el causante de la sintomatología depresiva, ya que produce trastornos del sueño y del apetito, del comportamiento y alteraciones psicomotoras, así como sintomas cognitivos $y$ psicológicos.

Aunque Dostoievski no delinea bien este personaje esperpéntico y menos aún, obviamente, su psicopatología, el relato de su historia por Trischátov parece indicar que la causa inicial de sus problemas estuvieron derivados del despilfarro del personaje, principalmente en bebida. Desde ese momento se inicia su deterioro personal que terminaria convirtiéndole en "le grand dadais", un personaje cómico y ridículo, de vestimenta estrafalaria, manos sucias, afrancesado (con todo lo peyorativo que esto significa para Dostoievski), y en el que los sintomas depresivos como son la falta de proyectos y de autocuidado, la anhedonia, la apatía, la falta de ilusiones, la pérdida de las normas morales, los sentimientos de culpabilidad y la desesperación serán, para Trischátov, signos premonitorios de un suicidio anunciado. Esta actitud vital de Andréyev se puede englobar en lo que Rojas (1978) llama suicidio moral o suicidio social, cuya característica principal es que el paciente pretende una autodestrucción a largo plazo, llevando a cabo una forma de vida degradante y que le excluye de todo posible trato social. El autor considera que algunos alcohólicos pueden ser incluidos en este tipo de suicidio. Como 
vemos, Andréyev podría ser un caso típico de suicidio moral que termina sus dias con un suicidio consumado. 


\section{El suicidio en el narcisismo maligno (personajes "tipo Cleopatra")}

Este tipo de personajes tipo "Cleopatra" fue descrito y denominado asi por Dostoievski en un artículo de Vremia de la primavera de 1861 en el que analiza el poema de Pushkin Noches egipcias. Este poema narra cómo Cleopatra se ofrece a pasar una noche con cualquier miembro de su séquito que esté dispuesto a perder la vida al amanecer, a cambio de disfrutar el supremo privilegio de sus favores. Para Dostoievski este poema es la ilustración de la perversión de la naturaleza humana y encarna el desorden psíquico moral producido por la satisfacción y el hartazgo, por la ausencia de todo ideal espiritual.

El mundo de Cleopatra es, dice Dostoievski en este artículo, uno en "el que se ha perdido toda fe" y puesto que "el futuro no ofrece nada, todo debe venir del presente, la vida debe alimentarse solo de lo que existe". En semejante mundo "todo se refugia en la carne, todo se arroja en el desenfreno carnal y para compensar la falta de impresiones espirituales más elevadas, los nervios y el organismo se alimentan con todo lo que sea capaz de despertar la sensibilidad. Las perversiones más monstruosas, los actos más anormales, poco a poco se vuelven cosas acostumbradas Sólo es posible para liberar a Cleopatra del tedio sentimientos violentos en los que se mezcla la sensualidad con la crueldad y cuyo resultado final es la ironía del desprecio". (Frank, 1993, p. 121). Cleopatra representa la decadencia moral de la Roma del último período. Para Dostoievski, la pérdida de un ideal religioso en Occidente ha convertido a Europa en una sociedad similar a la de la Roma decadente, donde varias formas de desorden moral y de sensualidad pervertida pululan incontroladamente y, en Rusia, la realización de las ideas occidentales que propagan los radicales tendrá el mismo efecto.

Para Dostoievski, Cleopatra y la decadencia romana es un modelo utilizado para desarrollar magistralmente un tipo de personajes en sus novelas, siendo esta psicologia de la decadencia y la perversión uno de sus temas principales.

Dostoievski hace referencia a Cleopatra en Memorias del subsuelo para ilustrar la falsedad de los preceptos racionalistas, que consideran que el hombre es innatamente bueno y que, una vez ilustrado sobre cuáles son sus auténticos intereses, con ayuda de la razón y la ciencia logrará construir una sociedad perfecta: "Cuentan que Cleopatra - y dispensadme este ejemplo, sacado de la historia romana-acostumbraba clavarles sus aguijones de oro 
en el pecho a las esclavas que le servian, y que sus gritos y contorsiones le producían vivo deleite. Me diréis que eso pasaba en tiempos relativamente bárbaros, que los nuestros aún lo son (relativamente también) y que todavía hay quien procede como Cleopatra; que si bien es cierto que el hombre tiene hoy más discernimiento que en los hombres de barbarie, aún está muy lejos de haber aprendido a obrar como mandan la razón y la ciencia...". Para "el hombre del subterráneo", aún en el caso de que todos los actos humanos, gracias a la ciencia, pudieran deducirse hasta matemáticamente, al ser humano puede invadirle el tedio y "el tedio fomenta la imaginación, puesto que por aburrimiento hincaba Cleopatra sus agujones en el pecho de las esclavas; pero eso sería poca cosa. Lo malo es que acaso los hombres considerasen como una dicha volver a la época de esos pensamientos... y es que en todos los tiempos y lugares no hubo en el mundo hombre que no quisiese conducirse según su voluntad y no con arreglo a los dictados de la razón y de su interés" (T. I, C. VII, p. 1466).

Los personajes más esplendorosamente encarnados en este modelo son el principe Valkovskii de Humillados $y$ ofendidos, Svidrigáilov de Crimen y Castigo, Stavroguin de Los demonios y el viejo Karamázov. En este último, Dostoievski, en la descripción inusualmente extensa de su fisonomia, alude explicitamente a este modelo: "él era el primero en burlarse de su cara, aunque, al parecer, estaba satisfecho de ella. Especialmente ufano estaba de su nariz, no muy grande, pero sí muy huida, con un caballete muy pronunciado "romana auténtica", decía; "con eso y una nuez, una verdadera cara de patricio romano de la época de la decadencia". De lo que, por lo visto, se envanecia" (T.III, P.I, L.I, C.IV, p. 36). Mientras que Fiodor Karamázov acabará siendo asesinado, dos de estos personajes, Svridigáilov y Stavroguin, tendrán el mismo final que la propia Cleopatra: el suicidio.

\section{Crimen y castigo}

1. Arkadii Ivanovich Svidrigáilov, uno de los personajes principales de Crimen y castigo, se caracteriza por la aceptación consciente de su desenfrenado egoísmo, que actúa exclusivamente en busca de placeres personales y sensuales, pero en la que sus goces se ven empañados por su asco de sí mismo. Posible asesino de su antigua esposa e implicado en acciones de violación y maltrato, ha llegado a un estado de hastío sólo paliado por la sensualidad; pero ahora también el vicio ha empezado a aburrirlo y, por ello, el paralizante tedio 
del vacío metafísico amenaza su destrucción. Svridigáilov fantasea con irse a América y desea volar en globo, seguramente expresando de forma simbólica sus deseos de evadirse de sí mismo. América será posteriormente la forma cifrada de denominar su propio suicidio. Svridigáilov va a San Petesburgo en busca de Dunia, que se convierte en la búsqueda de la salvación personal, aunque él sostenga que solo le impulsa el placer sensual. El haber sido rechazado por Dunia rompe el último hilo que unía a Svridigáilov a la vida, y la escena va pronto seguida por su suicidio. Sin embargo, antes de quitarse la vida, Svridigáilov, como había procedido con anterioridad, continúa tomando disposiciones económicas para asegurar el futuro de los hijos de Marmeládov. Su total amoralismo le hace igualmente capaz del bien y del mal, y encuentra un "orgullo secreto" en desconcertar a quienes tenían otra opinión de él.

Las últimas horas de su vida son descritas de forma sobria. Va a un sórdido hotel, donde recuerda la imagen de Dunia "Después de todo quien sabe si habria hecho de mí otro hombre..."(T. II, P. VI, C. VI, p. 369). Posteriormente "los ensueños sucedianse unos a otros y deslizábanse por su cerebro fragmentos de ideas, sin principio ni fin $y$ sin coherencia... no hacía más que ver flores..." Entre estas flores yace una joven de no más de catorce años que conoció Svridigáilov y que se había suicidado ahogándose. La niña fue "ofendida por una afrenta, que había henchido de espanto y de asombro su tierna, infantil conciencia, colmado de inmerecido sonrojo su alma de angelical pureza (p. 370)". Svridigáilov se despierta y observa la amenaza de inundación de la ciudad, cuyas aguas "sacarán a las ratas de los sótanos". Vuelve a dormirse soñando que intenta salir de la habitación pero divisa "entre un viejo armario y la puerta" a una niña de unos cinco años, mojada y llorosa, que refiere haberse escondido alli por miedo de que su madre le pegase por romper un jarrón. Lleva a la niña a la habitación, la acuesta y la tapa, pero al mirarla le parece que "algo insolente, retador, brilla en aquel rostro que nada tiene de infantil: es el vicio, es el rostro de una camelia, descarado rostro de una venal camelia francesa... ¡Cómo! ¡A los cinco años! -balbuceó Svridigáilov, espantado -...pero en aquel mismo instante despertóse" (p. 372). Escribe una nota "declarando que moría en el uso cabal de sus facultades y rogando que no se culpase a nadie de su muerte" (T.II, P.VI, C. VIII, p. 386). Sale a la calle, donde se pega un tiro ante los ojos de un judío borracho vestido de soldado con un casco de 
bronce al que llama Aquíles (p. 373), y al que comenta que se va a América.

\section{$\underline{\text { Los demonios }}$}

1. Nikolai Vsevolódovich Stavroguin: Este personaje fue en su infancia el discípulo de Stepán Trofimovich (idealista liberal de los cuarenta), a quien habían confiado su educación. Stepán contagió toda su incertidumbre e inestabilidad moral a su discípulo sin ofrecerle, en cambio, nada positivo que contrarrestara estos efectos perturbadores; el resultado de ello fue dejar un doloroso vacío en el alma de Stavroguin: "Más de una vez (Stepan) hubo de despertar a su amigo (Stavroguin), a la sazón de diez u once años, por la noche, para desahogar en llanto ante él sus sentimientos ofendidos o revelarle algún secreto doméstico, sin pararse a pensar que esto estaba rematadamente mal. Abrazábanse el uno al otro y lloraban... Stepám Trofimovich sabía hacer vibrar el corazón de su amigo hasta el diapasón más profundo y provocar en él la primera aún vaga sensación de aquella eterna, santa tristeza, que cuando un alma selecta la ha experimentado y conocido, no la cambia ya luego nunca por un vulgar contento (hay incluso aficionados que estiman en más esta pena que la más plena alegría, suponiendo que ésta fuera posible)" (T. II, P. I, C. II, p. 1098). Este pasaje define a Stavroguin como una personalidad emocionalmente consagrada a la búsqueda de alguna índole de absoluto y, a la vez, sugiere la perversión que brota de su carencia de toda meta positiva. Su busca es una experimentación espiritual totalmente centrada en sí misma, totalmente encerrada en el ego y por tanto, incapaz de entregarse a ese absoluto que, suponiase, estaba buscando.

Dostoievski expresa en la primera presentación de Stavroguin el elemento del que él no es consciente, la gratuidad de su escandalosa conducta imposible de explicar por motivos ordinarios o comunes. En la violencia de Stavroguin hay algo misterioso, sobre todo en su afán de autodegradarse, que transciende toda norma, que le induce a tirar de la nariz de Gaganov, a morder la oreja del gobernador, a casarse con la hermana idiota de Lebiadkin y a violar a una niña: Todos estos incidentes ejemplifican la negativa de Stavroguin a contener o frenar de algún modo sus impulsos, su rechazo de restricción interna o externa a la 
autonomia absoluta de su voluntad. Stavroguin podría realizar hechos temerarios "sin pizca de placer y únicamente por una necesidad imprescindible y de un modo indolente, sin ardor, casi aburrido. En cuanto a la cólera... su cólera era fría, serena y, si es lícito expresarse asi..., razonable, y por consiguiente, la más repulsiva y feroz que puede haber" (T. II, P. I, C. V, p. 1207). Todas las fuentes del sentimiento humano se han secado en Stavroguin; su demonismo es el de un racionalismo total que, habiendo vaciado la vida de todo significado y valor, ya no puede dar ninguna respuesta directa e instintiva a sus demandas más primitivas.

Stavroguin es una persona desilusionada, aburrida, indiferente, que se burla de su fe perdida y de sí mismo. Le parece de una evidencia elemental que Dios no existe, que la moral es absurda, que "todo está permitido" y que no hay castigos interiores. Shatov le increpa en la entrevista que tienen: “¿Es verdad que usted perteneció en Petesburgo a una sociedad secreta bestial y lúbrica? ¿Es verdad que el marqués de Sade podia haber sido recibido entre ustedes? ¿Es cierto que ustedes seducían y corrompian a menores?... ¿Es verdad que ustedes creían que no habia distinción entre diversión voluptuosa, bestial y cualquier proeza, incluso la de dar la vida por la Humanidad? ¿Es cierto que ustedes en ambas cosas encontraban una belleza y placer idénticos?". Y continúa Shatov: "No sé tampoco por qué el mal es odioso y la virtud hermosa, pero sé que el sentimiento de esa distinción se borra y pierde en señores como los Stavroguines... ¿Sabe usted por qué entonces contrajo aquel matrimonio tan oprobioso y ruin? Pues iporque en eso la ignominia y el atolondramiento rayaron en genialidad! ¡Oh, usted no se pasea al filo, sino que se arroja de cabeza a la sima! Usted se casó por el placer de atormentarse, por el placer de los remordimientos de conciencia, por el deleite moral. Esto fue un arrechucho de los nervios... ¡Un reto al sentido común resultaba ya de por sí bastante seductor! ¡Stavroguin y una mendiga escupible, idiota y coja! Cuando usted mordió la oreja al gobernador, ¿sintió usted voluptuosidad? ¿La sintió? Señorito ocioso, ¿la sintió?” (T. III, P. II, C. I, p. 1238-39).

Tal es el resultado del intento de rebasar los limites de la moral, de poner en práctica la convicción de que no existen fronteras morales de ninguna clase. Sus acciones degradantes y despreciables son, como en Raskólnikov, un experimento filosófico, pero Stavroguin resulta ser un estadio más avanzado del personaje de Raskolnikov; ha perdido su fe en la exaltación del yo como la suprema ley moral. 
En varias ocasiones a lo largo de la obra se nombran los pensamientos suicidas de Stavroguin, bien por conversaciones que tiene con otros personajes, como por ejemplo en el capitulo llamado Noche, en que Stavroguin confiesa a Kirillov: "Yo, desde luego, comprendo eso de pegarse un tiro... Algunas veces lo he pensado, y siempre se me ha ocurrido una nueva idea. Si cometiera una mala acción, o, sobre todo, una acción vergonzosa, es decir, vilipendiosa, sumamente ruin y ridícula, tal que la recordase la gente al cabo de mil años y me escupiesen por espacio de mil años, y de pronto la idea: un tiro en la sien y se acabó. ¿Qué importa entonces la gente ni que se estén escupiendo mil años?” (T.II, P.II, C.I, pag. 1226).

En este capitulo, él intenta descubrir su certeza existencial desde las ruinas de su pasado. Visita a Shatov y a Kirillov, que ahora enarbolan ideologías que él les inspiró pero que descartó después, pero se aburre con ellos como se aburre con Piotr y sus sueños políticos o con su historia amorosa con Liza, o con el intento de Dasha Shatova de salvar su alma vacía.

En los pasajes suprimidos por el autor se expone de forma más compleja el carácter de Stavroguin. Un capitulo de la novela (Con Tijón), en el que aparece "La confesión de Stavroguin", fue censurado y no se publicó durante la vida de Dostoievski. Este capítulo no sólo contiene la crucial revelación de toda la gama y profundidad de la depravación de Stavroguin (la confesión de haber violado a una niña de doce años) sino también su motivación filosófico-moral, sus tormentos internos y su anhelo de redención. Dostoievski tuvo que realizar cambios de última hora en su obra, lo que hace algo menos coherente el libro, quedando Stavroguin como una figura mucho más enigmática y misteriosa de lo que inicialmente debía ser y faltando la aclaradora motivación filosófico-moral que Dostoievski se había propuesto darle.

Así, en este capítulo, la ambición de Stravoguin de trascender todo lo humano, de arrogarse un poder supremo sobre la vida y la muerte, aparece de forma no consciente. Stavroguin no puede eliminar por completo su sensación de la diferencia entre el bien y el mal, como se aprecia en su célebre sueño de una "Edad de Oro" inspirado por el cuadro de Lorrain, la felicidad que siente en ese momento y el cambio de sentimiento producido por la visión de una arañita roja asociada en el subconsciente de Stavroguin con la muerte de 
Matryosha, la niña a la que violó. A Stravoguin le resulta insoportable este lacerante recordatorio de su propia maldad, pero deliberadamente se niega a borrar ese recuerdo; y esta insufrible necesidad de expiar su crimen, que nada de lo que cree o sabe puede ayudarle a absolver, gradualmente va enloqueciéndolo. Pero hasta su misma confesión es otra y más extrema forma de esa "sensualidad moral". Como dice Tijón su confesión "responde a la necesidad de un corazón mortalmente herido... Pero usted aborrece y desprecia ya por anticipado a todos cuantos hayan de leer lo aquí escrito y los provoca a la lucha" (T. IV, paralipómena de "Los demonios", p. 1591). Tijón discierne que Stavroguin, por sí mismo, jamás podrá alcanzar la verdadera humildad del auténtico arrepentimiento; su necesidad de sufrimiento y de martirio sólo puede llevarlo a provocaciones cada vez más espantosas. Tijón le sugiere se someta a la voluntad de un monje anciano y así se discipline a sí mismo mediante su total rendición a otro, pero Stavroguin rechaza esta sugerencia y se lanza a su perdición. Su figura es trágica, pues su incapacidad de creer en su propio renacimiento le lleva a su propia destrucción.

Otro pasaje fue publicado solamente en la pimera edición, suprimiéndolo el autor posteriormente. En él, Stavroguin habla a Daría sobre como se le presenta en alucinaciones su demonio: "He vuelto a verlo... Es un estudiante de inteligencia roma, con esa fatuidad del año sesenta, de una mentalidad lacayuna, un ambiente lacayuno y un alma y una educación iguales, y convencido, además, de poseer una belleza irresistible cuando no lo hay más repelente. Yo me puse furioso de que mi demonio pudiera aparecérseme con esa catadura tan siniestra. Jamás hasta ahora se me había presentado así... Puede que lo vea efectivamente, en el delirio, que esté fuera de mí... Yo no creo en él; por ahora no creo en él. De sobra sé que soy yo mismo, en distinta forma; me desdoblo y hablo conmigo mismo. Pero no por eso se enfadó él menos; tenía empeño en hacer constar que es un demonio independiente, en el que yo creo de veras" (T. IV, paralipómena de "Los demonios", p. 1572). El motivo de suprimir estas páginas podria ser evitar que se pudiera suponer que Stavroguin sufriese algún tipo de enfermedad mental.

Su suicidio, que pone fin a la novela, fue previsto por Dostoievski desde que concibió el personaje. Al no aparecer el capítulo de su confesión, no sabemos si Dostoievski deseaba aprovechar la premonición de Tijon de que "iba a cometer un nuevo crimen solamente para impedir la publicación de sus 
hojas". Tal como está el libro termina algo flojo y su suicidio pierde mucho de su significado histórico-simbólico, como condena de todas las ideologías que él mismo había difundido. No obstante, parece claro que su suicidio es el resultado final de su estado de apatía más que de una convicción.

Las últimas líneas de Los demonios son, por tanto, para describir de forma muy somera el suicidio de Stavroguin:

“... se había ahorcado allí mismo, detrás de la puerta.

Encima de un veladorcito había un trozo de papel con estas palabras: "No se culpe a nadie; he sido yo mismo". Allí, también encima del velatorio, había un martillo, un pedazo de jabón y un grueso clavo, puestos allí a prevención. El grueso cordón de seda, de antemano por lo visto elegido y apartado, con que se ahorcara Nikolai Vsevolódovich, estaba muy untado de jabón.

Todo indicaba la premeditación y la conciencia hasta el último instante.

Nuestros médicos, en la autopsia en absoluto y resueltamente negaron la locura" (p. 1515)

La preparación del suicidio y su nota de despedida son pobres y carecen de toda floritura retórica. Es solo una confirmación de lo que ya es conocido durante la novela: Stravoguin está desprovisto de vida.

Quizás el único intento real de Stavroguin de definirse a sí mismo y que puede explicar mejor su vacío existencial aparece en la carta final a Dasha. Dice: "He probado en todas partes mis fuerzas... soy capaz de querer hacer algo bueno y de sentir en ello placer; pero también deseo el mal y también en él siento satisfacción. Pero uno y otro sentimiento, cómo antes, siempre son leves y a veces no se producen. Mis deseos son harto flojos; no pueden servirme de guía. En una viga se puede atravesar un río pero en una astilla no... de mí sólo ha salido la simple negación, sin generosidad ninguna ni pizca de energía. Ni siquiera la negación me cuajó. Todo siempre liviano y débil. El magnánimo de Kirillov no pudo aguantar la idea y se pegó un tiro: yo lo tengo por generoso, porque estaba en su sano juicio. Yo nunca puedo perder el juicio, ni tampoco podría nunca creer en la idea hasta el extremo que él. Ni siquiera ocuparme en la idea hasta ese 
punto puedo ¡Nunca, nunca podré pegarme un tiro! Sé que debería matarme, barrerme de sobre el haz de la tierra como a un vil gusano; pero le temo al suicidio, porque le temo a demostrar generosidad. Sé que esté será otro error, el último error en una serie infinita de errores. ¿A qué conduce el engañarse para fingir generosidad? Indignación y bochorno en mí nunca podrán darse; así que tampoco desesperación" (T. II, P. III, C. VIII, p. 1513-14)

\section{Discusión}

Svridigáilov y Stavroguin, como hemos visto, tienen muchos rasgos en común. Ambos se caracterizan por un desprecio total a las normas morales y sociales, una exagerada confianza en sí mismos con una autoimagen ensalzada, gran independencia personal, dificultades para la expresión de sentimientos cálidos, total indiferencia hacia los sentimientos de las otras personas, ausencia de culpa y un sentimiento crónico de vacío y tedio que se intenta compensar con el desenfreno sensual. Para Dostoievski, estos tipos de personajes se caracterizan por la ausencia de ideas espirituales y por la ociosidad, que da lugar al tedio que conlleva a la búsqueda de emociones y al desenfreno carnal como forma de compensación. Desde el punto de vista clínico, este tipo de personalidad coincide con la personalidad antisocial, según la conceptualiza Kernberg (en Millon, 1999). Este autor considera que todas las personalidades antisociales poseen las características fundamentales de la personalidad narcisística y además una patología inusual en su sentido de la moralidad, es decir, en las funciones del superyó. Kernberg otorga una atención especial al sindrome que denomina "narcisismo maligno" o "narcisismo patológico", un patrón de personalidad caracterizado por una combinación de:

- Trastorno narcisista de la personalidad.

- Comportamiento antisocial.

- Agresiones o sadismo egosintónico dirigidos hacia los demás o hacia sí mismo, este último produciendo un sentimiento de triunfo en la automutilación o el suicidio

- Fuerte orientación paranoide. 
Por tanto, según refiere Kernberg, los pacientes con trastorno antisocial de la personalidad "suelen presentar un trastorno narcisista de la personalidad. Los sintomas típicos de las personalidades narcisistas son, en el área patológica del amor hacia si mismos: la excesiva autoreferencia y el egocentrismo: la grandiosidad y las características derivadas del exhibicionismo, una actitud de superioridad, imprudencia y ambición excesiva; extremada dependencia de la admiración, superficialidad emocional. En lo que se refiere a área de las relaciones objetales patológicas, los sintomas que predominan son la envidia (consciente e inconsciente); la devaluación de los demás como defensa contra la envidia, el comportamiento explotador reflejado en el abuso, la apropiación de ideas o propiedades de otros, y el otorgarse derechos especiales... El estado básico del yo de estos pacientes se caracteriza por un sentimiento crónico de vacío, evidencia de incapacidad para aprender, sentimientos de soledad, avidez de estímulos y una sensación difusa de que la vida no tiene sentido. Además, todos estos pacientes presentan algún grado de patología del Superyó. La patología habitual del Superyó de las personalidades narcisistas incluye la incapacidad para experimentar melancolía o una tristeza reflexiva; la presencia de cambios de humor importantes, y la predominancia de la "vergüenza" en contraposición a la "culpa" en la regulación intrapsíquica de su comportamiento social" (en Millon, 1999, pp. 457-8).

Como vemos, Dostoievski, en ambos personajes, aunque de forma mucho más desarrollada en Stavroguin, describe la mayoría de estos rasgos: el egocentrismo y la grandiosidad de ambos personajes, el exhibicionismo y la actitud de superioridad e imprudencia que llevan a Stavrogin a acciones como tirar de la nariz de Gaganov o morder la oreja del gobernador, el abuso y la explotación con la que ambos tratan a los demás, el desprecio a las normas sociales o morales, el hastío y tedio de Svridigáilov. Además, Dostoievski con una genialidad psicológica incomparable, expresa en palabras de Stravoguin la patología de su Supreyó, capaz de sentir vergüenza y no culpa en sus relaciones sociales.

Cuando Shátov increpa a Stavroguin la búsqueda de placer en la humillación y degradación, coincide con Cooper cuando describe las patologias narcisistas y masoquistas. Este autor comenta (en Millon, 1999), que cuando la autoestima en las personas narcisistas adquiere un carácter patológico, la persona empieza a derivar su satisfacción a partir del dominio de sus propias humillaciones; empieza a obtener placer a partir del malestar; así, Stravoguin se caracteriza por sus búsqueda cada vez más extrema de autodegradación y humillación, como expresa él mismo de 
forma explícita en su confesión en el capítulo no publicado Con Tijón: "Toda situación afrentosa, desmedidamente humillante, repulsiva, $\mathrm{y}$, ante todo, grotesca en que me haya encontrado en mi vida me ha inspirado siempre, además de una rabia sin límites, un deleite increíble... No es que me haya gustado la abyección (en este punto, tengo el juicio sano) sino que ese estado de embriaguez derivado de la penosa consciencia de mi ruindad, me gustaba" (T. IV, paralipómena de "Los demonios", p. 1582-3).

Stravoguin muestra de forma explícita esta patología del carácter; así a su doble negativo, su alucinación del demonio, lo describe como alguien "convencido de poseer una belleza irresistible cuando no lo hay más repelente". También hace mención a la búsqueda de emociones fuertes, tanto de tipo positivo como negativo, como forma de paliar su incapacidad para sentir y desear de forma auténtica. Estos datos coinciden con el patrón de conducta de tipo antisocial definido por Cloninger, que se caracteriza por una alta búsqueda de novedades, baja evitación del daño y una baja dependencia del refuerzo, postulando un bajo nivel de activación cortical.

Para Miller, las personas que se convierten en narcisistas no fueron amadas por sí mismas, sino que sirvieron para satisfacer los deseos parentales y el deseo no correspondido de glorificación de sus padres, y no obtuvieron la aceptación emocional genuina necesaria para desarrollar un auténtico sentido del Sí mismo. Kernberg añade a esta concepción que los futuros narcisistas además suelen poseer un status o talento especial en el seno familiar, como representar el papel de "genio" o ser el único hijo (Millon, 1999). Aunque Dostoievski no da a conocer la educación ni procedencia de Svridigáilov, en el caso de Stavroguin hace un extenso relato de su infancia y adolescencia. Nos describe críticamente la educación inestable y caprichosa recibida por Stepán Trofimovich y la actitud de la madre, que aunque le hablaba poco, siempre tenía la mirada puesta en él y, ya siendo Stavroguin adolescente, se interesaba mucho por sus triunfos en la alta sociedad petesburguesa "Lo que ella no había logrado, lo lograba ahora el joven oficial, rico y con porvenir" (p. 1008). No obstante, para Fiodor Dostoievski el responsable del carácter de Stavroguin fue la forma de conducirse, extravagante y sin autoridad, de su mentor, Stepán, que "provocó la sensación de aquella eterna y santa tristeza", la cual se relaciona con la manera encubierta de ser de las personalidades narcisistas, según Akhar y Thomson (en Millon, 1999), caracterizado por el aburrimiento crónico, el sentimiento de vacío y la incapacidad de amar. 
En ambos personajes, el suicidio es sobrio, poco elaborado, sin retórica, y prácticamente inesperado. Ambos acaban su vida con una escueta nota en que se declaran los propios autores de su muerte. En ambos personajes existen ideas y reflexiones previas sobre el suicidio: En Svridigáilov el suicidio es una forma de evadirse de sí mismo y de su realidad. El lo termina llamando de forma eufemística "irse a América". Su suicidio se relaciona con la frustración narcisística producida por el rechazo sin contemplaciones por parte de Dunia. Es curioso también la referencia de Svridigáilov sobre la eternidad como que en ésta solo hubiera una habitación del estilo de una sala de baño rural, negra de humo y en todos los rincones arañas y que esa fuera toda la eternidad. En la tradición folclórica rusa, (Ivanits, 1992) la sala de baño es considerado un lugar diabólico donde se recogen demonios y otros espíritus impuros; no estaba protegida por iconos y los campesinos llevaban sus cruces mientras se bañaban.

Para Stavroguin el suicidio significa una posibilidad más y la etapa final de su proceso de autodegradación: Stavroguin recalca que el suicidio puede ser una salida ante una situación ruin y vergonzosa, pero también el propio sentimiento de vergüenza, tan enraizado en la personalidad narcisística de Stavroguin, rechaza esta misma posibilidad, ya que teme que su suicidio sea una demostración ante los demás de generosidad, cuando realmente la única razón de Stavroguin para suicidarse es su hastío e incapacidad para sentirse vivo.

Estos dos personajes presentan, por tanto, según nuestro criterio, un trastorno de la personalidad de características narcisisticas y antisociales. En los trastornos de personalidad existe una mayor incidencia de conductas autoliticas y suicidios consumados que en la población general, especialmente en los trastornos antisocial, limite, histriónico y narcisista (o sea, en los trastornos de personalidad del grupo B del DSM-IV). Se calcula que el 5\% de los pacientes con trastorno antisocial de la personalidad se suicida (Roy, 1995). Según Rubio Larrosa (1997) la conducta suicida de los antisociales sería una forma primaria de mal control de la agresividad más que una conducta suicida elaborada, hipótesis que no es contradecida por los suicidios de estos personajes. 


\section{El suicidio "lógico"}

\section{E1 Idiota}

1. En esta obra, un joven tísico agonizante de dieciocho años, Ippolit Terentyev, se convierte en el primer personaje de la notable galería de rebeldes metafísicos de las obras de Dostoievski que defiende de forma razonada la opción del suicidio. Ippolit no se va a rebelar contra las iniquidades de un orden social sino que, anticipándose a Kirillov y a Iván Karamázov, va en contra de un mundo en que la muerte, y por tanto el sufrimiento humano, es una realidad ineludible.

Ippolit lee en casa del príncipe, donde se han reunido ha celebrar su cumpleaños, su "explicación indispensable" en donde anuncia que al día siguiente, al amanecer, se va a suicidar (T.II, P.III, C.V-VII, pp. 787-819). Con Ippolit, Dostoievski pone a Mishkin ante el más grande desafío a la felicidad de la vida. Ippolit comparte con Mishkin su obsesión por la muerte y su extático sentido de la vida, pero carece de la fe religiosa que sostiene al príncipe en una última armonía del mundo. Por esta razón, Ippolit no logrará alcanzar la transcendencia de sí mismo que es el secreto del resplandor moral del príncipe y la respuesta que provoca en los demás. La "explicación indispensable" de Ippolit contiene los rasgos principales de la cosmovisión de Mishkin, pero combinada con una opuesta actitud humana. Su preocupación por la muerte no rebaja sino que fortalece su preocupación por sí mismo, y se convierte en una patética megalomania. Ippolit reverencia la belleza infinita y el valor de la vida, pero es incapaz de superar su egocentrismo. Aunque instintivamente los sentimientos de Ippolit están al lado de las víctimas de la injusticia social y reconoce la virtud de la caridad, abandona toda preocupación por los demás para meditar sobre su propio estado. Llega a considerar que la muerte, que es universal, es un insulto y una "humillación" personal, lanzada contra él por la "naturaleza" o, mejor dicho, por el Creador de un mundo que exige el consentimiento personal a la indignidad y la injusticia de ser destruido. Para Ippolit, el hecho de que los demás posean tranquilamente la vida es una injusticia suprema, que debiera causarles un sentimiento de culpa y obligación moral. Así, utiliza su muerte inminente para acosar y desalentar a los vivos. El 
egocentrismo que inspira la "rebelión" de Ippolit también le mueve a adoptar una conducta que bloquea esa compasión y ese amor que tan desesperadamente anhela.

En esta "explicación indispensable" Ippolit justifica su suicidio ante el conocimiento de que aproximadamente le restan sólo dos o tres semanas de vida. En esta larga explicación relata sus últimos sueños, su odio ante aquellos que se quejan estando sanos, su desprecio hacia los humildes, sus buenas acciones, su apoyo a la caridad individual, su antagonismo con Rogochin y sus impresiones ante el cuadro de Holbein.

Ippolit describe cómo le apareció la idea del suicidio, a la que llama su convicción suprema contemplando las aguas del Neva y como se decide tras tener visiones (el espectro de Rogochin) en un estado de delirio: "A mi resolución definitiva contribuyó, por consiguiente, no la lógica, no una convicción lógica, sino la repugnancia. No es posible continuar en una vida que afecta formas como ésas, extrañas y para mí ofensivas. Esa aparición me había humillado. No me siento con fuerzas para someterme a una fuerza oscura que adopta la forma de una tarántula. Y sólo cuando, ya al caer la tarde, sentí, finalmente, en mí el momento decisivo de una plena resolución, respiré" (p. 810). Y continúa: "No reconozco ningún juez por encima de mí, y sé que ahora estoy fuera de toda jurisdicción judicial ...no quiero irme sin dejar unas palabras como respuesta, unas palabras libres, no forzadas, no para justificarme... ¡Oh, no; yo no tengo porque pedir perdón a nadie!... sino porque así me place a mí mismo hacerlo. En primer lugar, allá va esta extraña idea: ¿Por qué, en nombre de qué derecho, en nombre de qué principio me discutiriais ahora mi derecho a esas dos o tres semanas de mi plazo? ¿Qué juez tiene que ver aquí nada? ¿Quién necesita, no sólo que yo sea condenado, sino que soporte moralmente el plazo de mi condena? ¿Es que, efectivamente, le importa esto a alguien? ¿Por lo moral? Yo todavía comprendo que, si en un estado de salud floreciente y en la plenitud de mis fuerzas, atentase yo contra mi vida, cuando aún podría ser útil al prójimo, la moral podría hacerme un reproche, siguiendo la vieja rutina, por aquello de disponer de mi vida sin permiso o ella sabrá por qué. Pero ahora que ya me han leído el plazo de mi condena, ¿qué moral puede haber ahora por encima de vuestra vida y el último estertor con que exhaláis el postrer átomo de vida, escuchando los consuelos del príncipe, que, infaliblemente, con sus demostraciones cristianas, llegará a la feliz idea de que en realidad, es lo 
mejor, incluso que os muráis? (Los cristianos como él van a parar siempre a esa idea; este es su predilecto estribillo)" (p. 810-1). Pasa a comentar la poca importancia que tiene para él en este momento la belleza del mundo "cuando todo ese festín, que no tiene término, empieza cuando sólo a mí me consideran de sobra" (p. 811).

Posteriormente Ippolit refiere sus opiniones sobre la religión: "iLa religión! La eterna vida la admito, y es posible que siempre la haya admitido. Concedamos que la conciencia esté iluminada por la voluntad de una fuerza superior o que pose la vista en el mundo y diga: "Soy", o que de pronto se le ocurra a esa fuerza superior aniquilarla por alguna razón que tenga para ello (y hasta sin explicación del por qué), todo esto lo admito; pero otra vez surge esta pregunta: “¿Qué falta hace para nada de eso de mi humildad? ¿Es que no pueden, sencillamente, comerme, sin que, además, haya de alabar yo el que me coman? ¿Es que, en realidad, ofendo a alguien por no querer aguardar dos semanas?" No creo tal cosa, y mucho más inverosímil es suponer que, sencillamente, es necesaria mi vida insignificante, la vida de un átomo, para completar alguna universal armonía en el todo, para algún plus o minus, para algún contraste, etc., etc., exactamente igual que todos los días se requiere el sacrificio de muchedumbre de seres, sin cuya muerte no podría el mundo subsistir... Yo estoy conforme en, que de otro modo, es decir, sin el constante comerse unos a otros, habria sido imposible organizar el mundo; pero también convengo en aceptar que no comprendo nada de esa organización; pero, en cambio, he aquí lo que de veras conozco. Si ya una vez me hicieron reconocer que existo ¿qué me interesa a mí que el mundo esté organizado con errores, y que de otro modo no pueda subsistir? ¿Quién ni por qué me ha de juzgar después de eso? Como queráis; todo es imposible e injusto. Y sin embargo, yo nunca, y aun a pesar de todo mi deseo, pude figurarme que no hubiese vida futura ni Providencia. Lo más cierto de todo es que todo eso existe, sino que nosotros no comprendemos lo más mínimo de esa vida futura y de sus leyes. Pero si tan difícil y hasta imposible es comprenderlo ¿voy a ser yo el responsable de no tener fuerzas para comprender lo incomprensible? Verdaderamente, dicen, y de ese número es, sin duda, el principe, que aquí lo que hace falta es obediencia, obedecer sin razonar, por pura decencia, y que por mi docilidad seré infaliblemente recompensado en el otro mundo. Rebajamos demasiado a la Providencia atribuyéndole nuestras ideas, enojados por no poderla comprender. Pero, no obstante, si comprenderla es imposible, vuelvo a repetirlo, 
difícilmente habrá que responder de lo que no puede comprender el hombre. Y siendo así ¿iréis a juzgarme a mí por no poder comprender la verdadera voluntad y las leyes de la Providencia?

... Pero basta. Al llegar a estas líneas seguramente saldrá ya el sol y resonará en el cielo y se difundirá una fuerza potente, incalculable, por todo el planeta. ¡Sea! ¡Moriré mirando directamente a esa fuente de vida y de fuerza, y no echaré de menos esta vida! Si tuviese poder para no haber nacido, seguramente no habría aceptado la existencia en tan grotescas condiciones. Pero sí tengo el poder de morir, aunque dé ya lo descontado. Ni gran poder ni gran rebeldía tampoco.

...Ultima explicación: muero en modo alguno por no tener bríos para soportar esas tres semanas. ¡Oh! Yo habría tenido fuerzas de sobra si hubiese querido, que bastante consuelo habría sido para mí la sola conciencia de la ofensa que me habian inferido... Finalmente, es también seductor; la Naturaleza hasta tal punto ha limitado mi actividad en mis tres semanas de condena, que es posible que el suicidio sea lo único que yo pueda todavía emprender y realizar a plena satisfacción mía ¿Será que en el fondo quiero yo aprovechar la única posibilidad de acción? La protesta a veces no es un acto tan insignificante..." (p. 811-12)

Tras esta explicación, los oyentes se muestran indignados y se burlan de su actitud, Ippolit se intenta suicidar pero no lo consigue al no estar cargada la pistola, lo que provoca la risa. Ippolit jura repetidamente que se le ha olvidado colocar las balas. Uno de los personajes secundarios de la novela, Yevguenii Pávlovich, comenta que ha oído decir "que hay hombres que con toda intención se pegaron un tiro para que los aplaudieran, o por rabia de que no los aplaudiesen" ( $\mathrm{p}$. 817).

\section{Los demonios}

1. Aléksieyi Nilich Kirillov es descrito como "un hombre joven todavia, como de veintisiete años, decentemente vestido; un moreno, fornido y flaco, con una cara pálida, de matiz algo turbio, y ojos negros sin brillo. Parecía algo pensativo y ensimismado, hablaba a saltos e incurriendo en faltas de 
ortografia, y parecía como si perdiese el hilo y se embrollase en cuánto se metía a hacer una frase algo larga" (T.II, P.I, C.III., p. 1132) No obstante, ante una broma de Stepán, su rostro era capaz de asumir la más infantil expresión.

Dostoievski no vacila en dotar a Kirillov con muchos de los atributos del príncipe Mishkin, el prototipo del "hombre absolutamente bello": su amor a los niños, su afirmación de la vida, su captación escatológica del fin de los tiempos, la misma intuición extática de una plenitud sobrenatural en forma de crisis que presenta Mishkin en sus auras ("Hay segundos, sólo se dan cinco o seis segundos, en que de pronto siente usted la presencia de la eterna armonía, completamente lograda. No es cosa terrenal, no quiero decir que sea celestial... Es un sentimiento claro e indiscutible... Lo más terrible de todo es que sea una cosa tan inmensamente clara y sienta tal alegría. Si durase más de cinco segundos, el alma no aguantaría y tendría que desaparecer. En esos cinco segundos he vivido yo una vida y por ellos daría yo mi vida toda, porque lo valen") (T.II, P.III, C.V, p. 1459). Así, Dostoievski intenta mostrar las consecuencias que pueden resultar cuando estas emociones religiosas se convierten en ideas seculares y objetivas: La deificación del hombre llevará a Kirillov a su propia destrucción, así como a la de la humanidad ("dará lo mismo vivir que no vivir"), con su convicción de que el Reino de Dios existe solo con que la gente se entere, llegando a negar la existencia del mal ("todo es bueno") (T.II, P.II, C.I., p 1228).

En su presentación el judío Liputín le presenta como el escritor de un artículo sobre las causas concomitantes de los casos de suicidio en Rusia, y en general, de las causas que aumentan o disminuyen los suicidios en la sociedad. Kirillov se apresura en desmentir la existencia de este artículo. Más tarde, Kírillov expone en una conversación con el narrador sus pensamientos sobre el suicidio. Él, refiere, busca las causas de que la gente no se atreva a matarse; piensa que sólo hay dos causas: una muy pequeña, el dolor, y una muy grande. A continuación transcribimos esta conversación:

“ - El dolor es lo primero. Hay dos clases de suicidas: o los que se matan por una pena muy grande, o los que lo hacen por rabia, o porque están locos, o por cualquier otra causa...; esos lo hacen de pronto. Esos piensan poco en el dolor, sino que proceden de pronto. Pero los que están en su juicio..., esos lo piensan mucho 
- Pero ¿acaso los hay que estén en su juicio?

- Muchísimos. Si no fuera por los prejuicios, aún abundarian más, mucho: lo sería todo el mundo.

- Pero ¿acaso no hay medios de morir sin dolor?

- Imaginese usted -dijo, deteniéndose delante de mí -, imagínese usted una piedra del tamaño de una casa grande; está colgando, y usted, debajo de ella; si le cayera a usted encima, en la cabeza..., ¿ ¿sentiría usted dolor?

- Naturalmente que no habría dolor

- Tiene usted razón; pero en tanto no cayese, temería usted mucho que hubiese dolor. El primer hombre de ciencia, el primer doctor, sentiría mucho miedo. Todos sabrian que no habria dolor, y, no obstante, todos temerian que lo hubiese.

- Bueno ¿y la segunda razón, la grande?

- El más allá.

- Es decir, ¿la expiación?

- Es lo mismo. El más allá; simplemente, el más allá.

- Pero ¿no hay ateos que no creen en absoluto en el más allá?

Volvió a guardar silencio

-¿Piensa usted por usted?

- No hay más remedio que pensar cada cual por uno declaró, poniéndose colorado -. La libertad absoluta existirá cuando de lo mismo vivir que no vivir. Esa es toda la finalidad.

-¿Finalidad? ¡Pero entonces nadie querrá vivir!

- Nadie - profirió enérgicamente. 
- El hombre le teme a la muerte, porque ama la vida; he ahí como yo lo entiendo -observé -, y lo que manda la Naturaleza.

- Eso es ruin, y todo eso es un engaño - centelleabanle los ojos -. La vida es dolor, la vida es espanto, y el hombre es desdichado. Ahora todo es dolor y espanto. Ahora el hombre ama la vida. Y así obra. La vida se da ahora por dolor y espanto, y todo eso es un engaño. Ahora el hombre no es todavía ese otro hombre. Surgirá un hombre nuevo, feliz y orgulloso. Al cual le dará lo mismo vivir que no vivir: jese será el hombre nuevo! Quien suprima el dolor y el espanto, ése será un Dios. Y el otro Dios dejará de ser.

- Según eso ¿para usted existe Dios?

- Existe y no existe. La piedra no produce el dolor; pero en el miedo a la piedra hay dolor. Dios es el dolor del miedo a la muerte. Quien venza el dolor y el miedo, ése será Dios. Entonces empezará una nueva vida, entonces existirá el hombre nuevo, todo será nuevo... Entonces la historia se dividirá en dos partes: del gorila al aniquilamiento de Dios y del aniquilamiento de Dios a...

$-\dot{¿}$ Al gorila?

-...al cambio de la tierra y del hombre físico. Será Dios el hombre, y cambiará fisicamente. Y el mundo cambiará también, y los actos cambiarán, y las ideas y los sentimientos todos. ¿No cree usted que el hombre ha de cambiar también entonces en lo fisico?

- Si ha de dar lo mismo vivir que no vivir, todos se matarán, y en eso quizá consista el cambio.

- Eso es igual. Matarán a la mentira. Todo el que desee la plena libertad está obligado a atreverse a matarse. El que se atreva a matarse descubre el secreto del engaño. No hay más libertad que ésa: ahí está todo, y no hay nada más. Quien se atreve a matarse es Dios. Ahora todos pueden hacer que no haya Dios ni nada. Pero nadie lo hizo hasta ahora ni una sola vez.

- Suicidas los ha habido a millones.

- Pero ninguno por esa causa, sino todos por miedo y no con ese fin. No con el fin de matar el miedo. Quien se mata sólo por eso, por matar el miedo, ése inmediatamente será Dios. 
- Puede que no le dé tiempo -observé.

- Eso es lo mismo -repuso él serenamente, con tranquilo orgullo, casi con desprecio -. Lamento que usted parezca reírse añadió medio minuto después. " (T. II, P. I, C. III, p. 1147-48).

Esta conversación termina con la declaración de Kirillov de que se pasa la vida pensando en una sola cosa: "A mí Dios me ha atormentado toda la vida".

Dios, dice Kirillov, no es sino la imagen proyectada del dolor y del miedo a la muerte y desea suicidarse tan sólo para expresar la más alta capacidad de la voluntad del hombre ("El hombre sólo inventó a Dios para vivir sin suicidarse; en eso consiste toda la Historia universal hasta hoy. Yo solo, en toda la Historia universal, no he querido por primera vez inventar a Dios") (T.II, P.III, C.VI, p. 1477); él desea suicidarse para liberar a la humanidad de un Dios que no es más que ese temor ("Yo quiero privarme de la vida, porque ésa es mi idea, porque no quiero aguantar el terror de la muerte" (T.II, P.II, C.VI, p. 1318) ("El miedo es la maldición del hombre. Pero yo (con el suicidio) pongo de resalto mi libre albedrío; yo estoy obligado a creer que no creo") (T.II, P.III, C.VI, p. 1479). Quiere demostrar a Dios que la mejor de sus armas, el terror a la muerte, ha perdido su poder.

El pensamiento de Kirillov es similar al del superhombre en Nietzsche ("Si no hay Dios, yo soy Dios"). Kirillov está convencido de que semejante suicidio iniciará la época del Hombre-dios predicha por Feuerbach: "Y salvaré. Esto es lo único que puede salvar a todas las criaturas, $y$, en la siguiente generación obrar una transformación física, porque en la forma fisica actual, según lo que yo he pensado, no podrá vivir el hombre sin su antiguo Dios. Yo he estado tres años buscando el atributo de mi divinidad, hasta que, al fin, lo hallé: el atributo de mi divinidad es el libre albedrío. Esto es todo por lo cual yo puedo demostrar, en la más alta acepción, mi rebeldía y mi nueva terrible libertad. Porque es muy terrible. Yo me mataré para poner de manifiesto mi rebeldía y mi nueva terrible libertad" ((T.II, P.III, C.VI, p. 1478).

Su muerte será un martirio en aras de la humanidad, pero un martirio que invierta la significación del martirio de Cristo, quien es su modelo. En lugar de atestiguar la realidad y la existencia de Dios y de un mundo supraterreno, señalará su eliminación de la conciencia humana. ("Aquel hombre (Cristo) estaba por encima de toda la Tierra, constituía todo lo que merece la pena vivir por ello. Todo el planeta, con todo lo que contiene, sin ese 
hombre una locura... si las leyes de la Naturaleza no tuvieron piedad ni de $E l$ y lo dejaron vivir en medio de mentiras y por una mentira, resulta que el planeta entero es una mentira y no descansa sino sobre la mentira y la befa" (T.II, P.III, C.VI, p. 1477)

Pero ante la muerte la omnipotencia buscada se confunde con la impotencia radical. Descubre junto a él a Piotr Stepánovich, a quien desprecia y su muerte es sólo un útil instrumento para los planes destructores de éste.

La muerte de Kirillov termina siendo un acto demencial de una persona enloquecida y aterrada. La idea de la aniquilación de Dios, lejos de conducir al dominio del dolor y el miedo a la muerte, parece conducir a su mayor manifestación y a la enajenación. Así, antes de su suicidio pactado con Piotr, Kirillov intenta de forma absurda esconderse en un rincón y trae consigo el frenesí animal con que Kirillov clava los dientes en la mano a Piotr. Como el crimen de Raskólnikov, también el suicidio de Kirillov resulta ser la negación y refutación de sus propias grandiosas ideas.

\section{$\underline{\text { El adolescente }}$}

1. Kraft es descrito en su presentación como una persona de aspecto bondadoso y sumamente delicado, en el que resalta una especial dignidad "Había (en su cara) algo ya demasiado tranquilo en sentido moral; algo por el estilo de un orgulloso misterio, de sí mismo ignorado" (T.II, P.I, C.III, p. 1560). Durante los últimos dos años ha hecho un estudio físiológico, que él llama matemático, del pueblo ruso por el que ha llegado a la conclusión de que este es un pueblo de segundo orden que carece de papel independiente en los destinos de la Humanidad aunque será el material para una raza más noble. Preocupado por la falta actual de ideas morales, expresa la destrucción a la que se está sometiendo a su país con contenidos ecológicos muy actuales. Kraft se pega un tiro al anochecer. Arkadii se entera de este suicidio en la casa de Tatiana cuando está escuchando escondido una conversación de la anfitriona con Katerina. Se descubre y recrimina a ésta última: “¿Vale la pena no ya espiar, sino hasta vivir en el mundo al lado de seres como usted? ¡El hombre magnánimo termina suicidándose: Kraft se ha pegado un tiro por la idea!" (T.II, P.I, C.VIII, p. 1636). Más tarde, continúa: "Cuando es preciso, el hombre generoso sacrifica hasta la vida; Kraft se 
ha pegado un tiro; Kraft, por la idea, fijese usted, un joven, renunció a las ilusiones... Cuando una idea seduce, cuando hay una idea, la idea es lo principal; en la idea está todo" (T.II, P.I, C.IX, p. 1638). Kraft deja un diario, cuya última anotación, justo antes de suicidarse, refiere que escribe casi de noche y que no quiere encender la luz para no ocasionar un incendio "y encenderla para antes de pegarme un tiro volver a apagarla, como mi vida, no quiero". Según Vasin, en su diario no aparecen ideas importantes "Las últimas ideas suelen ser sumamente insignificantes. Un suicida como éste se lamenta en su diario de que, en un momento tan grave, ni siquiera le ha visitado una idea elevada, sino que por el contrario, todas eran menudas y vacias". Se preocupa, por ejemplo, del aspecto de su cadáver lo que le detiene de beber ron por el riesgo de que la hemorragia sea más intensa. Para Vasin "el propio Kraft se representaba su muerte en forma de conclusión lógica... a su muerte nos deja un cuaderno de doctas deducciones relativas a que los rusos... son una raza de individuos de segundo orden, basándose en la frenología, craneologia, y hasta en las matemáticas, y que, por tanto, en calidad de ruso, no vale la pena vivir. Si usted quiere (dice Vasin a Arkadii), lo más característico es que de todo puede sacarse cualquiera deducción; pero coger y pegarse un tiro a consecuencia de esa deducción, eso, sin duda, no siempre ocurre... algo hay que hasta tal punto nos muestra en él al hombre burdamente equivocado" (T.II, P.I, C.IX, p. 1641)

\section{Diario de un escritor}

1. En el capítulo I de Octubre del año 1876, en el apartado titulado Veredicto y tras haber relatado en el apartado previo dos suicidios entresacados de las notas de prensa, Dostoievski intenta elaborar las reflexiones que realizaria una persona materialista ante el suicido. Este suicidio es llamado por el propio Dostoievski un suicidio "lógico", y considera al hastío como el motor principal de este tipo de suicidio.

Las reflexiones del suicida materialista serian las siguientes: "¿Qué derecho tenía la Naturaleza a dotarme de razón sin contar con mi deseo? Conocer es lo mismo que padecer, y yo no quiero padecer; ¿por qué había de prestarme yo a sufrir? La Naturaleza me revela, mediante mi razón, cierta armonía del Cosmos... Me dice que debo acatar esa revelación, resignarme a cargar con el dolor, haciendo cuenta 
de la armonía del Cosmos y resignarme a vivir... Si yo fuere una flor o una vaca, puede que también hubiere para mí un goce. Pero mientras me esté siempre formulando preguntas no podré ser feliz, ni siquiera con esa dicha suprema inmediata de mi amor al prójimo y el amor a mí de la Humanidad, pues sé de sobra que mañana todo esto dejará de ser, así yo como toda esa dicha, todo ese amor y toda esa Humanidad, que todos hemos de quedar reducidos a la nada o vueltos al caos primitivo... no puedo ni podré ser feliz en tanto sepa que mañana me espera la nada. Y por más que digan que todo, por alguna razón, es necesario, según no sé que leyes omnipotentes, eternas y ciegas de la Naturaleza, yo les aseguro a ustedes que esa idea encierra una profundísima desconsideración que a mí me hiere en lo vivo y me resulta tanto más insufrible cuanto que nadie es culpable de nada.... no puede menos de ocurrírsele a uno esta donosa, pero insufriblemente triste idea: “ ¿Y si al hombre sólo lo hubiesen puesto entonces en el mundo por vía de descarado ensayo, para ver si una criatura semejante podía mantenerse o no sobre la Tierra?" Esa idea es tan triste también por el hecho de no haber nadie culpable, por no haber nadie que se haya ofrecido a ese ensayo y no poder maldecir a nadie, ya que todo es obra de ciegas leyes de la Naturaleza, que a mí me resultan incomprensibles y que mi conocimiento, en redondo, no puede aceptar... Y no pudiendo yo aniquilar a la Naturaleza, me aniquilo a mí mismo por la sencilla razón de que me carga padecer esa tiranía, de que nadie es culpable" (pp. 1088-90).

\section{Discusión}

Las argumentaciones que realizan los "rebeldes metafisicos" de Dostoievski a favor del suicidio son de índole filosófico y moral y han sido estudiadas por distintos autores. Corresponden a los suicidios llamados por Enrique Rojas (1978) y Geo Stone "suicidios filosófico": Según refiere el primero de estos autores, en estos suicidios el sujeto no padece ninguna enfermedad psíquica, sino que como mucho se trata de una personalidad extraña $o$ extravagante, que por un proceso reflexivo "descubre" la falta de sentido de su existencia o de la existencia humana en general. Así, ya no vive su futuro como anticipación, como expectación que forma parte del presente, sino que pierde su carácter ilimitado y se reduce, enfocándose en la muerte. 
Albert Camus en El mito de Sísifo (1951) llamará a este suicidio "suicidio superior" o "suicidio metafísico", ya que este suicidio es, en cada uno de estos personajes, producto de una idea. En Diario de un escritor, como veremos en otro apartado, Dostoievski rebate el suicidio con un único argumento: la inmortalidad del alma. Dostoievski expresa sin equívocos que "el suicidio, cuando se ha perdido la fe en la inmortalidad, resulta de una imprescindibilidad absoluta e inevitable para todo hombre que tenga alguna noción de su superioridad sobre los animales" (Año 1876, Diciembre, C.I, p. 1141). Por tanto, todos estos personajes, que tienen en común su agnosticismo y su falta de fe en la inmortalidad, llegarán a esta misma conclusión con diferentes razonamientos.

El personaje de El Idiota, Ippolit, defiende su derecho al suicido ante el padecimiento de una enfermedad terminal que acabará con su vida, según las previsiones médicas, en aproximadamente tres semanas. Esta situación en la actualidad promueve importantes debates y es la base del concepto de eutanasia, defendido ampliamente por grandes sectores de la sociedad.

Ippolit defiende su derecho al suicidio con los siguientes argumentos: Desde el inicio expresa que su decisión con respecto a acabar su vida no la toma por consideraciones exclusivamente racionales, sino ante el desmoronamiento de sus facultades psíquicas ante un episodio confuso-onírico terrorífico que no desea volver a soportar. Hecha esta aclaración y tras afirmar su negativa a la consideración de una ley moral superior a la del propio individuo, expone que la prohibición del suicidio en base a la utilidad social, argumento en principio acepta, en su caso no tiene lugar por su enfermedad terminal. El rechazo del suicidio basado en consideraciones sociopoliticas proviene de Aristóteles, quién afirmó que el suicidio es un acto injusto en contra del Estado. Así, dice Ippolit: "Yo todavía comprendo que, si en un estado de salud floreciente y en la plenitud de mis fuerzas, atentase yo contra mi vida, cuando aún podría ser útil al prójimo, la moral podría hacerme un reproche, siguiendo la vieja rutina, por aquello de disponer de mi vida sin permiso o ella sabrá por qué. Pero ahora que ya me han leído el plazo de mi condena, ¿qué moral puede haber ahora por encima...?” (p.810).

Posteriormente, Ippolit argumenta un razonamiento repetido por Dostoievski en otras ocasiones: aunque no niega la existencia de un ser superior, llamése Dios o Naturaleza, su existencia, su "arrojamiento al mundo" y la consciencia de este "arrojamiento" se ha realizado sin su consentimiento y es incomprensible para él, por lo que no puede considerarse responsable de ello: "Si tuviese poder 
para no haber nacido, seguramente no habria aceptado la existencia en tan grotescas condiciones".

Ippolit desarrolla el argumento, ya esgrimido por David Hume un siglo antes, sobre la poca importancia de un individuo con respecto al esquema general de las cosas. Hume argumentaría que no hay diferencias entre el valor absoluto de un ser humano y de una ostra para el orden general del mundo; Ippolit dice: “...mucho más inverosímil es suponer que, sencillamente, es necesaria mi vida insignificante, la vida de un átomo, para completar alguna universal armonía en el todo, para algún plus o minus, para algún contraste, etc., etc., exactamente igual que todos los dias se requiere el sacrificio de muchedumbre de seres, sin cuya muerte no podría el mundo subsistir..." (p. 811).

Ippolit rechaza explícitamente la obediencia y resignación exigida por la religión cristiana ya que considera que ésta rebaja a la Providencia atribuyéndole ideas humanas, enojada por no poderla comprender. De ello resulta que él no puede ser juzgado por no poder comprender la verdadera voluntad y las leyes de la Providencia. Con este último argumento rebate, por tanto, la tesis esgrimida por Santo Tomás que considera que el suicidio es un acto contra Dios.

Ippolit terminará su "explicación imprescindible" con su último argumento; su suicidio no es consecuencia del sufrimiento previsible durante estas tres semanas que le restan de vida, sino la creencia que éste es su último acto deliberado posible dada la incapacidad a la que le ha sometido su enfermedad.

Seguramente el personaje suicida de Dostoievski más famoso y sobre el que más se ha escrito sea Kirillov, de Los demonios. Kirillov constituye, sin lugar a dudas, una de las más grandes inspiraciones de Dostoievski. Este retrata a Kirillov cuidadosamente, y como se ha comentado anteriormente, le asigna muchos de los atributos de el Príncipe Mishkin, que Dostoievski considera característicos del "hombre absolutamente bello". Entre ellos sobresale la mezcla de seriedad y ternura, la ingenuidad, el amor por los niños, su exaltación de la vida. Y Kirillov y Mishkin son los únicos personajes a los que Dostoievski asigna sus auras epilépticas de tipo extático. Ambos las definen de forma muy similar y ambos personajes, al igual que Dostoievski, consideran que las sensaciones experimentadas en estas crisis valen más que la vida entera. Pero a diferencia de Mishkin y el propio Dostoievski, Kirillov no sufre la crisis convulsiva y el periodo confusional postcrítico. 
Camus, en su ensayo sobre Kirillov en El mito de Sísifo (1951) define el suicidio de Kirillov como suicidio superior y pedagógico; superior, porque es producto de una idea y pedagógico, porque su suicidio es un sacrificio. No es la desesperación lo que le impulsa a la muerte, sino el amor al prójimo. Su muerte es un sacrificio en aras de la humanidad, como el de Cristo, que es su modelo, pero invirtiendo su significado.

Dice Kirillov: "El hombre sólo inventó a Dios para vivir sin suicidarse; en eso consiste toda la Historia universal hasta hoy. Yo solo, en toda la Historia universal, no he querido por primera vez inventar a Dios (T.II, P.III, C.VI, p. 1477); La implicación de esta frase es evidente: Dios es la necesidad para el hombre de tener un centro, un valor de base; no encontrándolo en sí mismo, lo habia situado fuera de él, lo había proyectado en Dios, había supuesto que existía, si, pero encarnado en otro, y la fe en este otro había resuelto provisionalmente problemas existenciales. Esta necesidad radica en el miedo a la muerte; así, dice Kirillov, en su descabellada lógica impecable, si se vence este miedo a la muerte, se vence a Dios; es más, el que vence el miedo a la muerte es Dios. Y así este valor de base está en el mismo hombre, como expresa Feuerbach. Y ese valor es el libre albedrío. Para Kirillov, su suicidio es una reivindicación de la "nueva y terrible libertad del hombre", en la que en esta tierra se lleva a cabo la vida eterna, como confiesa a Stavroguin (p. 1227). Desde aquí cambiará la humanidad, hasta físicamente, y "surgirá un hombre nuevo, feliz y orgulloso" y en el que todo será bueno y hermoso.

Estos argumentos se entroncan fuertemente con los esgrimidos en la filosofia de Nietzsche, con la anunciación de "Dios ha muerto" y su filosofia del superhombre. Así, dice Nietzsche, en La genealogia de la moral (1887): "Ese hombre del futuro, que nos liberará del ideal existente hasta ahora y asimismo de lo que tuvo que nacer de él, de la gran náusea, de la voluntad de la nada, del nihilismo, ese toque de campana del mediodía, que de nuevo libera la voluntad, que devuelve al hombre su meta y al hombre su esperanza, ese anticristo y antinihilista, ese vencedor de Dios y de la nada-alguna vez tiene que llegar" (p. 110).

Pero ante estos grandiosos argumentos, Dostoievski resalta la actitud patética y ridícula de Kirillov en su suicidio. Aceptando hacerse responsable del asesinato de su amigo Shátov, termina sus días en presencia del abyecto Piotr Verjovenskii, de una forma enloquecida y denigrante. En su nota de despedida desea pintar una cara sacando la lengua. De esta forma, Dostoievski intenta refutar de una forma gráfica el núcleo esencial de estas ideas, el fracaso del proyecto de autodivinización basado en el agnosticismo 
y en la supremacía de la voluntad individual. Como dice Lavrin (1920), Dostoievski y Nietzsche, son los grandes transformadores de los valores modernos, pero cada uno de ellos llega a una conclusión totalmente opuesta. Existe un parentesco en la concepción del nihilismo de ambos autores: en ambos es entendido como un estado necesario dentro de un movimiento dirigido a metas determinadas; progresa en tres fases análogas: de la duda al pesimismo, de ahí a acciones en el espacio sin dioses y valores, y después a nuevos cometidos. Pero mientras este cometido en Nietzsche culmina en el superhombre, en Dostoievski finaliza en el suicidio o en la salvación mediante el reingreso en la comunidad por el sufrimiento y reconocimiento público de la culpa (Jünger, 1956).

Kraft, en El adolescente, también morirá a causa de una idea y también en este caso su suicidio es la conclusión lógica de la argumentación de "su" idea. Ésta conlleva unos resultados que el propio personaje no puede soportar: sus estudios de frenologia, craneologia y matemáticos le hacen deducir, sin lugar a dudas, que la raza rusa es una raza de segundo orden. Por tanto, es mejor morir. Y Kraft lleva su idea hasta su últimas consecuencias. En este punto destacamos también, como en el momento decisivo de su muerte, Kraft tampoco tiene ideas "elevadas", sino que su preocupación se basa más en consideraciones estéticas con respecto al hallazgo de su cadáver. Este tipo de preocupaciones han sido constatados por autores como Andress (1996) en estudios de pacientes suicidas.

En el caso del suicida materialista por hastío relatado en el capitulo I de Octubre de 1876 en Diario de un escritor, muchas de las argumentaciones a favor del suicidio son las mismas que refiriera en El Idiota Ippolit o Kirillov en Los demonios. Este suicida expresa su rebeldía ante el dolor que causa la razón y la conciencia de la muerte. Este dolor no puede ser mitigado por nada, ni siquiera con el amor a la Humanidad, ya que éste a la larga es inútil, pues todo acabará en la nada o en el caos. Por tanto, este personaje encarna al nihilista más extremo, nihilismo con el que Nietzsche, conocedor de su peligro tras "la muerte de Dios", arremete en sus obras. Aunque no niegue que puedan existir leyes eternas de la Naturaleza que rijan su propia existencia, a él estas leyes le resultan incomprensibles e inaceptables. Como no puede luchar contra la Naturaleza que dicta esas leyes, el suicidio le parece la única forma de no seguir padeciendo la tiranía de esas leyes que no entiende y de las que nadie es culpable.

En el capítulo I de Diciembre de 1876 Dostoievski retoma este artículo, ante el temor de que haya sido malentendido como un 
alegato del suicidio. En él, Dostoievski considera que las argumentaciones de este suicida son veraces y lógicas y que él las suscribe para una persona que haya perdido su fe en la inmortalidad del alma; además, Dostoievski considera que la filantropía no puede ser un sustituto de esta fe, es más, para Dostoievski el amor a la Humanidad sólo es posible como idea si se tiene fe en la inmortalidad del alma; sin ella, dice, éste amor a la Humanidad es inútil, absurdo y "absolutamente imposible" y frecuentemente se convierte en odio este "amor" a la Humanidad. 


\section{E1 suicidio violento}

\section{El adolescente}

1. Versílov, el padre de Arkadii, protagonista de la novela, está enamorado apasionadamente de Katerina. Ante la imposibilidad de conseguir su amor, y en un momento de enajenación, intenta matarla de un disparo; tras impedírselo su hijo Arkadii, se apunta él mismo al corazón. Arkadii consigue desviar la dirección del tiro, por lo que la bala da en el hombro de Versílov. Este acto fue, según Arkadii, en un momento en que Versílov perdió la razón y estaba gobernado por lo que el mismo Versílov llama su "doble".

\section{Diario de un escritor}

1. En el artículo de Enero de 1876, en el segundo apartado titulado La novela futura- Otra vez la familia casual comenta un suceso publicado en la prensa: el asesinato de la burguesa Perovna y el suicidio del criminal. Ambos vivían juntos y él se quedó sin trabajo, por lo que ella arrendó a otro el cuarto. Ella le pedía que la dejase, pero él tenía, dice Dostoievski, un "carácter de los nuevos" por lo que pensó "Ni para mí ni para nadie" y la asesinó delante de los hijos de Petrovna, de nueve y doce años. Dostoievski saca a relucir este suceso para preguntarse sobre el futuro de estos niños, en el que este recuerdo sombrio perdurará para siempre y les puede infundir vergüenza sobre su pasado y un odio sordo hacia la Humanidad (1876, Enero, C.I, p. 875).

2. Aunque este caso no es un acto suicida, sino de intento de asesinato, creemos que tiene interés incluirlo en este apartado por las consideraciones sobre él que realiza Dostoievski: En el capitulo I de Mayo de 1876 de Diario de un escritor (p. 979-92) comenta el juicio de la Kairova, mujer que intentó matar a la mujer legal de su amante; En este juicio la absuelven por trastorno mental. La Kairova es una mujer marginal, con múltiples antecedentes familiares de alcoholismo, entre ellos un hermano que "había perdido la 
razón por efecto de la bebida, y terminó pegándose un tiro" (p. 980); Entre las cartas que Dostoievski recibe sobre este caso, el autor destaca una en la que comenta lo siguiente: "La absolvieron acaso como a loca, y todavía hay que dar gracias a Dios. Por lo menos, el desenfreno moral no ha sido tomado por progreso de la razón, sino incluido en la categoría de las enfermedades mentales" (p. 980). Dostoievski, por el contrario, defiende la absolución de esta mujer, ya que es dificil conocer con seguridad las intenciones de la mujer, pues seguramente ni ella misma las sabría. Dice Dostoievski: "¿Y si hubiera ocurrido que después de agredir a ella una vez y, asustada, hubiera vuelto el arma contra sí misma y se hubiera degollado? ¿Y si, finalmente, no sólo no se hubiese asustado, sino que, por el contrario, al sentir los primeros salpicones de sangre caliente se hubiera puesto rabiosa, y no sólo le hubiera dado muerte a Velikánova, sino que, además, se hubiera puesto a insultar el cadáver, le hubiera cortado la cabeza a cercén, le hubiera arrancado las narices, los labios, y sólo después de haberle cercenado la cabeza se hubiese dado cuenta de lo que había hecho? Hago estas preguntas porque muy bien pudo ocurrir todo eso y salir todo eso de la misma mujer y la misma alma en una misma disposición de ánimo y en un caso idéntico"(p. 984).

\section{Discusión}

Si bien los actos suicidas acompañados de violencia hacia los demás son hoy en día de triste actualidad por su trágica utilización para fines terroristas, hasta hace relativamente poco los actos suicidas tras homicidios se debian, en su mayor parte, a motivos pasionales. Hoy en día, el asesinato de la pareja sentimental o de personas muy allegadas, seguido del suicidio del criminal, son noticias que aparecen casi diariamente en la prensa. Como vemos, la prensa rusa de la segunda mitad del siglo XIX también reseñaba estos sucesos. Y Fiodor Dostoievski, al que le interesaba de forma muy especial tanto las relaciones amor-odio como las motivaciones para el suicidio, no dejó de hacerse eco de estas noticias.

El último de los casos referidos, sobre el juicio de la Kairova, es extensamente abordado por Dostoievski: éste afirma que en el momento de efectuar el intento de asesinato, aunque ella sabía que agredía, no tenía conciencia del fin que perseguía con ello, sino que agredió "de puro furiosa y enconada", sin pensar en las 
consecuencias. Y que exactamente igual que agredió a su rival, podría ella, con "una misma disposición de ánimo" haberse suicidado. Esta afirmación corrobora en este caso las primeras teorias psicoanalíticas sobre el suicidio como homicidio frustrado o agresividad introyectada, ya expuesta por Stekel en 1910 en el simposio sobre el suicidio realizado por la Sociedad Psicoanalítica de Viena y posteriormente por Freud en Duelo y melancolía (1917), donde expuso que el origen del suicidio está en el deseo de matar a otro. Si la Kairova se hubiera suicidado, claramente este acto pertenecería al tipo creado por Hendin denominado suicidio como asesinato reflejo, el cual supone el paso a la acción o "acting" de un sujeto temperalmente violento que refleja a través del suicidio y de la autopunición una lucha interna contra el deseo de matar o de agredir a los demás.

El intento de asesinato y suicidio posterior frustrado de Versílov de El adolescente es utilizado por Fiodor Dostoievski para desarrollar, con mayor profundidad que en otras novelas, una de sus teorías psicológicas más conocidas: la teoría del doble. Esta teoria, que ha sido estudiada por autores y literatos relevantes (Silvia Plath realizó su tesis doctoral sobre este tema), tiene en Dostoievski varias vertientes: En ocasiones se basa en la aparición de personajes con vida propia o "cuasi-dobles" que son una manifestación más visible de algún aspecto interno de otro personaje principal. Este aspecto puede ser positivo o negativo. Así, por ejemplo, en Los hermanos Karamázov la vertiente negativa de Iván es Smerdiákov y Svridigáilov es la de Raskólnikov en Crimen y Castigo; como ejemplos de "cuasi-dobles" positivos en estas mismas novelas serian Sonia para Raskólnikov y Alíosha para Dimitri Karamazov. Otras veces los dobles aparecen como alucinaciones de los personajes en las que se plasma un aspecto (generalmente negativo) de su yo como, por ejemplo, la aparición del demonio a Ivan Karamázov.

Pero la vertiente más importante de la teoría del doble para el caso que nos ocupa se basa en el principio maniqueo de la dualidad del hombre, de dos personalidades que se contradicen y completan, engendrando una armonía superior. Según Dostoievski esta dualidad es necesaria y hasta indispensable para la integración de la personalidad y su plena actuación: la parte inferior, lo subconsciente del individuo será el impulso para la parte superior, racional. Lo que Arkadii llama "doble" de Versílov es esta parte inferior, inconsciente, es el responsable de las acciones violentas de éste y se caracteriza por los siguientes puntos: 
- No es, en principio, un elemento patológico "No admito de modo alguno que Versilov estuviese loco..." (T.II, P.III, C.XII, p. 1913), aunque si se agrava, añade Arkadii, puede llegar a serlo.

- No es solo el individuo humano el que lleva consigo "el doble"; cada emoción humana lleva en su germen la emoción contraria. Todo amor contiene un elemento de odio, el sufrimiento su elemento de placer y la humillación su elemento de orgullo. Esta dualidad aparecerá de forma explícita en todas sus novelas (véase, por ejemplo, las relaciones entre Katerina y Dimitri en Los hermanos Karamazov: "a ella la miré entonces, durante tres o cinco segundos, con un odio feroz, con ese odio entre el cual y el amor, hasta el amor más loco solo media un pelo" (T.III, P.I, L.III, C.IV, p. 106) "Tenemos muchos motivos para odiarnos, Katia; pero te juro y te rejuro que yo, en medio de mi odio, te amaba y tú a mí no" (T.III, P.IV, L.XII, C.V, p. 532). Esta dualidad es más violenta aún en el amor sexual. Para Dostoievski su experiencia de amor sexual es una lucha desesperanzada y torturante entre orgullo y sumisión y está más relacionado con el odio que con la piedad. Contiene en su forma activa el deseo de castigar (masculino de dominación) y en la forma pasiva de sufrir (femenino de sumisión). Dimitri Karamázov dice explícitamente: "Estar enamorado no significa amar. Enamorarse es compatible con odiar" (T.III, P.I, L.III, C.III, p.98) Los sentimientos de Iván hacia Katerina es un ejemplo claro de ello: "La amaba locamente aunque también es verdad que a veces sentía hacia ella un odio como para matarla" (T.III, P.IV, L.XI, C.VI, p. 473)

Esta dualidad de los sentimientos es percibida de forma consciente en Versílov, quien confiesa a Arkadii: "Puedo experimentar muy bien dos sentimientos distintos al mismo tiempo y, desde luego, contra mi voluntad" (T.II, P.II, C.I, p.1674). Más tarde, expresará toda su personalidad dual en casa de la madre de Arkadii y en presencia de éste, Sonia, Liza y Tatiana: "De veras me imagino estar partido en dos, y le tengo a eso un miedo horrible. Parece como si al lado tuviera uno a su doble; es uno inteligente y discreto; pero aquél se empeña a todo trance en hacer un desatino, y a veces algo sumamente cómico, y de pronto observa uno que uno mismo quiere hacer también esa payasada, y Dios sabe por qué; es decir, que quiere uno, sin querer, oponiéndose con todas sus fuerzas, quiere" Relata la anécdota de un médico que se puso a silbar en los funerales de su padre y refiere que a él le pasa lo mismo, motivo por el que no fue al funeral de Makar. "... vuelvo a coger la imagen (religiosa que pertenecía a Makar) y escucha: me dan ahora unas ganas tremendas de ir y arrojarla ahora mismo, en este mismo instante, a la estufa, desde aquí mismo. Estoy seguro de que del golpe que recibiera se partiria en dos mitades ni más ni 
menos"(T.II, P.III, C.X, p. 1882). Esta escena acaba tirando la imagen sobre la estufa y saliendo apresuradamente de la habitación tras gritar que este acto es una alegoría.

En el capitulo final de $E l$ adolescente, al reflexionar sobre las circunstancias en que Versílov atenta contra la vida de Katerina y la suya propia, Dostoievski pone en boca de Arkadii el análisis más completo sobre la idea del doble: "Versílov, en aquel momento, es decir, aquel último día y la víspera, no podía abrigar ninguna intención firme, y hasta pienso que ni siquiera pensaba en tal cosa, sino que obraba bajo el influjo de un torbellino de sentimientos. Por lo demás, no creo en una locura verdadera, tanto más cuanto que ahora tampoco está loco. Pero lo del doble, eso sí, lo admito sin ningún género de duda. Pero ¿Qué es eso del doble? El doble, por lo menos, según el libro de Medicina de un especialista que luego hube de leer, no es otra cosa que el primer grado de cierto trastorno, ya grave, que puede conducir a un final bastante desastroso. Además, el propio Versílov, en su escena en casa de mamá, nos explicó aquel desdoblamiento de entonces, de sus sentimientos y de su voluntad, con sinceridad tremenda. Pero vuelvo a repetirlo, no obstante: aquella escena en casa de mamá, aquel destrozo de la imagen, aunque de manera indiscutible, consumáronse bajo el influjo de un verdadero doble; a mí siempre parecióme, desde entonces, como que en parte mezclábase a ello también cierta maligna alegoría, cierto como odio a las esperanzas de aquellas mujeres, cierta rabia contra sus derechos y sus juicios, $\mathrm{y}$ he aquí que, a medias con el doble ¡hizo trizas la imagen! “¡Ea, caramba; que se hagan trizas también vuestras ilusiones!" En resumidas cuentas, que si terció allí el doble, también había, sencillamente, extravagancia”. Ahora de Versílov, dice Arkadii, sólo queda la mitad del antiguo Versílov, aunque conserva toda su inteligencia y carácter moral.

Por tanto, en el acto violento perpetrado por Versílov existió un "desdoblamiento" de sus sentimientos y voluntad, término que Karl Jaspers va a utilizar posteriormente en su Psicopatología general (1913) con idéntico significado. Para este autor tampoco son patológicas las alteraciones leves en la conciencia de la unidad del yo (pone como ejemplo, cuando se habla automáticamente y al mismo tiempo, uno se observa y se escucha) pero pueden llegar a ser graves si se intensifican o perpetúan. Así, este autor considera que "la vivencia real de desdoblamiento, la vivencia de la propia escisión, existe cuando ambas series de procesos psíquicos están desarrolladas al mismo tiempo de tal modo que se puede hablar de personalidades que vivencian ambas, en modo característico, que existen en ambas partes relaciones de sentimientos que no coinciden con las de la otra parte y que más bien se hallan 
enfrentadas mutuamente..." (p. 144). Versílov es plenamente consciente de su propia escisión y, como nos cuenta, es como estar partido en dos mitades que, en el mismo momento, sienten y quieren actuar de forma diferente. Actualmente, estas vivencias de desdoblamiento siguen estando escasamente descritas en Psiquiatría. Se diferencian de los trastornos de identidad disociativos en que en estos últimos la conciencia de unidad se mantiene sincrónicamente, pero no diacrónicamente. Por el contrario, el desdoblamiento tiene carácter sincrónico: las diferentes personalidades se vivencian simultáneamente. En su vertiente psicótica estarían emparentados con el mitologema de la pluralidad de egos de Sarró (Sanchez Blanque, 1982).

Fiodor Dostoievski relaciona la conducta agresiva de Versílov con este desdoblamiento, si bien parece dejar bien claro que en ningún momento existió una pérdida del juicio de realidad ni de capacidad de control, siendo este "doble" más bien una forma de llevar a cabo sin trabas sus deseos; así, Arkadii considera que en el fondo de su actuación existe "extravagancia" y deseos de revancha. Y para Arkadii, este "doble" forma una parte sustancial de la personalidad de verdadero Versílov, de la que no dependen ni su inteligencia ni su carácter moral (que en términos psicoanalíticos podría traducirse como una parte diferente al yo y al superyo, o sea, que corresponde al ello). 


\section{E1 suicidio "romántico"}

\section{E1 adolescente}

1. Lidia Ajmákova: Hijastra de Katerina Nikolayevna, joven enfermiza y extravagante de diecisiete años, muy hermosa y "además, una novelera", enamorada de Versílov con el que desea casarse. Katerina se niega a esta boda, seguramente por la aversión que profesa a éste desde que intentó seducirla a ella misma. Lidia, se envenena a causa de este enamoramiento con una disolución de fósforo, según los rumores, aunque la familia lo ocultó. Antes de conocer a Versílov, Lidia mantuvo un idilio con el príncipe Sokolskii, quedando embarazada de éste, motivo real por el que Versílov le propone matrimonio. Lidia parió una niña muriendo a las dos semanas (en realidad, no queda del todo claro si de suicidio o de muerte natural).

\section{Los hermanos Karamázov}

1. Ya en las primeras líneas de Los hermanos Karamázov Dostoievski relata de pasada el suicidio de "una señorita de la pasada generación". Dostoievski compara este suicidio con el proceder de Adelaida Ivánova, primera esposa de Fiodor y madre de Dimitri, joven rica, guapa y con talento que se casa con un mequetrefe como Fiodor. Dice Dostoievski: "Porque conocía yo a una señorita, todavía de la pasada generación, la cual, después de varios años de enigmático amor a un caballero, con el que, después de todo, habría podido casarse tranquilísimamente, concluyó por imaginarse ella misma invencibles obstáculos, y en borrascosa noche lanzóse desde escarpada orilla, semejante a un acantilado, a un harto profundo y rápido río, en el que pereció sin remedio por su propio capricho, sólo por parecerse a la shakesperiana Ofelia; de modo que si aquella escarpada orilla, tan conocida y predilecta suya desde hacía mucho tiempo, no hubiera sido tan pintoresca, sino simplemente una orilla llana, puede que no hubiese tal suicidio. Este hecho es verídico, y se impone pensar que en nuestra vida rusa, en las dos o tres últimas generaciones, se producirán no pocos hechos semejantes" (T. III, P.I, L.I, C.I, p. 23). 
2. Grúschenka, la mujer por la que rivalizan el viejo Karamázov y su hijo Dimitri, intentó ahorcarse tras ser abandonada por su primer amante, al que ella misma llama "el único e indiscutible". Tras éste abandono fue protegida por un viejo rico.

\section{Discusión}

Si una fecha podría considerarse como el inicio del Romanticismo, esta no sería otra que 1774 , la fecha de la publicación de Las desventuras del joven Werther de Goethe. Esta novela, escrita en forma epistolar, narra la historia de un joven apasionado y sentimental, que ante la imposibilidad de lograr el afecto de la persona amada, se suicida. El ambiente de esta época goethiana ha sido llamado de tedium vitae, de "dolor universal", de "mal romántico". Para Cabaleiro Goás (1951) esta época se caracteriza por la repugnancia de la vida, el empacho y el hastío, en la que "los hombres se sienten con falta de fe en sí mismos, se muestran vacilantes, hastiados y fatigados de la vida, de una vida sin rumbo ni objetivo, aburridos..., y con ese dolor, con esa amargura del vivir se encuentran paradójicamente dichosos. Werther es una expresión de esta psicología de su tiempo, de este "mal romántico". Goza en sus sufrimientos, manifestación de un masoquismo espiritual... No es este un suicidio pasional vulgar, es un suicidio simbólico de una época que vivió dolorida y amargada". Este tedium vitae, para este autor, se gesta en Rousseau, que, como dice citando a Pardo Bazan: "nació Juan Jacobo para enseñar a un siglo la triste ciencia de devorarse el corazón, y para suscitar la juventud que no rie, los aburridos, los fatales, los frenéticos y los suicidas" (pp. 32-35). Con esta novela y este ambiente, una epidemia de suicidios invade Europa en los que el libro de Goethe será encontrado al lado del cadáver.

Fiodor Dostoievski también hace referencia a este libro y al suicidio de su protagonista. En Enero de 1876, Dostoievki inicia su Diario de un escritor relatando varios suicidios en el primer capitulo, al que titula $A$ modo de introducción, a propósito de las osas mayor y menor, de la oración del gran Goethe y, en general, de las malas costumbres. Dostoievski compara dos suicidios actuales entresacados de la prensa con el suicidio de Werther. Dice: "Werther, el suicida, al quitarse la vida, en las últimas líneas por él escritas, se lamenta de no ver ya más la bellísima constelación de la Osa Mayor, y se despide de ella...¿Por qué quería tanto el joven Werther a esa constelación? Pues porque cada vez que la 
contemplaba caía en la cuenta de que no era él ningún átomo ni ningún cero ante ella; que todo ese abismo de divinas maravillas no era superior a su pensamiento y a su conciencia, no era superior al ideal de belleza que llevaba en su alma, siendo, por tanto, igual a ella y dotado de vida infinita. ¡Y que felicidad sentir ese gran pensamiento, que se le revelaba de quien era él! Le estaba agradecido únicamente a su semblante humano. "Gran Espíritu, te doy gracias por este rostro humano que me diste" He aquí cuál había de ser la oración del gran Goethe en todo el resto de su vida. Aquí acabamos del modo más sencillo, con ese rostro humano, sin andarnos con requilorios germánicos, y nadie piensa en despedirse ni de la Osa Mayor, ni de la Menor y hasta le daría vergüenza pensarlo" (1876, Enero, C.I, pp. 873-4).

Aquí vemos, por tanto, las dos caras del suicidio romántico de Werther: por una parte, el peligro del tedium vitae, su masoquismo y hastío, el sentimentalismo vacío que aparece en muchas de sus páginas; Dostoievski, en cambio, resalta en el Werther y en su romanticismo la defensa a ultranza de la Naturaleza y de la armonía de cada ser humano con el resto del universo. Y sobre todo, enfatiza la creencia de Werther en la inmortalidad del alma, al contrario que en los otros suicidios referidos en los cuales los suicidas "no tienen el menor barrunto de que posean un yo y sean criaturas inmortales. Apenas si han oído hablar de eso alguna vez" (p. 873).

Los suicidios que exponemos en estos apartados son suicidios típicamente "románticos", causados por la falta de correspondencia en el ser amado o por el placer masoquista propio del romanticismo. En estos también parece que "no tienen el menor barrunto de que posean un yo y sean criaturas inmortales" y Dostoievski los va a describir de una forma algo caricaturesca.

En el primer caso, el de Lidia Ajmákova de El adolescente, Dostoievski la describe claramente como joven enfermiza y extravagante y "además, una novelera", haciendo hincapié, por tanto, a la falta de madurez y autenticidad del personaje y la influencia decisiva de la lectura de novelas, presumiblemente románticas, en su actuación.

Al principio de Los hermanos Karamázov y de pasada, nos refiere el suicidio de una mujer. Nos describe este suicidio comparándolo al hecho de que Adelaida Ivánova, joven rica, guapa y con talento se casará con un hombre como Fiodor Karamázov, considerando que ambas actuaciones tiene las mismas motivaciones psicológicas. Y éstas parecen estar relacionadas con este "mal romántico" y el masoquismo espiritual. Así, Dostoievski nos refiere 
como la suicida se inventó múltiples obstáculos que le impedian llevar a buen fin su relación amorosa y que el suicidio no fue más que el último acto de un drama romántico en el que ella era una heroína similar a la Ofelia de Shakespeare; de forma irónica resalta la teatralidad y puesta en escena de este suicidio, destacando que si el acantilado no hubiera sido tan pintoresco, seguramente no se habría suicidado.

Por último, en el caso de Grúschenka y su intento de suicidio tras ser abandonada por su amante, aunque el motivo es el mismo, la falta de correspondencia por parte del ser amado, Dostoievski enfoca a este personaje desde otro punto de vista, desde las consecuencias de la humillación sufrida y del masoquismo consiguiente. Así lo expresa la propia Grúschenka: "yo les tengo mucho cariño a mis lágrimas de cinco años. Puede que solo le tenga cariño a mi ultraje y no a él” (T.III, P.III, L.VII, C.III, p. 286). Tras ver de nuevo a este hombre, dice: "No me atormentaba por él, sino de rabia contra mí misma" (T.III, P.III, L.VIII, C.VII, p. 341). En estas afirmaciones, Grúschenka expresa el placer masoquista que le proporcionó su situación ("Puede que solo le tenga cariño a mi ultraje"), que para Freud forma parte de la pulsión de muerte o masoquismo primordial, un masoquismo erógeno que en parte se transforma en libido, pero que de otra parte continua teniendo como objeto al ser propio. En el centro del narcisismo habita, según el psicoanálisis, la pulsión de muerte, y el yo puede llegar a matarse cuando introvierte las investiduras amorosas desengañadas; cuando el destino de la pulsión dirigida hacia afuera se ve sin objeto, la pulsión de muerte que en él se sublimaba, puede retornar sobre el sujeto con toda su carga destructora, desencadenando el suicidio. Dostoievski subraya en esta novela, que solo cuando Grúschenka redirige su libido a un nuevo objeto amoroso, Dimitri, es capaz de sustraerse por fin de ese masoquismo y de esa rabia. 


\section{El suicidio como forma de renacer}

\section{Crimen y castigo}

1. Nikolai Dementiev, un obrero pintor decorador, que estaba trabajando en la casa de la usurera cuando se cometió el crimen. Es acusado del asesinato tras encontrar y empeñar los pendientes de la vieja que Raskólnikov deja caer detrás de la puerta cuando se escondió. Nikolai intenta ahorcarse tras ser detenido en una posada por miedo a ser culpado del crimen. Posteriormente, Nikolai se autoinculpará del crimen siendo inocente.

2. Raskólnikov, tras acusar su crimen y estar en la cárcel, recordará el momento en que Afrosíniuschka, alcohólica, intenta suicidarse tirándose al río en su presencia. En ese momento él dudó entre imitarla (Pensó: "También eso puede ser una salida") o acudir a la comisaria a confesar su crimen. Para el narrador de esta obra estas ideas de suicidio significan el presentimiento de un error profundo y de una futura resurrección.

\section{Discusión}

Nikolai es acusado injustamente del asesinato de la vieja usurera y su hermana. Ante el temor a ser considerado culpable, desesperado, intenta escapar de esta situación ahorcándose. Su conducta momentos después del crimen, jugueteando con su compañero, sirve para descartar desde el punto de vista psicológico que él sea el criminal. No obstante, Nikolai se acusará del crimen posteriormente, aún siendo inocente. Las motivaciones de esta autoacusación derivan de sus creencias y educación, según Porfirii Petrovich, el detective policía que lleva el caso del crimen: Nikolai se educó en el campo bajo la fuerte dirección espiritual de un stáret, leyendo y releyendo los libros sagrados; cuando fue a Petesburgo, siendo aún menor de edad, se dejó llevar por las mujeres y el alcohol; en la cárcel, tras ser acusado, y sobre todo después de su intento de suicidio, recordó las enseñanzas del 
stáret sobre la aceptación del sufrimiento. Este deseo de aceptación del dolor es el que lleva a Nikolai a autoinculparse siendo inocente.

El verdadero culpable, Raskólnikov, ya en presidio, no se siente arrepentido por el asesinato, sino exclusivamente por haberse delatado. Se pregunta: “¿Por qué no se suicidó él entonces? ¿Por qué estuvo allí encima del agua y optó por ir a presentarse? ¿Es que tanta fuerza tenía el deseo de vivir y tan difícil era vencerlo? ¿No lo habia vencido Svridigáilov que tanto le temía a la muerte? Con dolor formulábase esa pregunta y no podía comprender que ya entonces, cuando estaba encima del río, presintiese, quizás en sí mismo y en sus convicciones, un error profundo. No comprendia que aquel presentimiento podía ser el anuncio de una futura crisis en su vida, de su futura resurrección, de su futuro nuevo modo de ver la vida" (T.II, Epílogo, C.II, p. 394). En el epílogo de este libro, Dostoievski emplea sus propias experiencias mientras estuvo en el penal de Omsk. Así, traslada a Raskólnikov su desprecio por los compañeros de prisión, su horror, sus sentimientos de autocompasión masoquista, el odio de los prisioneros hacia él por ser noble. Y también plasma en Raskólnikov lo que el mismo llamó el período de "regeneración de sus convicciones". Crimen y castigo finaliza con las siguientes lineas: "Pero aquí ya empieza una nueva historia, la historia de la gradual renovación de un hombre, la historia de su tránsito progresivo de un mundo a otro, de su conocimiento con otra realidad nueva, totalmente ignorada hasta allí. Esto podría constituir el tema de un nuevo relato, pero nuestra presente narración termina aquí” (p. 399). Y, según el narrador, esta nueva historia realmente se inició cuando Raskónikov consideró la posibilidad del suicidio.

En ambos casos, aunque de forma más explícita en el segundo, las ideas o el intento de suicidio representan el inicio de un cambio de dirección en sus vidas. Enrique Rojas (1978), en su clasificación sobre los actos suicidas, los considera gestos suicidas con intención catártica. En ellos, estos actos van a ser útiles para liberar tensiones y sentimientos displacenteros y van a tener una función profiláctica frente a otra acciones similares futuras. Así suele suceder en los intentos de suicidios únicos en que el sujeto cambia tras él el rumbo de su vida. Quizás, esta regeneración a partir del intento de suicidio podría relacionarse con la teoría de Melanie Klein sobre que el suicidio corresponde a la fantasía inconsciente de destrucción del self malo, conservando $\mathrm{y}$ protegiendo de la destrucción al objeto bueno.

El suicidio consumado como forma de renacer ha sido descrito, con una concepción diferente, por Hendin. Este autor relaciona 
estos suicidas con la identificación con el objeto perdido: los suicidas se ven a ellos mismos como incompletos en ausencia del objeto ausente y ven la reunión a través del suicidio como una forma de renacimiento. 


\section{El suicidio por sentimientos de culpa}

\section{E1 Idiota}

1. Kapitón Aleksiéyich Radomskii, el tío de Yeguevnii Pávlovich Radomskii, pretendiente de Aglaya; jefe de una oficina importante en Petesburgo, un cargo importante, de sesenta o setenta años, vividor y simpático, "vicioso", muy rico, cuya herencia ha prometido dejar a su sobrino. Se pega un tiro tras descubrirse que ha cometido un desfalco (P.III, C.II, p. 764)

\section{El adolescente}

1. El Príncipe Sokolskii joven: personaje secundario de esta novela, se corresponde con el tipo dostoievskiano de personaje apasionado, incapaz de controlarse, cuyo paradigma va a ser Dimitri Karamázov. Se caracteriza por sus honradas inclinaciones, su impresionabilidad y sensibilidad, pero sin el juicio y la fuerza de voluntad necesarios para dominar sus deseos. Guapo, joven, ingenuo, jugador, vividor y alegre aunque daba la impresión de que "la verdadera, luminosa y ligera alegría no anidaba nunca en su corazón". Ama y deja embarazada a Liza, hermana de Arkadii. Éste lo describirá en ese momento como un hombre moralmente enfermo, a dos dedos de la locura. El príncipe le confiesa su amor por Liza y su temor de que ésta le ame por lo ilimitado de su abyección, lo que no le impide traicionarla pidiendo la mano a una mujer adinerada y así pagar el chantaje al que está sometido por la falsificación de unas acciones. Finalmente es metido en prisión por este motivo y terminará perdiendo la razón, atormentado por los celos.

Previamente a su encarcelamiento, Sokolskii relata a Arkadii un incidente en el regimiento que servía, en que él miente y culpa a su sirviente Stepánov para salvarse de una amonestación. Ante esta situación el sirviente "limitóse a mirarme en silencio y (pero recuerdo su mirada, y nunca la olvidaré) a encogerse de hombros" y poco después pide el retiro del ejercito, aunque todos los oficiales fueron a visitarle 
y lo animaron a no rendirse. Dos semanas después solicita el retiro también el príncipe alegando motivos familiares. E1 principe refiere sus sentimientos de culpa al respecto que le llevan a las ideas de suicidio: "al cabo de un mes, ya volvía la vista a mi revolver y pensaba en la muerte. Yo lo veía todo muy sombrío, Arkadii Makárovich. Preparé una carta para el jefe del regimiento y para mis compañeros, confesando en absoluto toda mi mentira y rehabilitando el honor de Stepánov. Después de escrita la carta, me planteé la cuestión: Enviarla y vivir o enviarla y morir" (T.II, P.II, C.VII, p. 1738). Liza le convence para que no envie esa carta, alegando que realmente no había perjudicado a nadie, ya que Stepánov tampoco había sufrido realmente una represalia.

2. Makar, el marido legal de la madre de Arkadii, que se hace peregrino, relata a Arkadii una historia relativa a un soldado licenciado: Cuenta Makar cómo un soldado, tras licenciarse y volver a su aldea, se emborrachó y robó algo. Le prendieron y en el juicio él confesó todas sus culpas. Pero el jurado le consideró inocente y el soldado "dio en apesadumbrarse, en cavilar, en no comer, ni beber, ni hablar con nadie, y a los cinco días fue y se ahorcó. "Para que se vea lo que es vivir con un pecado sobre el alma" terminaba Makar Ivánovich". Para Makar el suicidio es el pecado más grande del hombre, pero el juez en este caso sólo es Dios "porque El solo sabe todo, todo limite y toda medida" (T.II., P.III, C.III, p. 1794)

\section{Los hermanos Karamázov}

1. Dimitri Karamázov, el prototipo de hombre apasionado e incapaz de controlarse, pero generoso y noble, también presenta ideas de suicidio, como por ejemplo, en sus reflexiones cuando espera a su hermano Alíoscha al atardecer: "iQué lóbrega noche, anubarrada, y se ha levantado viento! Me aposté aquí, al pie del sauce, para aguardarte, y de pronto pensé (¡Dios es testigo!): “¿Para qué pensar más, para qué esperar? Aquí está este sauce; pañuelo tienes, camisa tienes, una cuerda para anudarse en un periquete, $\mathrm{y}$, si es preciso, se echa mano de los tirantes, y no continúas en esta tierra, no sigues deshonrándola con tu presencia vil". Y he aquí que en ese instante siento pasos, llegas tú ¡Señor, pareció como si algo aleteara en mí porque 
hay, a pesar de todo, un hombre al que yo quiero, y ese hombre es mi hermanito rico, al que quiero más que a nadie en el mundo, al que únicamente quiero!" (T.III, P.I, L.III, C.XI, p. 136).

Posteriormente, cuando cree haber matado a Grigorii y piensa que Grúschenka se ha reconciliado con el oficial que lo ultrajó, el "único e indiscutible", decide suicidarse al día siguiente, pegarse un tiro al amanecer, dejando "el campo libre". Esa noche busca y le hace una fiesta a Grúchenska, tras escribir su nota de aclaración: "Me castigo por toda mi vida ¡Toda mi vida castigo!” (T.III, P.III, L.VIII, C.V, p. 321). Pero al ver a Grúschenka se percata que ésta realmente le ama a él; no obstante, el posible asesinato cometido no le permite seguir viviendo: "Ir por la pistola, volverse allí con ella, y en este mismo sucio y oscuro rincón, acabar de una vez. Un minuto, aproximadamente permaneció indeciso. Antes, al venir alli, había dejado a sus espaldas la ignominia completa: un latrocinio cometido por él y aquella sangre, aquella sangre. Pero entonces tenía el corazón ligero, joh, sí!, ligero. Porque ya entonces todo se había consumado; él la daba por perdida, se la cedía a otro, desaparecía ¡Oh! la sentencia hacíasele entonces fácil, por lo menos, antojabasele inevitable, imprescindible, porque ¿para qué continuar en el mundo? Pero ¿y ahora?... en sus ojos leía él de sobra a quién amaba. Pero he aquí que ahora no hacia falta más que vivir y, y no era posible vivir, no era posible, ¡oh, maldición!” (T.III, P.III, L.VIII, C.VIII, p. 346). Dimitri mismo se lo relata al fiscal y al juez que le acusan del asesinato de su padre: "Bueno, había decidido suicidarme. ¿Para qué seguir viviendo?. Esta pregunta se planteaba sola. Habiase presentado su primero e indiscutible amante, el hombre que la había deshonrado, que venía lleno de amor, a los cinco años, a reparar, casándose con ella, el ultraje. Vaya, yo comprendí que para mí todo se había acabado. Y detrás de mí, el oprobio, esa sangre, sangre de Grigorii. ¿Para qué vivir? Nada, que fui a desempeñar las pistolas para cargarlas y, al ser de día, meterme una bala en la cabeza... Por la noche, de juerga ¡Ah, diablo! Señores, acaben pronto. Tenía la firme intención de suicidarme; miren, cerca de aquí, en los alrededores, y había acordado conmigo mismo que sería a las cinco de la mañana, y en el bolsillo llevaba apercibido un papelito que había escrito en casa de Perjotin al cargar las pistolas" (T.III, P.III, L.IX, C.V, p. 376). Según confiesa Dimitri, sobre todo le atormentaba ante la idea de matarse, morir como un ladrón: "no solo no es posible vivir con vilipendio, sino que hasta es imposible morir cuando 
se es un canalla ¡No, señores; para morir, hay que ser honrado!" (T.III, P.III, L.IX, C.VII, p. 388).

Dimitri es, por tanto, un hombre de incontroladas pasiones, orgulloso y desenfrenado, pero que al mismo tiempo posee un alma noble y generosa. En él estas cualidades se conjuntan con una deformidad espiritual y una sensualidad incontenibles. En la vida cotidiana este oficial vulgar, juerguista libertino, derrochador infatigable, es el vivo retrato del militar insolente, dispuesto siempre a la ofensa y la violencia, "la francachela y la destrucción".

Pero bajo este cruel comportamiento se esconde un corazón vivo y sensible. Hombre de dos extremos, capaz de pasar de los pecados mortales a la vivificante belleza, conoce no sólo las caídas y las cimas, sino también la ascensión a las cumbres. Aunque capaz de elevar su alma a grandes alturas, carece de fuerzas para escapar del torbellino de vicios que le arrastra. Dostoievski expresa esta dualidad de Dimitri hasta describiendo su mirada: "Hasta cuando se emocionaba y hablaba con nerviosidad su mirada no parecía responder a su disposición interior y expresaba algo distinto, que en modo alguno guardaba relación con el momento presente. "Es dificil saber lo que piensa" solian decir los que hablaban con él. Algunos, al ver en sus ojos esa cavilosidad y adustez, sentianse a veces desconcertado ante su súbita risas, testimonio de alegres $y$ traviesos pensamientos, que coincidiesen en él con tan huraños pensamientos" (T.III, P.I, L.II, C.VI, p. 70). Se trata de una personalidad dotada intelectual y moralmente de un alma profunda y compasiva, de un hombre arrebatadizo y entusiasta, fervoroso admirador de Schiller y Hamlet, enamorado de la vida y de la poesía. "Amo la vida, demasiado la amé: eso es hasta ruin... Soy un vil, pero estoy satisfecho de mi mismo. Y, sin embargo, me atormento con eso de que soy un vil; pero, a pesar de todo, estoy satisfecho de mí mismo. Bendigo la creación, dispuesto estoy a bendecir ahora mismo a Dios u su obra; pero es menester exterminar a un venenoso insecto (él mismo) para que no medre, para que a los demás no le estropee la vida... ¿Qué puede haber más precioso que la vida?” (T.III, P.III, L.VIII, C.V, p. 323-4). En un sentido similar, haciendo hincapié a sus dos polaridades, dice al fiscal y al juez en su declaración cuando le acusan de la muerte de su padre: "Les está hablando un hombre bueno, bonísimo, sobre todo -no lo olviden ustedes -, un hombre que ha cometido un abismo de ruindades, pero que siempre ha sido y sigue siendo un hombre nobilísimo en esencia, en el fondo, en lo profundo; 
bueno; en una palabra; no acierto a explicarme. Precisamente, ese fue su tormento toda su vida: que estaba ansioso de bondad, que era un mártir de la bondad y la buscaba con un farol, con la linterna. Precisamente ese fue su tormento: toda su vida no hizo más que ruindades" (T.III, P.III, L.IX, C.III, p.365).

Es un improvisador neto de acaloradas charlas sobre cualquier tema, desde cuestiones intimas hasta filosóficas. Dimitri inicia de forma significativa su confesión a Aliosha con el himno a la alegría de Schiller y habla de su dualidad tremenda: de la corrupción a la pureza, Dimitri expresa su pasión por la belleza, que también existe en Sodoma "Lo que a la inteligencia parece ignominia, al corazón se le antoja belleza" "yo siempre amé las callejuelas, las silenciosas y oscuras callejuelas, por detrás de las plazas; allí se da la aventura, allí lo inesperado, allí la perla en el fango... Me gustaba la corrupción y también el bochorno de la corrupción” (T.III, P.I, L.III, C.IV, p. 100).

2. Intento de suicidio del padre de Katerina Ivánova, coronel, a raíz de faltar dinero de la caja del batallón. Durante tiempo el coronel lo prestaba a un individuo que hacia sus gestiones con éste y se lo devolvía con intereses y dádivas, pero un día se negó este individuo a devolvérselo. Cuando la autoridad le pide la devolución del dinero y ante la imposibilidad de devolverlo "Se levantó, dijo que iba a ponerse el uniforme; corrió a su alcoba, cogió su escopeta de caza, de dos cañones, la cargó, le metió una bala de soldado, se descalzó el pie derecho, se apontocó el arma en el pecho y con el pie tanteó el gatillo" (T.III, P.I, L.III, C.IV, p. 105). Gracias a su hija Agafia, que sospechó que podía ocurrir esto y le empujó, la bala se incrustó en el techo y no hirió a nadie.

3. El stárets Zósima cuenta la historia de un caballero acaudalado y bienhechor que conoció en su juventud. Este hombre, según le confesó, mató a la joven a la que amaba y por la que no era correspondido. Fue declarado culpable de la muerte un siervo, que murió a la semana en la enfermería de la cárcel de unas fiebres. Durante años, este hombre guardó el secreto de su crimen y "casi se olvidó de lo acaecido". Pero cuando se casó y tuvo hijos, empezó a sentirse muy culpable, "dio en representársele de un modo amenazador y amargo la sangre de su víctima, su juventud arruinada, su sangre, que clamaba venganza" (T.III, P.II, L.VI, C.II, p. 250), tenía 
terribles pesadillas y pensó en suicidarse o confesar su crimen. Tras conocer a Zósima, confiesa a la justicia su crimen, muriendo poco después.

4. Smerdiákov es el hijo natural de Fiodor y su asesino; su madre fue Lizaveta, una retrasada mental. Smerdiákov se avergüenza de esta procedencia, de ser hijo de Lizaveta. Smerdiákov padece epilepsia, tuvo su primer ataque a los doce años. Es un hombre extraordinariamente huraño y taciturno, solitario y altanero. Tras ir a Moscú a aprender cocina volvió muy bien vestido, cuidaba mucho la ropa cepillándola dos veces al día y se convirtió en un excelente cocinero. Smerdiákov es capaz de enseñar a los niños cosas tan ruines como hacer sufrir a los perros callejeros dándoles migas de pan clavadas con un alfiler. El narrador de la novela le define como un "contemplativo" que a menudo se quedaba ensimismado, con una "suerte de embebecimiento" en el que parecía no haber "mente ni idea" y, que al volver en sí no se acordaba de nada aunque si habrian existido unas impresiones duraderas". Concluye el narrador: "puede que de pronto, habiendo acumulado impresiones durante muchos años, lo deje todo y se vaya a Jerusalén a peregrinar y buscar la salvación de su alma, y puede que, asimismo, de pronto, un día le prenda fuego a su pueblo natal, y hasta puede que haga entrambas cosas juntas" (T.III, P.I, L.III, C.VII, p. 115). Grigori, el criado de Fiodor que le crió, lo define como "un chico mañoso, pero estúpido y enfermucho, y, lo que era peor, un ateo, y su ateísmo se lo habian inculcado Fiodor Pavlovich y su hijo mayor" (T.III, P.IV, L.XII, C.II, p. 514).

Iván, el hijo mayor de Fiodor, siente aversión por Smerdiákov, aunque al principio mantuvieran buenas relaciones. Iván "habiale enseñado a hablar con él, aunque admirando siempre cierta incoherencia o, mejor dicho, cierto desasosiego de su inteligencia y no comprendiendo qué era lo que aquel contemplador podía, de modo tan constante e irresistible, atosigar. Hablaba de cuestiones filosóficas... pero... venían a resultar de tercer orden, siendo otra cosa muy distinta lo que necesitaba. Sería así o no pero en todo caso, desde el principio, empezó a acusarse y ponerse de manifiesto un amor propio inexplicable, y al mismo tiempo, un amor propio resentido" (T.III, P.II, L.V, C.VI, p. 219). Además, Iván siente que Smerdiákov le trata con cierta familiaridad y complicidad, lo que le produce aún más repugnancia. El día antes del asesinato, Smerdiákov confiesa a Iván que en ocasiones piensa en quitarse la vida ante la 
presión que soporta por parte de Fiodor y de Dimitri. Smerdiákov confiesa a Iván haber sido el asesino de su padre el día que se suicida, considerándose un mero ejecutor de los deseos de Iván: "Usted fue quien le mató; usted ha sido y es el principal asesino, y yo no fui más que su instrumento, su fiel servidor, y siguiendo sus indicaciones, lo hice..." (T.III, P.IV, L.XI, C.VIII, p. 483). Smerdiákov se ahorca colgado de un clavo de la pared de su habitación dejando una nota que dice: "Me quito la vida por mi voluntad y deseo, para no acusar a nadie".

En el discurso del fiscal durante el proceso es descrito como un hombre de poca inteligencia, con cierta cultura y "desequilibrado por ideas filosóficas superiores a su inteligencia e intimidado por algunas doctrinas contemporáneas relativas al deber" (T.III, P.IV, L.XII, C.VIII, p. 545) que se suicida en un ataque de locura. El defensor, por el contrario, lo define como "malo, sumamente vanidoso, vengativo y envidioso... no quería a nadie, sino a sí mismo, teniendo de su persona una altísima idea. Para él la cultura se cifraba en un buen traje, puños limpios y zapatos bien dados de charol". Para éste, Smerdiákov no se suicidó por arrepentimiento, sino por desesperación y "el suicida, al atentar contra su vida, pudo en aquel momento sentir doble odio hacia aquellos a quienes toda su vida odiara" (T.III, P.IV, L.XII, C.XII, p. 570-1).

\section{Diario de un escritor}

1. El capítulo II de Octubre de 1877 se titula El suicidio de Hartung y nuestra pregunta eterna: “¿Quién es el culpable?. Trata, por tanto, sobre el suicidio del General Hartung al cuarto de hora de haber pronunciado la Audiencia territorial un veredicto condenatorio contra él. El general es un hombre con un cargo considerable y de la mejor sociedad que se conchaba con un usurero; al morir éste empiezan las inculpaciones: robos de letras, desaparición de documentos, de bienes, por valor de cien o doscientos mil rublos. El general no espera a conocer el veredicto disparándose un tiro en el corazón con un revolver que llevaba cargado en la habitación contigua. Deja una carta en la que "jura por Dios omnipotente" no haber procedido de mala fe en este asunto y perdona a sus enemigos. Para Dostoievski de esta tragedia "todos somos culpables: la moral y los hábitos de nuestra 
clase intelectual y los caracteres que en esa clase se producen y, finalmente, la moral y los hábitos de nuestros jóvenes tribunales, copiados del extranjero y que aún no se han vuelto rusos" (p. 1361).

\section{Discusión}

En todos estos casos la existencia de un acto reprobable realizado por el individuo es la causa del suicidio en sus diferentes versiones (suicidios consumados, suicidios frustrados, ideas de suicidio). No obstante, se podrian diferenciar entre diferentes motivaciones últimas para realizar el suicidio. En algunos casos la comisión del acto reprobable es, en sí mismo, la causa del suicidio, como en el caso del relato de Makar sobre el suicidio del soldado licenciado, el caso del caballero relatado por Zósima o en el caso de Dimitri Karamázov cuando cree haber asesinado al sirviente Grigorii. Pero en otros casos el suicidio se realiza cuando este acto reprobable es conocido o va a ser conocido por otros: Kapitón Aleksiéyich Radomskii, el tío de Yeguevnii Pávlovich Radomskii, se pega un tiro cuando se descubre el desfalco que ha cometido; el padre de Katerina Ivánova se intenta suicidar cuando le piden de forma apremiante el dinero de la caja y ante la imposibilidad de restaurarlo, lo que supondría el conocimiento, por parte de las autoridades, de sus negocios ilícitos con este dinero; y el general Hartung, en éste último caso corresponde a un hecho real, se suicida antes de conocer el veredicto. Para Dostoievski "Hartung se suicida por creer haber perdido el honor; el dinero puede quitar el seso tanto a los calaveras como al buen padre de familia. Se entrampó, casi sin darse cuenta, como muchos otros de su clase social. Justificó sus actos ante sí mismo no considerándose en ningún momento que había robado. Las irregularidades monetarias que cometió por asesoramiento del usurero fueron realizadas gradualmente, de forma que Hartung "iba perdiendo la verdad y hundiéndose cada vez más en la mentira" Hartung murió reconociéndose inocente aunque no haya error judicial al condenarle" (p. 1365).

Para Castilla del Pino (1982), "el sentimiento de culpa es mucho más llevadero y en todo caso aliviable mediante racionalizaciones si es ignorado por los otros, mientras que la culpa conocida es a veces intolerable y lleva incluso al suicidio precisamente por la depreciación del self que acompaña" (p. 164). Dostoievski contradice esta orientación en los relatos que pone en boca de 
Makar o de Zósima, enfocándolos desde el punto de vista religioso, y en el caso de Dimitri, que su resolución de suicidarse en absoluto tiene relación con el conocimiento de los demás de su delito, sino con la imposibilidad, sentida de forma íntima y personal, de seguir viviendo tras haber "derramado la sangre de Grigorii". Dostoievski, en los casos que Castilla del Pino considera como culpa conocida, no cree que estos suicidios se correspondan con sentimientos de culpabilidad, sino de honor. Así, Dostoievski expone las racionalizaciones realizadas por el general Hartung ("Justificó sus actos ante sí mismo no considerándose en ningún momento que había robado") y considera que en estos casos los sujetos no se consideran, al menos de forma consciente, culpables, aunque lo sean realmente.

En el personaje del príncipe Sokolskii joven de El adolescente las ideas de suicidio están claramente relacionados con la acusación falsa que hizo a su sirviente; éste no se defiende y es el único sujeto que conoce realmente lo acaecido hasta que el príncipe lo confiesa a Liza. No obstante, Dostoievski no explícita en cual de los dos grupos se halla este personaje. El hecho de que todos los oficiales fueran a visitar al sirviente para animarle parece indicar que su culpa era conocida por todos. No obstante, tanto la personalidad del príncipe como su deseo de rehabilitar el honor de su sirviente, nos inclina a pensar en un sentimiento de culpa real y no mediado por la opinión de los otros.

En el caso del suicidio de Smerdiákov, las motivaciones no están del todo claras; el hecho de que Smerdiákov se suicide tras confesar a Iván que él es el asesino y la desaprobación posterior y rotunda de éste, podría corroborar la opinión del fiscal como "desequilibrado por ideas filosóficas superiores a su inteligencia e intimidado por algunas doctrinas contemporáneas relativas al deber".

En realidad, Smerdiákov es el doble negativo de Iván: "Iván Fiodorovich, a la primera mirada, comprendió que el criado Smerdiákov estaba sentado en su alma" (T.III, P.II, L.V, C.VI, p. 219). Smerdiákov le dice a Iván cuando le confiesa que es el asesino: "yo pensaba que usted era también como yo" (T.III, P.IV, L.XI, C.VI, p. 471). Iván y Smerdiákov son un ejemplo obvio de los "dobles" utilizados frecuentemente por Dostoievski en toda su obra; aparentemente, Iván es de ambos el más fuerte y el más inteligente y Smerdiákov es el instrumento de su voluntad; los inconscientes deseos de muerte del padre de Iván se dirigen a Smerdiákov quien se comunica directamente con el inconsciente; por tanto, Smerdiákov es en esta relación el amo, el controlador del destino, ya que es capaz de traspasar la barrera de la consciencia cuyo 
deber es negar los impulsos negativos. El resultado final es que, aunque Smerdiákov sea descrito desde el inicio como enfermo, cobarde y poco inteligente, en realidad termina siendo superior a Iván; es el asesino de su padre, el "instrumento" de Iván, pero al mismo tiempo resulta más astuto y con mayor capacidad de apercibimiento que el mismo Iván. Actúa a partir del deseo no realizado de éste, como un doble suyo, aunque el personaje por sí mismo emerge durante la novela con gran fuerza.

Para algunos autores (Oates, 1999), el suicidio de Smerdiákov no entraría en este apartado relacionado con la culpa, ya que no es fácilmente entendible desde la psicología del personaje; para estos autores este suicidio solo se explica desde la necesidad de Dostoievski de terminar de forma dramática la novela; habiendo realizado el acto que el novelista le había asignado, el personaje no tiene identidad alguna ya. Podría apoyar esta teoría el hecho de que este personaje es transformado a lo largo de la novela, pasando de ser alguien al que no hay que prestarle mucha atención, como nos avisa el narrador ("me remuerde la conciencia distraer tan largo rato la atención de mis lectores a cuenta de tan vulgares criados; así que tornaré a mi cuento, esperando que de Smerdiákov ya habrá ocasión de hablar en el ulterior curso del relato" (T. III, P.I, L. III, C.II, p. 95) a un héroe "oscuro" o el antihéroe central de una gran fuerza. 


\section{El suicidio egoísta}

\section{Diario de un escritor}

1. En el capítulo II de Abril del año 1877 de Diario de un escritor, Dostoievski escribe un relato corto al que llama Sueño de un hombre ridiculo (Relato fantástico). Este relato narra la experiencia de un hombre que decide suicidarse; ha llegado a un estado de indiferencia total, todo le es lo mismo. Una noche fría y húmeda, cuando está volviendo a casa, al ver en el cielo una estrellita, decide pegarse un tiro esa noche. "Ya dos meses atrás lo había decidido yo solemnemente, y, con estar tan mal de cuartos como estaba, me había agenciado un bonito revólver, el cual habia cargado aquel mismo día. Y, sin embargo, dos meses eran pasados ya, y el tal revólver continuaba en la gaveta; tan me daba todo lo mismo, que quería aguardar a un momento en que no me diera tan lo mismo todo, aunque el porqué de ese aplazamiento lo ignoro. $\mathrm{Y}$ he aquí que yo todas las noches, durante esos dos meses, al volver a casa, creía que iba a ser aquella la noche en que me pegase el tiro. Aguardaba siempre el momento. Y de pronto sugirióme aquella estrellita la idea, y resolví terminantemente pegarme el tiro aquella noche. Lo que no sé es por qué la estrellita hubo de sugerirme la idea" (p. 1231).

En ese momento se encuentra con una niña harapienta de ocho años que le pide desesperadamente ayuda y él se la niega. Esa niña, según el héroe, es la que ha evitado que él se pegue un tiro. Pues aunque todo debia darle igual ya que se va a suicidar, siente compasión y piedad de esa niña.

El hombre ridículo se sienta en un sillón y se queda dormido, teniendo un sueño que le rebela una vida nueva. Sueña que se suicida y es trasladado a un planeta idéntico a la Tierra pero paradisíaco, en el que todos los seres son felices y reina la armonía. Estos hombres, dice nuestro héroe, no poseían la ciencia de la Tierra, pues su saber era más elevado y no la necesitaban para aprender cómo debían vivir, ya que ellos ya lo sabian. Creían sin reservas en la existencia de la vida eterna y mantenían una vital identificación con el Todo, que tras la muerte, estaban convencidos, sería aún mayor; "no hacian otra cosa que amarse los unos a los otros" (p. 1239) 
Pero con su llegada los hombres empiezan a aprender lo que es la mentira, y de ésta la voluptuosidad, la envidia y la crueldad; "Inicióse la lucha por la separación, por la particularización, por la personalidad, por el tuyo y el mío. Rompieron a hablar en distintas lenguas. Conocieron el dolor y le tomaron gusto; lampaban por el sufrimiento y decían que la verdad solo se compra a precio del martirio... cada uno de ellos se había vuelto más preciado para sí mismo que los demás; se había vuelto más preciado que nada en el mundo... volvierónse todos tan celosos de su yo, que cada cual se afanaba por rebajar, oprimir y empequeñecer el yo del prójimo por todos los medios posibles". Estos hombres empezaron a hacer "ciencia" para intentar encontrar la verdad y "el conocimiento de la vida empezó a estar por encima de la vida misma". Apareció la esclavitud, las guerras. Algunos "soberbios voluptuosos" querían o todo o nada y si no conseguían nada con fechorias, quedaba el recurso del suicidio. Hasta "hubo religiones consagradas al culto del no ser y del propio aniquilamiento en aras del eterno reposo en la nada"; estos hombres proclamaron que "el dolor es belleza". Nuestro héroe intenta convencer a estos hombres que, por su culpa, habian errado el camino. Pero ante la insistencia, ellos deciden recluirle en un manicomio, momento en que el protagonista se despierta.

Tras este sueño este personaje cambiará profundamente; y desde entonces intentará anunciar a todos la posibilidad de un paraíso en la Tierra (a expensas de parecer ridículo) con un único precepto: ama a la Humanidad como a ti mismo.

\section{Discusión}

En 1897, Emile Durkheim define el suicidio egoísta en su obra $\mathrm{El}$ suicidio. Para este autor, este tipo de suicidio aparece en aquellas sociedades en las que existe un elevado grado de desintegración social. En estas sociedades, los fines individuales se hacen prioritarios con respecto a los colectivos, el yo individual se hipertrofia con respecto al yo social. Por tanto, la característica principal de estas sociedades será la excesiva individualización y egocentrismo. Estas sociedades favorecen la existencia del individuo que ha perdido todo interés por las actividades públicas. 
"Le repugna salir de sí mismos. En desquite, el pensamiento y la vida interior ganan todo lo que pierde en actividad. Al desviarse de lo que le rodea, la conciencia se repliega sobre sí misma, se toma como su propio y único objeto y se da por tema principal observarse y analizarse. Pero con esta extrema concentración no hace sino profundizar el obstáculo que lo separa del resto del universo. Desde el momento en que el individuo se apasiona hasta tal punto por sí mismo, no puede sino desligarse más de todo lo que no sea él, y consagrar, al reforzarlo, el aislamiento en que vive" (p. 304). Si la actividad se convierte exclusivamente en vida interior, se hace insensible a todo lo que le rodea; ahora bien, como toda vida interior toma de fuera su materia, si ésta se separa demasiado radicalmente de los demás seres, no tiene nada en lo que se pueda aplicar y se convierte en un vacío, a la que sólo le es permitido reflexionar sobre su propia miseria. "Se complace en ello, se abandona a ello con una especie de goce malsano" La conciencia individual, por tanto, alcanza un desarrollo enfermizo y llega a ser la desgracia del hombre cuando se considera como un absoluto y busca en sí mismo su propio fin.

Este desarrollo del individuo presuicida en las sociedades desintegradas se corresponde en su totalidad con "el hombre del subsuelo" descrito por Dostoievski y en la situación anímica en que se muestra al "hombre ridículo" previamente al sueño que modificará profundamente sus convicciones: "Sentí de golpe y porrazo que para mí todo era lo mismo, que me daba igual que existiera el mundo o no existiera. Poco a poco iba viendo $y$ sintiendo que no habia nada fuera de mí... Desde aquel punto y hora dejé ya de preocuparme de los mortales, y casi no volví a fijarme en ellos. Lo cual no tardó en traslucirse en las cosas más nimias, pues ocurriame por ejemplo, cuando iba por las calles, que me daba tropezones con la gente. Y no se crea que porque iba sumido en cavilaciones; no podía ser asi, porque yo había dejado de pensar en nada; para mí todo era igual. ¡Y si, por lo menos, me hubiese entregado a resolver problemas! Pero no; ni uno solo he resuelto en la vida, y eso que, verdaderamente, los hay a porrillo. Pero como a mí todo me daba lo mismo, los problemas se alejaban de mí ellos solos" (p. 1230). "En aquel momento resultábame evidente de todo punto que la vida y el mundo dependían casi únicamente de mí. Puedo decir todavía más; que el mundo ahora casi parecía creado para mi solo. Prescindiendo por completo de que acaso realmente para nadie, después de mí, hubiese nada más, y el mundo entero, en cuanto mi conocimiento se extinguiera, se desvaneciese enseguida como una visión, cual un simple conocimiento mío y dejase de ser, pues quizás ese mundo y todos esos hombres sean únicamente yo mismo" (p. 1233). 
En estos casos, dice Durkheim, la vida no encuentra entonces su razón de ser y esta doctrina lleva al suicidio, exactamente como le ocurre al héroe de este relato. El suicidio egoísta, según el sociólogo francés, se caracteriza por una melancolía tranquila y dulce, una indiferencia ante todo, que hace que el desenlace final no tenga nada de violento ni de precipitado. Esta melancolía triste es reflejada de forma poética en el paseo nocturno del "hombre ridículo" la noche que decide suicidarse y la indiferencia total que presenta es tal, que, como nos reconoce él mismo, lleva dos meses pensando en quitarse la vida, pero no lo ha hecho aún porque "le daba tanto todo lo mismo que esperaba un momento en que no le diera tan lo mismo todo".

En este momento Dostoievski introduce un elemento nuevo que le permite al personaje salir de la indiferencia en la que está sumido; este elemento será el sentimiento de compasión ante el sufrimiento de una niña harapienta: “¿por qué sentiría yo entonces, de pronto, que no me era indiferente todo y que me daba lástima de la niña? Todavía recuerdo que verdaderamente me inspiraba piedad; sí, hasta el punto de sentir un dolor especialísimo, me inspiraba lástima”. Por fin el hombre ridículo es capaz de volver a mirar al mundo ante esta situación de sufrimiento ajeno, y ante su perplejidad, sufre este sentimiento de piedad y de vergüenza por no ayudarla independientemente de su decisión de quitarse la vida, o sea, independientemente de él mismo: " ¿Y podría realmente el reconocimiento de que yo voy a dejar de ser en seguida, y, por consiguiente, de que todo va también a dejar de ser, no tener el influjo sobre el sentimiento de piedad que inspira esa niña ni sobre el sentimiento de vergüenza por la brutalidad en que uno haya incurrido?". Ante estas preguntas sin respuesta, el personaje decide aplazar su muerte: "En unas palabras, que aquella niña me salvó" (p. 1233)

El sueño del personaje trata del paso de una sociedad ideal, basada en el amor y la integración con los demás seres a las sociedades materialistas, en las que prima la individualidad y el razonamiento sobre la hermandad y los sentimientos vitales. Este sueño relata el desastre de este paso y la incapacidad del hombre de percatarse de este desastre. El hombre ridículo vive este sueño como la anunciación de una verdad: la posibilidad de la vuelta a esta sociedad ideal basada en el amor. 


\section{El suicidio anómico}

\section{Diario de un escritor}

1. En Enero de 1876, Dostoievski inicia su Diario de un escritor relatando varios suicidios en el capítulo primero, al que llama "A modo de introducción, a propósito de las osas mayor y menor, de la oración del gran Goethe y, en general, de las malas costumbres". Dostoievski comenta que en la actualidad todos están convencidos de que donde quiera que entren lo que hay es suyo y de nadie más, y si no es suyo, no se enfadan, sino que lo resuelven en seguida, escribiendo notas como la siguiente: "Querido pápasha: Tengo veintitrés años, y aún no he hecho nada en la vida; estoy seguro de que no sirvo para nada; así que he decidido suprimirme" Y a continuación se pega un tiro. Dice Dostoievski: "Pero ahí todavía hay algo comprensible: “¿Para qué vivir como no sea por orgullo?" Pero otro, mira, llega y se suicida en silencio únicamente por no tener dinero para ponerle una pensión a su querida. Y esto es ya una perfecta cochinada. Aseguran en la Prensa que hacen eso por pensar demasiado. "Piensa que te piensa y de pronto dan en donde duele". Pero yo estoy seguro que no hay tal cosa, de que esa gente no está en condiciones de formarse idea de nada, es inculta hasta el salvajismo, y si algo quiere, es de un modo asaz vago, inconsciente; una cochinada perfecta: $\mathrm{y}$ no hay en todo eso nada de liberal. Y además, ni siquiera la pregunta de Hamlet: Pero el temor a lo de allá... Nuestros suicidas no tienen el menor barrunto de que posean un yo y sean criaturas inmortales. Apenas si han oído hablar de eso alguna vez. Y, sin embargo, tampoco son ateos... Sencillamente, que no tienen dinero para costearse una querida, y nada más" (pp. 873-4).

Dostoievski compara ambos suicidios con el suicidio de Werther, en el que éste se despide de la Osa Mayor con el convencimiento, que al igual que ella, él está.

2. En el capítulo II de Mayo de 1876, Dostoievski narra la carta de una suicida de veinticinco años, bastante larga, publicada en un periódico. Esta suicida era hija de propietarios acomodados, pero se hizo progresista y se fue a la ciudad a 
estudiar para comadrona; acabó los estudios con buenos resultados y obtuvo una plaza; ganaba bastante y ella mismo decía que no le faltaba nada, pero que estaba muy cansada; la carta, dice Dostoievski, revela un gran enojo y cansancio; da instrucciones a sus padres de con qué hay que vestirla (con la camisa y medias viejas, no con las nuevas); dice a sus padres y amigas que no le lloren aunque piensa que "puede que todo pare en risa". Dostoievski se escandaliza ante la idea de que las personas que la quieren puedan reírse de su cadáver; dicta disposiciones minuciosas sobre el escaso dinero que tiene: esto es una indicación de su convicción progresista de que las privaciones materiales son causa de la infelicidad; Resume Dostoievski: "Por lo visto, estaba cansada del puro hastío de vivir, y por haber perdido toda noción del poder; en una palabra: pérdida absoluta del más alto ideal de la existencia. Y murió la pobre chica. "No te lloraré, pobre; pero déjame que te tenga un poco de compasión, permítemelo; permíteme que te desee la resurrección en otra vida donde no te aburras. Mujeres lindas, buenas, honradas (que todo eso sois), ¿adónde os vais, por qué os atrae tanto la oscura, sorda tumba? Mirad: en el cielo brilla el radiante sol de primavera, echan hojas los árboles y vosotros no estáis entre los vivos" (p. 996-7). Concluye: "cansarse, aborrecer la vida, equivale a odiar a todo el mundo" (p. 997), y compara esta actitud con la de las mujeres que se alquilan de nodrizas por dinero, pero que terminan amando a los niños que crian.

3. En el capítulo I de Octubre del año 1876 de esta obra, en el apartado llamado Dos suicidios relata un suicidio en el que "todo, por fuera y por dentro, resulta un puro enigma": Es el suicidio de una joven, de diecisiete años, hija de un emigrante ruso muy famoso, nacida en el extranjero, rusa por su sangre pero nada rusa en su educación. Según Frank esta suicida fue Liza, hija de Herzen. Se mató impregnando un algodón de cloroformo que se aplicó a la cara tras acostarse. Su carta de despedida, escrita en francés, dice: "Parto para un largo viaje. Si esto no sale bien, júntense para celebrar mi resurrección con unas botellas de Cliquot. Si sale bien, ruego no me entierren sino después de cerciorarse de que estoy bien muerta, pues es muy desagradable eso de despertarse en un ataúd bajo tierra. ¡Eso no es chique!”. Para Dostoievski en la palabra chique se trasluce un reto, rabia, indignación. Dice: "Sólo las naturalezas vulgares se suicidan por razones materiales, visibles, exteriores; y a juzgar por el tono de esa carta, la suicida no podía tener ninguna razón de esas. Pero ¿contra que sería su enojo? ¿Contra la imaginada simplicidad 
e incoherencia de la vida? ¿Pertenecería al número de esos harto conocidos jueces y negadores de la vida, que se indignan contra la estupidez de la venida del hombre a este mundo, contra la inexplicable contingencia de esa aparición, contra la tiranía de una causa con la que no hay modo de reconciliarse? En esas líneas se trasluce la voz del espíritu sublevado ante la rectilineidad de los fenómenos, incapaz de soportar esa idea que desde la infancia habianle inculcado en la casa paterna. Y lo más feo es que se iría al otro mundo sin que le asaltara la duda. Duda consciente a esas cuestiones es lo más probable no alentara en su espíritu; creía de veras en cuanto en su infancia le enseñaran, creíalo al pie de la letra. Eso quiere decir que murió de "fría tiniebla y hastio", de un dolor, por decirlo así, animal e inconsciente; sencillamente, que le ahogó el vivir, de igual modo que si le faltara el aire. Su alma no se avenía inconscientemente a esa rectilineidad, e inconscientemente reclamaba algo más complejo" (p. 1087-8).

\section{Discusión}

El concepto de anomia fue inventado por Emile Durkheim, introduciéndolo por primera vez en su obra La división del trabajo en la sociedad, datada en 1893. Este concepto se refiere a la falta de dirección que suele aparecer en las épocas de grandes cambios y revolución social, en las que existe un derrumbamiento de los patrones sociales que solían gobernar la conducta, que quedan privadas de legitimidad. La anomia es un estado de sociedad en el que los valores tradicionales han dejado de tener autoridad, mientras que los nuevos ideales, objetivos y normas carecen todavia de fuerza.

En su libro El suicidio (1898), Durkheim retoma este concepto para definir un tipo de suicidio: el "suicidio anómico", que se produce cuando existe una carencia en la reglamentación social, "un fallo o dislocación de los valores sociales que lleva a una desorientación individual y a un sentimiento de falta de significación de la vida". Esta carencia aparece en momentos de "cambios rápidos en la estructura social, como los relacionados con la industrialización de los países subdesarrollados, que socavan la autoridad tradicional y los valores establecidos" 
La obra de Fiodor Dostoievski puede ser considerada en su totalidad como una denuncia constante del peligro que supone lo que posteriormente sería llamado por Durkheim "anomia", o sea, el cambio de los valores tradicionales que se produce en Rusia por el influjo de Occidente; y con su habitual sagacidad, en Diario de un escritor, ilustra una y otra vez el trágico final al que conduce esta anomia en muchos de los jóvenes rusos.

En Enero de 1876, Dostoievski inicia su Diario con dos suicidios entresacados de noticias periodísticas: dos jóvenes se quitan la vida por diferentes razones; el primero, ante los sentimientos de inutilidad de una vida que percibe carente de sentido, sin valores, y el segundo, ante una motivación en apariencia tan frivola como no poder pagar una pensión a la querida; en ambos casos, dice Dostoievski, es el resultado del convencimiento de que todos sus deseos deben ser satisfechos, y si no pueden serlos, se suicidan. Argumento idéntico al que utiliza Durkheim en la descripción del suicidio anómico, característico de la sociedad occidental actual en la que el bienestar y la economía es el fin supremo de los individuos y sociedades; por tanto, no existen limites a la satisfacción de los apetitos, ya que estos limites necesariamente no pueden ser de carácter individual, sino de alguna fuerza exterior a él que tenga un poder regulador, como la religión o el poder gubernamental. $\mathrm{Y}$ entonces, cuando los individuos de estas sociedades chocan con una resistencia que no les permite satisfacer sus deseos, se deshacen de una existencia que se les hace agobiante. Curiosamente, Durkheim nombra el suicidio de Werther (que se mata por un amor contrariado) como característico de este tipo de suicidio. Si bien para Dostoievski la creencia en la inmortalidad del alma, como veremos posteriormente, es el argumento principal en contra del suicidio, esta argumentación no fue suficiente para su admirado Werther.

En el capítulo II de Mayo de 1876 se hace más explícito aún la relación del suicidio con la anomia o la desaparición de los valores tradicionales. Dice Dostoievski: "Y en verdad que aquí se dan tantos suicidios desde hace algún tiempo, que ya nadie los menciona siquiera. La tierra rusa parece haber perdido la energía para retener a sus hijos. ¡Y cuantos hombres honrados...! pero es lo malo que aquí abundan demasiado los hombres honrados, es decir; más bien buenos que honrados; pero ninguno sabe en qué se cifra la honra, ni cree resueltamente en ninguna fórmula de honor, sino que niega todas sus fórmulas antiguas, aun las más evidentes, y eso casi en todas partes y todo el mundo" (p. 996), pasando seguidamente a relatar un nuevo suicidio, el de una chica de veinticinco años, de familia acomodada, que se "vino a Petesburgo a servir la causa del progreso" (con lo que Dostoievski 
nos indica someramente el traspaso de una sociedad en la que persisten los valores tradicionales a una sociedad occidentalizada). Esta chica consigue fácilmente sus propósitos, termina sus estudios y consigue un trabajo, pero está cansada, muy cansada. Observamos de nuevo la similitud con algunos de los suicidios anómicos descritos por Durkheim: "Aun hay otros que, sin tener que quejarse de los hombres ni de las circunstancias, acaban por cansarse de una persecución sin defensa posible, donde sus deseos se irritan en vez de calmarse. La toman entonces con la vida en general y la acusan de haberles engañado. Sólo que la varia agitación a la que se han entregado deja tras sí una especie de agotamiento, que impide a las pasiones decepcionadas manifestarse con la misma violencia que en los casos precedentes. Se hallan como fatigadas, a la larga, y así, resultan menos capaces de reaccionar con energia...Lo que entonces domina es un disgusto de la existencia más o menos irritado" (pp. 311-3). Ambos autores resaltan la importancia del pensamiento materialista, propio del mundo económico, de estos suicidios, en los que existe la convicción progresista de que las privaciones materiales son causa de la infelicidad. Dostoievski nos refiere que la carta expresa ante todo enojo y cansancio y considera que este último es de puro hastío de vivir. Estos sentimientos son muy similares a los expresados por Durkheim como característicos del suicidio anómico: irritación y hastío. Para Dostoievski este cansancio es causado por la pérdida absoluta del más alto ideal de existencia; Durkheim lo relacionará años más tarde con la carencia de objetivo de la pasión.

Por último, analizamos el tercero de estos suicidios, también verídico, relatado en octubre del mismo año en Diario de un escritor: el de una chica rusa, de diecisiete años, hija de un emigrante ruso famoso (probablemente Herzen). Dostoievski de nuevo nos informa de la ausencia de valores tradicionales en la educación de esta joven por la occidentalización de ésta: "nacida en el extranjero, rusa por su sangre pero nada rusa en su educación", que se plasma en el idioma que utiliza para su nota de despedida, el francés. En esta carta, mezcla de perversidad y desesperación, se traslucen los sentimientos que posteriormente Durkheim tipifica en el suicidio anómico: indignación y rabia y se caracteriza por una recriminación violenta contra la vida en general, contra lo que llama Dostoievski la "rectilineidad" de los fenómenos, la falta de valores inculcada en su educación progresista. Dostoievski compara este suicidio con el suicidio "resignado y manso" de una costurera que se tira por la ventana "porque no hallaba trabajo para mantenerse", que inspirará un mes más tarde el relato La Mansa. Termina su apartado resaltando la diferencia entre las dos suicidas: “QQué dos criaturas tan distintas! ¡Ni más ni menos que 
pertenecieran a dos planetas diferentes! ¡Y qué dos muertes tan distintas! Pero ¿Cuál de las dos sufrió más en la Tierra, si es que cabe hacer una pregunta tan ociosa?” (p. 1088).

Posteriormente, en el capítulo I de Diciembre de este año, Dostoievski reitera su interpretación sobre los motivos últimos del suicidio de la hija del emigrante ruso. En él, expone las críticas que ha recibido por sus consideraciones sobre este suicidio por un periodista llamado señor Eipe. Este periodista llama a esta suicida estúpida, se enoja con Dostoievski por preguntarse cual de las dos suicidas habria sufrido más, y llega a la conclusión de que este acto no merece la menor atención, ya que alguien que desea festejar su vuelta a este mundo bebiendo champaña no ha debido sufrir mucho. Dostoievski, por el contrario, considera que si la joven habló de champaña no era porque fuese amante de ésta, sino "por hacer alarde, al morir, de ruindad y vileza. Eligió el champaña para agravar más todavía lo feo y mezquino del cuadro, no encontrando nada mejor a ese fin que las libaciones con champaña para festejar su "resurrección de entre los muertos". Necesitaba dejarlo escrito asi para salpicar con ese fango todo cuanto abandonaba en la Tierra, para maldecir la Tierra y su vida terrena, escupirles y hacer testigos de su escupitajo a sus deudos, a los cuales se refería. ¿Por qué tal inquina en una muchacha de diecisiete años?... Nadie le había agraviado; ni necesitaba de nada; murió, al parecer, sin motivo. Pero precisamente esa esquela, precisamente el que se preocupara en semejante momento de hacer tan feo y rabioso alarde (salta a la vista), precisamente eso, hace pensar que su vida fue incomparablemente más pura que ese sucio alarde, y que la rabia, la furia sin igual de ese alarde, atestiguan, por el contrario, de su dolorosa y atormentada disposición de espíritu, de su desesperación en el postrer instante de su vida. De haberse suicidado por efecto de cierto apático hastio, sin saber por qué, no habría tenido ese alarde. Esa disposición de espíritu merece ser tratada con más humanidad. El dolor ahí es evidente, siendo indudable que se quitó la vida a impulsos de nostalgia espiritual y después de haber padecido mucho... Yo emití la hipótesis de que se habría suicidado por efecto de nostalgia (una nostalgia verdaderamente harto prematura) y carencia de finalidad en la vida, sólo a consecuencia de la bastarda educación que le dieron sus padres, educación que adolecía de conceptos erróneos respecto al alto sentido y la finalidad de la vida, amén de un deliberado propósito de borrar en su alma toda fe en su inmortalidad. Concedido que ésa no pasa de ser una suposición mia; pero es lo cierto que no pudo quitarse la vida con el solo objeto de dejar escrita una fea esquela para asombrar" (pp. 11445). 
Para Dostoievski, este suicidio se produce por la falta de valores espirituales, por "nostalgia espiritual" le llama. Para Durkheim el suicidio sería producto de "un fallo o dislocación de los valores sociales que lleva a una desorientación individual y a un sentimiento de falta de significación de la vida". Para Dostoievski estos valores serán fundamentalmente aquellos que se derivan de la creencia en una idea elevada, la creencia en la inmortalidad del alma. 


\section{Amenazas suicidas}

\section{E1 eterno marido}

1. Pável Pávlovich Trusotskii amenaza a su hija de ocho años, Liza, con ahorcarse, dos meses después de la muerte de su mujer, al enterarse de la infidelidad de ésta y de que Liza realmente no es hija suya. Liza le confiesa aterrada a Velcháninov cuando éste la lleva a casa de sus amigos, la familia Polgoriétsev: "Anoche quiso ahorcarse de un nudo corredizo -dijo la niña aprisa y alentando afanosa -. ¡Yo misma lo vi! Antes quería también ahorcarse; me lo ha dicho, me lo ha dicho. También antes quería, siempre quiso. Yo lo vi anoche" (T.II, C.VII, p. 996). Este mismo hecho es relatado por la patrona donde se hospedan, así como el maltrato que sufre Liza. Cuenta la patrona a Velcháninov que tras el suicidio de otro huésped en la pensión, Pável Pávlovich le pegaba pellizcos a Liza y le decía para asustarla: "yo también me voy a ahorcar; por tu culpa voy a ahorcarme; mira; aquí está la cuerda; con ella me ahorcaré" (T.II, C.VIII, p. 1005), haciendo un nudo corredizo en la cuerda). El motivo de este maltrato es el resentimiento y dolor de Pável por no ser realmente Liza hija suya.

\section{Los demonios}

1. Varvara Petrovna avisa a Daria cuando está planeando su boda con Stepan Trofimovich de las frecuentes amenazas de suicidio que éste suele realizar cuando tiene contratiempos: "Oblígale tú a obedecerte; si así no lo haces redundará en tu daño. El querrá ahorcarse, te amenazará con hacerlo..., no le creas: ésos son desatinos; pero anda, sin embargo, con ojo, que puede que suene la hora del Destino y de veras se ahorque. Así suele ocurrir con hombres como él; no lo hacen por energía, sino todo lo contrario: de puro débiles se ahorcan; así que no extremes nunca las cosas" (T. II, P. I, C. II, p. 1117). 


\section{Discusión}

Las amenazas suicidas son un grado menor de la realización de un gesto autolítico o un intento de suicidio sin finalidad de muerte. Ambos casos son casi siempre el resultado de una acción agresiva contra otros, al contrario del suicidio cuya finalidad es la muerte, cuyo objeto principal es la agresión contra uno mismo.

En este sentido se expresa Castilla del Pino (1966) cuando refiere que lo que distingue el intento de suicidio del suicidio es el hecho de que en éste la muerte es la finalidad, mientras que en el primero la muerte se trasforma en el medio con el cual obtener un tipo peculiar de relación humana. El que intenta el suicidio ejecuta una serie de actos que pueden conducirle a la muerte, pero que en todo momento están supeditados a la "presencia real o virtual del otro". Por tanto, el intento de suicidio en cierta medida es una simulación, ya que quiere obtener, aún con el riesgo de su muerte, un tipo de gratificación sádica y no masoquista. Según este autor, en el intento de suicidio las relaciones objetales no están perdidas, sino tan solo temen perderse: el intento de suicidio está más dirigido al otro -al objeto- que a sí mismo y es un casi desesperado último intento para conseguir de nuevo su amor y cuidado. Por eso, el intento de suicidio es siempre resultado de una angustia temor a la pérdida del objeto- mientras el suicidio es la anulación del sentido de la vida merced a la conciencia de la pérdida definitiva e irreparable del objeto. Obviamente, en el caso de las amenazas suicidas esta búsqueda de reacción en otras personas ante la idea de su muerte es aún más evidente.

Las amenazas suicidas de Pável Pávlovich se encuadran perfectamente en un acto de revancha. Este "eterno marido", feliz en su matrimonio y padre ejemplar, tras la muerte de su esposa descubre la duradera infidelidad de la mujer y la verdadera paternidad de la que hasta entonces era su adorada hija Liza: su antiguo amigo Velcháninov. Este descubrimiento hace que en Pável exista una lucha continua entre el amor hacia Liza y el odio (o entre los sentimientos de cariño y la necesidad de venganza). La conducta que expresa esta lucha no resuelta tanto hacia Liza como hacia Velcháninov son utilizados como motivos temáticos claves en la novela. Pável Pávlovich maltrata a la niña y la abandona por un odio dirigido tanto contra sí mismo como contra su indefensa 
víctima. Ella es un vivo recordatorio de sus humillaciones, y su amor se ha convertido en odio precisamente porque no puede escapar del pasado que tanto quisiera borrar. Este es el círculo infernal de la dialéctica dostoievskiana de orgullo y humillación, que sólo podría romperse transcendiendo el propio ego, en un acto de desinteresada superación del orgullo herido y de la aceptación de su amor. Pero Pável Pávlovich no es capaz de realizar este acto psicológico y moral, como tampoco lo son muchos otros personajes de sus novelas. Y dentro de este maltrato hacia la niña y hacia él mismo están las amenazas de suicidio.

En Los demonios Varvara avisa a Daria de algo muy conocido por los psiquiatras y contrario a las creencias populares: La posibilidad de que aquellas personas que realizan amenazas de suicidio como forma de coaccionar a otros para lograr sus deseos pueden acabar consumando un suicidio. Una historia de amenazas e intentos suicidas es en psiquiatría un gran factor de riesgo para el suicidio consumado, con más peso aún que el diagnóstico psiquiátrico (Hyman, 1987). Los pacientes con historia previa de intento de suicidio tienen el quíntuple o séxtuple riesgo de intentarlo de nuevo. Entre la cuarta parte y la mitad de los suicidios consumados han tenido un intento anterior.

Stepán Trofimovich Verjovensky es un personaje entrañable, que representa a un idealista liberal del decenio de los cuarenta. El narrador nos refiere que "...era hombre de conciencia (es decir, a veces) y por ello andaba con frecuencia tristón... Más adelante, además de la tristeza cívica, empezó a darse también al champaña" (T. II, P. I, C. I, p. 1079). Lo más destacable de este personaje es la cómica discrepancia entre sus poses retóricas y su actuación práctica. Dentro de esta discrepancia y de las tendencias melodramáticas de Stefán podrian englobarse sus amenazas de suicidio. Pero Varvara, que conoce profundamente el carácter de Stefán, sabe que si bien las amenazas de suicidio son "desatinos" suyos, no debe tensarse excesivamente la cuerda, pues "suele ocurrir con hombres como él; no lo hacen por energia, sino todo lo contrario: de puro débiles se ahorcan; así que no extremes nunca las cosas". 


\section{Reflexiones de Fiodor Dostoievski sobre el fenómeno del suicidio}

Fiodor Dostoievski, "el psicólogo de los psicólogos", como lo llama Stefan Zweig (1920), no podía eludir en sus novelas el tratamiento del suicidio. Y no sólo no lo elude, sino que es un tema recurrente que aparece en todas sus obras a partir de Memorias del subsuelo y que va adquiriendo paulatinamente mayor importancia. Como veremos posteriormente, en el año 1876, en Diario de un escritor, volverá una y otra vez sobre el tema del suicidio. Para ello, consulta noticias de periódicos, informes judiciales, expone habladurias que le relatan sus amigos, crea relatos sobre personas que se suicidan o deciden suicidarse, inventa explicaciones autojustificatorias de presuntos suicidas. Sus artículos de este año van a ser muy esclarecedores de la posición de Dostoievski sobre el suicidio.

En las novelas de Dostoievski, los personajes se preguntan continuamente sobre el sentido de la existencia; y la respuesta será diferente según sean creyentes o no. En los personajes creyentes, su fe les impedirá el planteamiento del suicidio, al otorgarles la creencia en la inmortalidad del alma, el amor a la vida y un sentimiento de armonía de tipo cósmico; en cambio, los personajes no creyentes intentarán dar un sentido a la vida, sustentando éste en una "idea" que llevarán hasta el último extremo: esta idea, según el personaje, será diferente: puede estar basada en el nihilismo, el hedonismo, el altruismo, o en la demostración de su superioridad individual. En todos estos casos, la frenética búsqueda de la consecución de esta idea les lleva al sufrimiento y al aniquilamiento de sí mismo, tornándose en ocasiones, como dice Zweig (1920), el suicidio en la salvación propia y suprema. El final de los personajes será el suicidio, la locura o la conversión a partir de la aceptación del sufrimiento y de la humildad.

Para René Girard (1961), los héroes no creyentes de las novelas de Dostoievski se caracterizan en el fondo por el odio a sí mismos. Este odio proviene, según este autos, de la promesa engañosa de autonomía metafísica, del fracaso de un proyecto de autodivinización: Si Dios ha muerto, el hombre debe ocupar su lugar. Pero esta voluntad de autonomía, cuyo prototipo ejemplar aparece en "el hombre del subsuelo" realmente engendra la esclavitud, ya que nunca se está tan próximo a los otros como cuando se cree totalmente separado de ellos: "Yo, yo soy uno y ellos, ellos son todos" (T.I, p. 1477), dice el hombre del subsuelo. Y 
ante esta esclavitud aparece el odio a sí mismo que conduce al individuo al masoquismo $\mathrm{y}$ en el último estadio a la autodestrucción; en este sentido se encuadran la mayoria de los suicidios que aparecen en sus novelas. La única verdad de este deseo metafísico resulta ser la muerte y esto es, para Girard, lo que Dostoievski quiere expresar. Tras Memorias del subsuelo aparece, en algunos personajes, al final, la renuncia al deseo metafísico. Al renunciar a la divinidad, el héroe renuncia a la esclavitud. El deseo metafísico engendra una cierta relación con el otro y una cierta relación consigo mismo. La conversión auténtica engendra una nueva relación con el otro y una nueva relación consigo mismo. Así, Dostoievski nos va a ofrecer en sus grandes novelas desenlaces dobles, que expresan el diferente final según que el personaje renuncie o no a este deseo de autodivinización: en Los demonios el final de Stavroguin es el de una muerte que solo es muerte, mientras que la muerte de Stepan Trojimovich es una muerte que en realidad es vida; en Los hermanos Karamazov, Dostoievski resalta en su desenlace el contraste entre la locura de Iván y la conversión redentora de Dimitri y en Crimen y Castigo el contraste ente el suicidio de Svridigáilov y la conversión de Raskólnikov.

Fiodor Dostoievski relata magistralmente el drama espiritual de sus personajes no creyentes, de aquellos personajes que han ido más allá de la religión y de la moral y que, a imagen y semejanza suya, sobrepasan los limites. Dostoievski, en una carta a Maikov desde Ginebra fechada en Agosto de 1867 confiesa en una frase que luego tacha "Y lo peor de todo es que mi naturaleza es vil y muy apasionada; en todo y por doquier llego al último límite. Me he estado extralimitando durante toda mi vida" (En Frank, T. IV, p. 259).Y, para Dostoievski, dentro de esta extralimitación, el suicidio puede ser o es una respuesta seria y éticamente aceptable desde una postura agnóstica. Por el contrario, desde sus creencias religiosas el suicidio supone, como para la Iglesia Rusa, el pecado más abominable. $\mathrm{Y}$ en esta tensión entre estas dos posiciones se mantiene Dostoievski, expresando ambos polos (hasta las últimas consecuencias), en los diferentes personajes de sus novelas. Porque, como dice Ivan Karamázov, el suicidio es sólo una consecuencia de la libertad del hombre. 


\section{Datos biográficos relevantes en relación con su concepción del suicidio}

Dentro de la biografia de Dostoievski podemos considerar los siguientes hechos como relevantes para su concepción del suicidio:

La educación profundamente religiosa que recibió en la infancia. Él mismo refiere en Diario de un escritor (T.III, 1873, p.802): "Procedia yo de una familia rusa auténtica y temerosa de Dios. En cuanto alcanza mi memoria, recuerdo que me amaban mis padres. Desde la más tierna infancia estábamos en casa familiarizados con el Evangelio. Ya a los diez años conocía yo todos los acontecimientos principales de la historia rusa, según la obra de Karamzin, que nuestro padre nos leía por las noches. La visita al Kremlin y a las viejas iglesias de Moscú fue para mí siempre algo solemne".

Por tanto, Dostoievski creció en el seno de una tradicional familia rusa en la que se cumplian y se enseñaban todas las obligaciones y preceptos de la iglesia ortodoxa. Entre estos preceptos se incluye la condenación del suicidio como el pecado más grave y la prohibición de enterramiento cristiano a los suicidas y de rezar por su perdón.

En este mismo párrafo el autor nos informa sobre las lecturas en voz alta en el seno familiar de las obras de Karamzin. Este autor expresa en su obra dos ideas que van a estar muy presentes en toda la obra de Dostoievski y que resultan fundamentales en su concepción del suicidio: la de la conciencia moral como una parte inextricable de la naturaleza humana, y la que afirma que la inmortalidad es una condición necesaria de todo orden del mundo que pretenda tener un sentido moral. Estas ideas son las dos ideas principales de la Critica de la razón práctica y fueron expuestas por el mismo Kant a Karamzin en una visita que éste le hizo en Königsberg un año después de la publicación de este libro y que Karamzin relata en sus Cartas (Frank, 1976). Kant explica que la conciencia del bien y el mal es innata a la humanidad y dicho conocimiento está indeleblemente grabado en el corazón humano. Sin embargo, la vida terrenal muestra una contradicción importante: los que eligen vivir de acuerdo con el bien y obedecer a la ley moral no siempre son los que prosperan y reciben su justa recompensa. Pero si Dios es caritativo y justo, esta contradicción no puede quedar sin resolver. Por lo tanto, postula la existencia de una vida inmortal después de la muerte física, en la cual los 
buenos reciben su recompensa, a pesar de que la razón humana nunca pueda probar este postulado.

También juega un papel importante en la educación de Dostoievski su nana y ama de llaves, Alyona, responsable de enseñarles a los niños a comportarse correctamente. No era sierva, sino ciudadana libre, pero sus comportamientos e ideas eran característicos de la clase popular rusa en la que se mezclan supersticiones paganas con un hondo cristianismo. Dostoievski recuerda en Diario de un escritor (Abril, 1876, p. 960) su generosidad y los relatos que contaba, típicos de la tradición campesina rusa. En esta tradición, el suicidio ocupaba un lugar destacado: atribuía al diablo, que en ocasiones se valía del influjo de un hechicero, la responsabilidad del abatimiento que daba lugar al suicidio; si la persona cambiaba de opinión en el último minuto, se atribuía, por el contrario, este cambio a fuerzas positivas sobrenaturales. Aún en el caso de que la víctima presentara un trastorno mental, la opinión popular insistía en la creencia bien asentada de que el suicidio es una acción del demonio. Ivanits (1992) expone un relato de la provincia de Oriol que narra cómo un joven llamado Efim padeció una depresión morbosa y se disparó una mañana tras perder los caballos que tenía a su cargo. Los campesinos reaccionaron de forma típica, recalcando que se había cometido un gran pecado y que no se debían leer salmos por el alma de Efim, ya que un suicida se le debe tratar igual que a un perro. Cuando fue llevado Efim al cementerio, el párroco comentó que no se estaba enterrando a un muerto, sino al mismo diablo; y una mujer del pueblo comentó que un peregrino había dicho que, aunque un suicida vertiera diez veces agua hirviendo sobre sí mismo, Dios no le perdonaría.

Por el contrario, los intentos de suicidio frustrados eran valorados en la tradición popular rusa de forma muy diferente. Hay relatos, normalmente en primera persona, de cómo campesinos que estaban rezando sus últimas oraciones eran salvados por la aparición repentina de un peregrino, una paloma, etc.

Además, existían una serie de creencias relacionadas con el destino de las personas después de muertas. Los cadáveres de los suicidas pertenecían al grupo general de muertos "impuros" que incluía hechiceros y brujas, borrachos, personas asesinadas, y personas ahogadas accidentalmente. Los campesinos temían enterrar estos cadáveres junto los muertos "puros" en el cementerio de la Iglesia y consideraban que era pecaminoso rezar por ellos. Más aún, pensaban que todos los cadáveres impuros eran perjudiciales para la tierra, la cual no los aceptaba, por lo que el cuerpo no se descomponía y salía de la tierra. El lugar donde se 
realizaba su enterramiento, frecuentemente el mismo donde ocurría la muerte, era considerado peligroso, puesto que la posibilidad de encontrarse con la persona muerta era especialmente grande. Se pensaba además que estos cadáveres podian visitar sus casas y hacerles daño.

Es de suponer que la nana Alyona les hiciera partícipe de muchos de estos relatos a los niños, al igual que les informaba con toda solemnidad que era pecado mortal comer cualquier alimento sin llevarse primero a la boca un trocito de pan o que los gritos que sufría en sus pesadillas eran causados por las visitas nocturnas que le hacía el domovoy o duende familiar ruso para estrangularla (Frank, 1976).

En la adolescencia tiene importancia la influencia en Fiodor Dostoievski de la literatura romántica, de la que fue un lector apasionado. A mediados del decenio 1830-1839, la cultura rusa pasaba por un periodo de transición, entre la influencia predominante de la literatura romántica germánica y la filosofia idealista, por una parte, y el comienzo de un viraje hacia el romanticismo social francés. Dostoievski llegó a la madurez en esta época y estuvo profundamente influido por ambas tendencias. De la primera tendencia, y especialmente de la lectura de las obras de E.T.A Hoffmann, Schiller y Goethe adquirió, además de su compromiso con la visión panteísta de Schelling, o sea, una concepción del hombre con un fuerte acento puesto en su relación con un mundo de fuerzas sobrenaturales o trascendentales, la idea del suicidio como una "explosión de la voluntad" como un gesto supremo de desafio metafísico. Del romanticismo francés (en especial de Balzac y Víctor Hugo) heredaria fundamentalmente su compromiso social y humanitario.

También en esta época es importante reseñar la amistad que mantuvo con Iván Nikolaévich Shilodvski, al que conocieron los hermanos Dostoievski cuando llegaron a Petesburgo. Fiodor tenía en esta época dieciséis años y Shilodvski veintiuno. Para el autor, este hombre fue, según confesó en sus últimos años a su amigo Soloviev, una de las personas que más había influido en su vida.

Shilodvski, un poeta romántico que tenía un puesto burocrático en el Ministerio de Hacienda, fue el guía y tutor literario de Dostoievski en su adolescencia. Alto y de aspecto llamativo, elocuente y conversador, impresionaba a todo el mundo por su vasta cultura y por el entusiasmo de sus conversaciones sobre temas elevados. Fue un típico romántico ruso de los años treinta, consumido por deseos que no podían satisfacerse dentro de los limites terrenales y desgarrado por pasiones tempestuosas. Se 
conservan siete poemas suyos, que se caracterizan por sus preguntas sobre el sentido de la existencia y cuyo consuelo es la creencia de que existe un Dios, quien a veces condesciende a mostrarse en la Naturaleza y que ofrece esperanzas de felicidad a los seres humanos. Este poeta, tan admirado por los hermanos Dostoievski, sufrió una fuerte crisis tras un desgraciado conflicto amoroso sobre la cual escribe a Mijail en Febrero de 1839: "estuve tentado de romper las cadenas de la existencia; de escapar de esta cautividad; y el lecho de agua, el lecho de mi amada Fontaka (un canal), me atraía tanto como el lecho nupcial a la recién desposada". Ante estos sentimientos, le confiesa a Mijail que trató de luchar contra la tentación de suicidarse rezando, pero fue en vano. Sin embargo, en la Navidad ocurrió el milagro "y entonces tuve fe". En aquel momento comprendió, dice, que "la vida es una cadena infinita de bondades de Dios" y suicidarse significa "renunciar a una parte de la benevolencia de Dios", y que constituye un acto de ingratitud para con Él, que "con toda su compasión se entrega Él mismo para (que yo viva) cada uno de los momentos". El suicidio, dice, está permitido sólo a aquellos que, como Werther y Chatterton, se han apartado completamente de la vida, y a quienes la vida misma ha rechazado. Pero esta no es su propia situación: se siente obligado (se entiende que ante Dios) por las horas que dedica a escribir poesia; por la carne que come y por el vino que bebe...". Continua esta larga carta exponiendo que la labor del poeta es reconocer la belleza del universo, que ésta es la necesaria unidad de la bondad de Dios y que el espíritu reconoce en sí mismo "sólo así tiende una red de simpatía o compasión en torno a las fronteras del ser, y en el centro de la red abraza a Dios mismo" (Frank, 1976, p. 126-130). Esta carta expresa, por tanto, la concepción íntegramente romántica de Shidlovski, el gran admirado de Dostoievski, en la que existe una exaltación de la pasión hasta limites de autodestrucción junto con un sentimiento religioso basado en la comunicación entre el individuo y la Naturaleza, el hombre y Dios, el Uno y el Todo, y en la responsabilidad moral que conlleva la conciencia de pertenecer a este Todo desde la propia individualidad.

Shilodvski se marchó de San Petesburgo a finales de 1839. Su vida osciló entre momentos de disipación y grandes borracheras con accesos renovados de fervor religioso. Ingresó durante un breve periodo en un monasterio, pero fue expulsado por problemas con el alcohol y con las mujeres. Posteriormente se hizo peregrino religioso predicando a la gente en las tabernas del pueblo. Murió en 1872 .

Para Dostoievski, Shidlovski significa la encarnación viva del héroe romántico, en el que resalta la gran dignidad de una pasión 
sin esperanza, el valor espiritual de sufrir por un ideal imposible, su papel de poeta como sacrificado "sacerdote" de este designio romántico, proclamando su fe y su amor a Dios en medio de sus sufrimientos. Además, Shilodvski representó para Dostoievski un ejemplo concreto de cómo podían combinarse los valores románticos con las formas ortodoxas del culto ruso, al que Shilodvski profesaba una adhesión inquebrantable, de la eficacia del pecado como camino para la felicidad y de cómo el verdadero compromiso religioso podía combinarse con la confesión de las dudas de fe.

Tras la salida del presidio de Omsk en Febrero de 1854, desde Semipalatinsk, Fiodor pide a Mijail varios libros, entre ellos el "Carus". Con este nombre Fiodor se refiere al famoso tratado de la época sobre psicología, escrito por el famoso médico, fisiólogo, pintor del romanticismo y hombre de letras alemán Carl Gustav Carus (1789-1869). El tratado se llama Psyche (Zur Entwicklungsgeschichte der Seele) (Sobre la historia de la evolución del alma) y data de 1846. Este tratado ha sido considerado por muchos autores como precursor del psicoanálisis.

Carus estaba totalmente al día en las teorias más recientes sobre fisiología y biología pero continuaba interpretándolas con los antiguos términos de la concepción "vitalista" de Schelling. El concepto idealista del universo que exponía Schelling, quien se negaba a considerar el mundo simplemente como un mecanismo desprovisto de alma, gobernado exclusivamente por leyes fisicas, fue conocido y admirado por Dostoievski desde su época de estudiante. Carus siguió esta concepción orgánica y vitalista de Schelling y Goethe, de quien fue amigo y admirador, y de los filósofos de la naturaleza. No obstante, Carus despojó a estas tesis, que estaban en boga en aquellos años, de su lenguaje astrológico y mágico. Dostoievski, naturalmente, asentía con entusiasmo a las ideas que expresaba Carus en sus libros, una persona "científica" y además, eminente fisiólogo, que no abandonaba la creencia en una especie de causa sobrenatural o en los preceptos de la moral cristiana.

Uno de estos preceptos cristianos en los que se basa Carus es "la ley del amor" que, según este autor, penetra en toda la naturaleza y se inicia en el hombre con la diferenciación sexual. Esta ley del amor despierta en el hombre el impulso hacia la devoción y el autosacrificio y por consiguiente, a la esencial conquista del egoísmo. Así, el hombre es moralmente educado y transformado, no sólo por los efectos del amor sexual, sino también por un amor a todos los elementos de la creación: la 
tierra, el alimento, las estrellas, el aire, etc. (Frank, 1986, pp. 251255).

Carus anuncia en su primera frase de este libro que el tema de éste es el poder de lo irracional y lo inconsciente, considerando inconsciente no sólo a la vida psíquica sino a todo lo de la naturaleza que posee vida anímica y difiere de la psyque sólo en grados de conciencia y de autoconciencia. Carus se expresa en su libro en los siguientes términos: "la clave para conocer la existencia de la vida consciente del alma está en la región del inconsciente"

En su obra, Carus constantemente hace hincapié en la necesidad de conservar el equilibrio entre las formas más elevadas de conciencia y las fuerzas inconscientes de la existencia. A este respecto, Carus hace constante referencia al peligro de una hipertrofia del intelecto en los niveles más elevados de conciencia; y piensa que el acto de suicidio es, en ciertos casos, una expresión del más elevado desarrollo de la libertad de la autoconciencia. Un suicida totalmente autoconsciente, incluso en el acto de destruir su vida -0 sea, destruyendo las bases inconscientes de la existencia- realiza una afirmación de la libertad de la autoconciencia. Muchos de los suicidios o pensamientos sobre el suicidio en las novelas de Dostoievski serán motivados por una concepción similar, y la autodestrucción personal se señalará frecuentemente como el efecto de un desarrollo patológico de la autoconciencia.

Otros tema que trata Carus en su obra y que se refleja en la obra de Dostoievski es la comparación que hace de la perversidad moral con la enfermedad física. Ambas son desviaciones de la condición normal de las fuerzas inconscientes que regulan la salud del organismo. Pero, al igual que la naturaleza posee los medios para restaurar el equilibrio en el caso de enfermedad física, también la conciencia moral tiene sus mecanismos "inconscientes" para restaurar la salud moral de la personalidad. La conciencia es, por tanto un regulador natural e instintivo de la psique humana, cuya distorsión o perversión conduce a una "enfermedad" literal del ser. Este será uno de los temas principales de las obras maestras que Dostoievski escribiría.

Por último, Dostoievski apoya totalmente y plasma en sus obras la tesis de Carus de que las premoniciones y visiones pueden tener cierto significado objetivo, porque toda la naturaleza es un vasto organismo y las relaciones entre sus partes en varios niveles inconscientes de ninguna manera están totalmente exploradas. 


\section{El suicidio según la doctrina ortodoxa rusa}

En algunos personajes de las novelas caracterizados por su religiosidad y bondad ("los hombres absolutamente buenos"), Dostoievski expondrá sus consideraciones sobre el suicidio desde el punto de vista del cristianismo ortodoxo.

En El adolescente el personaje que representa este tipo es Makar Ivánovich, el marido legal de la madre de Arkadii, que al irse ésta con Versílov, se hace peregrino ("vagabundo religioso"). Este personaje se caracteriza por poseer una sabiduria superior, a la manera de la tradición rusa del loco santo (yudorivi), el hombre sencillo cuya aparente locura confunde la sabiduría de los grandes. Makar representa muchos de los caracteres positivos prototípicos del "hombre absolutamente bueno" encarnados previamente en el príncipe Mishkin. Es definido por Versílov como un hombre que "en virtud de la ausencia de toda pizca de orgullo, obtienes el supremo decoro y aparece el hombre, que se respeta a sí mismo, indudablemente, en su posición, sea la que fuere y cualquiera que fuere su destino" (T.II, P.I, C.VII, p.1618). Cuando Arkadii le conoce le llama la atención su risa, pueril y seductora como sólo los niños pueden tener. Además, se caracteriza por su capacidad de alegrarse y maravillarse por la vida, su visión extática y animista del mundo, la presencia en su conciencia de la muerte y su fe cristiana. En el momento que sucede la novela, Makar ya tiene setenta años y está muy enfermo. Makar refiere: "El viejo viene obligado a estar contento en todo tiempo y debe morir en la plena lucidez de su alma, beatífica y finalmente harto de días, respirando su última hora y alegrándose, al partir cual espiga en la gavilla y después de haber cumplido su misterio" "Todo es misterio, amigo, en todo hay un misterio de Dios. En cada árbol, en cada brizna de hierba está ese misterio cruzado. Ya cante el pajarillo, ya sean las estrellas con toda su mole las que refulgen en el firmamento durante la noche, todo es un misterio y el mismo. Y en todos, el misterio más grande es que aguardará al alma del hombre en el otro mundo" (T.II, P.III, C.I, p. 1773-74). Ante la pregunta de Arkadii sobre su opinión sobre el suicidio, Makar responde que el suicidio es el pecado más grande del hombre, pero que el juez en este caso sólo es Dios "porque El solo sabe todo, todo límite y toda medida" (T.II., P.III, C.III, p. 1794) y recomienda rezar por ellos.

Un personaje de características similares es el stárets Zósima, el preceptor espiritual de Alíosha en Los hermanos Karamázov. Este anciano de sesenta y cinco años, enfermo, jovial, intuitivo, con 
poderes para curar o aliviar a los enfermos, predica una de las máximas morales de Dostoievski, "todos somos culpables ante todos". Y la recomendación sobre los suicidas es idéntica a la de Makar; Dice Zósima: “iAy de los suicidas! Pienso que más desdichados que ellos no los puede haber. Pecado es, nos dicen, pedirle por ellos a Dios; y la Iglesia parece echarlos de sí; pero creo, en lo secreto de mi alma, que si se podría rezar por ellos. Porque tocante a amor, no se enoja Cristo" (T.III, P.II, L.VI, C.III, p. 262).

Por tanto, aunque estos personajes, que encarnan para Dostoievski la sabiduría y la religiosidad, siguen la creencia ortodoxa del suicidio como pecado más grave, en ambos casos reflejan el desacuerdo de Dostoievski ante la prohibición de esta Iglesia de rezar por los suicidas. 


\section{La disertación sociológica del stárets Zósima: Un preludio del estudio sobre el suicidio en la sociedad occidental realizado por Durkheim}

Antes de morir, el stárets Zósima mantiene un largo coloquio con sus personas allegadas. Esta charla, según nos describe el narrador de Los hermanos Karamázov, la transcribió Aleksieyi Karamázov, para su memoria, en un manuscrito. En el Libro VI de la Parte II de esta novela se inserta este manuscrito en el que se relata la vida, creencias y doctrinas de este "hombre absolutamente bueno" que es el stárets Zósima. Y en este apartado, Dostoievski realiza una profunda reflexión sociológica y moral sobre el suicidio, refiriéndose de forma asistemática a dos tipos de suicidio que más tarde serian definidos y sistematizados por Emile Durkheim en su trabajo de 1897, El suicidio: el suicidio egoísta y el suicidio anómico. Para Durkheim, entre el egoísmo y la anomia existe una afinidad especial y generalmente no son más que dos aspectos diferentes de la misma realidad social. Esta misma realidad social para ambos autores corresponde a la sociedad occidentalizada basada en el agnosticismo y la glorificación de la técnica y la ciencia.

En boca de un amigo de la juventud que cometió un crimen, pensó en el suicidio y terminó confesándolo, pone Zósima las características del "suicidio egoísta" de Durkheim: "Porque todos se afanan ahora por retraerse cada vez más; todos quieren experimentar en sí mismos la plenitud de la vida, y sin embargo, todos sus esfuerzos les conducen, no a la plenitud de la vida, sino al suicidio, porque, en vez de hallar la plena definición de su ser, van a parar a la soledad absoluta. Porque todos, en nuestro siglo, se dividen en unidades, cada cual se retrae a su madriguera; todos se apartan de los demás, se esconden y esconden lo que tienen, concluyendo por apartarse de la gente y la gente de él. Junta en su soledad riquezas, y piensa :"iQué fuerte soy ahora y qué cubierto de todo estoy!" y no sabe el muy necio que cuánto más junte más se hundirá en una indefensión suicida. Porque el acostumbrarse a confiar en si mismo tan solo y a separarse del conjunto como unidad enseña a su alma a no creer en la ayuda ajena, en los hombres ni en la Humanidad, y solo tiembla ante la idea de que le arrebaten su dinero y los derechos por él adquiridos" (T.III, P.II, L. VI, C.II, p.247). Aquí Dostoievski está hablando del peligro que supone lo que Durkheim llama desintegración de la sociedad religiosa, doméstica y política, que conduce a una prioridad de los fines propios con respecto a los colectivos, y cuya característica 
principal va a ser la excesiva individualización y el egocentrismo. Este tipo de sociedades desintegradas propiciarán, según ambos autores, el suicidio (que Durkheim denominará "egoísta"), ya que el aislamiento y la falta de un fin que exceda y sobreviva al propio individuo crean en el sujeto una especie de "desencanto general" y una mayor vulnerabilidad ante las frustraciones de la vida.

Y páginas después, Zósima profundiza en otra característica de la sociedad generadora de suicidios: la falta de reglamentación moral propia de la sociedad occidental o anomia. Aquí Zósima definirá el otro tipo de suicidio designado por Durkheim, el suicidio anómico. Dice Zósima: "Mirad a los mundanos... Tienen la ciencia, pero en la ciencia no hay más que lo que depende de los sentidos. El mundo espiritual, la mitad superior del ser humano, queda excluida por completo, eliminada con cierto entusiasmo, hasta con odio. Proclamó el mundo la libertad, sobre todo en los últimos tiempos, ¿y que vimos en esa libertad? ¡Pues únicamente esclavitud y suicidio! Porque el mundo dice: “¿Tienes necesidades? Pues a satisfacerlas, ya que tienes los mismos derechos que los más distinguidos y ricos. No temas satisfacerlas; antes al contrario, multiplícalas" He aquí la actual doctrina del mundo. En eso ven la libertad. ¿Y que resulta de todo ese derecho a multiplicar las necesidades? En los ricos, soledad y suicidio espiritual, y en los pobres envidia, crimen, porque derechos les han dado, pero los medios de satisfacer sus necesidades ésos aún no se los han indicado... Comprendiendo la libertad como multiplicación y satisfacción rápida de las necesidades, falsean su naturaleza, pues despiertan en él muchos frivolos y absurdos apetitos y costumbres y las más necias patrañas. Viven tan sólo para envidiarse mutuamente, para el lujo y la ostentación. Dar comidas, viajar, tener coches, cargos, criados serviles, considerase algo indispensable, por lo cual sacrifican hasta la vida, el honor y el sentimiento de humanidad, con tal de satisfacer esas necesidades inexcusables, y hasta se suicidan al no poder satisfacerlas" (T.III, P.II, L.VI, C.III, p. 255). Este planteamiento es idéntico al de Durkheim al definir las sociedades anómicas, cuyo prototipo es la sociedad occidental, en las que la sociedad deja de realizar un papel moderador en los deseos del individuo. La satisfacción de los apetitos y el bienestar se santifican, la industria deja de ser un medio para convertirse en un fin, el individuo es arrastrado perpetuamente a sobrepasarse a sí mismo. Esta situación provoca una sobreexcitación permanente, una persecución sin término de nuevas cosas, imperiosas necesidades que pierden su valor y su atractivo cuando se consiguen y que lleva a buscar obtener otras, ya que los deseos se irritan con estos logros en vez de calmarse. Y así, ante el menor revés que sobrevenga, se pierden las fuerzas y se produce el desencantamiento, porque es dificil, dice Durkheim, "no 
sentir, a la larga, la inutilidad de una persecución sin término". Y entonces, se cometerá el suicidio como una forma de recriminación violenta contra la vida en general, a la que se acusará de haberle engañado. 


\section{El suicidio como "enfermedad moral"}

En los artículos de Diario de un escritor de 1876, Dostoievski se pregunta una y otra vez por los motivos, tanto a nivel individual como social, que llevan a diferentes personas a la consumación del suicidio. Su conclusión es siempre la misma: el suicidio es casi siempre producto de "una enfermedad moral" producida por la ausencia de una idea elevada de la vida en sus almas. Para Dostoievski esta enfermedad moral es consecuencia del influjo de Occidente en la sociedad rusa, que provoca un cambio desde los valores tradicionales a la supremacía del materialismo y a la exaltación de la razón.

En la creencia occidental, las privaciones materiales son causa de infelicidad, y Dostoievski en sus obras intenta demostrar una y otra vez la falsedad de esta creencia. Es más, en el capítulo III de Enero de 1876, reflexiona sobre la utopía de que la Humanidad lograse descubrimientos que permitieran acabar con las privaciones materiales y el trabajo y permitir a todos entregarse a pensamientos profundos sobre los fenómenos sociales; Esto sería, dice Dostoievski, el fin de la humanidad; ya los hombres no tendrian libertad, ni voluntad, "comprenderian que no hay felicidad en la holganza, que es el trabajo quien aviva la idea...y que la felicidad no está en la felicidad, sino en hacer por alcanzarla. Sobrevendrian el tedio y la tristeza; estaría todo hecho; no quedaría nada por hacer; se sabria todo, y no habría ya que aprender nada. Tendriamos suicidas en tropel, y no como ahora, por los rincones, sino que querrian los hombres irse de este mundo en masa, cogidos del brazo, suprimiéndose de un golpe a millares por algún nuevo procedimiento que les habría sido revelado con todos los demás descubrimientos" (p. 895). Justamente estos valores de indole exclusivamente materialista ocasionan, según Dostoievski, el aumento de suicidios que aparece en muchos jóvenes rusos, ya que, como en el caso de la hija del emigrante ruso relatado en Octubre de 1876, "sólo las naturalezas vulgares se suicidan por razones materiales, visibles, exteriores... (en este suicidio) se trasluce la voz del espíritu sublevado ante la rectilineidad de los fenómenos, incapaz de soportar esa idea que desde la infancia habianle inculcado en la casa paterna... su alma no se avenía inconscientemente a esa rectilineidad, e inconscientemente reclamaba algo más complejo" (p. 1088). Y dos meses más tarde continúa reflexionando sobre este suicidio: "Yo emití la hipótesis de que se habria suicidado por efecto de nostalgia (una nostalgia verdaderamente harto prematura) y carencia de finalidad en la vida, sólo a consecuencia de la bastarda educación que le dieron sus padres, educación que adolecía de conceptos erróneos respecto 
al alto sentido y la finalidad de la vida, amén de un deliberado propósito de borrar en su alma toda fe en su inmortalidad" (Diciembre, 1876, p. 1144).

Y estos jóvenes, se lamenta Dostoievski en Diario de un escritor, no se preguntan, como Hamlet o como Werther, sobre la posible existencia de un más allá: "Nuestros suicidas no tienen el menor barrunto de que posean un yo y sean criaturas inmortales" (Enero 1876, p.873). Esta apreciación aparece también en Los hermanos Karamázov, expuesta por el fiscal Ippolit Kírillovich durante su discurso en el juicio de Dimitri: "Ved, señores, ved como se suicidan nuestros jóvenes. ¡Oh! Sin plantearse la menor pregunta hamletiana respecto a aquello de: “¿Qué habrá allá?", sin rastro de tales preguntas, cual si la noción de nuestra alma y de todo cuanto nos aguarda más allá de la tumba la tuviesen enterrada de antiguo y cubierta de arena en lo más hondo de sus ser" (T.III, P.IV, L.XII, C.VI, p. 536).

Porque, para Dostoievski, la única razón para no suicidarse estriba, exclusivamente, en la inmortalidad del alma; es más, el autor afirma de forma rotunda: "está claro que el suicidio, cuando se ha perdido la fe en la inmortalidad, resulta de una imprescindibilidad absoluta e inevitable para todo hombre que tenga alguna noción de su superioridad sobre los animales ( $p$. 1141)". Y para ilustrar esta afirmación, Dostoievski ha inventado la disertación realizada por el joven materialista a favor del suicidio en el artículo de Octubre de 1876 de Diario de un escritor, que no es, dice, como afirman algunos de sus lectores, un alegato sobre el suicidio, sino que, como explica en Diciembre de ese mismo año "lo que se propone demostrar esa confesión de un hombre que va a morir de suicidio lógico es lo imprescindible de una conclusión: que sin fe en el alma y en su inmortalidad, la vida del hombre resulta antinatural, absurda e insufrible... de tanto pensar en su falta de finalidad y de tanto odiar la muda inercia que le rodea, llega mi suicida a la conclusión inevitable de la absoluta estupidez de la existencia del hombre en la Tierra... Sin una idea elevada no pueden existir ni el hombre ni la nación, pero la idea elevada en la tierra es "solo una", a saber: la idea de la inmortalidad del alma humana, porque todas las demás ideas elevadas de la vida con que puede vivir el hombre, "derivanse únicamente de ellas"... Mi suicida es precisamente un apasionado expositor de su idea, es decir de lo imprescindible del suicidio, pero no un hombre indiferente ni férreo. En efecto, sufre y se atormenta, y así creo haberlo expresado con toda claridad. Para él es evidente que no puede vivir y de sobra sabe que tiene razón y que no cabe rebatirlo... El mal estriba únicamente en haber perdido la fe en la inmortalidad... Afirmo que la consciencia de la absoluta 
incapacidad para prestar alguna ayuda o proporcionar alguna utilidad o alivio a la Humanidad en sus dolores, puede incluso convertir en odio vuestro amor a la Humanidad... añado (también sin pruebas) que el amor a la Humanidad es hasta de todo punto absurdo, incomprensible y "absolutamente imposible, como no vaya acompañado de la fe en la inmortalidad del alma humana"... Afirmo también y me atrevo a sostener, que el Amor a la Humanidad, en términos generales..., es, como idea, una de las más inaccesibles a la razón humana. Precisamente como idea. Solo el sentimiento puede justificarla. Pero ese sentimiento solo es posible precisamente a condición de estar convencidos de la inmortalidad del alma humana. (también sin aducir razones)" (p. 1138-1141).

Para Dostoievski "la inmortalidad, que nos promete una vida eterna, ata el hombre, por eso mismo, más fuertemente a la Tierra... solo en virtud de su fe en la inmortalidad alcanza el hombre su fin razonable en la Tierra. Sin fe en su inmortalidad rompense los lazos que unen al hombre a la Tierra, vuelvense más sutiles, más flojos y la pérdida del alto concepto de la vida (aunque solo se sienta en forma de inconsciente pesar) conduce indudablemente al suicidio. De aquí a la inversa la moraleja de mi artículo de octubre: "Cuando tan indispensable resulta la fe en la inmortalidad para la vida del hombre, será que es el estado normal de la Humanidad, y siendo así, no hay duda que existe también la inmortalidad del alma humana". En una palabra: que la idea de la inmortalidad es la vida misma, la vida viva, su fórmula definitiva y el principal venero de la verdad y la verdadera conciencia para la Humanidad" (p 1141).

Páginas después (pp. 1143-5), en este mismo capítulo, Dostoievski refuta la aseveración de un lector, el señor Eipe, de que el suicidio de ese joven materialista es el "desvario de un hombre medio loco", ya que, según Dostoievski, la conclusión de lo imprescindible del suicidio es para muchos europeos algo así como la última palabra en la ciencia. Dice Dostoievski: "Yo, en breves términos, he expresado "esta última palabra de la ciencia" de un modo claro y popular, pero solamente para refutarla, no mediante el raciocinio ni la lógica, porque con arreglo a la lógica es irrefutable... sino con la fe, con la conclusión de que es indispensable esa fe en la inmortalidad del alma humana, con la convicción de que esa fe es el único venero de la vida viva en la Tierra, de la vida, de la salud, de las sanas ideas y de las deducciones y conclusiones sanas".

Esta falta de creencia en la inmortalidad del alma es, para Dostoievski, la clave de la mayoría de los suicidios: "Quizá me salgan diciendo que en estos tiempos se matan también individuos 
que no se preocupan para nada de ninguna elevada cuestión, y sin embargo se suprimen enigmáticamente, sin ninguna razón visible. En efecto, asistimos a muchísimos suicidios (y su incremento constituye también un enigma), suicidios extraños e inexplicables, que no responden a ninguna necesidad, ni son consecuencia de ningún agravio, ni de material indigencia, ni secuela tampoco de amores contrariados o de celos, enfermedad, hipocondría o locura, sino sabe Dios de qué. Tales casos, en estos tiempos, constituyen una gran tentación, y como no se pueden negar que son una epidemia, hay quienes los consideran como un problema de los más pavorosos. No voy, naturalmente, a explicar todos esos suicidios, y, además, no podría (intercala una nota del autor comentando el gran número de cartas que recibe exponiendo casos de suicidios y preguntando su explicación); pero, en cambio, estoy convencido, sin ningún género de dudas, de que en su mayoría, en conjunto, directa o indirectamente, esos suicidas pusieron fin a su existencia por efecto de la misma enfermedad moral: la ausencia de una idea elevada de la vida en sus almas... solo de la fe, según dijimos más arriba, se derivan todo sentido y significación elevados de la vida, se derivan el ansia y el gusto de vivir. ¡Oh!, lo repito: hay muchos amantes de la vida sin ninguna idea ni noción elevadas de la vida, de vivir una vida sencillamente animal, en el sentido de tipo inferior; pero hay también muchísimos, y, lo que es más curioso, extraordinariamente toscos y viciosos de por sí, cuya naturaleza, sin embargo, quizá sin ellos mismos saberlo, lleva ya mucho tiempo de apesadumbrarse por los altos fines y significación de la existencia. Esos tales no se desazonan por el amor al buen comer, por el amor a la salchicha, a los buenos caldos, a la disipación, a los empleos, al poder oficial, a las zalemas de los subordinados, a los suizos guardando las puertas. Se pegan un tiro precisamente sin motivo alguno en apariencia; pero, no obstante, por pesar, aunque inconscientemente, por no haber podido atinar nunca con el alto sentido de la vida. Pero los hay también que, a mayor abundamiento, se pegan el tiro después de haber cometido previamente alguna escandalosa villanía, alguna cosa fea, monstruosa. ¡Oh! en muchos de esos casos es naturalmente dificil comprobar si lo tales suicidas pusieron fin a su existencia por la "nostalgia de una más alta finalidad de vida (pp. 1141-2)".

Continúa Dostoievski, en este artículo de Diciembre de 1876 de Diario de un escritor comentando que esta nostalgia, que en principio es solo accesible a espíritus elevados, puede aparecer también en criaturas vulgares e ignorantes, pues las ideas son muy contagiosas. Hasta los niños que aún no tienen experiencia se suicidan, ya que hasta ellos sufren y tienen nostalgia de una 
finalidad más alta de vivir, finalidad que es negada por la educación que otorgan muchas de las familias actuales.

Por tanto, Dostoievski da una respuesta clara a su constante indagación sobre el suicidio. Esta indagación está relacionada con aquello que Dostoievski confiesa que le ha atormentado toda su vida, tanto en su correspondencia personal como por boca de su personaje suicida más famoso, Kirillov: la existencia de Dios. En una carta a Maikov, fechada en Marzo de 1970, dice al hablar de sus proyectos de un nuevo libro: "Con su idea principal, que ha de desarrollarse a lo largo de cada una de sus partes, me he estado atormentado, consciente o inconscientemente, toda la vida; es el problema de la existencia de Dios" (T. III, p 1679-80). Y la respuesta está, exclusivamente, en la fe en la inmortalidad del alma. A. Alvarez (1971) considera, que, referente a la cuestión del suicidio, "Dostoievski sirve de puente entre el siglo XIX y el XX. Los personajes de sus novelas actúan el drama de una vida espiritual que ha ido más allá de la religión; así Kirillov, con plena conciencia y por una lógica propia, ineludible, se mata victoriosamente. Pero como individuo, Dostoievski se niega la lógica y no abandona sus creencias tradicionales. "Por así decir, el cristianismo era la excusa que se daba para escribir, para celebrar la vida que rezuman sus libros. Pero, al mismo tiempo, daba la medida de su desesperación. Por eso, en sus novelas, cuánto más grandes sean el amor y la caridad cristiana, más intensas serán la culpa y la duplicidad" (p. 283) 
V. CONCLUSIONES 
1. Fiodor Dostoievski ha descrito magistralmente en sus obras un gran número de fenómenos suicidas.

2. Se han agrupado los personajes suicidas que aparecen en sus obras en una de las siguientes categorías:

- Personajes víctimas de situaciones injustas o crueles.

- Personajes que padecen trastornos mentales.

- Personajes que presentan una personalidad narcisista patológica.

- Personajes cuyo suicidio se debe principalmente a una inteligencia reflexiva hipertrofiada.

- Personajes que presentan sentimientos de culpa tras una acción reprobable.

- Personajes cuyo suicidio es consecuencia de una situación pasional.

- Personajes cuyo suicidio se relaciona fundamentalmente con situaciones de desestructuración social.

- Personajes cuyos actos suicidas son exclusivamente un intento de manipular los sentimientos de otro.

3. Dostoievski trata con profusión el suicidio infantil, otorgando gran importancia a los antecedentes de abuso sexual y maltrato. Además, se anticipa al psicoanálisis al considerar que la existencia de fantasias sobre el suicidio en el niño protege de su consumación.

4. En los suicidios de adultos que son víctimas de situaciones humillantes o injustas considera el suicidio, al igual que en las primeras teorías psicoanalíticas, como un homicidio frustrado.

5. Algunos suicidios pasionales descritos por Dostoievski son considerados también como un deseo de matar al otro. En otros el autor enfatiza la existencia de un placer masoquista, anticipándose al concepto de pulsión de muerte de Freud.

6. Los trastornos mentales (psicosis, ludopatias, alcoholismo) son utilizados con frecuencia por el autor en personajes accesorios a la trama central cuando desea introducir un suicidio en su obra sin explayarse en su desarrollo. 
7. Los personajes denominados por Dostoievski "tipo Cleopatra", que se corresponden con la personalidad descrita por Kernberg como narcisismo maligno o patológico, muy a menudo acaban suicidándose.

8. Los personajes que realizan suicidios de tipo lógico o filosófico argumentan su decisión rebatiendo las tesis aristótelicas y tomistas en contra del suicidio y defendiendo las de Hume. Además, consideran el suicidio, al igual que algunos filósofos existencialistas, como la expresión última de la libertad del hombre.

9. Dostoievski considera que los sentimientos de culpabilidad son el pilar básico de un gran número de suicidios.

10. El autor refiere que aquellas personas que realizan amenazas o gestos suicidas como forma de coaccionar a otros para lograr sus deseos pueden acabar consumando un suicidio. Esta afirmación, opuesta a las creencias populares, es corroborada en los estudios psiquiátricos.

11. Dostoievski se anticipa a Emile Durkheim en una interpretación sociológica de la génesis de muchos suicidios, considerándolos como una consecuencia de los valores propios de la sociedad occidental. La descripción de estos suicidios es muy similar a la que realiza el sociólogo francés del suicidio egoísta y anómico.

12. Dostoievski considera que el suicidio, cuando se ha perdido la fe en la inmortalidad del alma, resulta de una imprescindibilidad absoluta e inevitable para toda persona que tenga alguna noción de su superioridad sobre los animales. 
VI. BIBLIOGRAFÍA 
Ajuriaguerra, J. y Marcelli, D.: "Psicopatología de las conductas agresivas". En: Manual de la Psicopatología del Niño, Barcelona, Toray-Masson, S.A., 1982, pp. 168-175.

Alvarez, A,: El dios salvaje: Un estudio del suicidio (1971), Ed. Norma, Santa Fe de Bogotá, 1999.

Andress, V.R.: "The crisis of suicide" En: Review \& Herald Publishing Association, 1996, http://www.glow.cc/lead/a-andress. htm.

APA: DSM-IV "Manual diagnóstico y estadístico de los trastornos mentales” Ed: Masson S.A., Barcelona, 1995.

Arechederra Aranzadi, J.J.: "Maltrato de menores", En Psicopatología y conductas delictivas, 2, Madrid, IM\&C, 1997.

Aristóteles: Etica Nicomaquéa. Ed: Gredos. Madrid, 1988.

Arranz Estevez, F.J.: "Epidemiología de la conducta suicida". En: La conducta suicida, Coord: S. Ros Montalbán, Editorial Libro del Año, S.L., Madrid, 1997.

Arranz Estevez, F.J.: "Factores psicológicos-conductuales y psicosociales de riesgo suicida". En: La conducta suicida, Coord: S. Ros Montalbán, Editorial Libro del Año, S.L., Madrid, 1997.

Baca-García E., Díaz-Sastre C., Prieto López R., Basurte Villamor E. y Saiz Ruiz J.: "Intento de suicidio y gonadotrofinas femeninas” Psiquiatría Biológica. 1997;4(2).

Bagley, C., Jacobson, S. y Rehin, A.: "Completed suicide: a taxonomic analysis of clinical and social data" Psychological Medicine, 1976, 6, 429-438.

Bagley, C.: "Changing profiles of a typology of youth suicide in Canada" Can J Public Health. 1992 Mar-April; 83(2): 169-70.

Bousoño García, M., García Prieto, A. y Bascarán Fernández, M.T.: "Aspectos bioéticos y morales". En Prevención de las conductas suicidas y parasuicidas, Masson, Barcelona, 1997, pp. 189-200.

Bravo, J.M.: "Introducción" En Los hermanos Karamázov, Ed: Cátedra, Madrid, 1987 
Breasted, JH: Development of Religion and Thought in Ancient Egypt. Ed. Scribner's Sons, New York, 1912.

Cabaleiro Goas, M.: Werther, Mischkin y Joaquin Monegro vistos por un psiquiatra. Trilogía patográfica (1951) Colección de psiquiatría clásica gallega, Lugo, 1998.

Camus, A.: El mito de Sísifo (1951), Alianza Editorial, Madrid, 1988.

Camus, A.: El hombre rebelde (1953), Ed. Losada, Buenos Aires, 1978.

Cansino Assens, R.: "Fiodor M. Dostoyevski: Su vida y su obra". En Obras completas de Dostoyevski, Aguilar s.a., $10^{\circ}$ ed., Madrid, 1982, pp. 9-100.

Cantrell, D. Dostoevsky and Psychology, 1996. En http://www. middlebury.edu/\%7Ebeyer/course/previous/ru351/studentpapers /Psychology.shtml

Carbonell Masiá, C. y González Seijo, J.C.: "Evolución histórica del fenómeno suicida". En Prevención de las conductas suicidas y parasuicidas, Masson, Barcelona, 1997, pp. 1-4.

Carr, E. H.: Dostoievski 1821-1881: Lectura crítico-biográfica Ed. Laia, Barcelona, 1931

Castilla del Pino, C.: Un estudio sobre la depresión (1966), Ed: Península, 8 ${ }^{a}$ edición, Barcelona, 1981; 243-274.

Castilla del Pino, C.: Introducción a la Psiquiatria: Problemas generales, Psico(pato)logía, Madrid, Alianza Universidad, 1982.

Clemente, M. y González, A.: Suicidio: Una alternativa social, Ed: Biblioteca Nueva, Madrid, 1996.

Conde López, V.J.M., Blanco Garrote, J.A. y Ballesteros Alcalde, $\mathrm{M}^{\mathrm{a}}$ C.: "El problema del suicidio y su prevención (I)", An. Psiquiatría (Madrid), Vol. 17, No 9, 2001, pp. 387-395.

Dante Alighieri: Canto XIII de "El infierno", La divina comedia, Ed: Oceano, Barcelona, 1998. 
De Dios Francos, A.: "Biología de las conductas suicidas". Monografias de Psiquiatría, Año VII, Número 1, Enero-Febrero, 1995 pp. 21-24.

De la Gándara Martín, J.J.: "El suicidio en niños y adolescentes". Monografías de Psiquiatría, Año VII, Número 1, Enero-Febrero, 1995 pp. 34-40.

Delgado, A.: "Abuso sexual" En Grandes sindromes de Pediatria, Bilbao, Cátedra de Pediatría de la Universidad del País Vasco, 1996, pp. 51-64.

Delumeau, J.: El miedo en Occidente. Ed. Taurus, Madrid, 1989.

Díaz Suárez, J., Sáiz Martínez, P.A., Bousoño García, M. y Bobes García, J.: "Concepto y clasificación de las conductas suicidas". En Prevención de las conductas suicidas y parasuicidas, Masson, Barcelona, 1997, pp. 13-20.

Dilman, I.: "Dostoyevsky: Psychology and the Novelist". En Phylosophy and Literature, Ed: A. Phillips Griffiths. Bambridge: Cambridge University Press, 1984, pp. 95-114.

Domenech Bisen, J.R.: "Enfermedad médica y suicidio" En: La conducta suicida, Coord: S. Ros Montalbán, Editorial Libro del Año, S.L., Madrid, 1997.

Domínguez González, P.: "Exploración clínica de la ideación y riesgo suicida". Monografías de Psiquiatría, Año VII, Número 1, Enero-Febrero, 1995 pp. 25-29.

Dostoyevski, F. M.: "Memorias del subsuelo". Obras completas, Aguilar s.a., $10^{\circ}$ ed., Madrid, 1982, Tomo I, pp. 1451-1523.

Dostoyevski, F. M.: "El cocodrilo". Obras completas, Aguilar s.a., $10^{\circ}$ ed., Madrid, 1982, Tomo I, pp. 1525-1549.

Dostoyevski, F. M.: "Crimen y castigo". Obras completas, Aguilar s.a., $10^{\circ}$ ed., Madrid, 1982, Tomo II, pp. 7-399.

Dostoyevski, F. M.: "El jugador". Obras completas, Aguilar s.a., $10^{\circ}$ ed., Madrid, 1982, Tomo II, pp. 401-499.

Dostoyevski, F. M.: "El Idiota". Obras completas, Aguilar s.a., $10^{\circ}$ ed., Madrid, 1982, Tomo II, pp. 501-959. 
Dostoyevski, F. M.: "El eterno marido". Obras completas, Aguilar s.a., $10^{\circ}$ ed., Madrid, 1982, Tomo II, pp. 961-1059.

Dostoyevski, F. M.: "Demonios". Obras completas, Aguilar s.a., 10 ed., Madrid, 1982, Tomo I, pp. 1061-1515.

Dostoyevski, F. M.: "El adolescente". Obras completas, Aguilar s.a., $10^{\circ}$ ed., Madrid, 1982, Tomo II, pp. 1517-1922.

Dostoyevski, F. M.: "Los hermanos Karamásovi”. Obras completas, Aguilar s.a., 10 ed., Madrid, 1982, Tomo III, pp. 7-596.

Dostoyevski, F. M.: "Diario de un escritor". Obras completas, Aguilar s.a., $10^{\circ}$ ed., Madrid, 1982, Tomo III, pp. 597-1495.

Dostoyevski, F. M.: "Del Dostoyevski inédito". Obras completas, Aguilar s.a., $10^{\circ}$ ed., Madrid, 1982, Tomo III, pp. 1499-1697.

Dube, S.R., Anda, R.F., Felitti, V.J., Chapman, D.P., Williamson, D.F., Giles, W.H.: "Childhood abuse, household disfunction, and the risk of attempted suicide throughout the life span", JAMA, 2001; 286: 3089-3096.

Durkheim, E.: El suicidio (1897). Ed: Akal S.A. Madrid, 1995.

Ey H., Bernard, P. y Brisset, Ch,: Tratado de Psiquiatria, Octava edición, Ed. Toray-Masson, Barcelona, 1980.

Fieser, J.: "Suicide", The Internet Encyclopedia of Philosophy, 1998. Disponible en http://www.utm.edu/research/iep/s/suicide. htm.

Frank, J: Dostoieuski: Las semillas de la rebelión, 1821-1849. Fondo de Cultura Económica, México, D.F. 1984.

Frank, J: Dostoievski: Los años de prueba, 1850-1859. Fondo de Cultura Económica, México, D.F. 1986.

Frank, J: Dostoievski: La secuela de la liberación, 1860-1865. Fondo de Cultura Económica, México, D.F. 1993.

Frank, J: Dostoieuski: Los años milagrosos, 1865-1871. Fondo de Cultura Económica, México, D.F. 1997.

Freud, S.: Obras Completas. Ed. Biblioteca Nueva, 4ª edición, Madrid, 1981. 
Gastanmiza Perez, X., Vacas Moreira, R. y Ros Montalbán, S.: "La conducta suicida en la infancia y la adolescencia" En: La conducta suicida, Coord: S. Ros Montalbán, Editorial Libro del Año, S.L., Madrid, 1997.

Girard, R.: Mentira romántica y verdad novelesca (1961), Anagrama, Barcelona, 1985.

Girard, R.: Literatura, mimesis y antropología (1978), Gedisa, $2^{\text {a }}$ ed., Barcelona, 1997.

Gómez Bosque, P. y Díaz Blanco, A.: "Antropología y Matemáticas" En La matematización de la ciencia, Valladolid, Universidad de Valladolid, 1964, pp. 38-47.

Gómez Bosque, P.: "Alteraciones mentales y cerebrales en el maltrato infantil". En: Problemas médicos en la escuela y su entorno, Coord: Gil Verona, J.A., Madrid, Editorial Médica Panaméricana, $2^{a}$ edición, 1999, pp. 221-233.

Gómez Bosque, P.: "Poesía y verdad: la sabiduría psicológica de Dostoiewski”. En Ensayos antropológicos y filosóficos. Colección de autores vallisoletanos, Ayuntamiento de Valladolid, 2001, pp. 101114.

González García-Portilla, M.P., Sáiz Martínez, P.A, Bobes García, J. y González-Quirós Corujo, P.: "Factores sociodemográficos". En Prevención de las conductas suicidas y parasuicidas, Masson, Barcelona, 1997, pp. 46-53.

González Seijo, J.C., Cocaña Rodríguez, I., Bousoño García, M. y Fernández Domínguez, J.M.: "Factores psicológicos y psicopatológicos". En Prevención de las conductas suicidas y parasuicidas, Masson, Barcelona, 1997, pp. 59-68.

González Seijo, J.C., Iglesias García, C., González-Quirós Corujo, P. y Ramos Vicente, Y.: "Factores familiares". En Prevención de las conductas suicidas y parasuicidas, Masson, Barcelona, 1997, pp. 54-58.

González Seijo, J.C. y Ramos Vicente, Y.: "Aproximación teórica al fenómeno suicida". En Prevención de las conductas suicidas y parasuicidas, Masson, Barcelona, 1997, pp. 1-4.

González Seijo, J.C., Ramos Vicente, Y., Carbonell Masía, C. y Bobes García, J.: "Poblaciones especificas de alto riesgo". En 
Prevención de las conductas suicidas y parasuicidas, Masson, Barcelona, 1997, pp. 69-77.

Gosh, T.B. y Victor, B.S.: "Suicidio" En Tratado de Psiquiatría (1995), $2^{a}$ edición; Dir: Hales, R. E., Yudofsky, S.C. y Talbott, J.A.; Ed: Ancora, S.A., Barcelona, 1996. pp. 1313-1334.

Guthrie, W.K.G.: Historia de la Filosofía griega, Editorial Gredos, Madrid, 1984; Tomo I, p. 166.

Gutier, M.: "Duelo y melancolía. Ochenta años después. El superyo. El suicidio" AAP, Vol. 1, Dinámica 3, 2000. Disponible en: http/www.aap.org.ar/publicaciones/dinamica/Vol1/3/dinami03_0 2.htm.

Henderson, S. y Lance, G.N.: "Types of attempted suicide (parasuicide)" Acta psychiat scand. (1979) 59, 31-39.

Hernandez Martinez, J.: "El proceso suicida". En: La conducta suicida, Coord: S. Ros Montalbán, Editorial Libro del Año, S.L., Madrid, 1997.

Hudson RP.: Disease and Its Control: The Shaping of Modern Thought. Westport, CT: Greenwood Press; 1983.

Hyman S.E.: "El paciente suicida". En Manual de Urgencias psiquiátricas. Salvat editores, Barcelona, 1987, pp. 17-23

Ivanits, L.: "Suicide and folk belief in Dostoevsky"s Crime and Punishment". In The golden age of Russian Literature and thought, ed. Derek Offord. New York: St. Martin`s Press, 1992, pp. 138-48.

Jaspers, K.: Psicopatología general (1913) F.C.E., México, 1999.

Jünger, E.: "Sobre la línea". En Acerca del nihilismo (1956). Ed: Paidós, Barcelona, 1994, pp. 15-69.

Kraepelin, E.: Introducción a la clínica psiquiátrica (1905) Ed: Nieva, Madrid, 1988.

Kraepelin, E.: "Las manifestaciones de la locura", En Los sintomas de la locura (1920), Edición Triacastela, Madrid, 1999

Landsberg, P.L.: El problema moral del suicidio (1942), Caparrós Ed. Colección Esprit, Madrid, 1995, pp. 95-129. 
Lavrin, J.: Dostoevsky and His Creation: A Psycho-critical Study, William Collins \& Sons, London, 1920, pp. 98-102.

Leatherbarrow, W. J.: "The Devils in the context of Dostoevsky's life and works", En Dostoeusky's The Devils, Edited por W. J. Leatherbarrow, Nothwestern University Press, 1999.

Lester, D.: "Ectomorphy ratios of completed suicides" Perceptual and motor skills, 1987, 64, 86.

Long, A.A.: La filosofía helenística. Alianza Universidad, Madrid, 1975 ; p. 201.

McCormick, RA, Russo AM, Ramirez LF, Taber JI: "Affective disorders among pathological gamblers seeking treatment" $A m J$ Psychiatry 1984; 142: 215-218.

Malinowski, B.: Crimen y costumbre en la sociedad salvaje. Ed. Planeta-Agostini. Barcelona. 1985.

Mardomingo Sanz, M.J.: "Suicidio y tentativas autoliticas" En Planificación terapéutica de los trastornos psiquiátricos del niño y del adolescente, Coord: Gutierrez Casares y Rey Sanchez; Ed: Smithkline Beecham, Madrid, 2000, pp. 1195-1231.

Martínez Pascual, B.: "Suicidio en pacientes con cáncer", Psiquiatría Pública, 1998; 10(4).

Martínez Rodríguez, J.M.: "El suicidio en la población mundial". Monografias de Psiquiatría, Año VII, Número 1, Enero-Febrero, 1995 pp. 8-13.

Menninger, K.: El hombre contra si mismo (1938) Ed. Península, Barcelona, 1972.

Millon, T.: Trastornos de la personalidad: Más allá del DSM-IV, Barcelona, Masson, 1999.

Miró, E.: "Depresión y suicidio", En Trastornos afectivos: ansiedad y depresión $2^{\mathrm{a}}$ edición. Dir: Vallejo Ruiloba y Gastó Ferres; Ed: Masson, Barcelona 2000, 675-684.

Moro, T.: Utopia (1516) Ed. Tecnos, Madrid, 1987; 95-96.

Nietzsche, F.: Asi hablo Zaratustra (1883) Alianza Editorial, 1993, pp. 114-117. 
Nietzsche, F.: La genealogía de la moral (1887), Alianza Editorial, Madrid, 1991.

Nordström, P. y Asberg, M.: "Análisis de la supervivencia y psicobiología del riesgo de suicidio". En: Avances neurocientíficos $y$ realidad clinica, ed. Sintesis, Madrid, 1999.

Nulan, S. B.: Cómo morimos. Alianza Editorial, Madrid, 1993.

Oates, J. C.: Tragic and comic visions in "The Brothers Karamázov”, 1999. En http://storm.usfca.edu/^southerr/karamazov .html.

OMS: CIE 10 “Trastornos mentales y del comportamiento". Ed: Meditor, Madrid, 1992.

Pinzón León, A.: Presentación del libro "Cioran: filosofía de la desesperanza", 2000. Disponible en http://filoesp.topcities.com /artics/LibroCioran.htm.

Proença, M.: "History of suicide"; En "The suicidology Web" 2001, http://www.suicide-parasuicide.rumos.com/en/articles/sui cide/histor y_ of _suicide.htm\#TOP.

Ramírez O., M.E.: "La horrorosa belleza del suicidio", En Psicomundo: la red psi en internet 1998. Disponible en http://www.Psiconet.com /ramirez/articulos2/suicidio.html.

Robins, E., Murphy, G. y Wilkinson, R.: "Some clinical considerations in the prevention of suicide based on a study of 134 sucessfull suicides" Am J Public Health 49: 888, 1959.

Rodríguez Juan, E.: "Introducción histórica". En: La conducta suicida, Coord: S. Ros Montalbán, Editorial Libro del Año, S.L., Madrid, 1997.

Rojas, E.: Estudios sobre el suicidio, Salvat Editores S.A., Barcelona, 1978.

Ros Montalban, S.: "Neurobiología de la conducta suicida. En: La conducta suicida, Coord: S. Ros Montalbán, Editorial Libro del Año, S.L., Madrid, 1997.

Rovaletti M.L.: Esquizofrenia: sentido e insensatez, Serie: Del Encuentro (XVIII) Relaciones $\mathrm{n}^{\circ}$ 168; Montevideo Abril, 1998. 
Disponible en http://fp.chasque.net:8081/relacion/9805 encuentro.htm\#serie.

Roy, A: "Suicidio". En Tratado de Psiquiatría (1995), 6a edición, Vol. 3; Dir: Kaplan H.I. y Sadock, B.J.; Ed: Intermédica, Buenos Aires, 1997.

Rubio Larrosa, V.: "Conducta suicida y trastornos de la personalidad". En: La conducta suicida, Coord: S. Ros Montalbán, Editorial Libro del Año, S.L., Madrid, 1997.

Sadock, V.A.: "Maltrato físico y abuso sexual del adulto" En Tratado de Psiquiatría, Vol. 3; Dir: Kaplan H.I. y Sadock, B.J.; Buenos Aires, Ed: Intermédica, $6^{\mathrm{a}}$ edición, 1997.

Sáiz Martínez, P.A:, González García-Portilla, M.P., Bousoño García, M. y Bobes García, J.: "Epidemiologia". En Prevención de las conductas suicidas y parasuicidas, Masson, Barcelona, 1997, pp. 35-45.

Sáiz Martínez, P.A:, González García-Portilla, M.P., Cocaña Rodríguez, I. y Bobes García, J.: "Epidemiologia". En Prevención de las conductas suicidas y parasuicidas, Masson, Barcelona, 1997, pp. 21-33.

Sanchez Blanque, A: "Psicopatología del yo" En Psiquiatría, Eds: Lopez Ibor, J.J., Ruiz Ogara, C. y Barcia, D., Ed. Toray, Barcelona, 1982, p. 424.

Sarró, B. y de la Cruz, C.: Los suicidios. Ed. Martínez Roca, Barcelona, 1991.

Schmitt, W. y Mundt, C.: "Differential tipology among patients with hard and soft suicide methods", Nervenarzt 1991 Jul; 62 (7): 440-4.

Schneider, B., Philipp, M. y Müller, M.J.: "Predictores psicopatológicos del suicidio en pacientes con depresión mayor durante un seguimiento de 5 años". Eur Psychiatry Ed. Esp. (2001); 8; 498-504.

Schopenhauer, A.: El mundo como voluntad y representación (1818), Ed. Porrúa, s.a., México, 1992.

Schopenhauer, A.: Sobre el dolor del mundo, el suicidio y la voluntad de vivir (1851), Técnos, Madrid, 1999. 
Segarra, R., Sánchez, P. y Robador, A.: "Instinto de vida". En Introducción a la psicopatología, Ed. Eguíluz Uruchurtu, IM\&C, Madrid, 2001, pp. 311-334.

Segui Montesinos, J. y Canet Mitjavila, J: "Conducta suicida y trastorno por angustia". En: La conducta suicida, Coord: S. Ros Montalbán, Editorial Libro del Año, S.L., Madrid, 1997.

Stange, C: Dostoevsky Research Station, 2001. Disponible en: http: //www.kiosek.com/dostoevsky/quotations.html.

Stone, G. y Aldiss, B. W.: Suicide and attempted suicide: Methods and consequences. Carrol \& Graff, N.Y., 1999.

Torrecilla Hernández: Niñez y castigo: Historia del castigo escolar, Universidad de Valladolid, 1998.

Troyat, H.: Dostoyeuski, Ed. Destino, $1^{\mathrm{a}}$ ed., Barcelona, 1946.

Valverde, J.M.: Nietzsche, de filólogo a anticristo, Planeta, $1^{\mathrm{a}}$ ed., Barcelona, 1993.

Zweig, S.: Dostoiewski (1920), Ed. Juventud, Barcelona, 1968. 